SÍLVIA MAYUMI TAKEY

FUZZY FRONT END DE INOVAÇÕES SISTÊMICAS:

QUADRO CONCEITUAL E ESTUDO DE CASOS

São Paulo

2016 


\section{FUZZY FRONT END DE INOVAÇÕES SISTÊMICAS: \\ QUADRO CONCEITUAL E ESTUDO DE CASOS}

Dissertação apresentada à Escola

Politécnica da Universidade de São

Paulo para obtenção do título de Mestre em Ciências.

Área de concentração:

Engenharia de Produção

Orientador:

Prof ${ }^{a}$ Livre-Docente

Marly Monteiro de Carvalho

São Paulo

2016 
FICHA CATALOGRÁFICA

Este exemplar foi revisado e corrigido em relação à versão original, sob

responsabilidade única do autor e com a anuência de seu orientador.

São Paulo, de de

Assinatura do autor:

Assinatura do orientador:

Takey, Sílvia Mayumi

FUZZY FRONT END DE INOVAÇÕES SISTÊMICAS:

QUADRO

CONCEITUAL E ESTUDO DE CASOS / S. M. Takey -versão corr. -- São Paulo, 2016.

$213 \mathrm{p}$.

Dissertação (Mestrado) - Escola Politécnica da Universidade de São Paulo. Departamento de Engenharia de Produção.

1.Projeto de Produto I.Universidade de São Paulo. Escola Politécnica.

Departamento de Engenharia de Produção II.t. 


\section{AGRADECIMENTOS}

Gostaria de agradecer à professora Marly por todas as orientações dadas para a realização deste trabalho, pela paciência e pela excelência durante todo o processo. Agradeço também ao Maicon Oliveira e Leonardo Gomes pelas recomendações contundentes na banca de avaliação.

Um agradecimento especial à Patrícia Sibinelli e ao Ricardo Corrêa, pelo incentivo e apoio à realização do mestrado em paralelo à atividade profissional na Promon, garantindo as condições necessárias na organização para que a pesquisa fosse possível.

Aos meus sócios da DEV Tecnologia Camilo Rodegheri, Marcelo Pesse e Artur Polizel pela coragem e comprometimento necessários para empreendermos juntos, proporcionando minha plena satisfação profissional. A todos os profissionais da DEV Tecnologia por tornarem possível o crescimento da empresa ao mesmo tempo em que buscamos a realização acadêmica e pessoal.

A Camila Siqueira e Gustavo Barros, profissionais que me auxiliaram a manter o equilíbrio emocional para conciliar tantas responsabilidades em paralelo.

À minha família, sem a qual eu não seria nada, por me amar e me apoiar sempre. À minha mãe, por todos os ensinamentos, dedicação, torcida e preces. Ao meu pai pela proteção e valores transmitidos. Ao meu irmão pela confiança mútua e à minha irmã por sempre me desafiar a ser melhor. À minha sobrinha Sophia pelas alegrias proporcionadas.

Ao amor da minha vida Allan Douglas por me proporcionar tanta felicidade e me ensinar tanto sobre como ser uma pessoa melhor. 


\section{RESUMO}

Inovações sistêmicas são aquelas que requerem reajustes significativos em co-opetidores do ecossistema de inovação. A relevância de inovações sistêmicas tem crescido por diversos motivos, tais como o caráter sistêmico de inovações relacionadas ao desenvolvimento sustentável, o amadurecimento da sociedade em rede e a disseminação da inovação aberta. $\mathrm{O}$ fuzzy front end, ou seja, a etapa inicial e difusa do processo de inovação, tem sido explorado considerando-se principalmente relações díades empresa-consumidor. O objetivo desta dissertação é explorar como se diferencia o fuzzy front end em inovações sistêmicas, em ecossistemas de inovação complexos, que demandam a coordenação com diferentes entidades externas ao controle direto da empresa focal. Para tanto, a metodologia conta com três macroetapas: revisão sistemática da literatura de fuzzy front end e inovação sistêmica, estudo de caso piloto de caráter preliminar e estudos de caso exploratórios em empresas em diferentes posicionamentos do ecossistema de negócios de Redes Inteligentes (Smart Grid) com análises intra e inter casos.

Palavras-chave: fuzzy front end, inovação sistêmica, gestão da inovação. 


\begin{abstract}
Systemic innovations are those that require significant changes in co-opetitors within the innovation ecosystems in which they are inserted. The relevance of systemic innovations has grown due to several reasons, such as the systemic characteristic of sustainable development innovation projects, the higher maturity of the network society and the dissemination of open innovation practices. The fuzzy front end, the initial and diffuse phase of the innovation process, has been explored considering mainly dyadic relations between company and consumers. The goal of this dissertation is to explore how does the fuzzy front end differentiate in systemic innovations, in complex innovation ecosystems, considering the need for coordination with external entities outside the control of the focal company. Therefore, the methodology has three macro-steps: a systematic literature review of fuzzy front end and systemic innovation, a pilot case study and exploratory case study with intra and cross-case analysis in different positions in the Smart Grid business ecosystems.
\end{abstract}

Keywords: fuzzy front end; systemic innovation; innovation management. 


\section{LISTA DE FIGURAS}

Figura 1. Estrutura da dissertação.

Figura 2 - Macro-etapas da pesquisa.

Figura 3 - Rede de palavras chave de FFE. Nota: Esta rede foi criada com software Ucinet usando dados importados do software Sitkis. 42

Figura 4 - Modelo conceitual de estratégia de IS. Fonte: Adner (2006). 84

Figura 5 - Complementação do modelo de Koen et al (2001) para FFE de IS. 116

Figura 6-Modelo conceitual para FFE de IS. 117

Figura 7-Representação ilustrativa do mapeamento do ecossistema. 121

Figura 8-Mapa de principais stakeholders da Vitalbox 127

Figura 9-Modelo de FFE aderente aos casos estudados. Fonte: Khurana e Rosenthal (1998). 144

Figura 10 - Mapeamento de atores do ecossistema da Empresa A. 158

Figura 11 - Quadro conceitual atualizado após análise dos estudos de caso exploratórios. 190 


\section{LISTA DE QUADROS}

Quadro 1 - Árvore de códigos inicial baseada no modelo de Koen et al (2001)

Quadro 2 - Critérios de seleção dos estudos de caso exploratórios...............................................................38

Quadro 3 - Modelos conceituais de atividades do FFE da amostra ..............................................................46

Quadro 4 - Elementos para co-desenvolvimento de IS segundo Van der Meer-Kooista e Scapens (2015).......58

Quadro 5 - Quadro resumo da análise de conteúdo da amostra de FFE ....................................................76

Quadro 6 - Tipologias de inovação comparadas com inovação sistêmica na amostra ....................................84

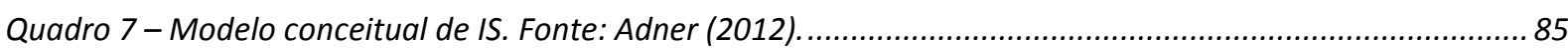

Quadro 8 - Síntese de Fatores de Influência na literatura de IS............................................................92

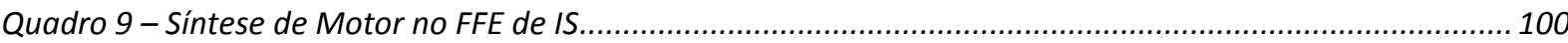

Quadro 10 - Síntese de Definição do conceito no FFE de IS. ............................................................... 113

Quadro 11 - Quadro resumo da análise de conteúdo da amostra de IS..................................................114

Quadro 12 - Processo de interpretação e fases de análise de stakeholders do projeto correspondentes.......... 119

Quadro 13 - Árvore de códigos da análise de conteúdo do estudo de caso. ...............................................128

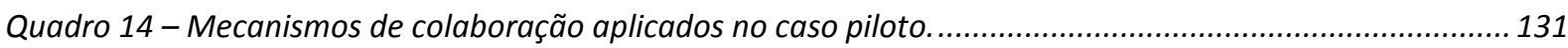

Quadro 15 - Análise de práticas de gestão de stakeholders aplicadas no projeto de inovação sistêmica. ........139

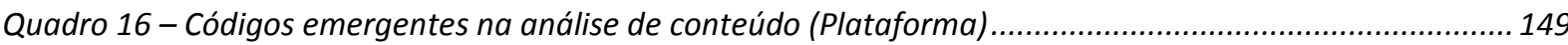

Quadro 17 - Códigos emergentes na análise de conteúdo (Nicho) ............................................................ 151

Quadro 18 - Importância relativa dos elementos do modelo conceitual nos casos estudados, separados em

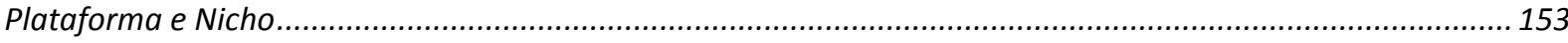

Quadro 19 - Mecanismos de coordenação aplicados nos casos estudados. ............................................... 168

Quadro 20 - Análise cruzada dos casos exploratórios. ...................................................................... 186 


\section{LISTA DE GRÁFICOS}

Gráfico 1 - Frequência relativa de códigos da literatura de inovação sistêmica e do caso piloto. 129

Gráfico 2 - Frequência relativa dos códigos da análise de conteúdo. 148 


\section{LISTA DE ABREVIATURAS E SÍMBOLOS}

$\begin{array}{cl}\text { DNP } & \text { Desenvolvimento de Novos Produtos } \\ \text { FFE } & \text { Fuzzy Front End } \\ \text { IS } & \text { Inovação Sistêmica } \\ \text { OE } & \text { Objetivo Específico } \\ \text { OG } & \text { Objetivo Geral } \\ \text { PMO } & \text { Project Management Office }\end{array}$




\section{SUMÁRIO}

1 INTRODUÇÃO

1.1 OBJETIVOS

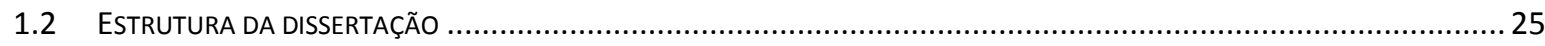

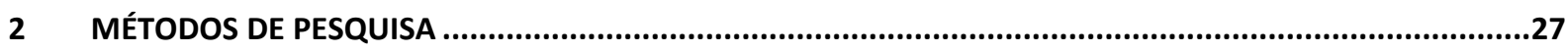

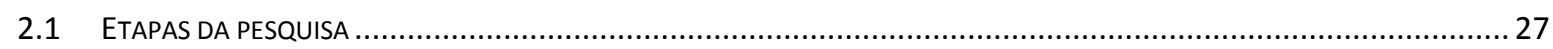

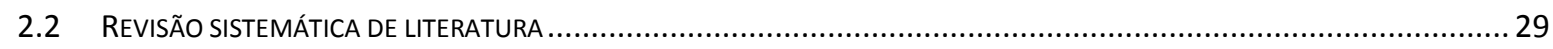

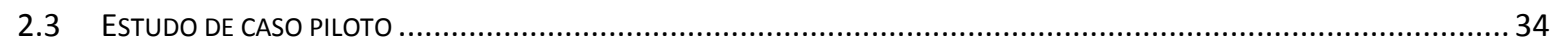

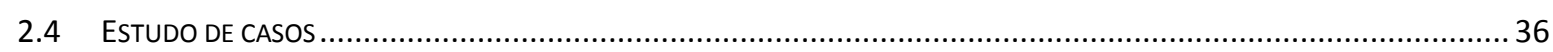

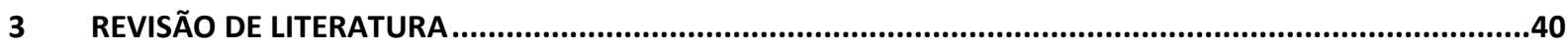

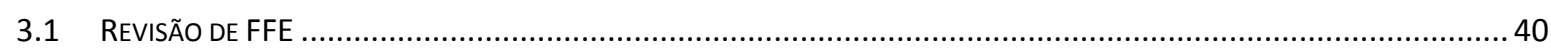

3.1.1 Panorâma da literatura de FFE: Resultados da análise bibliométrica ....................................... 40

3.1.2 Definições e Modelos de FFE: Resultados da análise de conteúdo .......................................... 43

3.1.2.1 Fatores de influência (ambiente externo) ................................................................... 51

3.1.2.2 Motor (liderança, cultura, papeis e estratégia de negócios) ..............................................54

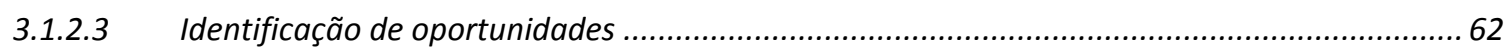

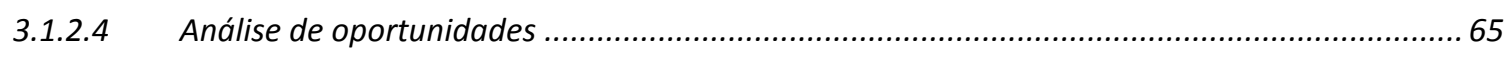

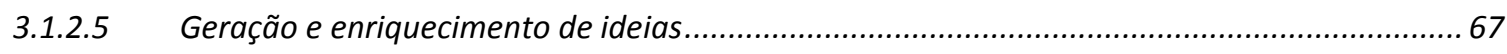

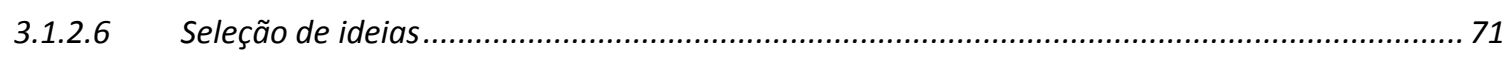

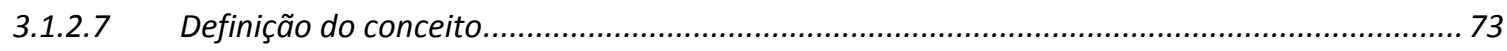

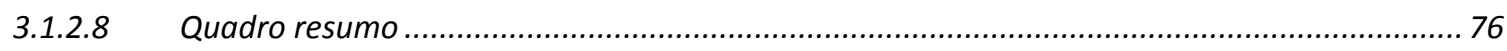

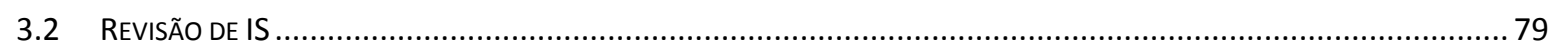

3.2.1 Panorâma da literatura de IS: Resultados da análise bibliométrica .......................................... 79

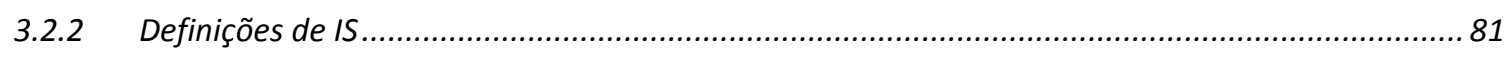

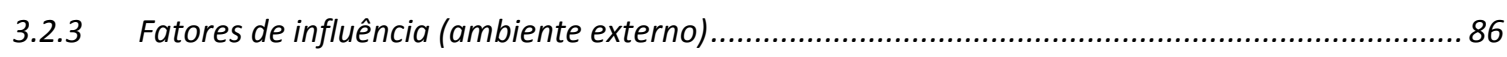

3.2.4 Motor (liderança, cultura, papeis e estratégia de negócios) ................................................. 92

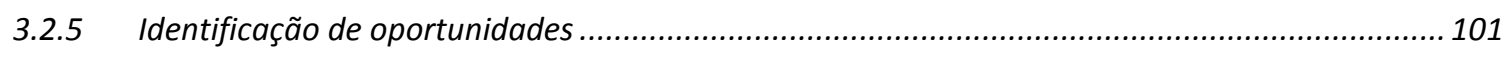




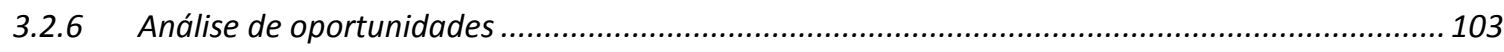

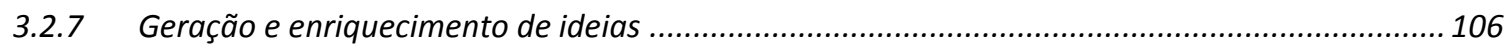

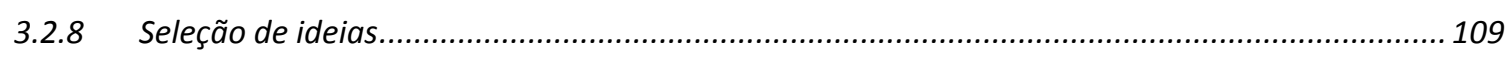

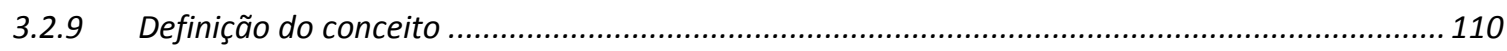

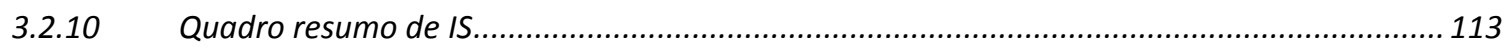

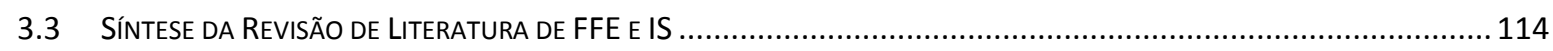

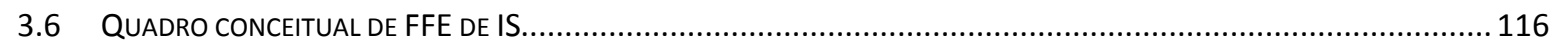

$4 \quad$ RESULTADOS DA PESQUISA: ESTUDO DE CASO PILOTO ................................................................122

4.1 CARACTERIZAÇÃO DO FFE DO PROJETO DE IS DO ESTUdO DE CASO PILOTO ................................................ 122

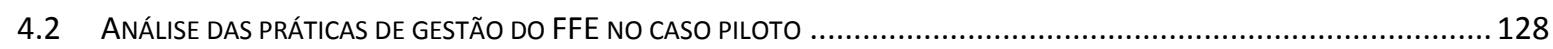

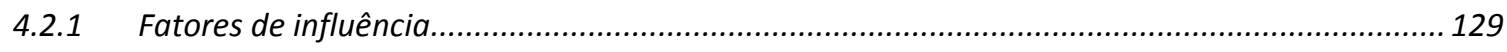

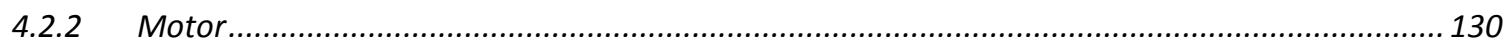

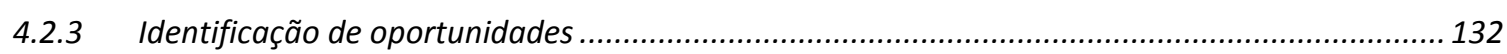

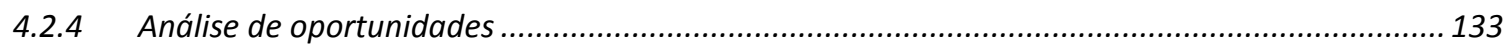

4.2.5 Geração e enriquecimento de ideias ....................................................................... 134

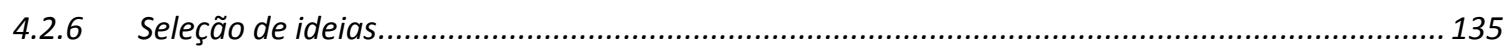

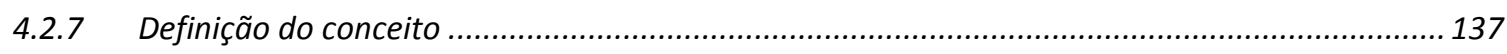

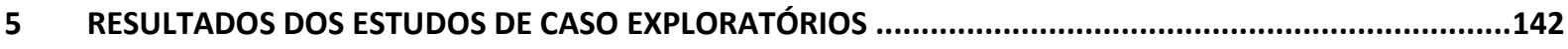

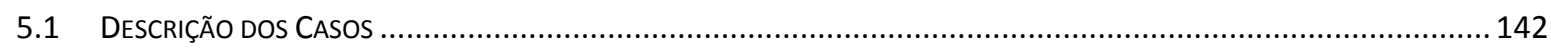

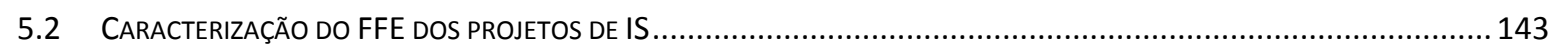

5.3 ANÁLISE DAS PRÁTICAS DE GESTÃO DO FFE NOS CASOS EXPLORATÓRIOS................................................. 147

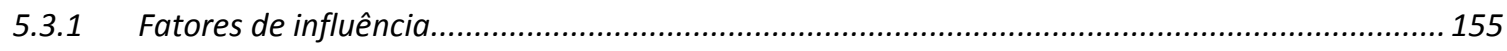

5.3.2 Motor - Mecanismos de coordenação ........................................................................... 160

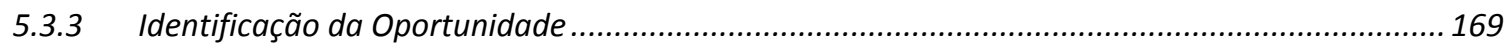

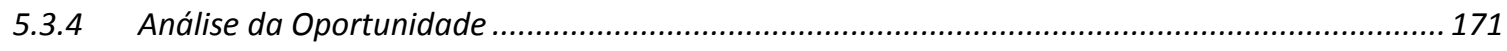

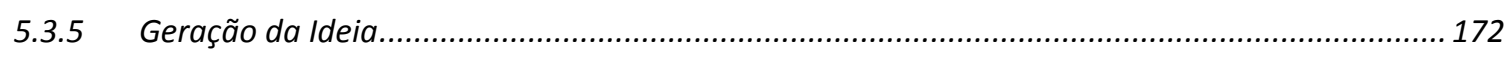

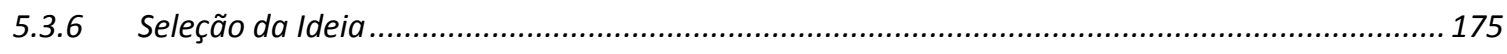




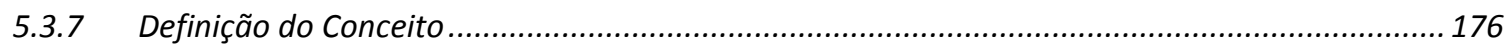

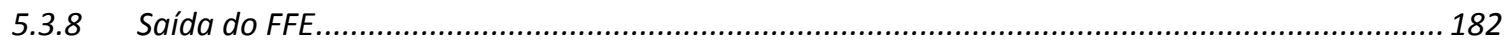

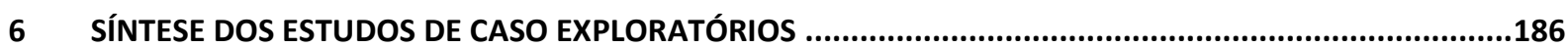

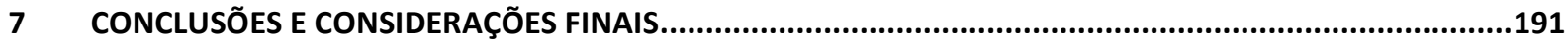

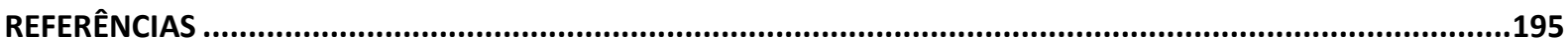

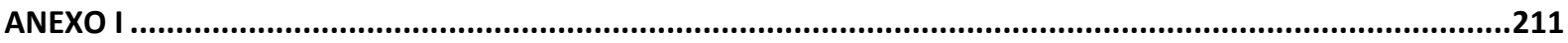

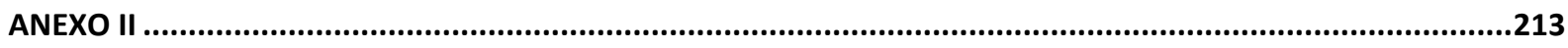

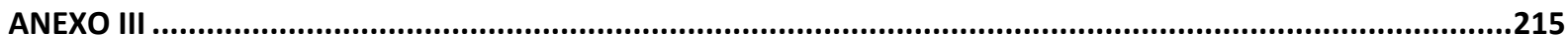




\section{Introdução}

Inovação sistêmica (IS) é aquela que gera valor somente se acompanhada de inovações complementares, contrapondo-se à inovação autônoma, que pode ser desenvolvida independentemente de outras inovações (CHESBROUGH E TEECE, 2002). Taylor e Levitt (2004) definem inovação sistêmica como aquela que altera os processos de negócios e exige que múltiplas empresas mudem suas práticas. Maula et al (2005) as definem como aquelas que requerem ajustes significativos de outras partes do sistema de negócios em que estão inseridas. Neste tipo de inovação, a excelência da empresa em desenvolver a inovação é insuficiente para garantir o seu sucesso comercial, se não acompanhada de inovações coordenadas bem sucedidas de fornecedores, complementares ou mesmo agentes reguladores e poder público.

Um exemplo de IS descrito por Adner e Kapoor (2010) é o projeto da aeronave super jumbo A380 da Airbus. A Airbus, como empresa focal enfrenta desafios substanciais para projetar e manufaturar a fuselagem do avião. Além do desafio interno, a inovação também depende de diversos fornecedores de subconjuntos e componentes. Alguns destes fornecedores enfrentam desafios significativos de inovação para entregar componentes que atendam aos requisitos desta nova aeronave (como motor, sistema de navegação), enquanto outros não precisam inovar nada. Recebendo estes vários componentes, a Airbus enfrenta desafios adicionais de integração desses componentes na fuselagem para entregar um produto funcional para os clientes de linhas aéreas. Para que a aeronave seja utilizada de forma produtiva pelas companhias aéreas, no entanto, vários outros atores do seu ambiente, fora da cadeia de suprimentos direta da Airbus, enfrentam desafios de inovação adicionais também. Complementares como aeroportos precisam investir e desenvolver nova infraestrutura para acomodar aeronaves destas dimensões, reguladores precisam especificar novos procedimentos de segurança, e fabricantes de simuladores de treinamento precisam desenvolver novas simulações em que a tripulação será capacitada.

Pressupõe-se que IS terá importância crescente por diversos motivos. Segundo Adner (2006), inovações sistêmicas podem criar valor que nenhuma empresa individualmente poderia criar sozinha. Mlenick (2013) destaca que a maior adoção de IS por parte de fornecedores auxiliaria a prevenir falhas sistêmicas e problemas de qualidade futuros. Leten et al (2013) destacam que na maioria das indústrias as pressões competitivas, incertezas 
tecnológicas, e custos associados com inovação tem tornado mais atrativo para empresas se organizarem em estruturas fluidas, como ecossistemas, ao invés de integração vertical. E este cenário não se limita a grandes empresas. Lipparini e Sobrero (1994) já destacaram que a competitividade de pequenas e médias empresas (PMEs) emerge da capabilidade de formação de redes e coordenação entre empresas, maximizando as competências específicas de cada empresa para a inovação. Para pequenos fabricantes, uma estratégia de fusão ou aquisição para acessar conhecimento necessário é difícil de gerenciar. Para evitar estas restrições, eles contam com uma rede de atores que colaboram entre si.

Como os processos de IS extrapolam as fronteiras da empresa, elas geralmente envolvem a coordenação de diferentes partes da rede de valor. Para Taylor e Levitt (2004), a IS tipicamente aumenta a produtividade geral no longo prazo, porém pode criar custos de troca ou de iniciação para alguns participantes e reduzir ou eliminar o papel de outros, o que torna sua iniciação e difusão mais complexa. Iansiti e Levien (2004) ressaltam a importância crescente de compreender a dinâmica de inovação em ecossistemas complexos para garantir a vantagem competitiva das empresas.

Em paralelo, observa-se que dentre as etapas do processo de inovação, a etapa denominada de fuzzy front end (FFE), que é a etapa inicial e difusa do processo de inovação, é apontada como a que mais carece de investigação e ao mesmo tempo a com maior potencial de aumentar a probabilidade de sucesso (KHURANA \& ROSENTHAL, 1997; KOEN ET AL, 2002; KIM E WILEMON, 2002). Shields e Young (1991) apud Heising (2012) estimaram que, em média, 75 a 90\% dos custos finais de produção de um produto são definidos durante as etapas iniciais de conceituação da inovação. Luoma et al (2008) apud Thanasopon et al (2016) apresentaram porcentagem semelhante, indicando que apesar de representar usualmente apenas $10 \%$ dos custos do projeto, $70 \%$ dos custos totais do projeto de desenvolvimento são comprometidos nesta etapa.

Define-se FFE como etapa inicial e em geral caótica que se inicia na identificação de oportunidades e geração de ideias e termina na aprovação de novos conceitos para uma fase mais estruturada do processo de inovação (SMITH E RENERTSEN, 1991; KOEN ET AL, 2002), usualmente dentro de um modelo tipo Stage Gate ${ }^{\circledR}$ (COOPER, 1990) executado por times de desenvolvimento de novos produtos. 
O conceito de FFE surge, portanto, no contexto do desenvolvimento de novos produtos dentro de uma única organização. Pesquisas que extrapolam os limites da organização abordam apenas um único ator adicional no ecossistema de negócios (VAN DER MEER-KOOISTRA E SCAPENS, 2015), tais como fornecedor (WAGNER, 2012) e usuários/clientes (MAGNUSSON, 2009; DAHL, 2002). Os estudos de colaboração entre funções (cross-functional colaboration) aparentam limitar-se a áreas dentro de uma mesma organização (MOENAERT ET AL, 1995). De Brentani e Reid (2012), Fixson et al (2012), Wagner (2012), Verworn e Birgit (2009), Rice et al (2001) indicaram que há uma lacuna nos estudos de FFE em relação a considerações de mais variáveis e stakeholders externos à organização (fatores provenientes do ambiente) na compreensão desta etapa inicial do processo de inovação.

Segundo Oliveira (2012), o FFE, também chamado de planejamento da inovação, é importante para as empresas, pois é nele que são definidas, avaliadas e selecionadas as propostas dos produtos que serão desenvolvidos e lançados no mercado e, portanto a elaboração de métodos que melhorem este processo traz benefícios para o desempenho das empresas no processo de inovação. Ainda segundo Oliveira (2012), é comum encontrar a frase "one size does not fit all", indicando a necessidade de diferenciação do método de planejamento de inovação segundo a tipologia de inovação em diversos estudos na literatura. No entanto, nenhum destes autores explora as diferenciações entre o FFE de inovações autônomas e sistêmicas, apresentando-se uma lacuna de pesquisa.

Analisando a literatura de IS sob o enfoque da etapa de FFE, para Gawer e Cusumano (2014) ainda não entendemos bem como surgem plataformas industriais, entendidas como produtos, serviços e tecnologias desenvolvidas por uma ou mais empresas que servem como fundações sobre as quais um número maior de empresas pode construir inovações complementares. Hellström (2015) apontou que um desafio comum para o desenvolvimento inicial de IS é a incerteza acerca de quem será o primeiro a fazer investimentos, ou de qual será a lucratividade dado que ela depende do investimento de outros. Adner (2006) apontou a insuficiência dos processos tradicionais de avaliação de novas oportunidades que consideram apenas os riscos da empresa focal, trazendo à tona a necessidade de ajustar expectativas iniciais tendo em vista os potenciais desafios e atrasos de inovações complementares. Esta expectativa inicial pode alterar completamente o perfil de risco do investimento, o que exige 
modelos de gestão e financiamento também completamente distintos. Observa-se que existem estudos abordam o surgimento de sistemas de inovação (BINZ ET AL, 2013; EDQUIST, 2010), porém os mesmos focam-se na unidade de análise indústria, região ou país, sendo mais voltados aos criadores de políticas públicas de fomento à inovação e do que a gestores de empresas que buscam inovações sistêmicas.

A teoria de inovação disruptiva introduzida por Christensen (1997), apoia-se na criação de novas redes de valor, explicando como tecnologias disruptivas conseguem atender melhor a segmentos de clientes não prioritários (low-end), para as empresas incumbentes. Não obstante, essa teoria não explica como as empresas inovadoras se coordenam para entregar uma nova proposta de valor aos clientes, que não poderia ser gerado por nenhuma delas isoladamente. Christensen e Raynor (2003), complementando a teoria, indicam que a empresa inovadora deve considerar não apenas o produto (ou o serviço a ser prestado - "job to be done" - ao cliente), como também inovar em seus canais de distribuição, buscando alinhamento de objetivos, porém não se aprofundam na teoria por trás desta coordenação.

Para exemplificar esta lacuna, no caso discutido por Christensen (1997) sobre estratégias para a inovação do carro elétrico se tornar disruptiva, o autor levanta possíveis novos compradores que podem se beneficiar das aparentes desvantagens deste produto (baixa velocidade e pouca autonomia), como por exemplo pais de adolescentes que fazem trajetos curtos e cujo principal requisito é segurança. Porém não discute as questões mais críticas em relação a esta inovação do ponto de vista sistêmico, como por exemplo, a coordenação com a indústria de baterias e infraestrutura de distribuição de energia elétrica. Neste sentido, seu foco permanece muito mais centrado na relação díade entre empresa e consumidor do que os complexos arranjos entre empresas que viabilizam a entrega de valor ao cliente final.

Acessando outra corrente teórica na área de gerenciamento de projetos, a gestão de stakeholders, observa-se potencial relação entre o chamado ambiente de stakeholders do projeto, entendido como todas as organizações que podem afetar e ser afetados pelo projeto, incluindo as relações entre eles (AALTONEN, 2011), e a gestão de IS. No entanto, não foi encontrada nenhuma referência na literatura relacionando a gestão de stakeholders como mecanismo para a iniciação de IS. 
Observa-se, portanto, que há tanto relevância quanto uma lacuna de pesquisa no tema, sugerindo a seguinte questão de pesquisa (QP): Como se diferencia o FFE de IS?. A presente pesquisa visa contribuir na redução desta lacuna de pesquisa.

\subsection{Objetivos}

O objetivo geral (OG) da dissertação é investigar como se diferencia o FFE em projetos de IS. Tendo isso em vista, os objetivos específicos (OE) são:

OE 1.0 - Investigar a etapa de FFE em projetos de IS, identificando se o conceito de FFE como aplicado na literatura de desenvolvimento de novos produtos se adequa a esta tipologia de inovação (isto é, se as etapas da FFE, entradas e saídas são as mesmas), ou se há necessidade de adequação. Neste caso devirá a necessidade de identificar quais são as subetapas e práticas de gestão empregadas para se iniciar uma IS, tanto na literatura como empiricamente.

OE 1.1 - Propor um quadro conceitual de FFE para projetos de IS.

OE 1.2 - Investigar como se dá a etapa do FFE de IS na prática, caracterizando as dinâmicas de coordenação e articulação do ecossistema de inovação.

\subsection{Estrutura da dissertação}

A dissertação em desenvolvimento está baseada na análise crítica da comparação entre a discussão teórica e evidências empíricas a serem coletadas na pesquisa de campo. A Figura 1 traz uma visão esquemática da dissertação. Por um lado, a dissertação evidencia o resultado da literatura sobre FFE e IS, chegando a discussões relativas ao modelo conceitual da etapa e das práticas de gestão indicadas na literatura. Por outro lado, as evidências empíricas extraídas de empresas com projetos de IS serão coletadas na forma de estudos de casos com empresas em diferentes posições no ecossistema de negócios. Esses estudos serão baseados na coleta de dados de entrevistas semi-estruturadas, documentos publicados e observações diretas. A coleta de dados empíricos foi separada em duas etapas: estudo piloto e estudos exploratórios. Por fim, pontos em comum e em contradição entre o levantamento teórico e empírico serão evidenciados, trazendo conclusões interessantes capazes de contribuir para a base conhecimento referente ao FFE de IS. 


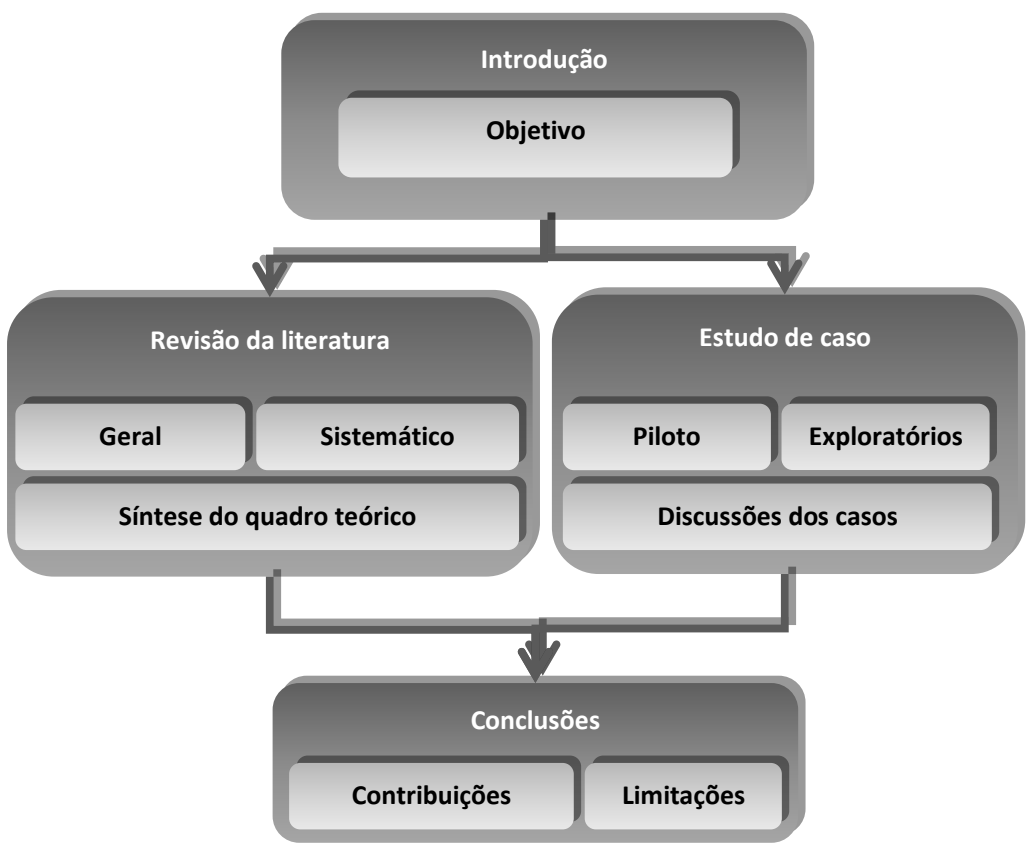

Figura 1. Estrutura da dissertação. 


\section{Métodos de Pesquisa}

Neste capítulo apresentam-se as opções metodológicas adotadas para o desenvolvimento da pesquisa.

Conforme apresentado no capítulo introdutório o objetivo da pesquisa é investigar como se diferencia o FFE em projetos de IS. Trata-se, portanto de pesquisa de caráter exploratório que adotará estratégia de pesquisa que mescla revisão sistemática de literatura e estudos de caso.

A escolha da metodologia de estudo de caso exploratório foi decorrente da revisão sistemática da literatura. IS é um termo relativamente recente, cunhado em 2002 por Chesbrough e Teece. Não foi encontrado nenhum artigo na amostra que fizesse referência a FFE ou mesmo modelos conceituais em fases do processo de inovação na literatura de IS. Ao mesmo tempo, não foi encontrada na literatura de FFE nenhuma menção a particularidades para casos de IS. A relevância de ambos os tópicos, isoladamente, foi confirmada pelos estudos analisados.

Segundo Eisenhardt (1989), quando pouco é conhecido sobre o fenômeno, e quando as perspectivas atuais podem ser inadequadas porque possuem pouca substanciação empírica, ou não apresentam consenso, a construção de teoria por meio de estudos de caso é uma metodologia de pesquisa adequada. Adicionalmente, observa-se que tanto na literatura de FFE como de IS a metodologia de estudo de caso foi a escolhida com maior frequência. Em específico, uma das características inerentes à IS é o seu caráter evolutivo e dinâmico, motivo pelo qual estudos de caso longitudinais que acompanham a formação dos novos ecossistemas de negócios tem sido aplicados.

\subsection{Etapas da pesquisa}

A metodologia está baseada em três macro-etapas, conforme ilustra a Figura 2. A primeira macro-etapa, levantamento sistemático da literatura, identifica as principais correntes teóricas relacionadas a FFE e IS, como subsídio para a construção do quadro teórico em termos de construtos, variáveis e como operacionalizá-las. Nesta fase adotam-se técnicas de bibliometria com análise de redes (NEELY, 2005) e de análise de conteúdo (LOCKE E GOLDEN-BIDDLE, 1997; PRASAD E TATA, 2005). 
Na segunda macro-etapa foi conduzido um estudo de caso piloto, com o objetivo de verificar potencial para pesquisa acadêmica e contribuir na definição dos construtos e variáveis que norteiam a pesquisa a partir de evidências empíricas de empresa engajada no desenvolvimento sustentável (VOSS ET AL, 2002). Os resultados da revisão bibliográfica e do estudo de caso exploratório evidenciam possível adaptação de modelos já consolidados em FFE para o caso de IS. Um exemplo é o framework de FFE não linear de Koen et al (2002), a ser aprofundado na seção 3.1.2.

A análise crítica da primeira macro-etapa aponta para diferenciações existentes entre práticas de gestão adotadas pelas empresas segundo seu posicionamento ou papel no ecossistema de negócios (IANSITI E LEVIEN, 2002; MAULA ET AL, 2005; ADNER E KAPOOR, 2010), o que aponta a necessidade de inclusão de casos representativos de cada posicionamento de atores que contribuem para a inovação e desenvolvimento dos ecossistemas de negócios, segundo a classificação de Iansiti e Levien (2004) de empresas plataforma (keystones) e empresas de nicho, a fim de garantir a generalização das conclusões e a análise contingencial de FFE em IS.

Iansiti e Levien (2004) também apresentam uma terceira classificação de empresa dominante, porém sua atuação é de eliminação de outras empresas no mercado, frequentemente expandindo em novos mercados em que eles dominam ou até mesmo eliminam. Tipicamente os dominantes prejudicam a saúde do ecossistema de negócios reduzindo a diversidade, eliminando competição, limitando escolhas do consumidor e reduzindo a inovação. Como o interesse de pesquisa é estudar projetos de inovação sistêmica que criam novas redes de valor para florescimento do ecossistema de negócios, projetos de empresas dominantes não foram inclusas na amostra.

Assim, a terceira macro-etapa contempla o estudo de casos mais aprofundado que tem como objetivo trazer dados de campo de maneira mais sistemática e abrangente, com empresas em diferentes posições ou papeis no ecossistema de negócios a fins comparativos. Esses estudos de caso são ainda de caráter exploratório, uma vez que se propõem a explorar a validade dos construtos levantados nas macro-etapas anteriores (VOSS ET AL, 2002). 


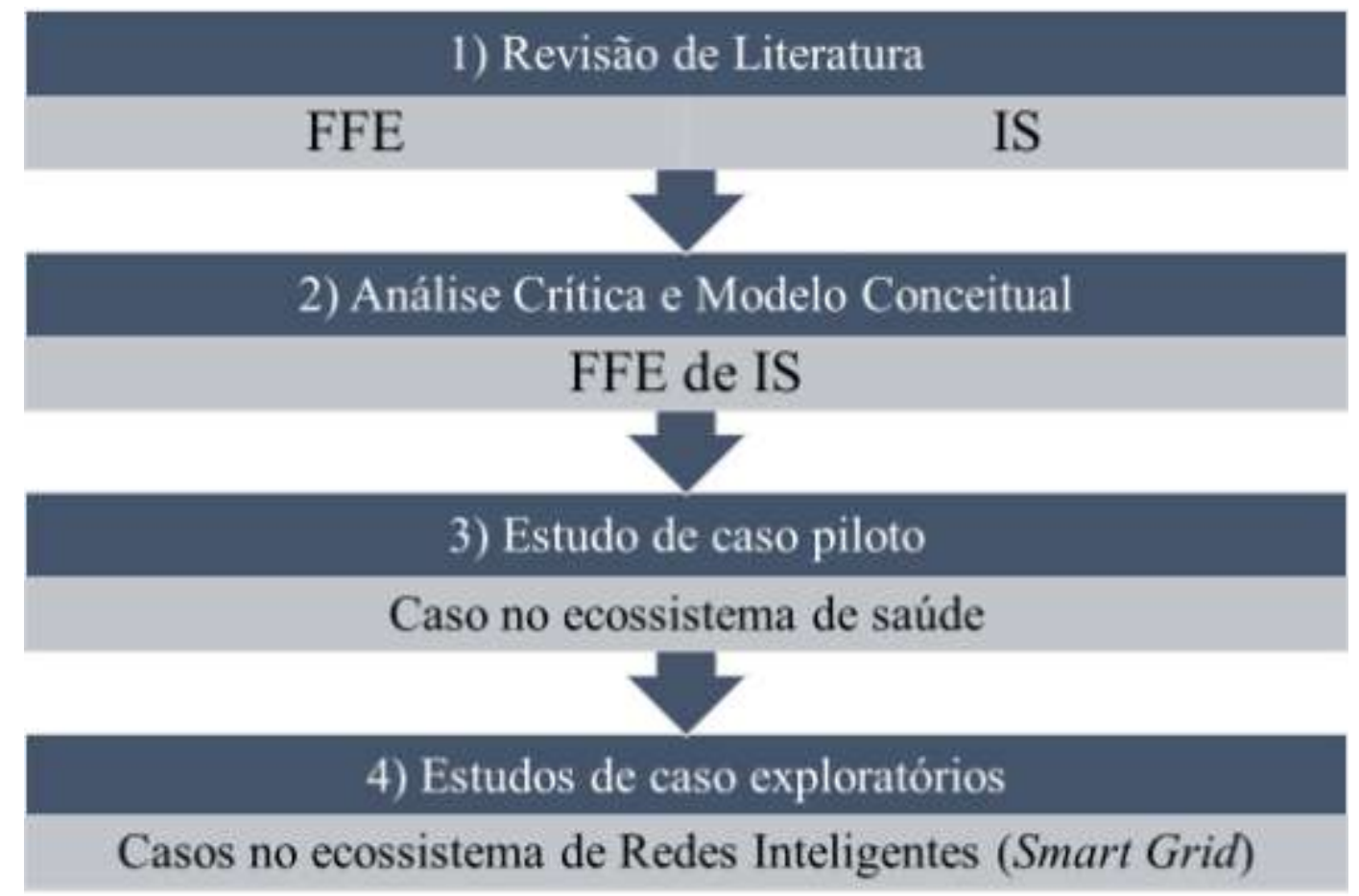

Figura 2 - Macro-etapas da pesquisa.

Tendo em vista que o objetivo da dissertação é investigar como as empresas estão lidando com FFE em IS, um maior detalhamento da metodologia associada a cada uma das macro-etapas de pesquisa é apresentado a seguir.

\subsection{Revisão sistemática de literatura}

Para obter um panorama geral da literatura sobre a intersecção de temas relacionados à sustentabilidade corporativa e ao sistema de indicadores de desempenho, foi consultada a base de dados ISI Web of Knowledge (Web of Science), contemplando publicações do início da base de dados até janeiro de 2016. Essa base foi escolhida devido à sua abrangência, bem como compatibilidade de sistema com a ferramenta de análise bibliométrica SITKIS. A revisão foi dividida em três sub-etapas:

1. Revisão do conceito de FFE, com ênfase em modelos conceituais e relações entre práticas de gestão e desempenho superior. Segundo Oliveira (2012), termos correlatos a FFE por outros autores são front-end, pré desenvolvimento e fases iniciais, por isso utilizados também como palavras chave da busca.

2. Revisão do conceito de IS, com ênfase nas unidades de análise empresas envolvidas em projetos de IS (e não a formação de ecossistemas, indústrias, mercados ou sistemas 
de inovação geográficos), dado o enfoque da pesquisa no olhar gerencial da firma e não de políticas públicas em um sentido macroeconômico. Adner (2006) aponta os seguintes termos correlatos: liderança em plataforma (GAWER E CUSUMANO, 2002), estratégia de plataforma - keystone strategy (IANSITI E LEVIEN, 2002), inovação aberta (CHESBROUGH, 2003), ecossistemas de inovação (ADNER E KAPOOR, 2010) e redes de valor (CHRISTENSEN, 1997). Dado que IS é um subtópico muito específico dentro da teoria de inovação aberta, não considerou-se este termo na seleção da amostra estudada.

Para obter a primeira amostra foram selecionados artigos dentro da base de dados ISI Web of Science por incluir artigos de outras bases de dados como Scopus, ProQuest e Wiley que foram publicados em periódicos indexados com fator de impacto calculado pelo JCR (Journal Citation Report). Além disso, esta base de dados fornece metadados essenciais para análise bibliométrica, incluindo resumos, referências, número de citações, lista de autores e palavras-chave. Foram considerados todos os artigos registrados na base até janeiro de 2016 na busca.

Foram utilizados os seguintes filtros para a etapa 1:

i. Tópico: "fuzzy front end" or "fuzzy-front-end" or "fuzzy-front end" or (("front-end" or "pre-development" or "early phases") and "innovation")

\section{ii. Tipo de documento $=($ ARTICLE OR REVIEW $)$}

Como resultado, foram obtidos inicialmente 326 artigos e revisões. De todos os 326 artigos foi feita a leitura dos resumos para exclusão daqueles que não tratavam do tema da pesquisa. Foram excluídos os artigos que estavam fora do escopo da pesquisa (72 apenas citam as fases iniciais porém não enfocam nas mesmas, mas sim em outras etapas do DNP, 25 tratavam de unidade de análise diferente de firma ou projeto, tais como indústrias, países ou regiões, 23 tratavam sobre outro significado de front-end, como contato direto com cliente no contexto de serviços ou circuito eletrônico de interface, 8 tratavam de fases iniciais de outros fenômenos que não a inovação, 2 tratavam de algoritmos com lógica fuzzy e 1 era específico para descoberta de novos medicamentos para indústria farmacêutica apenas), resultando em 195 artigos. 
Para selecionar os artigos mais relevantes para análise de conteúdo, calculou-se o fator de impacto de cada artigo (I) com base no número de citações $(C)$ e o fator de impacto do periódico onde foi publicado, obtido pelo Journal Citation Report (JCR), conforme equação (1), adaptado de Carvalho et al (2013). A adaptação foi a somatória de um também no número de citações, para comparação entre as publicações mais recentes que não possuem nenhuma citação.

$$
\mathrm{I}=(\mathrm{C}+1) *(\mathrm{JCR}+1)
$$

Listaram-se os artigos em ordem decrescente de fator de impacto, realizou-se uma análise de Pareto e foram selecionados os primeiros 50 artigos que representam $80 \%$ do fator de impacto total da amostra para análise de conteúdo. Para considerar artigos recentes (publicados há menos de cinco anos) que não receberam citações por serem novos e não por serem irrelevantes, foram selecionados 18 trabalhos publicados a partir de 2012 em periódicos de alto impacto (JCR superior a 2), totalizando uma amostra de 68 artigos, listados no Anexo I. Para a definição e modelos conceituais de FFE, considerou-se não apenas os modelos apresentados nos artigos selecionados na amostra, mas também os referenciados pelos artigos de maior impacto, incluindo livros.

Foram utilizados os seguintes filtros para a etapa 2:

i. Tópico: ("systemic innovation" or ("keystone advantage" and innovation) or "innovation ecosystem" or ("value network" and innovation) or ("platform leadership" and innovation) or (interdependen* and innovation)) and (firm or project).

ii. Tipo de documento=(ARTICLE OR REVIEW)

Obteve-se uma amostra inicial de 414 artigos. De todos os 414 artigos foi feita a leitura dos resumos para exclusão daqueles que não tratavam do tema da pesquisa. Foram excluídos os artigos que estavam fora do escopo da pesquisa (130 pela unidade de análise principal ser acima de firma ou projeto, tais como indústrias, redes, regiões ou países; 93 por tratarem exclusivamente de interdependências internas à empresa; 73 por enfocarem em interdependência em outros projetos/processos que não de desenvolvimento de inovação; 47 por tratarem de colaboração apenas em termos de troca de conhecimento, sem inovação 
interdependente; 1 por ser um artigo repetido na amostra, que apenas foi republicado em outro livro) resultando em uma amostra de 61 artigos.

Listando-se os artigos em ordem decrescente de fator de impacto, foram selecionados 9 artigos que representam $80 \%$ do fator de impacto total da amostra (sendo que dois são capítulos de um livro), somados a 16 artigos publicados nos últimos cinco anos da amostra em periódicos com JCR superior a 1 (neste caso foi utilizado um critério de corte menos restritivo, dado o número menor de artigos da amostra), totalizando uma amostra de 25 artigos, listados no Anexo II.

A partir da amostra de artigos realizou-se uma análise de redes de palavras-chave para cada tema principal (FFE e IS), utilizando os softwares SITKIS para organização dos dados (SCHILDT, 2002), bem como Ucinet6 associado à ferramenta NetDraw para desenhar os diagramas (BORGATTI; EVERENTT; FREEMAN, 2002) para identificação seus principais conceitos e construtos. Esta rede é construída com base nas palavras-chave utilizadas pelos autores na amostra, em que as ligações correspondem ao uso de ambas as palavras-chave de um mesmo artigo e a espessura da ligação é proporcional ao número de artigos citando duas palavras-chave no mesmo tempo. Esta abordagem foi escolhida a fim de compreender rapidamente uma visão geral das relações entre os construtos para a modelagem conceitual, baseado na literatura atual.

Fez-se uma primeira análise bibliométrica de frequência de publicações por ano e por periódico da amostra selecionada, bem como levantamento de abordagens metodológicas. Em seguida, procedeu-se à análise de conteúdo para identificar definições e modelos conceituais.

A análise de conteúdo foi realizada nas seguintes etapas:

1) Análise de conteúdo da literatura de FFE para seleção do modelo conceitual para servir de espinha dorsal da árvore de códigos da análise tanto da literatura de FFE quanto IS

2) Análise de conteúdo da literatura de FFE e IS com base no modelo conceitual definido na etapa anterior.

3) Criação de novos subcódigos dentro da árvore de códigos iniciais que emergiram durante a análise de conteúdo. Fez-se então uma terceira etapa de classificação dos trechos relevantes com base na árvore atualizada. 
Os modelos conceituais de FFE foram comparados e selecionou-se o mais abrangente, ou seja, o modelo que foi capaz de incluir todos os demais para estruturar a análise de conteúdo. Esta abordagem foi adotada pois, como sugere Webster e Watson (2002), deve-se estruturar a revisão bibliográfica a partir de conceitos e não autores.

Estruturaram-se em uma tabela todos os relacionamentos entre variáveis encontrados pelos autores (sejam eles comprovados por significância estatística ou por meio de articulação teórica, estudos de caso ou revisão de literatura). Em pesquisas quantitativas, este relacionamento é identificado na declaração das hipóteses ou proposições dos autores (e que foram suportadas estatisticamente), por exemplo $\mathrm{H} 1$ : a quantidade de parceiros tem uma relação em forma de $U$ invertido em relação ao desempenho de parcerias em projetos de pesquisa e desenvolvimento multi parceiros (MISHRA ET AL, 2015). Esta hipótese foi relacionada ao código Entr_MO (Motor) na análise de conteúdo. Em pesquisas qualitativas ou na seção de revisão de literatura dos artigos quantitativos, foram capturadas sentenças que evidenciam condições e suas consequências relacionadas com o tema desta pesquisa, por exemplo: "quando funcionam [CONDIÇÃO], ecossistemas permitem que empresas criem valor maior do que qualquer participante sozinho poderia criar sozinho [CONSEQUÊNCIA]” (ADNER, 2006). Foram identificados 1.204 trechos na literatura de FFE, 760 na de IS e 399 na de stakeholders.

Os relacionamentos de FFE e IS foram tratados separadamente e classificados segundo o modelo conceitual de FFE adotado (KOEN ET AL, 2001). A árvore de códigos inicialmente utilizada foi complementada com subtópicos emergentes durante a análise dos trechos. 
Quadro 1 - Árvore de códigos inicial baseada no modelo de Koen et al (2001)

\begin{tabular}{|l|l|}
\hline Sigla & \multicolumn{1}{c|}{ Descrição } \\
\hline Ativ_IO & Atividade de Identificação de oportunidades \\
\hline Ativ_AO & Atividade de Avaliação de oportunidades \\
\hline Ativ_GI & Atividade de Geração de ideias \\
\hline Ativ_SI & Atividade de Seleção de ideias \\
\hline Ativ_DC & Atividade de Definição do conceito \\
\hline Entr_MO & Entrada: Motor \\
\hline Entr_FI & Entrada: Fatores de influência \\
\hline
\end{tabular}

\section{Quadro 2 - Árvore de códigos final}

\begin{tabular}{|l|l|}
\hline Sigla & \multicolumn{1}{c|}{ Descrição } \\
\hline Ativ_IO & Atividade de Identificação de oportunidades \\
\hline Ativ_AO & Atividade de Avaliação de oportunidades \\
\hline Ativ_GI & Atividade de Geração de ideias \\
\hline Ativ_SI & Atividade de Seleção de ideias \\
\hline Ativ_DC & Atividade de Definição do conceito \\
\hline Ativ_DC_MN & Modelo de Negócios \\
\hline Entr_MO & Entrada: Motor \\
\hline Entr_MO_MC & Mecanismos de Coordenação \\
\hline Entr_FI & Entrada: Fatores de influência \\
\hline Entr_FI_ME & Mapeamento do ecossistema de negócios \\
\hline Entr_FI_PO & Posicionamento no ecossistema de negócios \\
\hline
\end{tabular}

Na sequência, realizou-se uma síntese e análise crítica integrada dos agrupamentos encontrados para cada um dos temas. Por fim, foi proposto um modelo conceitual de gestão de FFE específico para IS, à luz da análise crítica das duas amostras da literatura.

Para análise de conteúdo de gestão de stakeholders, os trechos que detalhavam práticas de gestão de stakeholders foram destacados e codificados ao longo da análise da literatura. Optou-se por não utilizar uma codificação prévia em um primeiro ciclo de análise. A partir desta codificação na literatura de stakeholders, a mesma árvore de códigos foi aplicada para analisar o conteúdo da literatura de inovação sistêmica, com eventuais inclusões caso necessário. Realizou-se por fim uma tabela comparativa entre as duas literaturas, sintetizando o referencial teórico.

\subsection{Estudo de caso piloto}

O método mais aplicado em pesquisas sobre inovações sistêmicas é o estudo de caso único, que explora a evolução da inovação sistêmica ao longo do tempo de forma 
retrospectiva ou longitudinal. Corroboram para a viabilidade de concepção de teoria a partir de estudos de caso os autores Einsenhart (1989) e Yin (2002). A abordagem qualitativa da presente pesquisa também se justifica por permitir a descrição e o entendimento de interações, significados e processos humanos reais (GEPHART, 2004). Considerando a discussão de diferenciações do FFE em IS, estudo de caso contempla duas fases: piloto e exploratório. Para a primeira fase, como o tema inovação sistêmica ainda está em processo de estruturação, com conceitos ainda em elaboração, a metodologia escolhida para coleta de dados empíricos iniciais é de natureza exploratória (FORZA, 2002).

Para o planejamento e execução do estudo de casos, aplicou-se a metodologia de estudo de casos recomendada por Miguel (2007). A unidade de análise selecionada foi a de projetos de inovação sistêmica contendo todas as fases do ciclo de vida propostas por Koen et al (2002), ou seja, incluindo a fase de FFE, fase de desenvolvimento estruturado e fase de comercialização.

Assim, o estudo de caso piloto teve como objetivo de validação e refinamento do protocolo de pesquisa. Essa fase piloto, juntamente à revisão da literatura, permite obter uma visão inicial de construtos a serem estudados nos estudos de caso exploratórios (VOSS; TSIKRIKTSIS; FROHLICH, 2002).

Para encontrar um caso adequado para o estudo piloto para teste do protocolo de pesquisa, realizou-se uma busca por IS envolvendo mais de um ator no desenvolvimento da inovação. A área de saúde foi pré-selecionada por reunir uma grande multiplicidade de atores com interesses conflitantes, por ser um problema de todos os países do mundo e por apresentar profundas falhas sistêmicas que exigem transformações estruturais, como por exemplo, a mudança no modelo de remuneração e na forma de mensurar custos e benefícios (Porter, 2013). Selecionou-se o caso do projeto de desenvolvimento da Vitalbox, uma plataforma de saúde pessoal, onde qualquer pessoa pode fazer uma análise online de riscos e obter um mapa da sua própria saúde, um serviço inovador, preventivo e cuja fonte pagadora não é o usuário final, o que caracteriza seu elemento sistêmico. O contato obtido foi o dos sócios-fundadores da empresa.

Os meios de coleta de dados selecionados foram análise documental das informações públicas do projeto e entrevistas presenciais, com roteiro semi-estruturado, com o sóciofundador e demais sócios (caso a primeira entrevista seja insuficiente para responder às 
questões propostas). Para análise de dados foram selecionados os principais modelos na revisão de literatura para classificação e avaliação da adequação das práticas de gestão de stakeholders para a inovação sistêmica em questão.

O protocolo de pesquisa foi composto por roteiro e questionário associados às perguntas de pesquisa, à luz do referencial teórico (ver anexo A). Para controle da pesquisa, o questionário foi revisado pela orientadora. Optou-se pela gravação da entrevista com o consentimento do respondente para posterior transcrição, o que permitu, além da análise de conteúdo, a validação de outros pesquisadores quanto à fidelidade ao protocolo de pesquisa. $\mathrm{O}$ questionário foi enviado para o entrevistado antes da execução da entrevista presencial para esclarecimento de dúvidas por correio eletrônico.

A coleta de dados resultou em uma coletânea de informações disponíveis no website da Vitalbox e duas horas e meia de gravação em áudio da entrevista com um dos sóciosfundadores da empresa e mensagens de correio eletrônico para confirmação das informações. Durante a entrevista um mapa de stakeholders e a linha do tempo do projeto foram esquematizados em próprio punho pelo entrevistado.

Utilizou-se para análise de conteúdo a árvore de códigos originada a partir do quadro síntese do referencial teórico obtido na primeira fase da pesquisa. Adicionalmente, modelos conceituais identificados na revisão de literatura foram utilizados para a avaliação da adequação das práticas de gestão do FFE. Cruzando-se as proposições da literatura e as evidências empíricas do estudo de caso, realizou-se uma discussão teórica para orientar os estudos de caso exploratórios.

\subsection{Estudo de casos}

A metodologia de pesquisa para condução do levantamento dos dados de campo de maneira mais aprofundada conta com estudos de caso de caráter exploratórios, permitindo evidenciar contrastes e consonâncias dos dados empíricos da etapa de estudo de caso piloto e de revisão da literatura (VOSS; TSIKRIKTSIS; FROHLICH, 2002).

Assim como no estudo de caso piloto, selecionou-se um ecossistema de inovação complexo, que está em formação: o ecossistema de Redes Inteligentes (Smart Grid), conforme recomendam Miyazaki e Kijima (2000). O termo Smart Grid pode ser definido como o uso de comunicação e de modernos recursos computacionais para melhorar a 
eficiência e confiabilidade das redes de energia elétrica, e possibilitar a melhoria na oferta e de novos serviços aos consumidores. Esta melhoria equivale a levar o poder da tecnologia da Internet à transmissão, distribuição e uso final da energia elétrica, o que tem o potencial de criar economias substanciais para os distribuidores e consumidores reduzindo as emissões de gases estufa (DA SILVA, 2011). Redes inteligentes são subsistemas dentro de um ecossistema maior: o de Internet das Coisas (Internet of Things).

Internet das Coisas é uma forma de rede que conecta qualquer coisa com a Internet por meio de sensores compatíveis com protocolos compactos, de forma a identificá-la, posicionála, rastreá-la e gerenciá-la inteligentemente (XIAO, 2010). Internet das Coisas tem sido viabilizada pela evolução da tecnologia de sensoriamento, desde etiquetas RFID até redes de sensores sem fio (Wireless Sensor Networks) que utilizam protocolos específicos de comunicação máquina a máquina como Zigbee e 6LoWPAN.

Aplicável em inúmeros segmentos de mercado (cidades inteligentes, automação predial/industrial, logística, saúde, agricultura, monitoramento ambiental), este paradigma tecnológico, para geração de valor para o cliente final requer a coordenação de uma rede de atores. Essa rede complexa envolve fornecedores de semicondutores, desenvolvedores de hardware, middleware e softwares de aplicação (composta por empresas de micro, pequeno, médio e grande porte), operadoras de telecomunicações, integradores de TI, especialistas em análise dos dados (data analytics/big data), comunidades de pesquisa, organizações que especificam e definem os protocolos de comunicação, governo, agências de fomento à inovação, agências regulamentadoras, entre outras.

Optou-se por um ecossistema diferente do de saúde, utilizado no primeiro estudo de caso, para aumento do poder de generalização das conclusões da pesquisa. Serão selecionados projetos realizados por empresas representantes de cada papel para o desenvolvimento desse ecossistema de negócios, conforme definido por Iansiti e Levien (2004). São eles:

- Plataforma (keystone): são reguladores da saúde do ecossistema. São hubs ricamente conectados que provêm as fundações para criação de muitos nichos, regulam conexões entre os membros do ecossistema e trabalham para aumentar a diversidade e produtividade. Eles provêm uma plataforma estável e previsível sobre a qual outros membros do ecossistema podem depender, e cuja remoção leva a um colapso de todo o sistema. Eles asseguram sua própria sobrevivência e saúde atuando diretamente na 
melhoria da saúde do ecossistema como um todo. Exemplos são a Microsoft Corporation no ecossistema de computação, Wal-Mart no ecossistema de varejo (IANSITI E LEVIEN, 2004) e a Cisco Systems no ecossistema de equipamentos para Internet (LI, 2009).

- Nicho: organização que exibe níveis típicos (ou menos do que típicos) de conectividade com outros participantes do ecossistema. Além de serem os atores mais numerosos dos ecossistemas, muitos estão alocados nas extremidades das redes, onde novas inovações estão sendo ativamente buscadas e onde novos produtos e serviços são desenvolvidos e novos mercados explorados. São críticos para a saúde do ecossistema porque eles originam a diversidade. Exemplos: NVIDIA (IANSITI E LEVIEN, 2004), Scientific-Atlanta e GeoTel Communications (LI, 2009).

Os critérios de seleção dos casos são apresentados no Quadro 2.

Quadro 2 - Critérios de seleção dos estudos de caso exploratórios.

\begin{tabular}{|c|c|}
\hline Critérios de seleção da amostra & Referências \\
\hline $\begin{array}{l}\text { O projeto de inovação tecnológica passou pela etapa de FFE de } \\
\text { forma bem sucedida, sendo aprovado para desenvolvimento. }\end{array}$ & Koen et al (2002) \\
\hline $\begin{array}{l}\text { A inovação gerada exigiu ajustes significativos em outros atores do } \\
\text { ecossistema de negócios. Por ajustes significativos entenda-se } \\
\text { inovações complementares, desenvolvimento de novas capacidades } \\
\text { ou mudanças nos processos de negócios. }\end{array}$ & $\begin{array}{l}\text { Chesbrough e Teece } \\
\text { (2002); Taylor e } \\
\text { Levitt (2004); Maula } \\
\text { et al (2005) }\end{array}$ \\
\hline $\begin{array}{l}\text { O projeto de inovação contribuiu para o desenvolvimento do } \\
\text { ecossistema de negócios, seja aumentando sua diversidade ou sua } \\
\text { produtividade. }\end{array}$ & $\begin{array}{l}\text { Iansiti } \\
(2004)\end{array}$ \\
\hline $\begin{array}{l}\text { Há pelo menos um caso em cada classificação de papel no } \\
\text { ecossistema de negócios ("plataforma" e "nicho"). }\end{array}$ & e Levien \\
\hline $\begin{array}{l}\text { Há casos de empresas com atuações diversas no ecossistema de } \\
\text { negócios de Redes Inteligentes (Smart Grid). }\end{array}$ & $\begin{array}{l}\text { Voss; } \quad \text { Tsikriktsis; } \\
\text { Frohlich, } 2002\end{array}$ \\
\hline
\end{tabular}

Buscando manter o rigor da pesquisa, os dados serão coletados de múltiplas fontes, tais como entrevistas semi-estruturadas, documentos publicados e documentos internos (VOSS; TSIKRIKTSIS; FROHLICH, 2002). As evidências empíricas consideradas para análise serão resultantes, portanto, da análise crítica do cruzamento dessas diversas fontes de dados (VOSS; TSIKRIKTSIS; FROHLICH, 2002).

Antes da realização da pesquisa de campo, será realizado um levantamento em dados gerais das empresas focais, buscando entender seu negócio, o ecossistema de negócios em que estão inseridas e como estão posicionadas no mesmo. Esse conhecimento prévio da empresa 
será capaz de melhorar o diálogo com os entrevistados, possibilitando, eventualmente, a identificação de linguagem compatível e jargões da empresa, bem como o foco maior das entrevistas ao dispensar questionamentos sobre dados já disponíveis publicamente.

O plano de pesquisa conta com a viabilização de pelo menos quatro casos. Para cada empresa, a previsão é de contatar o principal responsável pela coordenação dos projetos de inovação sistêmica dos projetos de inovação estudados. Caso permitido pelas empresas, as entrevistas serão gravadas para melhor análise das respostas. 


\section{Revisão de Literatura}

Neste capítulo serão discutidos os pilares teóricos da pesquisa, primeiramente cada construto em separado e por fim a apresentação de modelo conceitual que integra a literatura de FFE e IS.

\subsection{Revisão de FFE}

Nesse tópico será lapidado o conceito de FFE, apresentando inicialmente o panorâma dos artigos por meio de uma análise bibliométria e, posteriormente um maior aprofundamento por meio da análise de conteúdo dos artigos da amostra utilizando-se o modelo conceitual mais abrangente da literatura como padrão principal de codificação dos dados qualitativos.

\subsubsection{Panorâma da literatura de FFE: Resultados da análise bibliométrica}

O primeiro artigo relacionado a FFE da amostra foi publicado em 1992 por Smith \& Reinertsen, principais responsáveis pela difusão do termo. Este artigo é de caráter qualitativo, induzido a partir da experiência. Três anos depois foi publicado um artigo importante de Moenaert et al (1995), apresentando as primeiras análises quantitativas especificamente para a fase de FFE, considerando-se os impactos da colaboração entre as áreas de pesquisa e desenvolvimento e marketing para a redução das incertezas nesta etapa. Houve uma concentração de artigos relevantes em 2002, principalmente com as publicações de Koen et al e Kim \& Wilemon, que integram os conceitos trazidos pelos autores anteriores. A partir de 2009, o número de publicações anuais relevantes sobre o tema é crescente até 2012, e decrescente a partir entre 2012 a 2016, como evidencia a Tabela 1. Uma hipótese para esta tendência de queda é o atingimento da maturidade do tema, restando menos lacunas de pesquisa e com isso menor número de novas publicações. 
Tabela 1 - Número de publicações por periódico por ano (FFE)

\begin{tabular}{|c|c|c|c|c|c|c|c|c|c|c|c|c|c|c|c|c|c|c|}
\hline & \multicolumn{18}{|c|}{ Ano } \\
\hline Periódico & ลั่ & 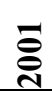 & 气్రి & 气̊̊̆ & 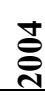 & 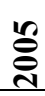 & 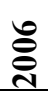 & ڤ్̀ે & 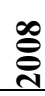 & ڤ્̀े & 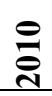 & $\bar{g}$ & $\stackrel{\text { בิ }}{\mathfrak{4}}$ & 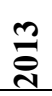 & $\underset{\sim}{\vec{n}}$ & 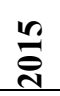 & 룰 & हैं \\
\hline $\begin{array}{l}\text { J Prod Innovat } \\
\text { Manag }\end{array}$ & 3 & 1 & & 1 & & 1 & 1 & 1 & & 3 & & 2 & 1 & & & & & 14 \\
\hline R\&D Manage & & 1 & 1 & 1 & & 1 & 2 & & 1 & 1 & & & & & & & & 8 \\
\hline Technovation & & & & & & & 1 & & & 1 & & & 1 & & 2 & & 1 & 6 \\
\hline $\begin{array}{l}\text { Res Technol } \\
\text { Manage }\end{array}$ & 3 & & 1 & & 1 & & & & & & & & & & & & & 5 \\
\hline Int J Proj Manag & & & & & & & & & & & & 1 & 1 & & 1 & & & 3 \\
\hline $\begin{array}{l}\text { Technol Forecast } \\
\text { Soc }\end{array}$ & & & & & & & 1 & & & & & & & 1 & & 1 & & 3 \\
\hline Expert Syst Appl & & & & & & & & & & & & & 3 & & & & & 3 \\
\hline $\begin{array}{l}\text { J Eng Technol } \\
\text { Manage }\end{array}$ & & & & & & & & & & & & & 1 & & 1 & & & 2 \\
\hline J Clean Prod & & & & & & & & & & & & & & 1 & & 1 & & 2 \\
\hline $\begin{array}{l}\text { J Supply Chain } \\
\text { Manag }\end{array}$ & & & & & & & & & & & & & 1 & & & & 1 & 2 \\
\hline J Acad Market Sci & & & & & & & 1 & & & & & & & & & 1 & & 2 \\
\hline Ind Market Manag & & & & 1 & & & 1 & & & & & & & & & & & 2 \\
\hline Manage Decis & & & & & & & & & & & & 1 & & & & & & 1 \\
\hline J Bus Venturing & & & & & & & & & & & & & 1 & & & & & 1 \\
\hline J Strategic Inf Syst & & & & & & & & & 1 & & & & & & & & & 1 \\
\hline Organ Stud & & & & & & & & & & & 1 & & & & & & & 1 \\
\hline $\begin{array}{l}\text { Manage Account } \\
\text { Res }\end{array}$ & & & & & & & & & & & & & & & & 1 & & 1 \\
\hline Res Policy & & & & & & & & & & 1 & & & & & & & & 1 \\
\hline Ieee T Eng Manage & 1 & & & & & & & & & & & & & & & & & 1 \\
\hline $\begin{array}{l}\text { Cirp Ann-Manuf } \\
\text { Techn }\end{array}$ & & & & & & & & & & & & & & 1 & & & & 1 \\
\hline Sloan Manage Rev & 1 & & & & & & & & & & & & & & & & & 1 \\
\hline $\begin{array}{l}\text { Int J Oper Prod } \\
\text { Man }\end{array}$ & & & & & & 1 & & & & & & & & & & & & 1 \\
\hline J Marketing Res & & & & 1 & & & & & & & & & & & & & & 1 \\
\hline Ann Biomed Eng & & & & & & & & & & & & & & 1 & & & & 1 \\
\hline $\begin{array}{l}\text { Trends Food Sci } \\
\text { Tech }\end{array}$ & & & & & & & & & 1 & & & & & & & & & 1 \\
\hline $\begin{array}{l}\text { J Manage Inform } \\
\text { Syst }\end{array}$ & & & & 1 & & & & & & & & & & & & & & 1 \\
\hline Adv Eng Inform & & & & & & & 1 & & & & & & & & & & & 1 \\
\hline J Manage Stud & & & & & & & & 1 & & & & & & & & & & 1 \\
\hline Total & 8 & 2 & 2 & 5 & 1 & 3 & 8 & 2 & 3 & 6 & 1 & 4 & 9 & 4 & 4 & 4 & 2 & 68 \\
\hline
\end{tabular}

Fonte: Elaborado pela autora. Nota: periódicos listados em ordem decrescente de publicações relacionadas a FFE e identificados pela abreviação do ISI. 
Mais de $30 \%$ dos artigos foram publicados pelos periódicos "Journal of Product Innovation Management"e " $R \& D$ Management", ambos direcionados para pesquisadores e gestores de desenvolvimento de novos produtos e tecnologias.

Para uma primeira análise de principais conceitos, campos de estudo e variáveis envolvidas nas pesquisas de FFE, analisou-se a rede de relacionamentos de palavras-chave da amostra. Nesta rede, as linhas indicam que as palavras chave foram citadas juntas em um mesmo artigo e a espessura da linha corresponde à intensidade da relação (quantas vezes foram citadas juntas). Os resultados foram separados em grupos de afinidade para uma primeira visualização de possíveis modelos conceituais.

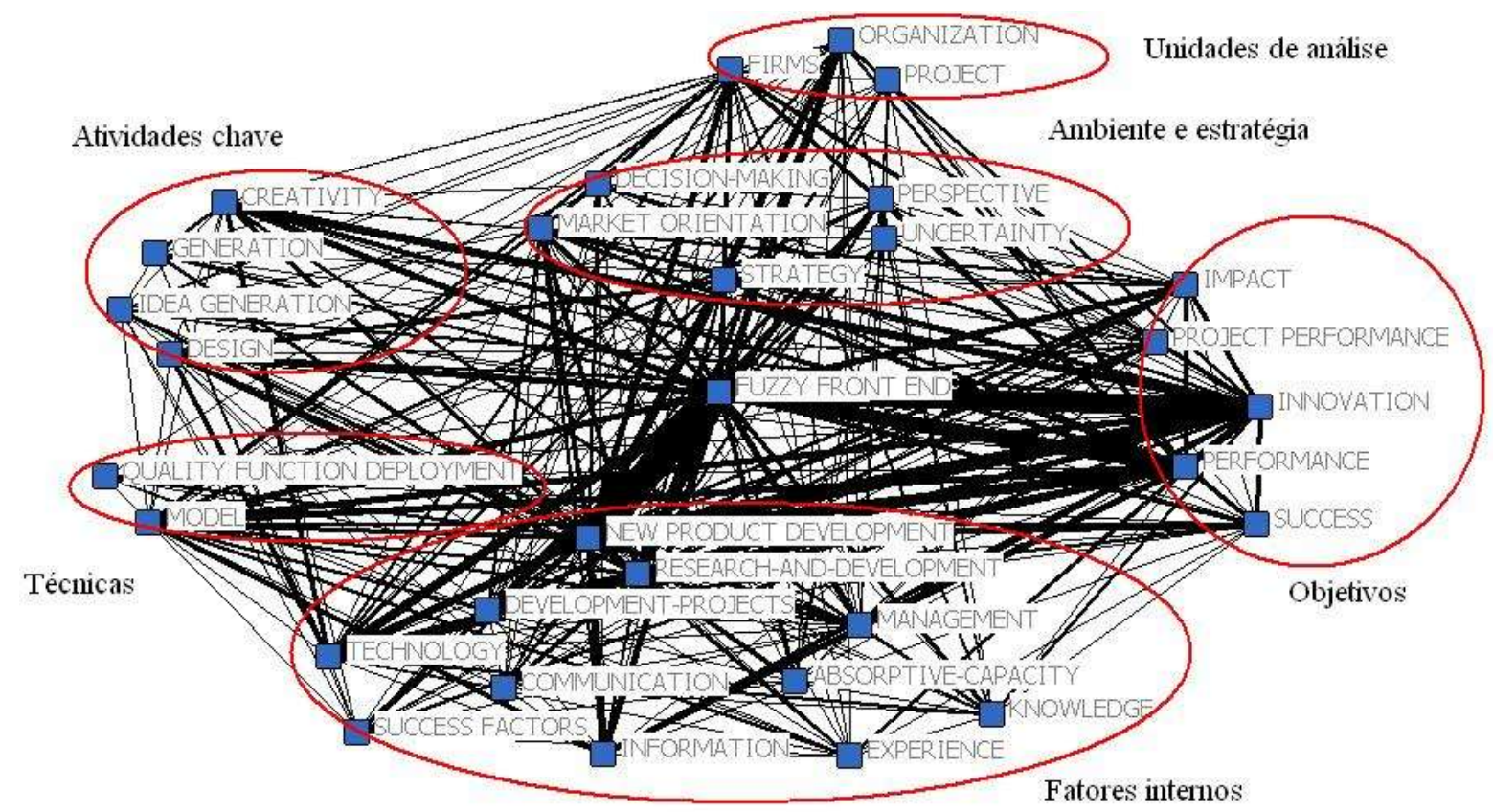

Figura 3 - Rede de palavras chave de FFE. Nota: Esta rede foi criada com software Ucinet usando dados importados do software Sitkis.

Observa-se na região ao topo da rede que as unidades de análise mais utilizadas nas pesquisas da amostra são empresas (firms, organization) e projetos, o que condiz com o escopo desta pesquisa. Os objetivos, ou variáveis dependentes, são inovação, sucesso, impacto e desempenho do projeto de desenvolvimento de novos produtos. A fase de FFE está intensamente relacionada à estratégia orientada ao mercado e processos de tomada de decisão das organizações em um ambiente de incertezas. Os fatores internos de sucesso mais estudados são processos de desenvolvimento de novos produtos, pequisa e desenvolvimento, 
comunicação, tecnologia, práticas de gestão, capacidade de absorver conhecimento, informação e experiência da organização. Destacaram-se palavras chave relacionadas às técnicas de Quality Function Deployment e modelagem. Atividades particularmente importantes são a geração de ideias e design, suportadas pela criatividade, fortemente relacionada à inovação.

Analisando a abordagem de pesquisa na Tabela 2, verifica-se predomínio de abordagens qualitativas na amostra de artigos. Dentre as pesquisas qualitativas, o método de pesquisa mais adotado é o estudo de caso e dentre as quantitativas, o survey. Como observa Moenaert et al (1995), o sucesso comercial de um projeto de inovação frequentemente só pode ser avaliado depois de dois ou três anos do lançamento de um novo produto. Sendo esta a principal variável dependente de análise (objetivo) observada na Figura 3, estudos longitudinais, pesquisa ação, simulação e experimentos têm aplicabilidade restrita pelo orçamento de pesquisa, havendo maior ênfase em estudos ex post facto.

Tabela 2 - Abordagens e métodos de pesquisa da amostra de FFE.

\begin{tabular}{|l|l|}
\hline Abordagem e método de pesquisa & Número de estudos \\
\hline Qualitativa & $\mathbf{4 6}$ \\
\hline Estudo de caso & 32 \\
\hline Teórico conceitual & 7 \\
\hline Revisão de literatura & 6 \\
\hline Pesquisa ação & 1 \\
\hline Quantitativa & $\mathbf{2 2}$ \\
\hline Survey & 14 \\
\hline Modelagem & 3 \\
\hline Experimento & 2 \\
\hline Amostra estatística & 2 \\
\hline Quase-experimento & 1 \\
\hline Total & $\mathbf{6 8}$ \\
\hline
\end{tabular}

Fonte: Elaborado pela autora.

\subsubsection{Definições e Modelos de FFE: Resultados da análise de conteúdo}

As definições formais de FFE identificadas nos artigos selecionados mostram elevado consenso entre os autores quanto aos seguintes elementos:

- Trata-se da primeira etapa do desenvolvimento de novos produtos;

- Antecede o processo formal e estruturado de desenvolvimento de produtos; 
- Seu término é marcado por uma decisão de aprovação ou rejeição de passagem para a próxima etapa.

No entanto, um ponto menos definido é o marco de início da etapa. Smith e Reinertsen (1992) consideram que é a identificação de uma necessidade; Kim e Wilemon (2002), a consideração de uma oportunidade pela primeira vez e Murphy \& Kumar (1997), a geração de uma ideia. Já Koen et al (2002) incluem a identificação da oportunidade como um elemento do FFE e separam formalmente as definições de oportunidade, ideia e conceitos:

- Oportunidade: Uma lacuna tecnológica ou de negócios existente entre uma situação atual e um futuro previsto e que uma empresa ou indivíduo percebe, de modo a capturar uma vantagem competitiva, responder a uma ameaça, resolver um problema ou melhorar uma dificuldade.

- Ideia: A forma mais embrionária de um bem ou serviço. Geralmente consiste numa visão de alto nível da solução prevista para o problema identificado pela oportunidade.

- Conceito: tem um formato bem definido, incluindo uma descrição visual e escrita, que comporta suas principais características e benefícios ao consumidor aliados a uma ampla compreensão da tecnologia necessária

Koen et al (2002) frisam, no entanto, que o ponto inicial pode ser qualquer uma das atividades propostas no modelo conceitual, não necessariamente a identificação da oportunidade.

Observando estas definições, percebe-se que a identificação de uma necessidade está inclusa na identificação de uma oportunidade. Massey et al (2002) configuram o FFE como um processo de resolução de problemas, incluindo a identificação do problema (que é uma forma de identificação de uma oportunidade) como uma etapa fundamental. Khurana e Rosenthal (1997) indicam como pré-fase zero do FFE a identificação preliminar de uma oportunidade. Há maior consenso, portanto, de que o FFE in pela identificação de uma oportunidade do que pela geração de uma ideia.

O modelo conceitual sugerido por Sarasvathy (2001) apud Brettel et al (2012) adota uma premissa diferente quanto ao ponto inicial do FFE de inovações com elevado grau de incerteza nesta etapa. Ao invés da busca por problemas não resolvidos ou lacuna tecnológica como atividade fundamental para o sucesso do FFE, esta linha teórica defende que o ponto 
inicial devem ser os recursos disponíveis, sejam eles competências e experiências ("quem eu sou"), colaboradores e especialistas habilidosos no campo de pesquisa apropriado ("o que eu sei”), relacionamentos com parceiros ao longo das redes de pesquisa e desenvolvimento ("quem eu conheço") e recursos financeiros e ativos tangíveis como equipamentos de pesquisa e desenvolvimento ("o que eu tenho"). A partir da interação entre estes meios, exploram-se os efeitos que podem ser derivados dele (daí a denominação de "efetuação") e apoiam-se na emergência do inesperado para identificação de oportunidades de inovação.

Apesar desta diferenciação na forma de identificação de oportunidades não há conceitualmente uma incompatibilidade entre o modelo de Koen et al (2001) e Sarasvathy (2001), devido ao fato de que o modelo de Koen et al (2001) reconhece o motor (que inclui os recursos disponíveis) e a não necessidade de iniciar o FFE por alguma atividade em especial. Ter uma ideia derivada de combinação inusitada de recursos disponíveis que inesperadamente resolve um determinado problema (oportunidade identificada) é uma situação plenamente compatível com o modelo conceitual proposto por Koen et al (2001). Além disso, nas considerações finais Brettel et al (2012) mencionam a possibilidade de ambidestria, em que a empresa apresenta proficiência tanto em modelos causais (definir objetivos finais e um plano para chegar até lá) quanto em modelos de efetuação.

Em relação às saídas da fase, o único produto final do FFE para Koen et al (2001), é o conceito definido, o que inclui objetivos, alinhamento com a estratégia da empresa, tamanho da oportunidade, necessidades e benefícios do mercado, plano de negócios, fatores de risco, questões de saúde, segurança e meio ambiente, patrocínio e planejamento do projeto. Khurana e Rosenthal (1997) incluem como saídas o conceito de produto (identificação preliminar de necessidades do consumidor, segmentos de mercado, situação de competidores, prospectos de negócios e alinhamento com planos estratégicos e de negócios existente), definição do produto (elaboração do conceito do produto, incorporando julgamentos do mercado alvo, ofertas, tempo e recursos, identificação de necessidades do consumidor, tecnologias, requisitos regulatórios, características e funções do produto, segmentos de mercado alvo, prioridades de design) e plano do projeto. Sintetizando, os resultados diretos mais frequentemente citados são a definição do produto, a justificativa do negócio (business case) e o plano da fase subsequente. 
As atividades inclusas no FFE são apresentadas em maior detalhe nos modelos conceituais de FFE, apresentados no Quadro 3. A maioria dos modelos apresenta uma visão processual e linear desta etapa, exceto Koen et al (2001), que apresenta atividades não sequenciais e recursivas. Segundo McCarthy et al (2006), os modelos dos processos de inovação podem ser lineares, recursivos ou caóticos. Os lineares apresentam processos com estágios relativamente fixos, discretos e sequenciais, mais apropriados para atividades com inovação incremental onde as tecnologias ou mercados são relativamente conhecidos. Os modelos recursivos apresentam múltiplos retornos paralelos aos estágios que criam resultados iterativos difíceis de serem previstos, representando a natureza dinâmica e fluídica do processo, sendo mais apropriado para inovações radicais. Nos caóticos, as fases iniciais possuem uma dinâmica caótica e resultados que parecem ser randômicos e imprevisíveis, sendo que nas fases finais eles são relativamente mais estáveis. Na amostra selecionada e nas referências citadas pela amostra não foram identificados modelos desta última categoria.

Zien et al (1997) e Kim e Wilemon (2002) destacam que a fase de FFE diferencia-se da etapa de desenvolvimento de novos produtos pelo seu baixo grau de formalização, método de gestão desestruturado e experimental com necessidade de criatividade, além de um caráter imprevisível ou incerto. Estas características parecem aproximar a etapa a um modelo não linear.

\section{(Continua)}

\section{Quadro 3 - Modelos conceituais de atividades do FFE da amostra}

\begin{tabular}{|l|l|}
\hline Autor & Descrição \\
\hline Smith & Modelo de front end com três estágios: \\
Reinertsen & (1) Screening de ideias \\
$(1991)$ & (2) Plano de negócios \\
& (3) Plano detalhado de projeto e especificações do produto \\
\hline $\begin{array}{l}\text { Khurana \& } \\
\text { Rosenthal (1997) }\end{array}$ & $\begin{array}{l}\text { Processo com três etapas e elementos de fundação. Etapas: } \\
\text { (1) Pré fase 0: identificação preliminar de oportunidades, análise de mercado e tecnológica } \\
\text { (2) Fase 0: definição do conceito do produto } \\
\text { (3) Fase 1: definição do produto e planejamento do projeto } \\
\text { Elementos de fundação: } \\
\text { (1) Estratégia de produto e portfólio } \\
\text { Montoya-Weiss } \\
\text { Driscoll } \\
\text { (2000) }\end{array}$ \\
$\begin{array}{l}\text { Processo dividido em quatro fases: } \\
\text { (1) Qualificação da ideia }\end{array}$ \\
(2) Desenvolvimento do conceito \\
Koen et al (2001) Atribuição de notas ao conceito \\
(4) Avaliação do conceito \\
\hline
\end{tabular}




\begin{tabular}{|l|l|}
\hline & • Identificação de oportunidades \\
& : Análise de oportunidades \\
& • Seração e enriquecimento de ideias \\
& - Definição de conceitos \\
\hline
\end{tabular}




\section{(Continua)}

\begin{tabular}{|c|c|}
\hline Autor & Descrição \\
\hline $\begin{array}{l}\text { Sarasvathy } \\
(2001) \text { apud } \\
\text { Brettel et al } \\
(2012)\end{array}$ & $\begin{array}{l}\text { Efetuação: modelo baseado em quatro dimensões chave: } \\
\text { (1) Meios: ponto de partida da equipe de desenvolvimento da inovação deve ser os } \\
\text { recursos acessíveis } \\
\text { (2) Perdas acessíveis: esforço de inovação limitado ao quanto os envolvidos estão } \\
\text { dispostos a investir na ideia. } \\
\text { (3) Parcerias: parcerias e pré-comprometimentos devem ser realizados nas fases iniciais da } \\
\text { inovação } \\
\text { (4) Reconhecimento do inesperado: inesperado como um aspecto positivo e fundamental } \\
\text { do processo de FFE e não algo a ser eliminado }\end{array}$ \\
\hline $\begin{array}{l}\text { Reid e De } \\
\text { Brentani (2004) }\end{array}$ & $\begin{array}{l}\text { Modelo de FFE para inovações radicais: } \\
\text { (1) Informações do ambiente como entrada } \\
\text { (2) Problemas e oportunidades não estruturados são identificados por boundary spanners e } \\
\text { passados para gatekeepers } \\
\text { (3) Gatekeepers transmitem a informação para tomadores de decisão de nível corporativo, } \\
\text { que por sua vez transmitem para tomadores de decisão de nível de projeto para } \\
\text { inicializar o desenvolvimento }\end{array}$ \\
\hline $\begin{array}{l}\text { Langerak et al } \\
(2004)\end{array}$ & $\begin{array}{l}\text { Atividades de pré-desenvolvimento em quatro etapas: } \\
\text { (1) Planejamento estratégico } \\
\text { (2) Geração de ideias } \\
\text { (3) Avaliação de ideias } \\
\text { (4) Análise de negócios }\end{array}$ \\
\hline $\begin{array}{l}\text { Boeddrich (2004) } \\
\text { apud Brem et al } \\
(2009)\end{array}$ & $\begin{array}{l}\text { Modelo de front end baseado nas seguintes atividades: } \\
\text { (1) Direcionamentos estratégicos para inovação } \\
\text { (2) Geração e adoção da ideia } \\
\text { (3) Screening de ideias e desenvolvimento do conceito } \\
\text { (4) Projetos preliminares }\end{array}$ \\
\hline $\begin{array}{l}\text { Sandmeier et al } \\
(2004) \text { apud } \\
\text { Brem et al (2009) }\end{array}$ & $\begin{array}{l}\text { Modelo de front end baseado nas seguintes fases: } \\
\text { (1) Oportunidades de mercado e tecnologia } \\
\text { (2) Ideias de produtos e negócios } \\
\text { (3) Rascunho de conceito de produto e plano de negócios } \\
\text { Ao longo de todas as fases há integração com conhecimento tácito interno e externo (clientes, } \\
\text { fornecedores, produção...) }\end{array}$ \\
\hline Hong et al (2004) & $\begin{array}{l}\text { Processos de planejamento de fuzzy front end, considerando como entrada um ambiente de } \\
\text { projetos incerto? } \\
\text { (1) Gerenciamento de peso } \\
\text { (2) Envolvimento do consumidor } \\
\text { (3) Envolvimento dos fornecedores } \\
\text { (4) Design baseado em metas } \\
\text { (5) Avaliação de capabilidades internas } \\
\text { (6) Avaliação de ameaças de competidores } \\
\text { Estes processos resultam em esclarecimento dos objetivos do projeto. }\end{array}$ \\
\hline $\begin{array}{l}\text { Bröring et al } \\
(2006)\end{array}$ & $\begin{array}{l}\text { Modelo simplificado com dois grandes blocos de atividades: } \\
\text { (1) Conscientização, coleção e geração de ideias } \\
\text { (2) Avaliação e seleção de ideias }\end{array}$ \\
\hline $\begin{array}{l}\text { Kobayashi } \\
(2006)\end{array}$ & $\begin{array}{l}\text { Processo sequencial específico para planejamento de ciclo de vida formado pelos seguintes } \\
\text { passos: } \\
\text { (1) Passo 1-1: planejamento de produção master } \\
\text { (2) Passo 1-2: especificação de metas } \\
\text { (3) Passo 1-3: estimação preliminar do fator X } \\
\text { (4) Passo 1-4: geração de ideias com uso da técnica TRIZ no nível de produto } \\
\text { (5) Passo 1-5: avaliação do conceito no nível de produto } \\
\text { (6) Passo 1-6: geração de ideias no nível de componentes } \\
\text { (7) Passo 1-7: avaliação do conceito no nível de componentes }\end{array}$ \\
\hline
\end{tabular}




\section{(Continua)}

\begin{tabular}{|c|c|}
\hline Autor & Descrição \\
\hline $\begin{array}{l}\text { Crawford \& } \\
\text { Benedetto (2006) } \\
\text { apud } \\
\text { Soukhoroukova } \\
\text { et al (2012) }\end{array}$ & $\begin{array}{l}\text { Processo composto por fases e gates: } \\
\text { (1) Fase 1: Identificação e seleção das oportunidades de produtos. Gate: Direção - Para } \\
\text { que direção deveríamos olhar? } \\
\text { (2) Fase 2: Geração de ideias de produtos. Gate: revisão inicial - ideia tem valor? } \\
\text { (3) Fase 3: Avaliação das ideias e projetos de produto. Gate: avaliação completa - } \\
\text { deveríamos tentar desenvolver o projeto? }\end{array}$ \\
\hline $\begin{array}{l}\text { Griffiths-Hemans } \\
\& \text { Grover (2006) }\end{array}$ & $\begin{array}{l}\text { Processo de fluição de ideias em três etapas: } \\
\text { (1) Criação da ideia } \\
\text { (2) Concretização da ideia } \\
\text { (3) Comprometimento com a ideia }\end{array}$ \\
\hline Brem et al (2009) & $\begin{array}{l}\text { Dentro de um contexto de cultura de inovação e criatividade, alimentados por know-how de } \\
\text { mercado e de tecnologia: } \\
\text { (1) Coleta de ideias } \\
\text { (2) Criação de ideias } \\
\text { (3) Classificação e enriquecimento da ideia (filtro 1) } \\
\text { (4) Melhoria, priorização e documentação das ideias (filtro 2) } \\
\text { (5) Nova classificação (filtro 3) } \\
\text { O modelo prevê também um fluxo de descarte de ideias, com possibilidade de pool de ideias e } \\
\text { reavaliação do mérito da mesma no futuro. }\end{array}$ \\
\hline Cooper (2011) & $\begin{array}{l}\text { Inclui as seguintes atividades no pré-desenvolvimento de inovações complexas: } \\
\text { (1) Descoberta: geração de ideias } \\
\text { (2) Gate de decisão } 1 \\
\text { (3) Definição de escopo } \\
\text { (4) Gate de decisão } 2 \\
\text { (5) Construção de business case } \\
\text { (6) Gate de decisão } 3 \\
\text { Em todas as atividades são previstas interações com o consumidor ou usuário do produto }\end{array}$ \\
\hline Riel et al (2013) & $\begin{array}{l}\text { Processo de ideação formado pelas seguintes atividades: } \\
\text { (1) Pré-requisito: análise interna, análise externa, estratégia de inovação, } \\
\text { comprometimento da alta gestão, acordo de metas, comprometimento de recursos } \\
\text { (2) Geração: gestão de stakeholders, gestão de redes, gestão de parceiros, caixa de } \\
\text { ferramentas de ideação, ideação conduzida, wild cards } \\
\text { (3) Seleção: comunicação da ideia, avaliação da ideia e transferência da ideia }\end{array}$ \\
\hline
\end{tabular}

(Conclusão). Fonte: Elaborado pela autora.

Comparando-se os modelos, observa-se que em termos de atividades consideradas o modelo de Koen et al (2001) é o mais abrangente, com o poder de incluir os demais modelos, como mostra a Tabela 3. Os únicos itens que não estão explicitamente inclusos no de Koen et al (2001) são: (1) estrutura organizacional do projeto, papeis, incentivos e normas (do modelo de Khurana e Rosenthal, 1997) e (2) avaliação do conceito e plano de negócios (dos modelos de Smith \& Reinertsen, 1991 e Montoya-Weiss \& Driscoll, 2000). O primeiro item pode ser incluso na definição de "motor" da organização que dirige as cinco atividades chave controláveis pela organização. O segundo item está implicitamente incluso nas atividades de seleção de ideias e definição de conceito, onde podem ser aplicadas metodologias de priorização de portfólio, definição de critérios para considerar o conceito atrativo e testes para 
avaliação das inovações potenciais. O plano de negócios pode estar incluso na definição do conceito.

Desta forma, considerou-se o modelo de Koen et al (2001) com as adaptações supracitadas como modelo conceitual para estruturação da análise de conteúdo da amostra. Outro argumento para esta seleção é que o modelo recursivo não exclui a possibilidade de haver um processo linear, porém o inverso não é verdade. Detalhando-se o modelo selecionado tem-se os seguintes componentes:

- Fatores de influência: características do ambiente do projeto que influenciam no front end de inovação relativamente não controláveis pela empresa, incluindo canais de distribuição, regulamentações, clientes, competidores, economia, evolução tecnológica e capacidades.

- Motor (engine): liderança, cultura, papeis e estratégia de negócios que impulsionam as atividades do FFE controláveis pela empresa.

- Atidades-chave do FFE controláveis pela empresa:

○ Identificação de oportunidades

○ Análise de oportunidades

○ Geração e enriquecimento de ideias

○ Seleção de ideias

- Definição de conceitos 
Tabela 3 - Comparação do modelo de Koen et al (2001) e os outros modelos estudados.

\begin{tabular}{|c|c|c|c|c|c|c|c|}
\hline Modelo de Koen et al (2001) / Outros modelos & 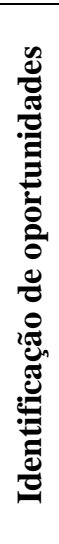 & 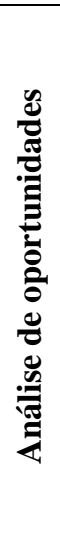 & 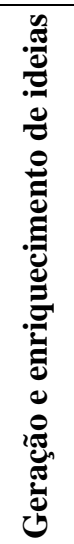 & 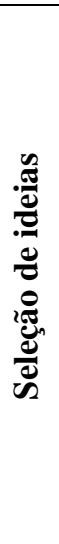 & 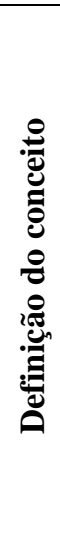 & 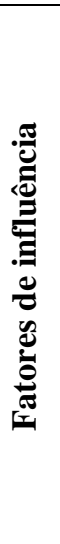 & $\frac{\dot{\theta}}{\dot{\theta}}$ \\
\hline Smith \& Reinertsen (1991) & & & $\mathrm{x}$ & $\mathrm{x}$ & $\mathrm{x}$ & & \\
\hline Khurana \& Rosenthal (1997) & $\mathrm{x}$ & $\mathrm{x}$ & & & $\mathrm{x}$ & & $\mathrm{x}$ \\
\hline Montoya-Weiss \& Driscoll (2000) & & & $\mathrm{x}$ & $\mathrm{x}$ & $\mathrm{x}$ & & \\
\hline Sarasvathy (2001) & $\mathrm{x}$ & $\mathrm{x}$ & & $\mathrm{x}$ & & & $\mathrm{x}$ \\
\hline Reid e De Brentani (2004) & $\mathrm{x}$ & & & & & $\mathrm{x}$ & \\
\hline Langerak et al (2004) & & & $\mathrm{X}$ & $\mathrm{x}$ & $\mathrm{x}$ & & $\mathrm{x}$ \\
\hline Boeddrich (2004) & & & $\mathrm{X}$ & & $\mathrm{x}$ & & $\mathrm{x}$ \\
\hline Sandmeier et al (2004) & $\mathrm{x}$ & $\mathrm{x}$ & $\mathrm{X}$ & & $\mathrm{x}$ & & \\
\hline Hong et al (2004) & $\mathrm{x}$ & & & & & $\mathrm{x}$ & $\mathrm{x}$ \\
\hline Bröring et al (2006) & & & $\mathrm{X}$ & $\mathrm{x}$ & & & \\
\hline Kobayashi (2006) & & & $\mathrm{X}$ & $\mathrm{x}$ & $\mathrm{x}$ & $\mathrm{x}$ & $\mathrm{x}$ \\
\hline Crawford \& Benedetto (2006) & $\mathrm{x}$ & & $\mathrm{X}$ & $\mathrm{x}$ & $\mathrm{x}$ & & \\
\hline Griffiths-Hemans \& Grover (2006) & & & $\mathrm{X}$ & $\mathrm{x}$ & & & \\
\hline Brem et al (2009) & & & $\mathrm{X}$ & $\mathrm{x}$ & & & \\
\hline Cooper (2011) & & & $\mathrm{X}$ & $\mathrm{x}$ & $\mathrm{x}$ & & \\
\hline Riel et al (2013) & & & $\mathrm{X}$ & $\mathrm{x}$ & & $\mathrm{x}$ & $\mathrm{x}$ \\
\hline
\end{tabular}

Fonte: Elaborado pela autora.

\subsubsection{Fatores de influência (ambiente externo)}

Foram encontrados 113 trechos nos artigos da amostra tratam de fatores de influência no FFE, seja descrevendo como tais fatores impactam no sucesso do projeto ou apresentando técnicas para gerenciamento destes fatores.

Brem e Voigt (2009) mencionam que a estratégia de inovação é dependente de diferentes tipos de incertezas, distinguindo as tecnológicas, as de mercado e as de urgência. Distinguem ainda seis tipos de influência externa que afetam a inovação: 
1) Influências políticas (estabilidade do governo, política de impostos, bem estar social, etc);

2) Influências sócio culturais (distribuição de renda, consumerismo, educação etc);

3) Influências ambientais (leis de proteção, disposição de resíduos, localização etc);

4) Influências econômicas (inflação, renda, ciclos de negócios etc);

5) Influências tecnológicas (gasto do governo em pesquisa, velocidade de transferência tecnológica, taxas de obsolescência, etc);

6) Influências legais (leis trabalhistas, segurança de produtos, legislação de negócios etc).

Os autores frisam que a observação destas influências é uma função interdepartamental, especialmente entre tecnologia e marketing. Bröring et al (2006) citam que indústrias podem ser distinguidas entre si por seus produtos, atores, seus processos de aprendizado, tecnologias básicas, entradas, estruturas de demanda, processos de competição e instituições (como padrões, regulações etc), o que implica em sistemas de inovação diferentes em cada indústria. Frishammar et al (2012) sugere que empresas precisam de proficiência em varredura e análise do ambiente externo, incluindo ofertas oferecidas ou prospectadas por competidores e requisitos legais nas definições emergentes do produto sendo desenvolvido.

Uma técnica sugerida por Ilevbare et al (2014) para gerenciar as incertezas do ambiente externo é a aplicação do método de roadmapping, sendo particularmente relevante para o planejamento durante o FFE de inovação que envolve tomadas de decisões estratégicas em situação de alta incerteza e complexidade. A característica principal que separa a técnica das demais é a dimensão visual que ela traz ao planejamento estratégico, evidenciando onde estamos, onde queremos chegar e como podemos chegar lá, além de deixar visível a conexão entre as tecnologias e capabilidades (camada inferior do roadmap) às necessidades de mercado (camada superior do roadmap) por meio de inovação (camada do meio do roadmap). Os autores defendem que esta técnica permite que as incertezas e riscos associadas também fiquem mais visíveis a todos os stakeholders do projeto, melhorando a gestão dos mesmos.

Quanto menos familiar é o mercado e a tecnologia para a organização, menor é a capacidade das áreas de marketing, pesquisa e desenvolvimento de reduzir a incerteza do FFE (MOENAERT ET AL, 1995). A incerteza de mercado e de tecnologia são maiores em casos de inovação radical (VERWORN ET AL, 2008), porém a incerteza de mercado não é significativamente ampliada em função do grau de inovação do produto em indústrias dirigidas por tecnologia, ao contrário da incerteza técnica (VERWORN, 2009). A turbulência 
do mercado ou da tecnologia não moderam, no entanto, a relação entre a estratégia orientada a mercado e o desempenho no desenvolvimento de novos produtos, segundo Langerak et al (2004).

Segundo Khurana e Rosenthal (1998), quanto maior a proximidade com o cliente, menor o grau de formalidade necessário no processo de front end. Ainda segundo estes autores, situações competitivas de liderança de mercado permitem adiar pontos de incerteza do produto a lançamentos futuros.

Van Aken e Weggeman (2000) indicam que redes organizacionais informais são adequadas para o processo de FFE, com o propósito de aprendizado a partir de fontes externas, principalmente se a empresa não está familiarizada com o avanço tecnológico envolvido. Estas redes informais serão produtivas se as vantagens de aprendizado entre as organizações participantes forem balanceadas, se o tempo para aproveitar estas vantagens for aproximadamente igual, se os parceiros tiverem conhecimentos básicos comparáveis, mas conhecimentos especializados distintos e se estiverem dispostos a confiar uns nos outros. Alinhado a estes conceitos, Koen et al (2001) destacam que um dos fatores de influência desta etapa de inovação é a "sexta força de Porter", ou a força de empresas complementares. Novos conceitos de inovação aberta inagurados por Chesbrough (2003) também seguem esta linha.

Ainda explorando o modelo das forças de Porter, os fornecedores constituem outro fator de influência. Para Khurana e Rosenthal (1997) e Kim e Wilemon (2002), parece haver relação entre ter uma visão mais abrangente da cadeia de valor, com aproximação de fornecedores, consideração dos elos a jusante, serviços/logística e cooperação horizontal (joint ventures, licenciamento, alianças) no estágio de definição do produto e o sucesso no desenvolvimento de novos produtos. Wagner (2012) comprova quantitavamente que quanto maior a integração com fornecedores no FFE, maior o desempenho em projetos de desenvolvimento de novos produtos, em termos de qualidade, tempo de desenvolvimento, design e integração ao produto final do componente fornecido. Esta relação é enfraquecida caso o fornecedor detenha ativos exclusivos e é fortalecida caso a integração ocorra também na etapa subsequente do processo de inovação.

Dois artigos da amostra (ANDERSSON ET AL, 2008; VAN DER MEER-KOOISTA E SCAPENS, 2015) chamam a atenção por reconhecerem como fatores de influência os co- 
inovadores externos à organização focal, possuindo relação com os objetivos específicos desta pesquisa.

Andersson et al (2008) menciona que o potencial da inovação na área de tecnologia da informação do caso estudado na pesquisa era essencialmente distribuído entre competidores e bases de TI, cada um atendendo o mercado de forma independente, compatível com o conceito de trabalho de IS adotado neste trabalho. Esta fragmentação fator aumenta a complexidade de orquestrar recursos complementares no caso de inovações em TI que exigem alteração arquitetural, e padrões da indústria podem ter um papel complementar na articulação entre os atores. No caso estudado pelos autores relatou-se a inabilidade dos diferentes fornecedores em entender a situação problema como um todo quando implementa suas soluções, que em sua maioria ficaram confinados em seu próprio paradigma tecnológico (e.g. interfaces proprietárias). Nesta situação, uma incerteza do mercado era quem iria tomar a responsabilidade pela iniciativa de inovação arquitetural. Atores do ecossistema indicaram o próprio projeto de pesquisa dos autores (que estava aplicando o método de pesquisa ação) como potencial arena para desenvolvimento de um padrão de interfaces indústria, por ser isento. Concluiu-se que melhorar a competência de boundary-spanning entre os atores era crítico para o FFE nestas condições, para que pudessem perceber seu conhecimento de tecnologias, contextos de uso, modelos de negócios como componentes de um ambiente maior.

Van der Meer-Kooista e Scapens (2015) observam que mesmo grandes fabricantes de equipamentos originais (Original Equipment Manufacturers) não possuem todo o expertise necessário dentro da empresa para desenvolver novos produtos, especialmente os produtos complexos em que uma grande gama de expertise e diferentes formas de conhecimento são requisitadas. Mais do que terceirização tradicional, os fornecedores das OEMs estão se tornando co-desenvolvedores, sendo responsáveis pelo desenvolvimento de produtos inteiros e não apenas tarefas específicas. Na análise do estudo de caso os autores apontam ainda um ponto falho no projeto estudado mostrando que as redes de vendas do produto não foram adequadamente desenvolvidas nas fases iniciais do projeto. Citam ainda que em alguns casos os pequenos fornecedores especializados da OEM foram os iniciadores do processo de codesenvolvimento.

\subsubsection{Motor (liderança, cultura, papeis e estratégia de negócios)}


Esta é a parte do modelo conceitual mais tratada pela amostra, correspondendo a $38 \%$ das relações revisadas, que podem ser agrupadas nas seguintes subcategorias: cooperação interna, cultura, grau de formalização do processo/da gestão dos projetos, integração com a estratégia, financiamento, papeis e responsabilidades (incluindo o perfil adequado das pessoas para assumir tais papeis).

A cultura é um elemento fundamental do motor do FFE, porém pouco explorado com abordagem quantitativa, possivelmente pela dificuldade de operacionalizar variáveis relativas a este conceito. Zien e Buckler (1997) indicam sete princípios para desenvolver uma cultura favorável: (1) sustentar identidade da empresa como inovadora, (2) ser experimental em todas as funções, (3) estruturar relações entre pessoal técnico e de marketing, (4) gerar intimidade com o consumidor, (5) engajar toda a organização, (6) não esquecer da valorização individual e (7) contar histórias poderosas com o propósito de inspirar a inovação. Koen et al (2002) reforçam ainda a importância de um ambiente que permita a tomada de risco, com abertura e confiança para compartilhamento de opiniões, tempo suficiente e incentivos para a geração e enriquecimento de ideias. Griffiths-Hemans e Grover (2006) encontraram suporte à hipótese de que uma cultura que formalmente apoia a inovação está relacionado a um maior grau de comprometimento com a concretização de novas ideias, em linha com as descobertas de Frishammar et al (2012). Cooper (2011) enfatiza a importância da valorização do risco, de prover tempo livre e de incentivar projetos informais em paralelo à burocracia da empresa para promover inovações mais radicais. Soukhoroukova et al (2011) acrescenta que mercados de ideias podem ser veículos para ampliar a cultura de inovação.

Khurana e Rosenthal (1998) apontam que as empresas bem sucedidas no FFE o fazem ou pela manutenção de uma cultura forte ou pela formalização do processo. Há consenso entre os autores de que é preciso balancear firmeza e flexibilidade na gestão do processo (SMITH E REINERTSEN, 1992; KHURANA E ROSENTHAL, 1997; VAN AKEN E WEGGEMAN, 2000). Frishammar et al (2012) enfatiza a importância de aplicação de práticas de gestão de projetos para aumentar a velocidade e qualidade das atividades do FFE. Salomo et al (2007) não encontram suporte à relação entre formalidade do processo e sucesso do projeto, provendo indícios de que esta causalidade é negativamente moderada pelo grau de novidade do produto. Bocken et al (2014) sugerem que pequenas e médias empresas desempenham 
melhor no FFE devido à sua estrutura enxuta que favorece a participação de todas as áreas da empresa, e elas em sua maioria possuem processos informais de inovação.

Quanto à cooperação interna, Moenaert et al (1995) indicam que a redução de incertezas eficiente no FFE está positivamente relacionada à transferência de informação entre P\&D e marketing e negativamente relacionada com o grau de centralização do projeto. Zien e Buckler (1997), Kim e Wilemon (2002), Koen et al (2002), Hong et al (2004), Wu et al (2015) apresentam estudos que reforçam a importância de manter a cooperação entre áreas internas favorecem o FFE. Verworn et al (2009) relacionam a eficiência e satisfação geral no desenvolvimento de novos produtos com boa comunicação interna e envolvimento de diferentes funções na geração e seleção de ideias. Brem e Voigt (2009) afirmam que eventos e reuniões regulares do time auxiliam a troca de conhecimento entre departamentos no FFE, porém o sucesso da abordagem depende da seleção do especialista certo na hora certa.

Artto et al (2011) sugerem que escritórios de gerenciamento de projetos (PMOs) ou arranjos organizacionais similares possuem um papel importante no gerenciamento de projetos de inovação no FFE, realizando funções de facilitação para geração de ideias ou oportunidades, grupos de inovação, desenvolvimento de comitês para seleção de ideias, estratégia de inovação, processo de inovação, definição de coordenadores do processo, sistemas de gerenciamento de ideias, campanhas de ideias, forças tarefas e processos de geração de ideias baseados em desafios. Os autores observam ainda que apenas sistemas de informação computacionais e os processos de inovação são insuficientes para a facilitação no FFE, sendo necessária uma equipe de suporte e facilitação energizando o processo. Sugerem que estruturas matriciais dos projetos e rotacionamento de funções (job rotation) são favoráveis para envolvimento de todas as áreas da organização no FFE. Mecanismos de recompensa por outro lado não parecem ter efeitos significativos, embora outros estudos destaquem a importância de reconhecimentos não pecuniários (e.g. COOPER, 2011). Outro fenômeno observado é que os executivos tendem a delegar as decisões para os coordenadores dos grupos de desenvolvimento, criando uma lacuna entre a liderança e o restante da organização, lacuna também observada por Brem e Voigt (2009).

Andersson et al (2008) vai além das fronteiras da organização e discute o desenvolvimento de conhecimento em configurações interorganizacionais para inovação arquitetural, que como discutido anteriormente é uma categoria dentro da tipologia de IS. 
Nestes cenários, como cada stakeholder tenta definir a arquitetura sob sua própria perspectiva, inovação em tecnologia da informação tipicamente envolve um período de negociação das configurações possíveis antes que qualquer arquitetura seja considerada dominante. Para isso, empresas tentam orquestrar uma inovação coletiva o que requer a criação de pontes entre tecnologias e comunidades inicialmente separadas para o processo de design.

Os autores sugerem que uma forma eficaz de melhorar esta troca de conhecimentos, o layout das relações entre as organizações imite o arranjo dos componentes que formam a arquitetura do produto. Uma das conclusões dos autores é que em indústrias onde não há um ator dominante como locus da inovação, uma tarefa estratégica é estabelecer uma plataforma política que é percebida como neutra o suficiente para facilitar a emergência de inovação arquitetural, sugerindo o alinhamento com universidades, institutos de pesquisa e associações de indústrias para estabelecimento de bases comuns.

Van der Meer-Kooista e Scapens (2015) argumentam que no caso de IS (chamada no artigo de "co-desenvolvimento"), o gerenciamento do projeto precisa de alguma forma de controle inter organizacional já na etapa de iniciação (FFE). A colaboração entre as organizações no co-desenvolvimento da IS, segundo os autores, ocorre dentro de uma organização temporária inter-organizações. Esta organização temporária pode ser definida como um grupo de duas ou mais organizações não temporárias colaborando em direção a um objetivo de tarefa conjunta com duração definida explicitamente ex-ante ou por uma data específica ou pelo estabelecimento de uma tarefa ou condição pré-definida. Este tipo de organização é caracterizado por quatro dimensões: tempo de duração, tarefa a ser realizada, time e transição (que pode ser entendida como o objetivo da organização temporária). Por ser uma organização temporária, a confiança entre os participantes deve ser construída rapidamente.

Van der Meer-Kooista e Scapens (2015) apontam ainda diversos autores que sugerem efeitos disfuncionais dos sistemas de gestão e contabilidade formais no contexto de pesquisa e desenvolvimento, sendo mais apropriados mecanismos sociais de controle, ou controle de clã. No entanto, alguma estruturação se faz necessária para evitar uma situação completamente caótica. Neste sentido, os autores encontram no framework de estruturas mínimas de Kamoche e Cunha (2001) um modelo que conceitualmente se adequa no caso estudado, que é de uma IS. Este framework faz uma analogia do processo criativo de desenvolvimento de 
produto com uma improvisação de jazz, em que os músicos não tocam uma partitura específica, mas criam dentro de um conjunto de diretrizes e estruturas consensualizadas. No caso do co-desenvolvimento de IS, dentre as estruturas mínimas os autores citam estruturas financeiras, como orçamento do projeto de desenvolvimento (coerente com o conceito de perdas acessíveis descrito por Brettel et al (2012)), estruturas técnicas, como requisitos e restrições mínimas impostas pela tecnologia e uma estrutura social para permitir que os times das diferentes organizações trabalhem juntos. O Quadro 4 resume e exemplifica os elementos para co-desenvolvimento de IS segundo Van der Meer-Kooista e Scapens (2015).

Quadro 4 - Elementos para co-desenvolvimento de IS segundo Van der Meer-Kooista e Scapens (2015)

\begin{tabular}{|c|c|c|}
\hline Elemento & Tipo & Exemplos do caso estudado \\
\hline \multirow[t]{4}{*}{ Estruturas mínimas } & Técnicas & $\begin{array}{l}\text { Definição das áreas técnicas necessárias para o } \\
\text { projeto: mecatrônica, eletrônica e software. }\end{array}$ \\
\hline & Econômicas & $\begin{array}{l}\text { Definição macro de modelo de compartilhamento de } \\
\text { riscos (investimentos no projeto) e retornos } \\
\text { (percentual do lucro do produto resultante) - em } \\
\text { contrato, porém sem detalhamento }\end{array}$ \\
\hline & Institucionais & $\begin{array}{l}\text { Experiências anteriores de trabalhos conjuntos e } \\
\text { expectativa de trabalhos futuros entre as } \\
\text { organizações }\end{array}$ \\
\hline & Sociais & $\begin{array}{l}\text { Interação diária, reunião semanal, colocação da } \\
\text { equipe das organizações em um mesmo espaço } \\
\text { físico. }\end{array}$ \\
\hline \multirow[t]{4}{*}{$\begin{array}{l}\text { Dimensões de } \\
\text { organizações } \\
\text { temporárias }\end{array}$} & Tempo & $\begin{array}{l}\text { Não fica claro qual foi o prazo estabelecido a priori } \\
\text { no contrato entre as partes, porém o prazo realizado } \\
\text { foi de } 2 \text { anos e } 4 \text { meses. }\end{array}$ \\
\hline & Tarefa & $\begin{array}{l}\text { Desenvolvimento de microscópio eletrônico de mesa } \\
\text { com altíssimo poder de aumento }\end{array}$ \\
\hline & Time & $\begin{array}{l}\text { FEI (fabricante de microscópios convencionais) } \\
\text { NTS (desenvolvedor de mecatrônica) } \\
\text { Sioux (desenvolvedor do software) } \\
\text { Benchmark (desenvolvedor de eletrônica) }\end{array}$ \\
\hline & Transição & $\begin{array}{l}\text { Ampliaçao de receitas a partir de vendas do novo } \\
\text { produto }\end{array}$ \\
\hline
\end{tabular}

Wowak et al (2016) destacam que no ambiente competitivo atual é praticamente impossível para organizações criarem novos produtos inovadores sozinhas. Com isso surge o que chamaram de desafio de orquestração da base de fornecedores. Segundo os autores, as 
atividades gerenciais relacionadas à orquestração são afetadas por três elementos chave: abrangência (diversidade de recursos a serem orquestradas), profundidade (níveis hierárquicos dos recursos) e ciclo de vida (grau de maturidade dos recursos). Além disso, cada fornecedor possui recursos valiosos para melhorar o FFE e contribuir para um produto superior. Para tirar vantagem destes recursos deve-se identificá-los ter acesso aos mesmos (estruturação), coordenar estrategicamente seus recursos com os recursos dos fornecedores (integração) e agir rapidamente para tirar vantagem de oportunidades de mercado específicas (alavancagem). Os autores sugerem ainda a teoria de torneio para seleção de quais dos fornecedores participantes do FFE devem participar das próximas etapas de desenvolvimento da inovação.

A integração do FFE com a estratégia é destacada como fundamental por autores como Khurana e Rosenthal (1997) e Cooper (2011), para fornecer a visão do produto, planejamento de tecnologia e de portfólio. Segundo Langerak et al (2004), quanto maior a proficiência no planejamento estratégico, melhor é o desempenho do desenvolvimento de novos produtos em termos de objetivos de volume, vendas e participação no mercado.

Hong et al (2004) propõem que quanto maior a incerteza dos ambientes do projeto de inovação, maior a necessidade de esclarecer a missão e objetivos do projeto e de se identificar previamente as incertezas envolvidas. Brettel et al (2012), no entanto destacam que para situações de extrema incerteza, a abordagem causal relacionada ao pensamento estratégico tradicional pode ser menos efetiva do que a abordagem efetual, em que se parte dos recursos existentes e a exploração do que pode ser criado, a partir de um modelo mental não de antecipar o futuro, mas reconhecendo o inesperado. Brettel et al (2012) fazem um paralelo entre efetuação e as práticas destacadas por Kim e Wilemon (2002) para sugerir que esta abordagem possui valor para o gerenciamento do FFE.

As duas abordagens, no entanto, não são irreconciliáveis dentro de uma mesma organização. Brettel et al (2012) sugerem que é ideal certo nível de ambidextria da organização nas abordagens causal e efetual. De forma correlata, estudo anterior de Verganti (1999) já havia identificado a complementaridade entre competências de antecipação (capacidade de aprendizado sistêmico, pensamento pró-ativo embasado, relacionadas com a abordagem causal) e competências de reação (flexibilidade, comunicação, redundâncias, relacionadas com a abordagem efetual) no FFE de inovações. 
Reid e Brentani (2004) argumentam também que estudos anteriores focam-se no FFE de inovações incrementais, em que a estruturação estratégica das oportunidades pode ser feita no nível organizacional e os indivíduos são dirigidos para coleta de informações. Para inovações radicais, teoriza-se que o movimento é contrário: os indivíduos detectam padrões a partir do ambiente externo e ativam a ação da organização. Este modelo parece fazer sentido para inovações sistêmicas, pois a partir da identificação da oportunidade deve ser definido um reposicionamento estratégico, visando a reconfiguração das competências internas (TUSHMAN \& ANDERSON, 1986) e dos relacionamentos no ecossistema de negócios (IANSITI E LEVIEN, 2004). Koen et al (2002) ressaltam a importância da disponibilidade de financiamento suficiente para desenvolver novas ideias e proteger o FFE.

Quanto a papeis e responsabilidades, Khurana e Rosenthal (1997) apontam que parece haver relação entre estabelecer uma estrutura organizacional de FFE e sucesso, indicando a existência de quatro papeis principais: a gestão sênior, o comitê executivo de revisão, o líder e o time do projeto de desenvolvimento. Kim e Wilemon (2002) e Koen et al (2002) destacam a importância do apoio do suporte contínuo da gestão sênior para o sucesso do FFE. Segundo Khurana e Rosenthal (1998), o estilo desta gestão sênior varia conforme a situação, podendo ser do tipo "investidor" (não atua diretamente, apenas financia), como "direcionador" (lidera e guia o caminho) ou como "treinador", orientando sempre que a equipe encontra algum problema. Outro papel comumente defendido na literatura é o do campeão do produto (KIM E WILEMON, 2002), que tem a responsabilidade de promover e defender a ideia do produto internamente. Cooper (2011) apontam que a gerência sênior no FFE tem como papel assegurar uma decisão clara de go/no-go e garantir que os recursos estejam alocados no projeto.

Segundo Akbar e Mandurah (2014), os papeis não são uniformes ao longo do processo de inovação. Na atividade de geração de ideias eles são menos definidos, pois todos são envolvidos igualmente no processo de geração de ideias. À medida em que a ideia é refinada e transformada em um conceito, emergem papeis de liderança/gerência individuais.

Reid e Brentani (2004) definem papeis específicos para o FFE de inovações disruptivas: o de "fronteira" (boundary spanner), responsável pela interface ambiente externoempresa, identificando novas oportunidades e ameaças a partir da detecção de padrões e intuição, o de "guardião do portão" (gatekeeper), responsável por filtrar as informações 
relevantes entre a fronteira e a organização (frequentemente a fronteira e o guardião do portão são a mesma pessoa) e o promotor do projeto (project broker), que possui um papel similar ao do campeão do produto. A diferença em relação a projetos de inovação incremental é que a competência de FFE é organizacional e na inovação radical a competência é individual. Segundo Bocken et al (2014) os canais de acesso a informações externas no FFE dos indivíduos são Internet e eventos de networking.

Quanto ao perfil individual dos profissionais que participam desta etapa, Stevens e Burley (2003) demonstram que grupos com índice de criatividade superior (baseado no teste de personalidade MBTI) são mais produtivos no FFE, redirecionam ou transformam os projetos após o seu início com maior frequência e os $20 \%$ mais criativos são responsáveis por $80 \%$ do lucro auferido na amostra estudada. Isto indica que as pessoas selecionadas para operar o FFE são ao menos tão importantes quanto o processo em si para o sucesso da iniciativa. Outros autores destacam outras características relevantes como o perfil generalista conhecimento simultâneo de tecnologia, mercado, estratégia e competências da empresa (SMITH E REINERTSEN, 1992; KIM E WILEMON, 2002). Heising (2012) apenas alerta que a autonomia dada aos colaboradores tem uma relação tipo U invertido com o sucesso do FFE.

De Ana et al (2013) identificaram que durante a fase de FFE (chamada de fase de descoberta) do caso estudado na pesquisa o time executor do projeto buscou compreender cada uma das "vozes" dos diferentes stakeholders (cliente, do prestador de serviço, do financiador do serviço), não apenas de clientes líderes, a fim de desenvolver uma solução mais apropriada. Heising (2012) sugere que o gerenciamento ativo de stakedholders relevantes, isto é, a identificação precoce, integração, e criação de aceitação de stakeholders relevantes, leva a aumento do sucesso do FFE. Além de stakeholders o autor cita o grau de dinamismo do ambiente externo como fator de influência, sendo que quando maior este grau: a) mais forte o efeito do posicionamento estratégico da ideação no resultado do FFE, b) mais fraco o efeito positivo da formalização no sucesso do FFE e c) maior o impacto da autonomia dos funcionários no sucesso do FFE. Tyl et al (2015) também destaca que o designer no FFE deve considerar os diversos stakeholders ao longo do ciclo de vida do produto ou serviço que está sendo desenvolvido. 
Brettel et al (2012) destaca como um dos principais pilares da abordagem de efetuação o fato de ela ser guiada pelo envolvimento precoce de parceiros na inovação, constatando empiricamente que isso contribui para o resultado superior do projeto. Frishammar et al (2012), Hallstedt et al (2013) e Wowak et al (2016) também destacam a importância de aproximar fornecedores no FFE. Rohrbeck et al (2009) sugerem que centros de pesquisa conjuntos da universidade e empresa como uma forma de ampliar a colaboração entre academia e indústria para inovação. As descobertas de Thanasopon et al (2015) de que a competência de abertura da empresa no FFE (no sentido de open innovation) está positivamente relacionada ao sucesso de inovações em serviços.

A sociabilização do conhecimento incluindo conversas presenciais mostra-se um mecanismo importante principalmente nas etapas iniciais da inovação segundo Akbar e Mandurah (2014). O tempo despendido para geração de ideias é baixo/moderado em relação ao tempo despendido no refinamento das ideias, o que sugere que estas interações abundantes acontecem de forma bastante concentrada no FFE. Diversos autores incluindo Alam (2006) indicam que devido à complexidade das fases iniciais da inovação, em especial nas inovações de serviços, a interação com os clientes é intensa para reduzir o tempo do ciclo. Porém para a interação efetiva é preciso identificar os indivíduos apropriados e garantir o comprometimento dos clientes no processo. Para isso, sugere que clientes sejam envolvidos com foco específico em um número limitado de projetos de desenvolvimento que sejam homogêneos entre si.

\subsubsection{Identificação de oportunidades}

Segundo Koen et al (2002) a identificação de oportunidades efetiva envolve métodos de vislumbrar o futuro, tais como roadmapping, análise de tendências tecnológicas e do consumidor, inteligência competitiva, pesquisa de mercado e planejamento de cenários. Börjesson e Williander (2006) destacam também o método de "varredura do ambiente" (environmental scanning) em seu estudo do processo de inovação da Volvo. Rohrbeck e Schwarz (2013) utilizam o termo prospectiva estratégica (strategic foresight) como processo de identificação de sinais fracos do ambiente para busca de novas inovações. Cooper (2011) apresenta que a identificação de oportunidades é um grande desafio no desenvolvimento de estratégia, pois a maioria das empresas tende a focar-se nas áreas em que ela já atua, limitando as possibilidades de inovação, e por isso também sugere que sejam investidos recursos em varredura do ambiente externo. Kostoff (2006) apresentam uma técnica de 
varredura do ambiente baseada inicialmente em mineração de dados, chamada de descoberta baseada em literatura, uma abordagem sistemática de conectar disciplinas a princípio desconectadas. Após a mineração, sugerem o envolvimento de especialistas externos por diferentes mecanismos (e.g. workshops, escrita conjunta de artigos científicos, roadmapping).

Reid e Brentani (2004) levantam a hipótese de que em inovações incrementais os problemas ou oportunidades tendem a ser identificados e/ou estruturados pela organização, enquanto em inovações de descontinuidade tendem a ser identificadas por indivíduos, por meio de intuição. Scheiner et al (2015) também enfatizam a importância do indivíduo, chamado de guardião do portão de tecnologias (technology gatekeepers) e seus esquemas cognitivos na identificação de tecnologias e mudanças (fontes de oportunidades), sendo que os mesmos controlam o fluxo de informação do ambiente externo para dentro da companhia. Os autores citam estudos que mostram que os guardições do portão são proficientes em tecnologia ou com alta capacidade social, e discutem a importância da intuição (referenciada como gut feeling) no processo de identificação de oportunidades. Concluem que a intuição é importante na atividade, porém apresenta perigos se considerada isoladamente e que deve ser considerada em combinação com outras técnicas.

Alam (2006) sugere interação com os clientes para identificação de oportunidades. Sugere ainda que se foquem as perguntas no resultado desejado, e não nas soluções dos problemas, a fim de identificar a real necessidade. De Ana et al (2013) utilizam o termo Voz do Cliente como processo pelo qual necessidades são identificadas, que pode incluir pesquisa etnográfica (técnica abordada em profundidade por Rosenthal e Capper (2006) no contexto de desenvolvimento de inovação), entrevistas em profundidade, grupos focais, sombra (shadowing) e observações. Estas sugestões estão em linha com a abordagem causal. Segundo Brettel et al (2012), a maior parte da literatura de P\&D assume que a atividade chave é descobrir oportunidades e explorá-las, e para isso utilizar-se de análise competitiva, opções reais que se baseiam em predição do futuro baseado na informação. Ou seja, considerar um efeito e focar na seleção dos melhores meios para criar tal efeito. Brem e Voigt (2009) utiliza os termos market pull/demand pull/need pull para se referenciar ao caso em que a fonte de inovação é uma necessidade mal atendida o que resulta em demandas de resolução de problemas (inventar um produto para o pedido - invent-to-order). 
De forma diametralmente oposta, Brettel et al (2012) apresentam que na abordagem de efetuação o foco inicial deve ser nos meios, ou nos recursos disponíveis. Andersson et al (2008) apresentam no caso estudado um exemplo de aplicação desta abordagem (embora não tenham realizado esta correlação explicitamente no texto): o projeto se iniciou quando um fornecedor de sistema contactou um instituto de pesquisa para discutir interesses mútuos relacionados ao uso de tecnologia da informação na indústria de transportes. O desejo era alavancar sua competência central de entendimento do consumidor iniciando o projeto de pesquisa com um instituto reconhecido por seus estudos de tecnologia da informação orientados a usuários. Veja que neste caso a busca por oportunidades se iniciou na identificação de competências chave e desenvolvimento de parcerias.

Esta abordagem efetual pode ser relacionada com o termo technology-push, considerando-se a tecnologia como um tipo de meio a ser utilizada na inovação. Brem e Voigt (2009) relacionam o termo aos casos em que o estímulo para o desenvolvimento de novos produtos e processos vem da pesquisa (interna ou externa) e o objetivo é fazer uso comercial deste novo know-how. Os autores ainda associam esta abordagem com inovações radicais e disruptivas, o que está em linha com o estudo de Brettel et al (2012). Brem e Voigt (2009) apenas alertam para o risco de isolamento da área de pesquisa com o restante da empresa nesta abordagem, levando a ineficiências. Também em linha com Brettel et al (2012), Brem e Voigt (2009) sugerem uma combinação entre as abordagens causal (market pull) e efetual (technology-push) e também sugerem o foco na formação de redes e parcerias para a abordagem efetual.

Uma originalidade presente no estudo de Brem e Voigt (2009) é o conceito de regulatory push, ou seja, a identificação de oportunidades provenientes de novas leis, regulações ou iniciativas políticas, por meio de monitoramento do ambiente regulatório. Os autores também sugerem que as equipes de monitoramento de tecnologia, ambiente e mercado que atuam de forma autônoma se reunam de forma regular para discutir tendências e identificar as oportunidades. Também sugerem a condução workshops com stakeholders internos e externos e grupos de elaboração de cenários.

Bröring et al (2006) cunham a capacidade da empresa de perceber uma oportunidade de awareness (consciência), e a mesma está relacionada com o construto de capacidade de absorção (absorptive capacity), definida por Cohen e Levinthal (1990) como a habilidade de 
uma empresa reconhecer o valor de informações novas e externas, assimilá-las e aplicá-las para fins comerciais.

Além do cliente, os fornecedores também são citados como fontes potenciais de novas oportunidades (BOCKEN ET AL, 2014). De Ana et al (2013)) e Tyl et al (2015) apontam também os stakeholders de forma ampla como fontes de novas oportunidades de inovação.

\subsubsection{Análise de oportunidades}

A análise de oportunidades tipicamente envolve a determinação de como a oportunidade se enquadra nas forças de mercado e tecnologia da empresa, a descrição detalhada do segmento de mercado mostrando porque ele representa uma grande oportunidade, a análise de fatores econômicos, culturais, demográficos, tecnológicos e regulatórios que impactam o segmento de mercado, a análise de competidores e avaliação das necessidades não atendidas dos consumidores (KOEN ET AL, 2002).

Andersson et al (2008) utilizam o termo "fase de diagnóstico" para se referir a este conjunto de atividades. No estudo de caso, citaram o uso de entrevistas, seminários e workshops para coleta e discussões de lições aprendidas para cumprimento desta fase. Brem e Voigt (2009) cita grupos de construção de cenários para análise das oportunidades identificadas. Já Bocken et al (2014) sugerem a técnica de análise do ciclo de vida, Groenveld (1997) e Ilevbare et al (2014) sugerem a técnica de technology roadmapping, Rohrbeck e Schwartz (2013) e Scheiner et al (2015) sugerem a prospectiva tecnológica (strategic ou corporate foresight) e Wowak et al (2016) sugerem a abordagem de opções reais (real options) para avaliação de oportunidades.

Moenaert et al (1995) demonstram que quanto mais os times do FFE reduzem as incertezas (lacuna entre as informações necessárias e as obtidas) sobre as necessidades do consumidor, tecnologia, competição e recursos necessários, maior a probabilidade da inovação ser comercialmente bem sucedida. A redução de incerteza da tecnologia inclui a definição de: (a) design do produto, (b) estratégia de P\&D para o projeto de desenvolvimento, (c) estratégia tecnológica dos competidores, (d) características das tecnologias aplicadas, (e) escolha das tecnologias de produtos, (f) recursos tecnológicos necessários ao projeto, (g) recursos de $\mathrm{P} \& \mathrm{D}$ dos concorrentes e (i) pessoal de $\mathrm{P} \& \mathrm{D}$ necessário ao projeto. A redução de incerteza do mercado inclui a definição de: (a) necessidades dos consumidores, (b) recursos 
de marketing e vendas necessário, (c) competição, (d) mercado potencial, (e) comportamento de compra dos consumidores, (f) pessoal necessário de marketing e vendas, (g) estratégia de marketing da competição, (h) a sensibilidade de preço dos consumidores potenciais e (i) a estratégia de marketing para o projeto de desenvolvimento.

Verworn et al (2008) encontram suporte à relação entre a redução da incerteza técnica e a eficiência do projeto de desenvolvimento de novos produtos, mas não à relação entre redução de incerteza de mercado e eficiência. Os autores justificam este comportamento devido à amostra estudada comercializar bens industriais a poucos clientes, com os quais podem interagir de uma forma mais próxima, e, portanto, com menor incerteza. Já a relação entre redução de incerteza e efetividade dos projetos de desenvolvimento em termos de diferenciação e aceitação dos consumidores é suportada tanto para incertezas de tecnologia como de mercado. Thanasopon et al (2016) encontram relação entre redução de incertezas, em especial de mercado, para o sucesso de inovações em serviços, além de evidências de que o grau de abertura da empresa para atores externos positivamente influencia esta redução de incertezas.

Smith e Reinertsen (1992) destacam também a importância da gestão do risco na análise de oportunidades no FFE. Salomo et al (2007) encontram evidências quantitativas da relação positiva entre o planejamento de riscos do projeto e o sucesso do desenvolvimento de novos produtos. Frishammar et al (2012) adiciona que não basta reduzir incertezas do produto, mas também é preciso reduzir incertezas do processo produtivo. Como atividades chave citam a análise de matérias primas e identificação de janelas de processos, metáfora utilizada para referir-se a restrições inerentes do processo produtivo.

A abordagem de análise de oportunidade é bastante distinta quando se trata de efetuação (BRETTEL ET AL, 2012), pois neste caso as incertezas mercadológicas e tecnológicas não devem ser reduzidas, mas sim incentivadas e reconhecidas como fonte de geração de valor no FFE. Ao invés disso, o esforço está em formar parcerias e précompromissos entre os parceiros a fim de gerar um ambiente propício e seguro para exploração de competências, reduzindo incertezas relativas à disponibilidade dos recursos (meios). Argumenta-se que em projetos de com grau de novidade muito alto as análises competitivas do mercado tornam-se obsoletas muito rapidamente, sendo portanto inefetivas. 
Cooper (2011) utiliza o termo diligência (due dilligence) para referir-se a este a conjunto de atividades e mescla as abordagens causal e efetual. Segundo o autor, a gerência sênior deve avaliar as áreas de oportunidades sob duas dimensões chave: (1) é possível alavancar as competências centrais, ativos, e forças para alavancar esta área? (2) qual o tamanho das oportunidades nesta área em termos de tamanho e crescimento do mercado, possibilidades tecnológicas, e potencial de lucro?

\subsubsection{Geração e enriquecimento de ideias}

A geração e enriquecimento de ideias é a atividade mais explorada na literatura de FFE dentre as cinco identificadas no modelo conceitual adotado. Esta exploração vai desde discussões da cultura favorável para a geração de ideias até técnicas específicas e características individuais dos geradores de ideias.

Akbar e Mandurah (2014) enquadram a atividade de geração de ideias como um processo de geração de conhecimento, envolvendo a capacidade de encontrar aplicações de forma criativa para o conhecimento conceitual. Brem e Voigt (2009) apresentam duas formas de obter novas ideias: uma é coletar ideias previamente presentes (pelo menos nas mentes de uma pessoa ou grupo) e a outra é gerando novas ideias por meio de um processo pensado previamente utilizando métodos de criatividade. Brem e Voigt (2009), Heising (2012) e Riel et al (2013) citam a criação de categorias ou áreas para focar a geração de ideias como positivamente relacionadas com o sucesso do FFE.

Cooper (2011) cita como métodos de ideação mais efetivos a Voz do Cliente (também citado por De Ana et al (2013)) utilizando técnicas etnográficas, visitas a clientes, grupos focais, análise de usuários líderes e co-criação junto aos clientes. O autor também cita a captura de ideias dos colaboradores, muitas vezes por tecnologia da informação, em um processo sistemático (Massey et al (2002) apresentam um bom exemplo de sistema para auxílio à geração e enriquecimento de ideias), além da análise formal de tendências tecnológicas para identificação de potencial de inovação disruptiva e mineração de patentes. De Ana et al (2013) acrescenta o uso de quadros de histórias (storyboards) para ilustração de 
diferentes cenários durante a ideação. Kobayashi (2006) sugere o método TRIZ para geração de ideias. Soukhoroukova et al (2011) apresenta vantagens de adoção de mercados de ideias.

Griffiths-Hemans e Grover (2006) encontram evidências de que quanto maior a valorização do erro como parte do processo de inovação, maior o grau de criatividade das ideias geradas. Surpreendentemente, neste estudo não foi suportada a hipótese de que uma cultura organizacional que suporta formalmente a inovação por meio de programas de recompensa, reconhecimento e outros incentivos oficiais aumenta a criatividade das ideias. Isto pode indicar que a não punição em caso de falha é mais favorável para estimular a geração de ideias pelos funcionários, e que a obtenção de auto realização (motivação intrínseca) é o principal estímulo da criatividade, sendo o programa de incentivos (motivação extrínseca) visto como um substituto inferior a este objetivo maior, o que pode até inibir a criação de ideias. Se esta premissa for válida, a prática de gestão mais favorável é conceder recursos e condições seguras para que o profissional desenvolva novas ideias.

Diversos autores ressaltam a importância da formação de redes internas e externas para geração de ideias. Koen et al (2002) recomendam o contato direto com consumidores e usuários do produto, conexões entre diferentes times funcionais, job rotation entre engenheiros, cientistas e inventores promovendo compartilhamento de conhecimento e colaboração com outras empresas e instituições para melhorar esta atividade. Kijkuit e Van der Ende (2007) encontram suporte à hipótese de que quanto maiores as redes de pessoas ao redor das ideias na fase de geração, e quanto maior a densidade das redes durante a fase de enriquecimento da ideia, maior a probabilidade de aceitação da mesma. Bjork e Magnusson (2009) mostram uma significativa relação entre a conectividade de provedores das ideias (ou seja, o número de pessoas que geraram a ideia em conjunto) e a qualidade das ideias geradas. Segundo as descobertas destes autores, a qualidade das ideias geradas aumenta linearmente com o grau de centralidade dos indivíduos que as geraram, medida pelo número de indivíduos adjacentes ao provedor da ideia. Frishammar et al (2012) relacionam a colaboração entre funções como necessária para geração de ideias. Heising (2012) relaciona o sucesso do FFE com a diversificação de origens de ideias.

Em particular, as redes que envolvem o consumidor são destacadas na literatura. Flint (2002) sugere que diversas ideias de novos produtos podem ser inúteis ou até prejudiciais se forem geradas internamente sem um entendimento bem fundamentado do cliente. Este 
entendimento começa com as necessidades atuais e depois busca-se antecipar as futuras, e recomenda-se o uso de técnicas como entrevistas em profundidade, etnografia e observação participativa. Kim e Wilemon (2002), Koen et al (2002), Alam (2006), Van Trijp et al (2008), Rohrbeck et al (2009), Frishammar et al (2012) e Bocken et al (2014) também enfatizam o envolvimento do consumidor na geração de ideias. Magnusson (2009) estuda as vantagens de utilizar consumidores como geradores de ideias e verifica que quanto menos ele conhece sobre os aspectos técnicos envolvidos, maior a originalidade e radicalidade das ideias criadas. Andersson et al (2008) afirmou ter sido imperativo o recrutamento de uma organização representante de usuários no FFE de IS do caso estudado.

Lettl et al (2006) mostra que nos casos estudados a participação de clientes na ideação foi útil inclusive em inovações radicais. Porém estes clientes tinham um perfil distinto do cliente comum: primeiro eram altamente motivados a desenvolver a nova solução por serem usuários extremos do produto (similar ao conceito de usuários líderes). Segundo deveriam estar inseridos em um contexto de suporte para habilitar a inovação, como contato e acesso a detentores de know-how tecnológico em sua rede pessoal.

Bröring et al (2006) citam fontes externas para geração de ideias nos casos em que se reconhece que o escopo no qual as empresas geram ideias sozinhas é limitados às suas experiências e conhecimentos prévios. No caso estudado, a forma de se obter conhecimentos complementares para geração de ideias foi a formação de uma joint venture, e a competência de capacidade de absorção. Riel et al (2013) e Tyl et al (2015) sugerem a integração com stakeholders internos e externos na ideação desde as fases iniciais.

Apesar da reconhecida importância da conectividade entre diferentes pessoas com diferentes conhecimentos para a geração de melhores ideias, Schirr (2012) alerta para a ineficiência (menos ideias por participante) e ineficácia (menor qualidade das ideias) dos métodos de ideação em grupo se comparados com métodos de ideação individual, comprovada por diversos estudos empíricos. As razões são: (1) as pessoas tendem a não se dedicar com tanto afinco, especialmente se a contribuição individual não for óbvia; (2) os membros do grupo desejam ser aceitos, o que leva a um conservadorismo; (3) a linha de pensamento é interrompida quando cada um tem que esperar a vez de falar novamente e (4) os indivíduos em grupo tendem a compatibilizar o desempenho com o participante menos produtivo. 
Técnicas e ferramentas para as quais há evidências de contribuição com a qualidade e quantidade de ideias geradas são: o uso intencional de analogias, preferencialmente analogias distantes, utilizando múltiplos domínios de conhecimento e sem fornecer desenhos iniciais de solução (DAHL E MOREAU, 2002); e programas de inovação internos com suporte de sistema web para geração colaborativa de ideias, com ou sem anonimidade, com mecanismos de avaliação coletiva das ideias e com ou sem o conceito de mercado de ideias (BOTHOS ET AL, 2012; SOUKHOROUKOVA ET AL, 2012).

Griffiths-Hemans e Grover (2006) suportam a primeira hipótese, ao encontrar uma relação positiva entre o expertise do originador da ideia e o nível de criatividade das ideias geradas. Além do expertise, a motivação intrínseca e o estilo de pensamento mais lateral do que vertical do originador da ideia também estão relacionados a maiores níveis de criatividade das ideias. Dahl e Moreau (2002) encontraram uma relação positiva entre originalidade das ideias e valor percebido pelo consumidor, o que justifica o esforço gerencial de estimular a criatividade na geração de ideias. Riel et al (2013) relaciona o enriquecimento de ideias com a competências de empreendedorismo, traduzida como a capacidade de construir histórias para vender sua ideia a promotores e convencer decisores.

Apesar das ideias poderem ser originadas de várias fontes, Riel et al (2013) atentam que o início da ideação deve ser feito pela liderança executiva, apresentando claro comprometimento às atividades de geração de ideias, de forma a evitar que os colaboradores sintam que estão fazendo um trabalho proibido quando trabalham em novas ideias. Spanjol et al (2009) sugerem também que uma orientação estratégica da empresa para o mercado e para a tecnologia contribuem para a geração de ideias.

Como técnica mais específica da área de eco-inovação, Bocken et al (2014) sugere as técnicas de biomímica (estudo de modelos da natureza e então imitar ou obter inspiração destes designs e processos para resolver problemas humanos), ecologia industrial e cradle-tocradle (criar e reciclar ilimitadamente), além dos tradicionais brainstormings. Como resultado do survey desta pesquisa, experimentos mostraram-se úteis para geração e enriquecimento de ideias.

Andersson et al (2006) são os únicos autores da amostra a apresentar a geração de ideias no FFE de uma IS. No caso estudado, foi desenvolvido um plano para criação de um padrão (standard) comum para integração dos diferentes componentes da solução, utilizando 
o conhecimento de todos os atores da rede de valor da indústria. Este padrão foi considerado uma instância do conhecimento arquitetural, traduzindo as capabilidades tecnológicas, a sensibilidade do contexto dos usuários e o entendimento do modelo de negócios. $\mathrm{O}$ enriquecimento da ideia neste caso também passou por uma etapa de prototipagem, a partir da qual foram sugeridas melhorias. Para resolução de conflitos entre os diferentes atores que possuíam um viés de trazer as ideias do padrão para mais próximo de seus próprios padrões, a participação das organizações representantes de usuários foi fundamental.

\subsubsection{Seleção de ideias}

A principal questão envolvendo a seleção das ideias no FFE é o nível de rigor a ser aplicado nos critérios de decisão (KOEN ET AL, 2002), visando minimizar os dois tipos de erro possíveis (aprovar uma ideia ruim ou não aprovar uma ideia boa), dado o elevado nível de incerteza (VAN RIEL ET AL, 2011).

Como recomendações gerais, Smith e Reinertsen (1992) sugerem que se gerencie a carteira de ideias, alertando que algumas empresas não investem na criação de novas tecnologias por não ser um processo gerenciável, o que pode levar à sua descontinuidade. Estes autores sugerem que não se adote o modelo de funil quando há uma baixa taxa de fracassos, mas que modelos financeiros sejam utilizados para tomada de decisão.

Reinertsen (1999) sugere um modelo conceitual quantitativo para descrever o raciocínio econômico da seleção de ideias, considerando o valor esperado de uma aposta de novo produto, que depende da probabilidade de sucesso e da magnitude dos ganhos e perdas possível. Neste modelo, deve-se considerar o custo da primeira seleção, e, caso ideias ruins passem pelo primeiro portão de decisão, contabiliza-se um desperdício de investimento requerido para se alcançar o próximo portão, composto tanto pelo custo de investigar com maior profundidade as ideias ruins, como pelo custo de atraso no lançamento das ideias boas. Perceba que se o custo de atraso for muito maior do que o custo de investigação das ideias ruins, faz sentido simplificar ao máximo o processo de seleção, mesmo que com isso passe uma quantidade maior de ideias ruins para a próxima etapa. Uma abordagem formal para a seleção de ideias e conceitos é a adoção de modelos de priorização, utilizando diversos métodos como o AHP, analytic hierarchy process (LEE ET AL, 2012) e sistema especialista 
fuzzy considerando o alinhamento estratégico e o equilíbrio ótimo entre lucro versus risco, curto prazo versus longo prazo e crescimento versus receitas (OH ET AL, 2012).

Mas métodos formais e critérios objetivos claros não são suficientes para fazer uma ideia avançar dentro das organizações. A formação de redes informais e promoção interna da ideia são tão ou mais importantes para a concretização das oportunidades. Neste sentido, Rice et al (2001) chamam a atenção para a lacuna de iniciação - o vácuo entre uma ideia de inovação radical proveniente de um breakthrough tecnológico e o projeto de desenvolvimento da ideia - e propõem um framework de perguntas que os inventores devem responder em termos de tecnologia, mercado e estratégia corporativa para conseguir mobilizar as outras áreas da organização e ressaltam que o principal problema é de comunicação. Kijkuit e Van der Ende (2007) propõem que conexões fortes nas redes das ideias durante as fases de desenvolvimento e avaliação da ideia aumentam as chances de aceitação da mesma.

Akbar e Mandurah (2014) enquadra a seleção de ideias como uma atividade de avaliação de conhecimento, que envolve conhecimento amplo e genérico assim como conhecimento de experiência e de contexto/objetivos específicos da organização. Soukhoroukova et al (2011) sugerem que mecanismos de filtro de ideias necessitam de (1) informação a ser usada na seleção (descrição escrita, figuras, ou até modelos simples), (2) seleção dos respondentes cujas opiniões serão consideradas na decisão (preferencialmente múltiplos e muldisciplinares) e (3) o método para explicitar estas opiniões (votações, matrizes multicritério). Sugerem ainda que a filtragem imediata de ideias obviamente inferiores reduzem a chance de sobrecarga de informações e inércia cognitiva aos avaliadores. Feedbacks imediatos também contribuem para melhoria de qualidade das ideias. Como instrumento para estas duas funcionalidades, os autores sugerem o uso de mercado de ideias como mecanismo de seleção.

Cooper (2011) indica que faltam mecanismos, processos, sistemas ou métodos para selecionar as ideias vencedoras, dando a elas visibilidade e suporte na organização, para assegurar recursos necessários, e direcionando ideias corajosas do desenvolvimento ao lançamento. De Ana et al (2013) mostram no caso estudado o uso da técnica de "fichas de poker" por stakeholders participantes do FFE, para indicar as ideias preferenciais, além de entrevistas de feedback das ideias e questionários (surveys). 
Hallstedt et al (2013) sugerem que se traga também a perspectiva de sustentabilidade nos critérios de seleção de ideias no FFE.

Assim como nas demais atividades do FFE, competências pessoais também fazem a diferença. Griffiths-Hemans e Grover (2006) demonstram que quanto maior a credibilidade e influência do originador da ideia, maior o grau de comprometimento para a concretização da mesma. Alam (2006) sugere também a participação de diferentes áreas funcionais no processo de seleção. Van Riel et al (2011) encontram suporte empírico para a hipótese de que perspectiva de longo prazo, atitude empreendedora, envolvimento de gestores seniores e nível de experiência dos tomadores de decisão estão positivamente relacionados com a efetividade do processo de seleção de ideias. Curiosamente, o envolvimento da média gerência na seleção de ideias não contribuiu para esta efetividade.

Cooper (2011) e Heising (2012) tratam do conceito de estratégia de gestão de portfólio de ideias e projetos inovadores, com uso de técnicas como cestos estratégicos, de forma a balancear o investimento da empresa e minimizar riscos. Heising (2012) adiciona a hipótese de que a formalização e institucionalização da gestão do portfólio de ideias tem relação em formato U invertido com o sucesso do FFE.

Brettel et al (2012) apresenta uma abordagem de seleção completamente distinta no caso da efetuação: considera-se neste caso um valor de perdas aceitáveis como critério determinante do momento de parada na exploração dos recursos disponíveis para encontrar uma inovação. Uma das vantagens de consideração deste critério, ao invés de critérios relacionados ao retorno esperado da inovação é que se pode estimar mais facilmente de forma precisa no FFE. Cooper (2011) também critica a dependência excessiva dos gestores seniores em ferramentas financeiras e métodos de retorno do investimento para fazer a seleção de ideias, afirmando que os mesmos funcionam bem para projetos menores e pouco inovadores, mas invariavelmente leva a decisões ruins em projetos de inovação com maiores risco e escopo.

\subsubsection{Definição do conceito}

Há certa divergência na literatura em relação à importância e características desta atividade no FFE. Khurana e Rosenthal (1997) e Kim e Wilemon (2002) destacam a importância da definição clara e precoce do conceito do produto, porém tratam de inovações 
incrementais. Khurana e Rosenthal (1998) ressaltam que produtos radicais geralmente são definidos de forma menos explícita no front end, mas há evidências de que há benefícios em deixar mais explícitas outras dimensões, como alinhamento estratégico, estimativa de investimentos e tempo de desenvolvimento. Koen et al (2001) não encontraram evidências de que a proficiência na definição de conceitos está relacionado a maior nível de inovação da empresa. As empresas mais inovadoras tiveram desempenho similar às pouco inovadoras. Os autores cogitam que talvez as empresas mais inovadoras sejam mais críticas em relação ao seu próprio grau de proficiência nesta atividade, mas que mais informações são necessárias para explicar este resultado que para eles foi surpreendente.

Artto et al (2011) e Frishammar et al (2012) incluem entre as saídas desta atividade de FFE a definição de mercados alvo, necessidades do consumidor, propostas de valor, custos e preços esperados, principais funcionalidades, e tecnologias que serão mais úteis ao produto. Frishammar et al (2012) descrevem atividades que podem levar a ideia até o conceito, tais como revisão de literatura relacionada à ideia e testes preliminares em laboratório para avaliar a viabilidade de desenvolvimento. Os autores também acrescentam a necessidade de definição não apenas do conceito do produto mas também do conceito do processo para produzi-lo, desde o FFE.

Cooper (2011) cita o termo caso de negócio (business case) que pode também ser associado à definição do conceito no FFE. Construir um caso de negócios sólido segundo o autor é uma tarefa difícil, especialmente para inovações radicais que usualmente incluem soluções novas e complexas, novos mercados, e às vezes novas tecnologias. Para a construção do caso de negócio é preciso uma equipe multifuncional, idealmente com dedicação integral, e é composto por avaliação de mercado, pesquisa de mercado da Voz do Cliente identificando necessidades não atendidas, teste do conceito para validação, avaliação do valor econômico para o cliente, avaliação técnica, definição de riscos tecnológicos e análise de propriedade intelectual, avaliação de operações e cadeia de suprimentos para determinação de manufaturabilidade, custos e investimento. Este caso de negócios deve então ser aprovado pela gestão sênior.

Em termos de eficiência do processo de desenvolvimento de novos produtos, a minimização de desvios das especificações é favorável (VERWORN, 2009). Segundo Salomo et al (2007) o sucesso do projeto de produto está relacionado à estabilidade de objetivos, que 
indiretamente relaciona-se a um conceito de produto bem definido. Smith e Reinertsen (1992) e Khurana e Rosenthal (1997) sugerem o congelamento das especificações do produto e a inserção de melhorias aos poucos em lançamentos futuros, movendo-se a passos pequenos para testar a reação dos consumidores e evitar atrasos na definição do conceito por causa da inserção infinita de novos requisitos.

Akbar e Mandurah (2014) associam a atividade de definição do conceito com o processo de refinamento do conhecimento, envolvendo modificação, exclusão ou "poda" de aplicações ou características para fazer o novo projeto implementável/entregável, alinhado com recursos organizacionais, operações e outras restrições. Associam também com o conceito de cristalização do conhecimento, que envolve a quebra do projeto em partes menores (diferenciação), para depois montar as partes em um todo coerente (integração), resultando em uma forma concreta e explícita, passível por exemplo de aplicação de patente ou declaração de projeto. Para esta atividade de integração, habilidades de liderança baseada em pensamento sistêmico foram importantes.

Há poucos estudos detalhando técnicas, métodos e práticas para melhorar o desempenho desta atividade na amostra. O caso melhor estruturado é o da Nortel, apresentado por Montoya-Weiss e O'Driscoll (2000), que desenvolveu um sistema com suporte eletrônico que ajuda geradores de ideia (funcionários da empresa) a traduzir suas ideias embrionárias em conceitos robustos e auxiliar tomadores de decisão a avaliar e comparar os conceitos sistematicamente para investimento. Isto é possível porque há modelos de questões a serem respondidas pelos profissionais que padronizam a forma de comunicar e avaliar os conceitos, com um guia que explica cada uma das questões detalhadamente. Isso permite que todos os profissionais consigam demonstrar o valor do conceito sem a necessidade de treinamentos custosos e sem restringir a atividade a especialistas. Dahan e Houser (2002) apresentam diferentes técnicas de teste virtual dos conceitos criados no FFE.

Kihlander e Ritzen (2012) discutem as formas de se avaliar o conceito desenvolvido. Sugerem que a avaliação seja uma integração das abordagens racional-analítica, intuitivaemocional e política-comportamental. Citam ainda a necessidade de inclusão de muitos atores no processo de avaliação do conceito, e foram considerados pontos chave a experiência pessoal, a competência e redes dos atores. Estes atores precisam ser suportados para lidarem com incerteza e complexidade, aceitando intuição e emoção como guias e às vezes aceitar "ir 
com o fluxo". Notam ainda que a diferença de maturidade entre alternativas de solução resultam em comparações injustas na avaliação dos conceitos. $O$ uso de templates de avaliação podem ter um impacto no processo de decisão, colocando parte do poder nas mãos de quem elabora os templates.

Andersson et al (2008) ao tratar da definição do conceito no FFE de uma IS, citou a necessidade de negociação de configurações possíveis antes que uma arquitetura possa ser considerada dominante. Ficou claro também no caso estudado pelos autores que os atores envolvidos (tanto os fornecedores de tecnologia como as organizações que embarcariam tais tecnologias) estavam incertos em como desenvolver um modelo de negócios viável para os dados produzidos pela tecnologia embarcada. Foi imperativo buscar o balanceamento entre abertura da arquitetura e proteção de componentes (black boxing) na definição do conceito para que as partes não se sentissem ameaçadas. Kihlander e Ritzen (2012) também cita a necessidade de gerir conflitos de interesses na definição do conceito entre atributos, sistemas e requisitos, e por consequência a maior parte do tempo é gasta em negociação e balanceamento para definição de trade-offs, o que requer alinhamento com os objetivos e estratégias da organização. Tyl et al (2015) sugere que se utilize ferramentas de modelamento de negócios para auxiliar nas diferentes interações do projeto.

Van der Meer-Kooista e Scapens, que também tratam de FFE de IS, citam o desenvolvimento de um caso de negócios (business case) preliminar provendo uma estrutura econômica ao projeto, ao definir os custos alvo para o produto, a margem de lucro, e o preço de venda. Este caso, no entanto, não era totalmente rígido, já que o mercado não era bem conhecido, e os trade-offs entre funcionalidades e preços não foram determinados nas fases iniciais. Definiu-se também um modelo de compartilhamento de riscos e retornos entre as partes envolvidas, sujeita a renegociações futuras.

\subsubsection{Quadro resumo}

Elaborou-se um quadro resumo (Quadro 5) sumarizando a relação entre os elementos do modelo conceitual e os autores da amostra estudada.

(Continua)

Quadro 5 - Quadro resumo da análise de conteúdo da amostra de FFE

\begin{tabular}{|l|l}
\hline Elemento & Autores na amostra
\end{tabular}




\begin{tabular}{|l|l|}
\hline $\begin{array}{l}\text { Fatores } \\
\text { influência }\end{array}$ & de \\
& $\begin{array}{l}\text { Andersson et al (2008); Brem e Voigt (2009); Brettel et al (2012); } \\
\text { Bröring et al (2006); Heising (2012); Ilevbare et al (2014); Koen et al } \\
\text { (2001); Kim e Wilemon (2002), Khurana e Rosenthal (1997); Kihlander } \\
\text { e Ritzen (2012); Langerak et al (2004); Moenaert et al (1995); Rohrbeck } \\
\text { et al (2009); Salomo et al (2007); Stevens e Burley (2003); Stevens } \\
\text { (2014); Van Aken e Weggeman (2000); Verworn (2009); Verworn et al } \\
\text { (2008); Van der Meer-Kooista e Scapens (2015); Wagner (2012). }\end{array}$ \\
\hline
\end{tabular}


(Continua)

\begin{tabular}{|c|c|}
\hline Elemento & Autores na amostra \\
\hline Motor & $\begin{array}{l}\text { Akbar e Mandurah (2014); Alam (2006); Andersson et al (2008); Artto } \\
\text { et al (2011); Bocken et al (2014); Brem e Voigt (2009); Brettel et al } \\
\text { (2012); Cooper (2011); Dahan e Houser (2002); de Ana et al (2013); } \\
\text { Frishammar et al (2012); Griffiths-Hemans e Grover (2006); Hallstedt et } \\
\text { al (2013); Heising (2012); Hong et al (2004); Kihlander e Ritzen (2012); } \\
\text { Khurana e Rosenthal (1997); Kim e Wilemon (2002); Koen et al (2001); } \\
\text { Langerak et al (2004); Moenaert et al (1995); Poskela e Martinsuo } \\
\text { (2009); Reinertsen (1999); Rohrbeck et al (2009); Salomo et al (2007); } \\
\text { Smith e Reinertsen (1992); Soukhoroukova et al (2011); Spanjol et al } \\
\text { (2009); Stevens (2014); Stevens e Burley (2003); Thanasopon et al } \\
\text { (2016); Tyl et al (2015); Van Aken e Weggeman (2000); Van der Meer- } \\
\text { Kooista e Scapens (2015); Verganti (1999); Verworn (2009); Verworn } \\
\text { et al (2008); Wowak et al (2016); Zien e Buckler (1997) }\end{array}$ \\
\hline $\begin{array}{l}\text { Identificação } \\
\text { de } \\
\text { oportunidades }\end{array}$ & $\begin{array}{l}\text { Alam (2006); Andersson et al (2008); Bocken et al (2014); Börjesson et } \\
\text { al (2006); Brem e Voigt (2009); Brettel eet al (2012); Bröring et al } \\
\text { (2006); Cooper (2011); de Ana et al (2013); Kijkuit e Van der Ende } \\
\text { (2007); Koen et al (2001); Kostoff (2006); Reid e De Brentani (2004); } \\
\text { Rohrbeck e Schwarz (2013); Rosenthal e Capper (2006); Scheiner et al } \\
\text { (2015); Spanjol et al (2009); Stevens e Burley (2003); Thanasopon et al } \\
\text { (2016); Tyl et al (2015). }\end{array}$ \\
\hline $\begin{array}{l}\text { Análise de } \\
\text { oportunidades }\end{array}$ & $\begin{array}{l}\text { Andersson et al (2008); Bocken et al (2014); Börjesson et al (2006); } \\
\text { Brem e Voigt (2009); Brettel et al (2012); Cooper (2011); Frishammar et } \\
\text { al (2012); Groenveld (1997); Koen et al (2001); Langerak et al (2004); } \\
\text { Moenaert et al (1995); Rohrbeck et al (2009); Rohrbeck e Schwarz } \\
\text { (2013); Salomo et al (2007); Smith e Reinertsen (1992); Stevens (2014); } \\
\text { Thanasopon et al (2016); Verworn (2009); Verworn et al (2008); } \\
\text { Wowak et al (2016) }\end{array}$ \\
\hline $\begin{array}{l}\text { Geração e } \\
\text { enriquecimento } \\
\text { de ideias }\end{array}$ & $\begin{array}{l}\text { Akbar e Mandurah (2014); Alam (2006); Andersson et al (2008); Bjork } \\
\text { e Magnusson (2009); Bocken et al (2014); Bothos et al (2012); Brem e } \\
\text { Voigt (2009); Bröring et al (2006); Cooper (2011); Dahl e Moreau } \\
\text { (2002); de Ana et al (2013); Flint (2002); Frishammar et al (2012); } \\
\text { Griffiths-Hemans e Grover (2006); Heising (2012); Kijkuit e Van der } \\
\text { Ende (2007); Kijkuit e Van der Ende (2010); Kim e Wilemon (2002); } \\
\text { Kobayashi (2006); Koen et al (2001); Langerak et al (2004); Lettl et al } \\
\text { (2006); Magnusson (2009); Massey et al (2002); Riel et al (2013); } \\
\text { Rohrbeck et al (2009); Soukhoroukova et al (2011); Spanjol et al (2009); } \\
\text { Tyl et al (2015); Van Trijp e Van Kleef (2008); Wowak et al (2016). }\end{array}$ \\
\hline
\end{tabular}


(Continua)

\begin{tabular}{|c|c|}
\hline Elemento & Autores na amostra \\
\hline $\begin{array}{l}\text { Seleção } \\
\text { ideias }\end{array}$ & $\begin{array}{l}\text { Akbar e Mandurah (2014); Alam (2006); Brem e Voigt (2009); Bröring } \\
\text { et al (2006); Cooper (2011); de Ana et al (2013); Griffiths-Hemans e } \\
\text { Grover (2006); Hallstedt et al (2013); Heising (2012); Kijkuit e Van der } \\
\text { Ende (2007); Kijkuit e Van der Ende (2010); Koen et al (2001); } \\
\text { Langerak et al (2004); Oh et al (2012); Reid e De Brentani (2004); Rice } \\
\text { et al (2001); Smith e Reinertsen (1992); Soukhoroukova et al (2011); } \\
\text { Van Riel et al (2011); Wowak et al (2016) }\end{array}$ \\
\hline $\begin{array}{l}\text { Definição do } \\
\text { conceito }\end{array}$ & $\begin{array}{l}\text { Akbar e Mandurah (2014); Andersson et al (2008); Artto et al (2011); } \\
\text { Cooper (2011); Dahan e Houser (2002); Frishammar et al (2012); } \\
\text { Khurana e Rosenthal (1997); Kihlander e Ritzen (2012); Kim e } \\
\text { Wilemon (2002); Kobayashi (2006); Koen et al (2001); Lee et al (2012); } \\
\text { Montoya-Weiss e O'Driscoll (2000), Salomo et al (2007); Smith e } \\
\text { Reinertsen (1992); Tyl et al (2015); Van der Meer-Kooista e Scapens } \\
\text { (2015); Verworn (2009); Wowak et al (2016). }\end{array}$ \\
\hline
\end{tabular}

(Conclusão). Fonte: Elaborado pela autora.

\subsection{Revisão de IS}

Nesse tópico será lapidado o conceito de IS, apresentando inicialmente o panorâma dos artigos por meio de uma análise bibliométrica e, posteriormente um maior aprofundamento por meio da análise de conteúdo dos artigos da amostra utilizando-se o modelo conceitual de FFE mais abrangente da literatura como padrão principal de codificação dos dados qualitativos.

\subsubsection{Panorâma da literatura de IS: Resultados da análise bibliométrica}

O primeiro artigo da amostra de IS também foi publicado no início da década de 90 , coincidentemente com a amostra de FFE. No entanto, a análise longitudinal revela que o número de publicações aumenta em 2010, com pico em 2013, ano que concentra um terço da amostra, indicando que o desenvolvimento do tema é recente e também crescente na literatura, como mostra a Tabela 4. 
Tabela 4 - Número de publicações por periódico por ano (IS

\begin{tabular}{|c|c|c|c|c|c|c|c|c|c|c|c|c|}
\hline & \multicolumn{12}{|c|}{ Ano } \\
\hline Periódico & 亏̆ & 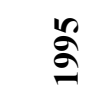 & 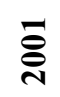 & 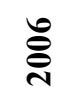 & ڤે & 릇 & 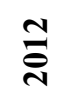 & $\stackrel{m}{\tilde{N}}$ & $\underset{\vec{N}}{\mathbb{I}}$ & $\stackrel{\sim}{\stackrel{\sim}{N}}$ & 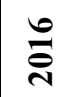 & हैّ \\
\hline TECHNOL FORECAST SOC & & & & & & & 1 & & & & 1 & 2 \\
\hline CALIF MANAGE REV & & & & & & & & 1 & 1 & & & 2 \\
\hline J OPER MANAG & & & & & 1 & & & & & 1 & & 2 \\
\hline ADV STRATEG MANAGE & & & & & & & & 2 & & & & 2 \\
\hline J CLEAN PROD & & & & & & & & 1 & & 1 & & 2 \\
\hline J SERV MANAGE & & & & & & & & & 1 & & & 1 \\
\hline RES POLICY & & 1 & & & & & & & & & & 1 \\
\hline ORGAN STUD & & & & & & & & & 1 & & & 1 \\
\hline HARVARD BUS REV & & & & 1 & & & & & & & & 1 \\
\hline GROUP ORGAN MANAGE & & & & & & & & & & 1 & & 1 \\
\hline J BUS VENTURING & 1 & & & & & & & & & & & 1 \\
\hline J STRATEGIC INF SYST & & & & & & & & & 1 & & & 1 \\
\hline STRATEGIC MANAGE J & & & 1 & & & & & & & & & 1 \\
\hline PROD PLAN CONTROL & & & & & & & & & & 1 & & 1 \\
\hline EUR J INFORM SYST & & & & & & & & 1 & & & & 1 \\
\hline STRATEG MANAGE J & & & & & & 1 & & & & & & 1 \\
\hline GLOB STRATEG J & & & & & & & & 1 & & & & 1 \\
\hline J PROD INNOVAT MANAG & & & & & & & & & 1 & & & 1 \\
\hline ACAD MANAGE REV & & & & & & & & 1 & & & & 1 \\
\hline J INF TECHNOL & & & & & & & & & & 1 & & 1 \\
\hline Total & 1 & 1 & 1 & 1 & 1 & 1 & 1 & 7 & 5 & 5 & $\mathbf{1}$ & 25 \\
\hline
\end{tabular}

Fonte: Elaborado pela autora. Nota: periódicos listados em ordem decrescente de publicações relacionadas a IS e identificados pela abreviação do ISI.

Observa-se que os periódicos que concentram mais de $70 \%$ da amostra de IS são voltados a políticas de inovação, tecnologia, estratégia e sustentabilidade. Esta constatação sugere que o nível de análise de IS é superior ao de FFE: enquanto IS é discutido em esferas de gestão pública ou alta diretoria de empresas, o FFE concerne principalmente áreas de pesquisa e desenvolvimento. Destaca-se a presença de publicações no Journal of Cleaner Production, que sugere um relacionamento entre desenvolvimento sustentável e inovação sistêmica.

Analisando as abordagens e métodos de pesquisa na Tabela 5, verifica-se que há mais do que o dobro de pesquisas qualitativas em relação a quantitativas, indicando-se um estágio de maturidade deste campo do conhecimento inferior ao do FFE em termos de definição e 
validação empírica de modelos conceituais e construtos, apesar de ambos terem surgido na mesma época. Segundo Hobday et al (2000), produtos e sistemas complexos geram problemas extremos de medição, tanto para propósitos acadêmicos quanto práticos, pois cada produto e projeto tende a ser diferente, inviabilizando a aplicação de técnicas de benchmark de desempenho tradicionais, o que pode explicar ao menos em parte esta discrepância.

Tabela 5 - Abordagens e métodos de pesquisa da amostra de IS.

\begin{tabular}{|l|l|}
\hline Abordagem e método de pesquisa & Número de estudos \\
\hline Qualitativo & $\mathbf{1 6}$ \\
\hline Estudo de caso & 12 \\
\hline Teórico conceitual & 2 \\
\hline Revisão de literatura & 1 \\
\hline Teoria fundamentada (grounded theory) & 1 \\
\hline Quantitativo & $\mathbf{9}$ \\
\hline Survey & 5 \\
\hline Estudo longitudinal com amostra estatística & 4 \\
\hline Total & $\mathbf{2 5}$ \\
\hline
\end{tabular}

Fonte: Elaborado pela autora.

Observa-se, assim como no caso do FFE o grande predomínio de estudos de caso como método de pesquisa em IS, representando $75 \%$ da amostra dentro da abordagem qualitativa e $50 \%$ da amostra total.

\subsubsection{Definições de IS}

Além das definições já apresentadas no capítulo introdutório, foram identificados trechos ao longo da análise de conteúdo da amostra que podem reforçar ou complementar o conceito de IS.

Amit e Zott (2001) definem que complementaridades estão presentes sempre que ter um pacote de mercadorias provê maior valor do que o valor total de ter cada mercadoria vendida separadamente. Chesbrough et al (2014) discute o conceito de ecossistema de negócios, citando Bateson (1979) e Moore (1993) que descreve como empresas criam um novo ecossistema de negócios baseado em quatro estágios evolucionários: nascimento, expansão, liderança e renovação. Moore (1993) afirma ainda que empresas participantes cooperam e competem para satisfazer necessidades dos consumidores e entregar novos produtos e serviços. Liu e Rong (2015) cita estudos que se referem ao movimento de co- 
evolução de ecossistemas de negócios dirigido por interações mutuamente influenciadoras como "processo co-evolucionário".

Chesbrough et al (2014) também utilizam a teoria de redes de valor (value network) de Normann e Ramirez (1993), que as chamam de constelações de valor, definidas como redes inter-organizacionais conectando empresas com diferentes ativos e competências em resposta ou em antecipação de novas oportunidades de mercado. Outro construto correlacionado pelo autor são comunidades de inovação, que são associações voluntárias de atores que possuem objetivos de inovação compartilhados, sendo uma característica destas comunidades a dependência entre os processos de criação e captura de valor. Com base nestas definições Chesbrough et al (2014) utilizam o termo ecossistemas de inovação aberta: um ecossistema de negócios composto de comunidades de fornecedores, clientes, e outros stakeholders que praticam inovação aberta dentro de uma rede.

Morgan et al (2013) utiliza a definição de redes de valor como entidades que consistem em diversos atores individuais ou organizacionais que transformam e transferem vários recursos e capabilidades complementares. Estas redes são vistas como veículos para produção, síntese e distribuição de ideias e cada vez mais o sucesso de uma empresa é relacionado à profundidade de suas ligações com seus parceiros de rede. Já Pinho (2014) utiliza a definição de redes de valor como combinações espontâneas de atores interagindo para co-produzir ofertas de serviços, intercambiá-las e co-criar valor. Ren et al (2015) ao discutir co-criação, conceitua como duas partes que devem estar ativamente envolvidas na criação de valor umas com as outras. Co-criação de valor para os autores não significa que uma parte cria valor, enquanto outra o consome, mas as duas entidades devem ser ativas na criação de valor.

Ethiraj e Posen (2013) focam-se em inovação em ecossistemas de produtos complexos. Um ecossistema de produto inclui os componentes que funcionam juntos para prover valor para o usuário final. A arquitetura do ecossistema do produto inclui o agrupamento de funções em componentes e o mapeamento de dependências entre eles.

Gawer e Cusumano (2014) definem plataformas industriais como os produtos, serviços, ou tecnologias desenvolvidas por uma ou mais empresas, e que servem como fundações sobre as quais um número maior de empresas pode construir inovações complementares e potencialmente gerar efeitos de rede. Há semelhanças entre este conceito e 
o design dominante, que quando emerge, estabelece os padrões de que formas e características usuários esperam que um produto em particular tenha no futuro. Gawer e Cusumano (2014) também fazem um paralelo entre a plataforma industrial e a empresa keystone (IANSITI E LEVIEN, 2004), a empresa que dirige a inovação da indústria para um sistema evolutivo de componentes desenvolvidos separadamente.

Adner e Kapoor (2010) apresentam a ideia de inovação em um sistema de empresas interdependentes cuja performance depende das ações de seus participantes, guiados por um objetivo comum no nível do sistema. Em específico subdividem os participantes interdependentes da inovação sistêmica em componentes e complementares em relação a uma empresa focal. Componentes são provenientes de fornecedores que estão antes da empresa focal na cadeia de valor, enquanto complementares são provenientes de empresas que ofertam produtos ou serviços que precisam ser entregues junto ao produto ou serviço da empresa focal para que haja (ou aumente a) geração de valor.

Mlenic (2013) aborda o conceito de IS como aquela em que a coordenação e cooperação são necessárias no seu processo de desenvolvimento em oposição à inovação autônoma (independente), conceito que foi introduzido por Teece $(1984,1988)$.

Pode-se abstrair destas definições que o conceito de IS inclui como elemento chave a interdependência entre inovações em organizações distintas (que não estão sob uma mesma gestão), que precisam ocorrer de forma sincronizada e coordenada para que sejam bem sucedidas e gerem valor aos clientes finais. Note que se trata de interdependência de inovações e não pura interdependência entre organizações (que é inerente a qualquer cadeia de valor, e, portanto presente em qualquer tipo de inovação).

Outras tipologias de inovação comumente associadas a IS são apresentadas no Quadro 6. 


\section{Quadro 6 - Tipologias de inovação comparadas com inovação sistêmica na amostra}

\begin{tabular}{|c|c|c|c|}
\hline Referência & $\begin{array}{l}\text { Tipologia de } \\
\text { inovação }\end{array}$ & Descrição & Relação com IS \\
\hline $\begin{array}{l}\text { Henderson e Clark } \\
(1990) \text { apud Ethiraj } \\
\text { e Posen }(2013)\end{array}$ & $\begin{array}{l}\text { Inovação } \\
\text { arquitetural }\end{array}$ & $\begin{array}{l}\text { Mudanças na forma como } \text { os } \\
\text { componentes se interrelacionam, sem } \\
\text { alterar os componentes em si. }\end{array}$ & $\begin{array}{l}\text { É um tipo de inovação } \\
\text { sistêmica. }\end{array}$ \\
\hline $\begin{array}{l}\text { Christensen e } \\
\text { Rosenbloom (1995) }\end{array}$ & $\begin{array}{l}\text { Inovação } \\
\text { disruptiva }\end{array}$ & $\begin{array}{l}\text { Produtos mais baratos, simples, } \\
\text { menores ou mais convenientes do que } \\
\text { os de incumbentes. Com o passar do } \\
\text { tempo e desenvolvimento tecnológico, } \\
\text { invadem os mercados existentes, } \\
\text { eventualmente dominando-os. }\end{array}$ & $\begin{array}{l}\text { Inovações } \\
\text { implicam em desenvolvimento } \\
\text { de novas redes de valor } \\
\text { (ecossistema de negócios), } \\
\text { sendo também um tipo } \\
\text { específico de IS. }\end{array}$ \\
\hline $\begin{array}{l}\text { Cooper } \quad(2000) \text {; } \\
\text { Mlenic }(2013)\end{array}$ & $\begin{array}{l}\text { Inovação } \\
\text { radical }\end{array}$ & $\begin{array}{l}\text { Variação que só pode ser medida } \\
\text { adicionando novas dimensões na } \\
\text { avaliação do do produto, redefinindo a } \\
\text { percepção do mercado. }\end{array}$ & $\begin{array}{l}\text { Autores indicam que } \\
\text { inovações radicais geralmente } \\
\text { são sistêmicas. }\end{array}$ \\
\hline
\end{tabular}

Fonte: Elaborado pela autora.

Ao contrário do estudo de FFE na área de desenvolvimento de produtos, não foram encontrados modelos conceituais abrangentes sobre o FFE em IS na amostra. Adner (2006) traz um modelo conceitual de desenvolvimento de estratégia de IS (Figura 4), cobrindo parte do FFE (principalmente a parte de análise de fatores de influência e análise de oportunidade), fundamentalmente para estabelecer expectativas corretas em relação à IS nas suas fases iniciais.

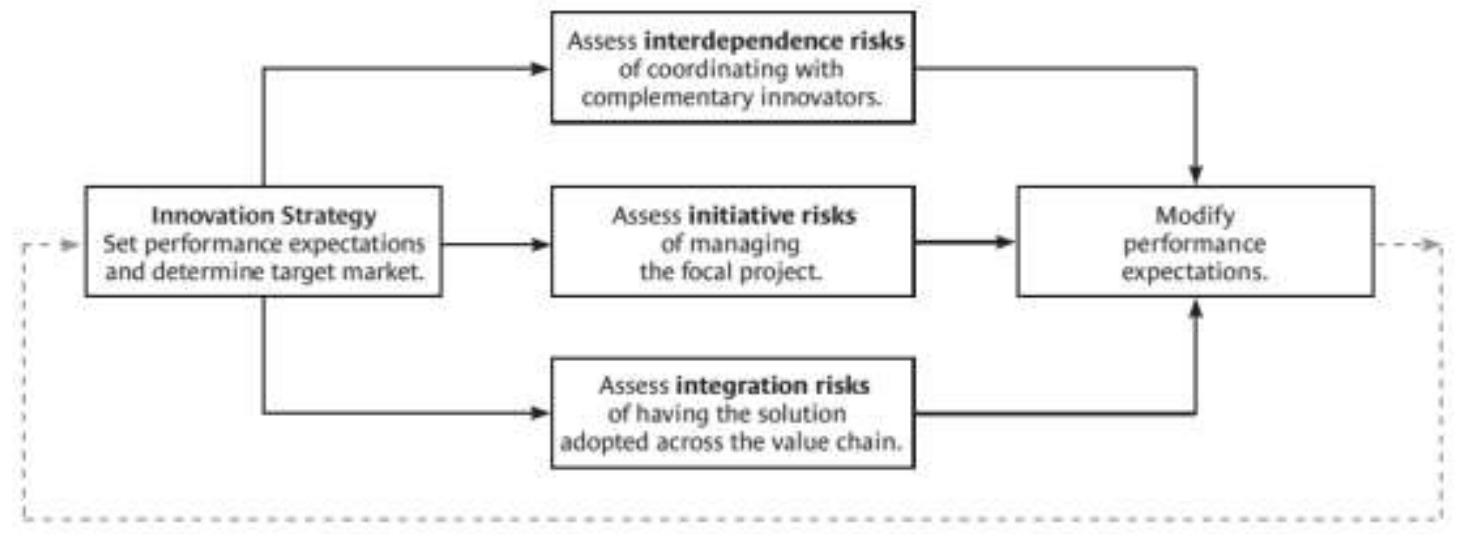

(Revise and rethink innovation strategy.)

Figura 4 - Modelo conceitual de estratégia de IS. Fonte: Adner (2006).

Por ser o único a propor um modelo conceitual parcial de FFE em IS, buscou-se trabalhos posteriores deste mesmo autor verificando evoluções deste modelo conceitual. Foi 
então que se identificou no livro The Wide Lens (ADNER, 2012) um modelo mais abrangente de IS, apresentado no Quadro 7.

Quadro 7 - Modelo conceitual de IS. Fonte: Adner (2012).

\begin{tabular}{|c|c|c|c|}
\hline Etapa & Atividade & Descrição & Ferramentas \\
\hline \multirow[t]{3}{*}{$\begin{array}{l}\text { Observar o } \\
\text { ecossistema }\end{array}$} & $\begin{array}{l}\text { Entender por } \\
\text { que as coisas } \\
\text { dão errado }\end{array}$ & $\begin{array}{l}\text { Conscientização de que sucesso da inovação depende não } \\
\text { apenas da execução da empresa focal, mas do sucesso de } \\
\text { outras empresas complementares do ecossistema. Avaliação } \\
\text { de três tipos de risco da inovação: riscos de execução, riscos } \\
\text { de co-inovação e riscos de adoção da cadeia de valor para } \\
\text { estabelecimento de expectativas no mais apuradas início do } \\
\text { projeto. }\end{array}$ & $\begin{array}{l}\text { Framework de } \\
\text { riscos de inovação } \\
\text { (Figura 4) }\end{array}$ \\
\hline & $\begin{array}{l}\text { Riscos de } \\
\text { co-inovação }\end{array}$ & $\begin{array}{l}\text { A lógica de co-inovação é a de multiplicação, e não de } \\
\text { média: as probabilidades de sucesso das inovações de cada } \\
\text { componente que constitui a IS devem ser multiplicadas para } \\
\text { avaliação da probabilidade de sucesso da IS. A pergunta } \\
\text { mais importante a ser respondida é quando será possível } \\
\text { alinhar o ecossistema necessário para a proposta de valor } \\
\text { completa se concretizar. }\end{array}$ & $\begin{array}{l}\text { Multiplicação de } \\
\text { riscos }\end{array}$ \\
\hline & $\begin{array}{ll}\text { Riscos } & \text { de } \\
\text { adoção } & \text { da } \\
\text { cadeia } & \end{array}$ & $\begin{array}{l}\text { Avaliação de custos totais e benefícios relativos de cada } \\
\text { elemento da cadeia que precisará adotar a IS. A lógica de } \\
\text { adoção da cadeia é a de mínimos: a adoção é determinada } \\
\text { pelo elo mais fraco. Caso um intermediário tenha mais } \\
\text { custos que benefícios com a IS, ele não irá adotar, não se } \\
\text { concretizando nenhum dos valores previstos em cada elo da } \\
\text { cadeia. }\end{array}$ & $\begin{array}{l}\text { Ligações } \\
\text { rompidas }\end{array}$ \\
\hline \multirow[t]{3}{*}{$\begin{array}{l}\text { Escolher } \\
\text { sua posição }\end{array}$} & $\begin{array}{l}\text { Mapear o } \\
\text { ecossistema }\end{array}$ & $\begin{array}{l}\text { Tornar o ecossistema e suas dependências explícitas. } \\
\text { Começa pela identificação de todos os parceiros e especificar } \\
\text { suas posições, os fornecedores, intermediários e } \\
\text { complementares. Depois se identificam mudanças nas } \\
\text { atividades e conexões que são esperadas de cada } \\
\text { participante. Por fim, avalia-se como estas mudanças afetam } \\
\text { a probabilidade de que o sistema inteiro irá de fato se alinhar } \\
\text { para entregar a proposta de valor da IS. }\end{array}$ & Blueprint de valor \\
\hline & $\begin{array}{l}\text { Definir } \\
\text { papeis } \\
\text { relações }\end{array}$ & $\begin{array}{l}\text { Identificação de quais atores no ecossistema se qualificam } \\
\text { para liderança e quais não irão investir em nada além de seu } \\
\text { papel de seguidor (caso lucrativo). O prisma de liderança é } \\
\text { construído a partir da lógica de custo total/benefício para } \\
\text { avaliar o excedente de cada ator no blueprint de valor. Então } \\
\text { analisa-se se cada ator tem excedente suficiente para } \\
\text { justificar o investimento nos deficits do sistema. }\end{array}$ & $\begin{array}{l}\text { Prisma } \\
\text { liderança }\end{array}$ \\
\hline & $\begin{array}{l}\text { Definir } \quad 0 \\
\text { lugar certo } \\
\text { na hora certa }\end{array}$ & $\begin{array}{l}\text { Avaliar a hora de entrada no mercado (ser o primeiro ator ou } \\
\text { não) considerando-se o desafio de execução do inovador } \\
\text { focal em relação ao desafio de inovação dos complementos. }\end{array}$ & $\begin{array}{l}\text { Matriz do } \\
\text { primeiro ator }\end{array}$ \\
\hline
\end{tabular}




\begin{tabular}{|c|c|c|c|}
\hline Etapa & Atividade & Descrição & Ferramentas \\
\hline \multirow[t]{2}{*}{$\begin{array}{l}\text { Ganhar o } \\
\text { jogo }\end{array}$} & $\begin{array}{l}\text { Mudar } \quad \text { o } \\
\text { jogo }\end{array}$ & $\begin{array}{l}\text { Verificar a estratégia de reconfiguração do ecossistema. } \\
\text { Alavancas de reconfiguração sugeridas: } \\
\text { 1) O que pode ser separado? Há oportunidade de } \\
\text { desacoplar elementos que estão atualmente } \\
\text { empacotados de uma forma que pode criar valor? } \\
\text { 2) O que pode ser combinado? Há oportunidade de } \\
\text { acoplar elementos que estão atualmente separados } \\
\text { de uma forma que crie valor? } \\
\text { 3) O que pode ser recolocado? Há oportunidade de } \\
\text { mudar elementos existentes para outras posições no } \\
\text { ecossistema para criar valor? } \\
\text { 4) O que pode ser adicionado? Há elementos que não } \\
\text { estão presentes cuja introdução pode criar valor? } \\
\text { 5) O que pode ser subtraído? Há elementos existentes } \\
\text { cuja eliminação pode ser acomodada de forma a } \\
\text { permitir a criação de valor? }\end{array}$ & $\begin{array}{l}\text { Cinco alavancas } \\
\text { para } \\
\text { reconfiguração do } \\
\text { ecossistema }\end{array}$ \\
\hline & $\begin{array}{l}\text { Sequenciar } \\
\text { para o } \\
\text { sucesso }\end{array}$ & $\begin{array}{l}\text { Definição da ordem de alinhamento de parceiros para } \\
\text { viabilizar a IS. Sugerem-se três técnicas: } \\
\text { 1) Mínimo Footprint Viável: encontrar a menor } \\
\text { configuração possível de elementos que podem ser } \\
\text { trazidos juntos e ainda criar valor comercial único; } \\
\text { 2) Expansão em etapas: definir a ordem em que } \\
\text { elementos adicionais podem ser inclusos de forma } \\
\text { que cada novo elemento se beneficie do sistema } \\
\text { vigente e aumente o potencial de criação de valor } \\
\text { para o próximo elemento a ser adicionado; processo de } \\
\text { Transferência no ecossistema: prom foram } \\
\text { alavancagem de elementos que de um ecossistema } \\
\text { desenvolvidos na construção de um segundo } \\
\text { para habilitar a construção de um se } \\
\text { ecossistema. }\end{array}$ & $\begin{array}{l}\text { Mínimo Footprint } \\
\text { Viável; } \\
\text { Expansão em } \\
\text { etapas; } \\
\text { Transferência no } \\
\text { ecossistema }\end{array}$ \\
\hline
\end{tabular}

\section{(Conclusão)}

O autor em seu livro exemplifica casos reais que embasaram a construção do modelo conceitual.

\subsubsection{Fatores de influência (ambiente externo)}

Fatores de influência do ambiente externo, de forma coerente com a definição conceitual, mostraram-se mais relevantes percentualmente na amostra de IS do que na de FFE.

Adner (2006) indica que a chave para criar estratégia no caso de IS é considerar os atrasos e desafios que são inerentes a redes colaborativas, ao invés de considerar apenas desafios internos à organização. Para isso sugere uma metodologia para avaliar riscos 
ecossistêmicos de forma sistemática. Um primeiro passo do método é especificar as diferentes categorias de risco que o ecossistema apresenta e entender como elas se relacionam com o mercado alvo. $\mathrm{O}$ autor cita três tipos de risco principais: riscos de iniciativa (incertezas familiares de gerenciamento de projetos), riscos de interdependência (incertezas de coordenação de inovações complementares) e riscos de integração (incertezas apresentadas pelo processo de adoção ao longo da cadeia de valor).

Uma vez identificados os riscos e problemas associados, a solução apresentará a si mesma. O autor exemplifica: se complementos chegarão tarde no mercado ou serão excessivamente caros, a empresa pode reagir encontrando novos parceiros. Se uma empresa complementar não tem incentivos para desenvolver sua oferta, a empresa focal pode criar um licenciamento exclusivo para que o parceiro relutante não precise se preocupar com competição.

Adner (2006) adiciona ainda que quanto mais no início da cadeia de valor for a IS, maior o número de intermediários que devem adotá-la antes que possa atingir volumes de vendas. Quanto maior o número de intermediários, maior a incerteza quanto sucesso de mercado. Por isso o analista deve considerar os custos e benefícios de adoção da inovação por cada intermediário ao longo da cadeia de valor. Se em qualquer um dos elos os custos superarem os benefícios, isso será suficiente para o insucesso da inovação. Nesta análise, o autor alerta que é fácil subestimar custos indiretos, como por exemplo, custos de transição. Outra análise é a do estágio de desenvolvimento da inovação pelos complementares. Se estiver em andamento, a empresa focal pode atrasar seu próprio desenvolvimento ou pagar para acelerar a inovação do complementar. Se o complementar precisar ainda ajustar seus processos para explorar a inovação, a empresa focal pode realizar o estudo de reconfiguração pela outra empresa, por exemplo. Outra estratégia é buscar intervenção do governo.

Outra diferenciação da análise de riscos no caso de IS é que a probabilidade de sucesso do desenvolvimento deve ser calculada como o produto das probabilidades de sucesso da inovação de cada um dos seus componentes. Este cálculo pode contradizer a impressão inicial de que uma inovação tem alta probabilidade de sucesso (por exemplo, se há três inovações em componentes necessárias para a IS, cada uma com $80 \%$ de chance de sucesso, a probabilidade total é de cerca de 50\%). Estes fatores externos devem ser considerados para estabelecimento da expectativa em relação ao projeto, uma vez que os processos decisórios, ferramentas de 
análise variam de acordo com a relação de risco/retorno (vide diferenças na lógica de investimentos anjo, capital semente, venture capital, private equity, etc).

Por fim, Adner (2006) comenta que operar em um ecossistema requer a consideração das fronteiras (quais atividades serão feitas pela empresa focal, quais com parceiros, quais deixar em aberto aguardando o mercado) em um novo nível de complexidade. Além de analisar incentivos e capabilidades, a empresa focal deve endereçar a questão da liderança no ecossistema, escolhendo se seu posicionamento deve ser mais ativo ou mais passivo no desenvolvimento da inovação, cada um com suas vantagens e desvantagens.

Alexy et al (2012) exploram a questão da revelação estratégica de conhecimentos desenvolvidos pela empresa (spillover voluntário), com o objetivo de criar condições para iniciar relacionamentos colaborativos com outros atores, encorajando-os a utilizar o conhecimento revelado e assim influenciar o ecossistema para convergir em direção à trajetória preferencial da empresa reveladora. Pode ser uma estratégia útil especialmente em contextos de alta incerteza tecnológica, incerteza da existência ou disposição de investimento de parceiros e altos cursos de coordenação formal (em consórcios, alianças etc).

Dentro do tópico fatores de influência do modelo conceitual de FFE a contribuição destes atores é relevante por dois pontos: um é que no caso de posicionamento passivo da empresa em uma IS, é importante ter mecanismos para perceber e tirar proveito dos conhecimentos estrategicamente revelados por empresas que lideram ativamente o FFE da IS, o que também envolve a sua capacidade de absorção (absorptive capacity). O outro é que no caso de IS é importante não apenas gerenciar os fatores de influência provenientes do ambiente externo sobre a empresa focal, como também estrategicamente ter o papel de gerador de fatores de influência para outras empresas do ecossistema.

Estendendo este último tópico, pode-se sugerir que compreender quais são os fatores de influência dos outros atores que co-desenvolvem a IS e não apenas o da empresa focal é importante para a tomada de decisão no FFE, o que tem potencial de aumentar exponencialmente o esforço necessário da empresa durante as etapas iniciais da inovação.

Amit e Zott (2001) citam a configuração da rede de atores em termos de densidade e centralidade como determinante importante de vantagens da rede. Outras características da rede citadas pelos autores como fatores de influência são o seu tamanho e heterogeneidade. A 
própria emergência de redes de empresas em que coexistem mercados e mecanismos de governança hierárquica segundo os autores aumenta as possibilidades de arranjos organizacionais para criação de valor.

Chesbrough et al (2014) sugerem que ligações em profundidade entre atores habilitam empresas a utilizar seus conhecimentos e recursos atuais, e acrescentam que estas ligações são desenvolvidas por proximidade geográfica a parceiros e alto nível de confiança entre participantes. Por outro lado, ligações abrangentes (wide ties) auxiliam empresas a explorar tecnologias existentes. Os autores citam o conceito de rede de valor como fator de influência, sendo importante considerar a posição da empresa dentro da rede de valor conectando fornecedores e clientes, incluindo a identificação de potenciais complementares e competidores. A rede de valor criada ao redor de um modelo de negócios configura o papel que fornecedores, clientes, e terceiros exercem na influência sobre o valor capturado da inovação. A rede de valor aumenta o fornecimento de bens complementares do lado da oferta e pode ampliar os efeitos de rede sobre clientes do lado da demanda.

Ethiraj e Posen (2013) observam que assimetrias em dependências de componentes podem conferir influência desproporcional de algumas empresas de componentes em estabelecer e ditar a trajetória de progresso do sistema como um todo. Neste sentido, Gawer e Cusumano (2014) teoriza a respeito de plataformas, que são frequentemente associadas a efeitos de rede: quanto mais usuários adotam a plataforma, mais valiosa a plataforma se torna aos usuários, devido ao acesso crescente à rede de usuários e geralmente a um conjunto crescente de inovações complementares. Este efeito de rede em IS também é destacado por Oh et al (2015).

Plataformas industriais tendem a facilitar e aumentar o grau de inovação de produtos e serviços complementares. O insight do artigo é que líderes de plataforma, como qualquer líder de mercado, deve ao mesmo tempo pensar nos competidores de mercados adjacentes como gerenciar a evolução da sua tecnologia, modelos de negócios, parcerias, e capabilidades de marketing, não importa o quão bem sucedidos sejam. Um ponto crítico, portanto é acompanhar constantemente a evolução do ecossistema. Eles precisam continuar evoluindo a plataforma e o ecossistema, assim como modelos de negócios associados, para se manter competitivos à medida que competidores surgem e em que mercados e tecnologias mudam. 
Como proposição, Gawer e Cusumano (2014) recomendam a líderes de plataforma o desenvolvimento de uma visão de como um produto, tecnologia, ou serviço podem se tornar uma parte essencial da arquitetura de um ecossistema maior, identificando ou criando um elemento com potencial de plataforma (ou seja, desempenhando uma função essencial e fácil para outros se conectarem) e identificando empresas terceiras que podem se tornar complementares à sua plataforma (pensando de forma ampla). Assim líderes de plataforma ajudam a reduzir o custo de entrada de mercados complementares, e provê demandas aos complementos.

Heger e Rohrbeck (2012) apresentam um estudo de caso de desenvolvimento de novos campos de negócios em que se realizou uma análise de rede de valor utilizando o método MACTOR, no qual são detectados os papeis de cada organização, seus objetivos em relação à qualidade de experiência, seu tamanho e relevância (faturamento, número de empregados), tendências e tecnologias disruptivas, que podem ameaçar a organização focal, seu próprio poder de influência sobre os outros atores e a exposição ao poder de influência dos demais atores. Uma observação importante é que segundo Pinho (2014) o papel dos atores e as relações de interdependência mudam dinamicamente, podendo ser beneficiário (cliente) em um momento e criador de valor (fornecedor) em outro. Ou seja, a análise da rede de valor não pode ser estática considerando apenas a fotografia de um momento.

Outro método apresentado por Heger e Rohrbeck (2012) é o de análise de cenários, de forma a consolidar todas as perspectivas relevantes para responder a questão de como um novo campo de negócios pode se desenvolver no futuro. A força do método é a habilidade de integrar um alto número de fatores de influência. Antes de iniciar a análise de cenário deve ser realizada especificação de horizonte de tempo, escopo, e perspectiva de atores, ou seja, o papel para o qual se deseja gerar insights e recomendações. Em um workshop de um dia, os fatores de influência mais importantes das áreas política, sociológica, econômica e tecnológica foram coletados e consolidados em fatores chave. Em encontros subsequentes para cada fator foram projetados possíveis estados futuros. Uma observação é que Rohrbeck é o único autor presente tanto na amostra de FFE como IS.

Segundo Hellström (2015) a criação e captura de valor em ecossistemas são amplamente determinados pela arquitetura do sistema. A arquitetura da indústria pode ser definida como padrões que circunscrevem a divisão do trabalho e receita, ou simplesmente 
definem "quem faz o que" e "quem captura o que". Uma vez que estes padrões se tornam estabelecidos, é desafiador para que novos modelos de negócios sustentáveis ambientalmente sejam bem sucedidos em se tornar sustentáveis economicamente também. O potencial de eficiência, lock-in e inovação para criar valor sistêmico, depende das condições iniciais do contexto. Identificar os direcionadores de valor de cada negócio individual de membros do ecossistema é importante para estabelecer pré-requisitos para estabelecimento do ecossistema.

Adner e Kapoor (2010) verificam que maiores desafios técnicos em componentes de fornecedores aumentam a participação no mercado da empresa focal, por aumentar seu domínio sobre ativos especializados essenciais, enquanto maiores desafios em componentes complementares reduzem esta vantagem.

Leten et al (2013) destaca o papel de um orquestrador que não é um ator ativo do ecossistema para os mercados finais e, portanto não constitui uma ameaça competitiva para seus parceiros. No caso estudado, o exemplo de orquestrador é uma instituição de pesquisa que atende demandas de pesquisa e desenvolvimento para as empresas de uma determinada indústria. Este fator de influência externo pode ser o viabilizador de IS no ecossistema, especialmente naqueles em que o custo de pesquisa e desenvolvimento se torna excessivamente custoso.

Liu e Rong (2015) sugerem que empresas em ecossistemas expandam suas visões para além dos parceiros da cadeia de fornecimentos, incluindo parceiros não diretamente de negócios como agências governamentais, associações de indústrias, stakeholders, e competidores que possuem ideias e concepções compartilhadas para futuros desenvolvimentos. Mlecnik (2013) destaca também a importância de frameworks de políticas estáveis e incorporação social em jornadas de inovação. O autor cita que no estudo de caso a existência de subvenções para inovação de agências governamentais foi importante para o sucesso da inovação.

Lipparini e Sobrero (1994) contingencia que em realidades em que ambos os atores da IS são pequenos, a proximidade geográfica ou as capabilidades relacionais das empresas tornam-se determinantes para orquestração da inovação. Segundo os autores, a proximidade da rede de fornecedores, facilitando a troca de informações e aprendizado conjunto também tem papel importante em promover inovação tecnológica complementar. (Vale comentar que este estudo é relativamente antigo, quando as telecomunicações e Internet ainda não eram tão 
evoluídas. Potencialmente atualmente a proximidade física seja menos determinante). Os autores propõem que um fator de influência relevante é a experiência prévia dos empreendedores das pequenas e médias empresas em posições anteriores em empresas maiores chamadas de "incubadoras", a partir da qual as novas empresas saíram (spun off), tanto pelo conhecimento técnico obtido no desenvolvimento de produtos complexos com diversos componentes integrados como pela rede de contatos pessoais com outros produtores, potenciais clientes, e fornecedores inovadores.

Morgan et al (2013) também destacam o relacionamento de uma empresa com os provedores de ativos complementares na rede de valor é determinante do potencial de criação de valor. Esta criação de valor depende do quão alinhados estão os objetivos dos coinovadores e o comprometimento dos mesmos para investir em ativos complementares.

O Quadro 8 apresenta uma síntese dos fatores de influência abordados na literatura de IS.

\section{Quadro 8 - Síntese de Fatores de Influência na literatura de IS}

\begin{tabular}{|c|c|c|}
\hline Prática no FFE & Elemento da prática & Fontes \\
\hline \multirow[t]{3}{*}{$\begin{array}{l}\text { Mapeamento do } \\
\text { ecossistema }\end{array}$} & $\begin{array}{l}\text { Identificação de riscos } \\
\text { componentes e complementos }\end{array}$ & Adner (2006), Adner e Kapoor (2010) \\
\hline & Análise da arquitetura do ecossistema & Ethiraj e Posen (2013), Hellström (2015) \\
\hline & $\begin{array}{l}\text { Identificação e análise da rede de } \\
\text { atores }\end{array}$ & $\begin{array}{l}\text { Amit e Zott (2001), Heger e Rohrbeck (2012), } \\
\text { Morgan et al (2013), Chesbrough et al (2014), } \\
\text { Liu e Rong (2015) }\end{array}$ \\
\hline \multirow[t]{2}{*}{$\begin{array}{l}\text { Posicionamento } \\
\text { no ecossistema }\end{array}$} & $\begin{array}{l}\text { Posicionamento de liderança no } \\
\text { ecossistema }\end{array}$ & Adner (2012), Gawer e Cusumano (2014) \\
\hline & $\begin{array}{l}\text { Posicionamento de orquestrador do } \\
\text { ecossistema }\end{array}$ & Lipparini e Sobrero (1994), Leten et al (2013) \\
\hline
\end{tabular}

\subsubsection{Motor (liderança, cultura, papeis e estratégia de negócios)}

No texto original de Koen et al (2001), este elemento trata da liderança, cultura e papeis apenas na relação entre entidades internas à organização. No entanto, para iniciar uma IS, são necessários mecanismos de coordenação, compartilhamento de conhecimentos e novos tipos de papeis que transcendem as fronteiras da organização. Alexy et al (2012) em sua síntese da literatura concluem que as organizações preferem não colaborar, mas às vezes simplesmente precisam, seja porque tecnologias e mercados cruciais para inovar são 
controlados por outros ou devido ao grau de especialização de alguns elementos da cadeia de valor.

O posicionamento estratégico passa a ser crucial, principalmente em termos de definição de fronteiras da organização e relacionamentos externos. Segundo Adner (2006), pode até ser estratégico alocar recursos externamente, em parceiros, do que alocar internamente no seu próprio projeto, dependendo de onde os gargalos críticos estiverem localizados. Ren et al (2015) também mencionam investimentos idiossincráticos bilaterais para consolidar relações entre as partes. Adner e Kapoor (2010) verificam empiricamente que a vantagem de utilizar integração vertical aumenta ao longo do ciclo de vida da tecnologia. Nas fases iniciais (FFE), em que o nível de incerteza é muito alto verifica-se que a integração vertical não se mostrou uma escolha estratégica favorável, pelo menos na indústria de semicondutores. Chesbrough et al (2014) sugerem que inovação aberta pode ser considerada uma estratégia de geração de valor alternativa à integração vertical. Em linha, Amit e Zott (2001) argumentam que em uma economia em rede há uma alternativa à propriedade e controle dos recursos e capabilidades, que é a parceria e acordos de compartilhamento de recursos.

Amit e Zott (2001) também definem redes estratégicas em ligações interorganizacionais estáveis que são estrategicamente importantes para as empresas participantes. Estas ligações podem tomar forma de alianças, joint ventures, parcerias de fornecimento de longo prazo, entre outros. Chesbrough et al (2014) sugere que uma empresa configura uma rede de valor por meio de aquisições, acordos de licenciamento, alianças que não envolvem compartilhamento de ações, contratação, entre outros. Classificam ainda as ligações entre empresas em formais (baseadas em contrato) e informais (baseadas em relacionamento). Redes de inovação são frequentemente baseadas em repetidas interações entre empresas e criação de confiança, que se torna a base dos mecanismos de coordenação. Evidência empírica sugere que ligações mais institucionalizadas são mais duradoras do que as informais. Alerta-se que interações repetidas com os mesmos parceiros pode levar à redução do potencial de inovação devido à redundância de informação.

Chesbrough et al (2014) também mencionam a alternativa de investimento de risco feita por grandes corporações em spin offs (corporate venture capital), para provisão de financiamento para descobertas em fases iniciais. Os autores também categorizam 
investidores nas fases iniciais de inovação em quatro tipos: exploradores de inovação (estendem descobertas realizadas inicialmente em laboratórios de P\&D da empresa), mercadores de inovação (exploram comercialmente descobertas inicialmente realizadas em laboratórios de P\&D da empresa), arquitetos de inovação (provê arquiteturas e plataformas para outras entidades realizarem suas inovações, assegurando que o sistema inteiro funciona) e missionários de inovação (que visam inovações de impacto social).

No estudo de caso em profundidade de como o restaurante Chez Panisse promoveu o desenvolvimento de um ecossistema de alta cozinha na Califórnia, Chesbrough et al (2014) enfatizam a importância da visão (descrita como quase "obsessão") da fundadora da empresa em relação ao conceito de uso de ingredientes de alta qualidade. Atuando como missionária de inovação, a inovadora colocou a missão social de promover este conceito acima do lucro imediato. Aliado a seu carisma pessoal, foi capaz de convencer sua rede de fornecedores a alterarem seus processos produtivos segundo seus exigentes requisitos, além de criar uma organização não governamental para promover iniciativas de micro fazendas orgânicas e reduzir o risco de mudança garantindo a compra de produtos dos fornecedores. De certa forma, a empresa atuou como uma investidora de risco (venture capitalist) social, arcando com os custos de iniciação da IS.

A categoria de arquitetos de inovação tem semelhança com a definição de líderes de plataforma (GAWER E CUSUMANO, 2014), que são organizações que de forma bem sucedida estabelecem seus produtos, serviços ou tecnologias como uma plataforma industrial e alcançam uma posição onde podem influenciar a trajetória do sistema tecnológico e de negócios no qual a plataforma é o elemento principal. Estes líderes podem inclusive promover investimentos em inovações complementares, semelhante à observação de Adner (2006). Similar ao observado no estudo de caso de Chesbrough et al (2014), Gawer e Cusumano (2014) sugerem que líderes de plataforma que querem desenvolver capabilidades de inovação do ecossistema externo precisa desenvolver uma visão para sua plataforma e promovê-la entre atores chave potenciais no presente e no futuro. Eles devem ainda formar coalizões mutuamente benéficas ao redor da plataforma. Como recomendações gerais, incluem ainda:

- Manter a inovação na competência central, assegurando que continua provendo uma função essencial (e difícil de substituir) para o sistema em geral, fazendo com que valha a pena às outras empresas conectado à sua plataforma; 
- Realizar investimentos de longo prazo em atividades de coordenação da indústria, cujos frutos criam valor para todo o ecossistema.

Fatores que determinam o sucesso do líder de plataforma são legitimidade, identidade coletiva e trabalho institucional, posicionando a empresa como um intermediário confável.

Liu e Rong (2015) também sugerem que o alinhamento de visão permite que as empresas do ecossistema combinem seus esforços de pesquisa e desenvolvimento e trabalhem juntos para desenvolver a IS. Os autores sugerem a atividade de gerir a avaliação de alianças, o que inclui não só escolher os atores certos com as habilidades certas como também convencer os atores certos a trabalhar em conjunto no desenvolvimento da inovação. O FFE se inicia com uma comunicação regular entre os participantes do ecossistema para identificar potenciais projetos e parcerias. Os autores recomendam a formalização dos métodos de interação entre os atores, o que significa estabelecer uma estrutura de comunicação comum para estimular o envolvimento dos parceiros e encorajá-los a contribuir no codesenvolvimento. Criar novos produtos em conjunto significa que ambas as partes podem acessar as tecnologias do outro, e então recombiná-las. Outra atividade chave é coordenar a promoção da plataforma, que no caso estudado foi realizada por meio de diversas conferências setoriais.

Heger e Rohrbeck (2012) em estudo de caso de exploração de novos campos de negócios sugerem que exploração de mercado colaborativa em workshops presenciais permitiu o compartilhamento de perspectivas de outras empresas que exercem diferentes papeis na rede de valor, contribuindo para este alinhamento de visão. Esta participação dos diferentes atores no FFE aumentou a credibilidade e confiança nos resultados, segundo os autores. Os autores indicam ainda algumas práticas adotadas neste processo participativo, que contribuírm para o resultado:

- Prover tempo suficiente para contextualizar e re-contextualizar participantes do que já foi conquistado no passado e o que era esperado da próxima tarefa;

- Reuniões presenciais periódicas e pelo menos uma reunião por telefone a cada quinze dias;

- Dois eventos de formação de time (team building), uma no início da atividade e outra na metade do projeto (que durou um ano); 
- Visualização de progressos do projeto, incluindo o status de contribuições individuais;

- Distribuição de tarefas preparatórias uma semana antes das reuniões;

- Uso de questionários pré estruturados para coletar dados efetivamente;

- Discussões em workshops suportadas por modelos que tinham que ser preenchidos colaborativamente;

- Paineis de discussão com número reduzido de participantes simultaneamente;

- Documentação do projeto em wikis (sites que podem ser editados em tempo real por todos os participantes);

- Uso de fóruns de discussão;

- Ferramentas de mapa mental online para estruturação de novos tópicos colaborativamente durante conferências por telefone;

- Uso de softwares de mensagem instantânea para facilitar interação direta.

Hellström (2015) sugerem que é insuficiente a empresa focal incentivar seu próprio modelo de negócios, procurando preencher as funções faltantes no ecossistema a fim de atingir objetivos no nível do sistema. Nem sempre é financeiramente viável ou possível preenchê-las. Ao invés disso, mudanças em modelos de negócios de outros atores, alcançadas por meio de colaboração permitindo a criação de valor inacessível para uma empresa isoladamente. $\mathrm{O}$ valor de mecanismos de colaboração é habilitar a criação de modelos de negócios, sob a premissa de que arquiteturas industriais podem ser formatadas e redefinidas pelos atores envolvidos.

Kapoor (2013) nota que interações colaborativas são mais intensas quando o relacionamento é gerenciado por uma unidade organizacional dedicada, mais baixa quando gerenciada pelo departamento de engenharia e moderado quando gerenciado pelo departamento de marketing. O autor nota que no mercado de semicondutores os atores da indústria interagem principalmente compartilhando informações de mercados ou aplicações específicos e em planos de P\&D e roadmaps tecnológicos. Customizar produtos para compatibilizar com complementares e desenvolvimento de produtos em conjunto requerem maior comprometimento das partes e representam a segunda forma mais frequente de interação, seguida de marketing conjunto, estabelecimento de padrões, licenciamento, e investimento em complementares. 
Meuer (2013) apresenta arquétipos de configurações interempresas. As coalizões orgânicas caracterizam-se pela ausência de diferenciação vertical, uma hierarquia plana, interessante quando há elevado grau de incerteza no ambiente. Fundações burocráticas baseiam-se em hierarquia rígida, interessante quando as condições do ambiente são estáveis. Em coalizões de parceiros intensamente interdependentes a relação se caracteriza pela interdependência que leva as empresas a combinarem recursos e agir coletivamente, em busca de objetivos comuns e mostra-se um arquétipo relacionado com alto desempenho no caso de inovações gerenciais. O quarto arquétipo é o de fundações recíprocas, em que cada empresa tem sua especialização e customizam seus produtos para compatibilizar com as empresas parceiras, de forma descentralizada, interessante em casos de elevada heterogeneidade entre os participantes.

Mishra e Shah (2009) operacionalizam o construto de competência colaborativa no contexto de desenvolvimento de novos produtos. Trata-se de um construto multidimensional composto por envolvimento de fornecedores, envolvimento de clientes e envolvimento de times multifuncionais. Este envolvimento auxilia no desenvolvimento de uma linguagem comum e uma sintaxe compartilhada para representar diferenças e entender as interdependências críticas nas fronteiras das organizações. Segundo os autores, o envolvimento de fornecedores e clientes juntos simultaneamente nas fases iniciais do desenvolvimento de inovação é benéfico porque permite que os fornecedores integrem requisitos específicos dos clientes no design de componentes. $\mathrm{Na}$ avaliação empírica, verificou-se que esta competência colaborativa está relacionada com desempenho superior de projeto de desenvolvimento de inovação, que media o desempenho comercial superior.

Mishra et al (2015) verificam que quanto maior o orçamento para parcerias, mais significativas são as contribuições dos parceiros e que envolvimento dos parceiros no FFE tem se mostrado efetivo para melhoria do design, manufaturabilidade, redução de defeitos e retrabalho e tempo de desenvolvimento. O número de parceiros envolvidos no projeto tem uma relação do tipo $U$ invertido com o sucesso de projetos de pesquisa e desenvolvimento: aumentar a profundidade de relação com parceiros por meio de comunicação e propriedade intelectual compartilhada é importante, porém o número excessivo de parceiros dificulta a comunicação frequente e efetiva, tornando o processo muito custoso. $\mathrm{O}$ uso de integradores (indivíduos com suficiente conhecimento de negócios assim como conhecimento técnico) 
melhora a comunicação e o compartilhamento de propriedade intelectual ao longo das fronteiras das organizações.

Leten et al (2013) destacam a importância do orquestrador na formatação do ecossistema de inovação, estimulando a colaboração entre parceiros de pesquisa, estabelecendo uma agenda de pesquisa, e adicionando valor através de suas capacidades. Ainda segundo os autores, a combinação de propriedade intelectual compartilhada e exclusiva permite que cada parceiro construa ativos intangíveis de forma ágil e efetiva em termos de custos. Neste artigo os autores destacam o papel de um orquestrador que não atua diretamente no mercado final (non-player). Do ponto de vista de uma empresa focal, pode-se inferir que uma estratégia interessante é buscar uma entidade relativamente neutra para orquestrar a IS.

Alexy et al (2012) teorizam que revelar parte do conhecimento próprio, seja em forma de problemas em forma de soluções, uma empresa focal pode pode iniciar relacionamentos colaborativos com outros atores para reformatar o ambiente competitivo e aumentar seu acesso a tecnologias e mercados. A revelação seletiva é definida pelos autores como a divulgação voluntária de recursos especificamente escolhidos, usualmente baseados em conhecimento, que a empresa poderia ter mantido proprietários, de forma que eles se tornem disponíveis para o público em geral, incluindo competidores da empresa. Segundo os autores, arranjos prevalentes como alianças, joint ventures, ou aquisições, que usualmente ocorrem sob um contrato, nem sempre são mecanismos viáveis de colaboração, daí a relevância da revelação seletiva. Esta técnica também é citada por West e Kuk (2016). Um caso extremo de revelação são sistemas de código aberto (MORGAN ET AL, 2013).

Plataformas abertas (open source) têm como característica a descentralização de ações e tomada de decisão e utilização de mecanismos sociais ao invés de autoridade hierárquica para incentivar esforços de outras organizações. Neste caso o conhecimento da empresa ultrapassa suas fronteiras, oferecendo potencial de redução de riscos, geração de economias de escala, e aprendizado e criação de valor conjuntos. Elementos facilitadores desta estratégia de criação de valor são comprometimento na rede de valor, troca de conhecimentos, alinhamento de objetivos e governança efetiva.

McDermott et al (2013) destacam que uma perspectiva na arquitetura de empresas em IS é a de modularidade: padronizando as interfaces entre os agentes tomadores de decisão, empresas podem melhorar suas capabilidades em termos de aprendizado e inovação. Esta 
observação é baseada na ideia de que estes processos facilitam a implementação de sistemas abertos e resultam em comunicação melhorada, permitindo transferência e integração de conhecimento superior. Modularização habilita o orquestrador da cadeia de valor a lidar com níveis crescentes de complexidade associada à rápida atualização tecnológica. Como contraponto, a padronização aumenta o risco de que capabilidades distintivas sejam terceirizadas e reduz a variedade de parceiros com quem a empresa pode interagir.

Lipparini e Sobrero (1994) destacam como fator crítico dentro do contexto de IS envolvendo pequenas e médias empresas a habilidade pessoal do empreendedor de criar, gerenciar e recombinar um conjunto de relacionamentos com fornecedores externos. Confiança e reputação desenvolvida em relacionamentos anteriores são importantes para suportar esta habilidade. Estes empreendedores buscam ativamente novas combinações entre as várias ligações interempresas. A pesquisa dos autores indicou que quando os empreendedores fundadores estão no projeto de IS o percentual de fornecedores envolvido é significativamente superior do que quando o fundador não está presente.

Mlecnik (2013) também aborda IS no contexto de pequenas e médias empresas onde competências e recursos para atrair parceiros para $\mathrm{P} \& \mathrm{D}$ conjunto são limitados. No caso estudado pelo autor, a presença de um agente setorial auxiliando a pequena empresa na disseminação de conhecimento arquitetural entre os participantes do ecossistema foi fundamental para o FFE da IS. Este agente insistiu em atrair mais contribuidores da inovação além do que a empresa focal havia inicialmente vislumbrado, ampliando o potencial de ganho sistêmico da inovação. Outro fator importante foi a realização de projetos de demonstração para ganho de experiência e aprendizado entre fornecedores. A partir de uma base de conhecimento arquitetural formada entre os atores, foi formada uma parceria de pesquisa e desenvolvimento colaborativa e a maioria dos fornecedores envolvidos se beneficiou do esforço conjunto. Após esta etapa a inovação havia sido atingida, porém era preciso chegar até o consumidor final. A aliança com uma plataforma que reunia um pool de clientes potenciais foi fundamental para a disseminação. $\mathrm{O}$ autor conclui ainda que IS requer gestão e coordenação substanciais, conhecimento tácito, comunicação informal regular e processos de aprendizado organizacional. Atenção explícita deve ser dada para a geração gradual de uma base de conhecimento colaborativa, com prototipagem e alianças estratégicas. 
A categorização de parceiros na IS pode facilitar a colaboração no processo de inovação. Liu e Rong (2015) exemplificam esta categorização no estudo de caso em que os parceiros foram divididos em três grandes grupos: parceiros de hardware, parceiros de ferramentas de desenvolvimento e outros parceiros funcionais. Pinho (2014) classifica três tipos de interdependência: interdependência de papeis dinâmicos (o papel do ator pode mudar de provedor a consumidor), interdependência temporal (interações ocorrem sequencialmente em tempos diferentes) e auto-interdependência (criação de valor depende das próprias ações dos atores.

Ren et al (2015) mencionam o modelo DART (diálogo, acesso, redução de risco e transparência) como os quatro pilares da co-criação de valor. Os autores verificam empiricamente que investimentos bilaterais idiossincráticos influenciam positivamente a interdependência de recursos que por sua vez influencia positivamente a co-criação de valor. A co-criação e interdependência de recursos influenciam positivamente a qualidade da parceria.

Hellström (2015) aproxima a visão de arquiteturas de indústria que podem ser reformatadas e redefinidas pelos participantes (alinhada com a definição de IS) com a teoria de efetuação (SARASVATHY, 2001). Na amostra de literatura de FFE esta abordagem também foi destacada por Brettel et al (2012) para situações de extrema incerteza.

Sintetizando as descobertas da literatura, os principais elementos motor no FFE de IS são mecanismos de coordenação e colaboração entre atores do ecossistema da inovação. O Quadro 9 apresenta um resumo das práticas encontradas.

\section{Quadro 9 - Síntese de Motor no FFE de IS}

\begin{tabular}{|c|c|c|}
\hline Prática no FFE & Elemento da prática & Fontes \\
\hline \multirow{10}{*}{$\begin{array}{c}\text { Mecanismos de } \\
\text { coordenação e colaboração }\end{array}$} & $\begin{array}{l}\text { Alocação de recursos em } \\
\text { parceiros }\end{array}$ & $\begin{array}{l}\text { Adner (2006), Gawer e Cusumano (2014), Ren et } \\
\text { al (2015) }\end{array}$ \\
\hline & Inovação aberta & Chesbrough et al (2014), Morgan et al (2013) \\
\hline & Alianças & Amit e Zott (2001), Chesbrough et al (2014) \\
\hline & Joint Ventures e Aquisições & Amit e Zott (2001), Chesbrough et al (2014) \\
\hline & $\begin{array}{l}\text { Parceria de fornecimento de } \\
\text { longo prazo }\end{array}$ & Amit e Zott (2001) \\
\hline & $\begin{array}{ll}\text { Acordo } & \text { propriedade } \\
\text { intelectual } & \end{array}$ & Chesbrough et al (2014), Leten et al (2013) \\
\hline & Contratação & Chesbrough et al (2014) \\
\hline & Corporate Venture Capital & Chesbrough et al (2014) \\
\hline & Compartilhamento de visão & Chesbrough et al (2014), Liu e Rong (2015) \\
\hline & Plataforma industrial & $\begin{array}{l}\text { Morgan et al (2013), McDermott et al (2013), } \\
\text { Gawer e Cusumano (2014), Hellström (2015) }\end{array}$ \\
\hline
\end{tabular}




\begin{tabular}{|l|l|l|}
\hline & Orquestrador não-ator & Leten et al (2013), Mlecnik (2013) \\
\cline { 2 - 3 } & Revelação seletiva & Alexy et al (2012) \\
\cline { 2 - 3 } & Networking pessoal & Lipparini e Sobrero (1994) \\
\hline
\end{tabular}

\subsubsection{Identificação de oportunidades}

Alexy et al (2012) as empresas podem revelar seletivamente problemas tecnológicos atuais ou futuros para que outras empresas proponham soluções. Desta forma, assim como na análise dos fatores de influência, não basta ativamente buscar oportunidades para o próprio negócio, mas também ativamente apresentar oportunidades para que outros atores identifiquem, sendo essa uma diferenciação de FFE de IS em relação à inovação autônoma.

Amit e Zott (2001) apontam que em mercados virtuais, oportunidades de criação de valor podem resultar de novas combinações de informações, produtos físicos e serviços, configurações inovadoras de transações, e reconfiguração e integração de recursos, capabilidades, papeis e relacionamentos entre fornecedores, parceiros e clientes. Os autores citam Schumpeter, que por sua vez enfatiza a importância da tecnologia e considera novas combinações de recursos (e serviços que eles provêm) como as fundações para novos produtos e métodos de produção. Os autores citam também que a criação de valor pode ser derivada de atenuação de incertezas, complexidade, assimetria de informações e condições de negociação, bem como por meio de minimização de custos de transação.

Heger e Rohrbeck (2012) sugerem atividades de prospectiva (foresight) para suportar decisões de longo prazo como atividades de inovação e planejamento estratégico por meio da identificação de trajetórias alternativas para tecnologias emergentes, tendências e criação de cenários futuros. No estudo de caso apresentado, a identificação de oportunidades ocorreu principalmente na fase 1 do processo de corporate foresight, definindo-se primeiramente requisitos dos clientes. Liu e Rong (2015) também sugerem que empresas de ecossistemas que colaboram em inovação para desenvolver produtos complexos começam pelo aprendizado de demandas dos clientes. Estes exemplos alinham-se mais com a abordagem clássica causal de inovação (em oposição com efetuação). 
No caso estudado por Leten et al (2013), a existência de um agente de pesquisa e desenvolvimento como fim permite que seja criada propriedade intelectual que é acessível (mediante subscrição) aos parceiros deste agente, sendo uma fonte de oportunidades. Esta mediação da propriedade intelectual também favorece a atuação deste agente como orquestrador do ecossistema de negócios. Os autores citam também que os líderes de plataforma devem antecipar o futuro para não perder o controle da transição entre uma plataforma e outra.

Mlecnik (2013) apresenta que no estudo de caso foi identificada uma abertura para a empresa focal desenvolver um mercado de nicho em construção sustentável, usando os produtos e máquinas que estavam à sua disposição. Estes dois últimos exemplos são alinhados com a abordagem efetual, em que se parte da identificação dos recursos disponíveis.

Mlecnik (2013) também descreve que o parceiro da empresa focal não era direcionado por inovação radical, sendo sua principal motivação para embarcar no co-desenvolvimento foi compliance com regulações e padrões relevantes. Para despertar atenção dos co-inovadores, a empresa focal desenvolveu um business case revelando o potencial do projeto e de projetos futuros com as novas tecnologias. Isto fez com que fornecedores percebessem que os direcionadores de inovação sustentável já estavam sendo usados por gerentes, autoridades, clientes, arquitetos, consultores e contratantes em direção a casas de alta eficiência energética. A ideia de embarcar na inovação foi então engatilhada por pressão de mercado, falta de knowhow sobre padronização neste novo paradigma tecnológico e consciência de que as bases dos componentes necessários já estavam disponíveis para uso e que eram apreciados pelos consumidores. Neste caso, oportunidades de mercado detectadas e demanda regional por projetos de demonstração empurraram os fornecedores do ecossistema em direção à inovação, mesmo quando não havia nenhuma política ou regulação do governo.

Morgan et al (2013) defendem que sistemas de código aberto criam maior oportunidade para ideias inovadoras e criatividade (em comparação com sistemas proprietários), devido ao acesso a conhecimento superior fora da empresa e flexibilidade de uso dos componentes, que facilitam experimentações e mistura e recombinação dos mesmos. Para adquirir conhecimento e ideias externamente, empresas também participam de conferências e colaboram com muitos fornecedores, universidades e institutos de pesquisa. Empresas dispendem tempo compartilhando expertise e competências e contribuem com 
vários esforços que motivam novos stakeholders a revelarem complementos para uso na oferta para o cliente final da empresa. Ao formar redes com novos participantes e tentando fortalecer qualquer ligação fraca, empresas, como entrantes, precisam sinalizar o alto nível de comprometimento por meio de trabalho árduo e engajando-se com outros participantes da rede. Este comportamento gera novas oportunidades de inovação, condizente com a abordagem de efetuação.

Após esta revisão verifica-se que as práticas de identificação de oportunidades no FFE de IS são similares à da inovação autônoma, exceto por práticas que estão relacionadas a mecanismos de coordenação e colaboração (Quadro 9).

\subsubsection{Análise de oportunidades}

Adner (2006) alerta que os processos de diligência vigentes atualmente na maioria das empresas são desenhados para avaliar oportunidades em que a empresa pode criar valor sozinha. Quando o valor é criado em um ecossistema, atender a referências tradicionais é necessário porém insuficiente para o sucesso. Isso é um problema porque a diligência é central para estabelecimento de expectativas para a nova iniciativa, as quais, caso incorretas, prejudicam a execução. Por isso o autor recomenda a avaliação de riscos de interdependência através da análise de probabilidade conjunta dos diferentes parceiros estarem aptos a cumprir seus compromissos dentro de um espaço de tempo específico, dada pela multiplicação das probabilidades de sucesso de cada uma das partes. Sugere ainda a avaliação dos riscos de integração, somando-se os tempos de ciclo de adoção para estimar o atraso causado por intermediários na entrega de valor ao cliente final.

Adner (2006) sugere ainda um método sistemático de mapear o ecossistema de inovação, conforme os seguintes passos:

1) Identificar todos os intermediários que devem adotar sua inovação antes dela chegar ao consumidor final;

2) Identificar todos os complementos (outras inovações necessárias para sua inovação) requisitados para que você e cada um dos seus intermediários entreguem a proposta de valor ao cliente final;

3) Estimar os atrasos causados por sua interdependência com seus próprios complementares; 
4) Estimar os atrasos causados pelo processo de adoção e pelo tempo que cada intermediário leva para integrar sua solução nas decisões, ciclos de desenvolvimento, produtos e assim por diante;

5) Estimar os atrasos causados pela interdependência com intermediários com seus próprios complementares e os problemas de integração para a adoção da inovação;

6) Estimar o tempo para sua inovação chegar a mercado com base nas estimativas anteriores;

7) Reavaliar as expectativas iniciais da iniciativa e ajustar a estratégia de acordo.

Heger e Rohrbeck (2012) apresentam perguntas típicas de análise de oportunidades: há uma demanda mal servida? Se sim, quanto os clientes estão dispostos a pagar? Como a demanda pode ser satisfeita? Devemos endereçar o mercado com um produto, um serviço, ou um híbrido que combine produto físico e serviço? Quais tecnologias emergentes devem ser usadas para construir o produto e serviço? Quem irá produzir? Há uma oportunidade de negócios interessante financeiramente? Esta incerteza multi dimensional traz um dilema da galinha e do ovo: se a empresa não conhece quais tecnologias deveria aplicar em um certo produto, não será capaz de definir as suas propriedades. Se as propriedades do produto são desconhecidas, não se pode avaliar o potencial de clientes e quanto estão dispostos a pagar. Se a disposição a pagar é desconhecida, também é desconhecido o potencial de negócios. $\mathrm{O}$ dilema resulta em um desafio duplo de planejamento: lidar com incerteza e lidar com interdependências entre os aspectos múltiplos de um novo campo de negócios. A sugestão dos autores é utilizar prospectiva estratégica como método de reduzir incertezas e dar visibilidade para as interdependências, cujo método mais popular é o de construção de cenários.

Como análise integrante da prospectiva estratégica Heger e Rohrbeck (2012) sugerem o esclarecimento de como lidar com parceiros na rede de valor, em particular verificando se pode haver mudanças no poder entre os atores e identificando potenciais novos compradores e fornecedores. Assim identificam-se novas parcerias ou conflitos latentes que podem favorecer ou impedir a entrada bem sucedida no mercado.

Os autores fazem ainda recomendações para melhorar o resultado da prospectiva estratégica. Primeiramente, o time selecionado para a prospectiva deve ter seis características: ser curioso e receptivo, de mente aberta e apaixonado, ter conhecimento tanto amplo como profundo, forte rede pessoal externa e forte rede pessoal interna. A diversidade de perspectivas diferentes dentro do time também é essencial. A fase zero recomendada para o método é a coleta de informações, seja base de documentação sobre tecnologias, publicações 
de periódicos científicos, relatórios e estudos publicados por institutos de pesquisa, estudos internos conduzidos por parceiros do projeto, além de artigos publicados em meios não científicos.

Liu e Rong (2015) sugerem a avaliação de alianças, processo em que a gerência sênior intencionalmente avalia oportunidades de projeto potenciais e identifica os parceiros de negócios apropriados para se juntar ao time de exploração destas oportunidades. A evidência empírica deste estudo sugere que empresas do ecossistema que estão interessadas em desenvolver produtos complexos estão ativamente buscando colaboração em oportunidades de inovação e avaliando cada um para possíveis alianças para o projeto. Estas empresas também mantêm documentação detalhada e categorizada de acordo com os tipos de negócios e capabilidade das demais empresas. Este processo dá às empresas uma consciência maior de quais os recursos disponíveis no ecossistema.

Observa-se que a prospectiva estratégica (HEGER E ROHRBECK, 2012) e avaliação de alianças (LIU E RONG, 2015) podem ser ferramentas complementares de avaliação de oportunidades no FFE, considerando-se a complementaridade entre a abordagem causal e a efetual.

Mishra e Shah (2009) indicam que fornecedores tem mais probabilidade de identificar problemas potenciais como especificações contraditórias ou designs irrealísticos se envolvidos no FFE. Além disso, este envolvimento precoce abre possibilidades de aquisição externa e terceirização, reduzindo a complexidade interna de projetos e provendo pessoal extra para encurtar o caminho crítico de projetos de desenvolvimento de novos produtos.

Além de fornecedores, Mlecnik (2013) destaca o conhecimento inicial fornecido por um stakeholder importante no campo do caso estudado, que é uma organização sem fins lucrativos, estabelecida com financiamento de uma agência governamental pró inovação pela ciência e tecnologia. Esta organização consiste em uma rede de agentes que desenvolveu estudos de inovação e se engajou em interações não competitivas com o objetivo de estimular pesquisa e inovação no campo selecionado.

Mlecnik (2013) descreve de forma detalhada como a IS do caso estudado foi construída. Em um primeiro momento a empresa focal do caso buscou a organização sem fins lucrativos de fomento à inovação na área tentando descobrir se seus produtos podiam 
contribuir de alguma forma. No início, a inovação para a empresa focal era de natureza incremental e não sistêmica, buscando aproveitar uma oportunidade específica diretamente ao cliente final, identificada a partir de informações disponíveis gratuitamente em panfletos e sites da Internet. No entanto, ao longo do processo de análise da oportunidade percebeu-se que apenas aquela oferta autônoma seria insuficiente para a proposição de valor. O agente começou conduzindo uma revisão construtiva da percepção de vários aspectos da inovação (vantagens relativas, complexidade, compatibilidade, demonstrabilidade, visibilidade) e explicou estes aspectos para os fornecedores, que então reconheceram a oportunidades de inovação modular, arquitetural e sistêmica, de forma evolutiva. Neste processo foram identificadas lacunas de conhecimento das partes em relação ao funcionamento do sistema como um todo, e a partir do momento em que as lacunas foram sendo preenchidas, as oportunidades de IS foram sendo identificadas. Projetos de demonstração também foram importantes neste processo de análise das oportunidades.

Observa-se que as práticas de análise de oportunidades são parecidas com as práticas adotadas na avaliação de fatores de influência de IS. Outro insight importante é o caráter evolutivo da IS, em que à medida em que atores são agregados à inovação, ampliam-se as oportunidades possíveis de geração de valor, havendo aparentemente ciclos progressivos de FFE e NDP no caso da IS.

\subsubsection{Geração e enriquecimento de ideias}

Apesar de ser uma atividade chave para o FFE, segundo a rede de palavras chave da Figura 1, atividades de geração de ideias não é tratada explicitamente nas pesquisas de IS, apenas indiretamente, o que pode indicar um ponto de complementação entre as literaturas.

Chesbrough et al (2014) destacam o papel do diálogo entre empresas, consumidores e fornecedores para a co-criação de ideias no caso estudado. Outra prática de geração e enriquecimento de ideias citada foi a abertura de um local físico em que todos eram convidados a entrar, tornando-se um espaço para compartilhamento de ideias com todos os stakeholders. Os fornecedores eram encorajados a mandar novos insumos sem que se tivesse uma demanda específica, de forma a incentivar a geração de novas aplicações (efetuação). 
Havia também um sistema sabático em que os chefs passavam parte do tempo trabalhando e parte do tempo explorando o mundo em busca de inspirações. Antigos funcionários que seguiram em outros rumos também eram convidados para participar esporadicamente da operação da empresa, trazendo novos insights. Até críticas na mídia serviam de inspiração para ideias inovadoras.

Para Lipparini e Sobrero (1994), pequenas e médias empresas tiram vantagem ao recorrer a empresas externas para superar a inércia que afeta muitas empresas deste porte com produtos bem sucedidos. As empresas externas trazem uma injeção de novas ideias que podem levar as empresas a parcerias de longo prazo em que a dimensão relacional prevalece sobre a transacional. Estas relações próximas, baseadas em reciprocidade e comprometimento mútuo e pessoal clamam pelo envolvimento precoce de fornecedores no desenvolvimento de inovação. Trata-se de uma lógica de aprendizado por cooperação, em que empresas podem lucrar com o compartilhamento precoce de informações críticas e fluxo contínuo de sugestões técnicas e gerenciais. Os autores também encontram evidência empírica que quando a inovação é liderada pelo fundador, a relevância de contribuições radicais e arquiteturais dos fornecedores aumentará e as contribuições incrementais diminuirão.

Liu e Rong (2015) citam a prática de co-visão como habilitadora de alinhamento de negócios e objetivos de inovação entre as empresas do ecossistema, consolidando seus esforços em pesquisa e desenvolvimento. A análise sugere que esta visão compartilhada permite que as empresas do ecossistema trabalhem juntas para suportar múltiplos projetos de desenvolvimento. Uma vez que se cria uma visão conjunta, elas procedem no planejamento e design de produtos e plataformas baseadas no ecossistema. Este processo de criação é chamado pelos autores de co-design, no qual há um engajamento que abrange todo o ecossistema desde o planejamento do desenvolvimento do novo produto, da estratégia de plataforma e organização de esforços para geração de soluções. Os autores teorizam com base em estudos que apontam que o caso de inovação em produtos complexos requer participação ativa de múltiplas organizações, que gera a combinação de tecnologias para produção de novas ideias e novas funcionalidades em produtos existentes para atender necessidades dos clientes.

Os autores por fim sugerem que há dois tipos de estratégia para geração e enriquecimento de ideias: a comunidade conectada e a estratégia de parceiros-líderes. No 
primeiro caso, a empresa focal oferece ferramentas de desenvolvimento relevantes a cada parceiro da comunidade e coloca seu conhecimento e expertise à disposição para contribuir no desenho de soluções. Estes movimentos habilitam um desenvolvimento de produtos contínuo, mantendo-se o engajamento e expandindo-o quando novas oportunidades aparecem. Além de fomentar esta comunidade, os pesquisadores descobriram que algumas empresas do ecossistema adotam a estratégia de parceiros-líderes. Quando novas oportunidades de produtos aparecem, a empresa focal que possui tecnologias importantes (relacionadas a estas oportunidades) selecionarão os atores de melhor desempenho que também detêm soluções importantes para serem parceiros-líderes. Com estes parceiros, as empresas focais formam o time central do desenvolvimento, enquanto os demais auxiliam desenvolvendo aplicações complementares.

Mlecnik (2013) também demonstra em seu estudo de caso a importância da interação regular entre os atores do ecossistema para obtenção de inputs valiosos de implicações econômicas e técnicas dos novos métodos propostos. A busca de benchmarks internacionais e participação em workshops com outras empresas do ecossistema também proveu insights sobre novos métodos construtivos. Um ambiente virtual foi criado para que os parceiros pudessem compartilhar ideias e resultados dos estudos. Os parceiros também extraíram e trocaram informações de feiras setoriais, periódicos técnicos especializados, clientes potenciais e experimentação com protótipos. Pacotes de trabalho para inovação foram distribuídos entre todos os parceiros envolvidos, formando uma ação "de bando" (pack action).

Gawer e Cusumano (2014), tratando especificamente de empresas líderes de plataforma, sugerem que a geração de ideias neste caso envolve a criação de fundações reutilizáveis para desenvolvimento de produtos que requerem planejamento e gestão específicos. Regras de design que aparentam operar em plataformas são estabilidade da arquitetura do sistema e o reuso planejado ou sistemático de componentes modulares.

Morgan et al (2013) propõem que a participação de uma empresa em redes de valor de alta densidade de complementares habilita a criação de valor com sistemas de código aberto, permitindo que empresas melhorem suas ofertas ao cliente por meio de desenvolvimento colaborativo de novos produtos, facilitado pela troca de conhecimento. Também propõem que a participação da empresa em redes de valor de baixa densidade de complementares habilita a 
criação de valor com sistemas de código aberto permitindo que as empresas desenvolvam tecnologias que aumentam o valor de ofertas existentes, por meio do acesso a conhecimento novo e diverso.

Assim como observado na identificação de oportunidades, as práticas para geração de ideias na IS são baseadas em mecanismos de coordenação e colaboração entre parceiros. $\mathrm{O}$ grau de abertura das empresas parece ser uma variável moderadora do sucesso da geração de ideias neste contexto.

\subsubsection{Seleção de ideias}

Poucos trechos foram identificados relacionados à atividade de seleção de ideias. Nenhum dos estudos citou um processo formalizado, com critérios pré-definidos para seleção de um conjunto de ideias geradas. Os artigos, em especial os que apresentam estudos de caso, descrevem estágios evolutivos em que as ideias vão se transformando e se reconfigurando ao longo do tempo. Mlecnik (2013), por exemplo, descreve como uma ideia de inovação autônoma evoluiu para uma inovação modular, arquietural e por fim sistêmica. Chesbrough et al (2014) apresenta a evolução do ecossistema criado pelo restaurante Chez Panisse: no estágio de nascimento, os stakeholders eram fornecedores, família, amigos e eventualmente spin offs de colaboradores. No estágio de expansão local, os stakeholders expandiram também para artistas culinários, jornalistas de comida, vendedores de vinhos, clientes e spin offs de colaboradores com maior frequência. No estágio de expansão global, foram acrescentados educadores, escolas de culinária e parceiros corporativos.

Esta noção de evolução da inovação em estágios relativamente longos é condizente com o modelo conceitual de Adner (2012) apresentado no Quadro 7. Seguindo este modelo, deve-se selecionar no FFE do primeiro estágio da IS um mínimo footprint viável, ou seja, a configuração mínima de atores suficientes para geração de valor comercial ao cliente final. Depois de um ciclo de desenvolvimento deste footprint mínimo podem ser agregados novos atores de forma incremental. Esta observação é condizente com a ideia de que a IS tem caráter evolutivo, com vários ciclos de FFE e NPD ao longo do seu desenvolvimento.

Gawer e Cusumano (2014) sugere que gestores devem sair do pensamento de escolha de portifólio para um pensamento de escolha de plataforma, definido como entendimento das 
amarras comuns que ligam as ofertas das empresas, mercados, e processos em conjunto e exploram estas comunalidades para criar crescimento alavancado e variedade.

\subsubsection{Definição do conceito}

Uma hipótese levantada neste estudo é que no caso de IS o resultado final do FFE não é apenas um novo conceito de produto, mas sim um novo modelo de negócio (ADNER E KAPOOR, 2010; HELLSTRÖM, 2015), que determina a forma como o valor criado por uma rede complexa de atores será capturado e distribuído. Amit e Zott (2001) apresentam conclusão semelhante no caso de IS em mercados virtuais. Segundo estes autores, o modelo de negócios descreve o conteúdo, estrutura, e governança de transações desenhadas para criação de valor por meio de exploração de oportunidades de negócios. O conteúdo de transações se refere a produtos ou informações que são trocados e os recursos e capabilidades que habilitam esta troca. A estrutura se refere às partes que participam das trocas e a forma como estas partes estão interligadas (sua sequência, por exemplo). A governança se refere às formas com que o fluxo de informação, recursos, e produtos são controlados pelas partes relevantes. Refere-se também à constituição legal das organizações e incentivos para os participantes nas transações. O modelo de receita se refere a modelos específicos em que modelos de negócios habilitam a geração de receita. Morgan e Finnegan (2014) acrescentam a definição de modelo de negócios como descrição do valor que uma empresa oferece para um ou vários segmentos de clientes e a arquitetura da empresa e suas redes de parceiros para criar, vender e entregar este valor e capital de relacionamento, de forma a gerar fontes de receita sustentáveis e lucrativas.

Chesbrough et al (2014) também relacionam inovação no ecossistema com criação de novos modelos de negócios. Define o modelo de negócios como um dispositivo cognitivo para ilustrar como uma empresa cria e captura valor para entregar a seus clientes. Inclui a arquitetura de receita, custos e lucros associados com a entrega de valor da empresa. Segundo os autores, a adaptação e transformação de um modelo de negócios não é uma tarefa fácil. É crucial ter uma proposta de valor única durante o nascimento da empresa, mas é mais importante manter um modelo sustentável ao longo do tempo que se adapte a ambientes de negócios de rápida mudança. 
Segundo Hellström (2015), empresas que lutam por IS radicais devem mudar o foco do esforço de inovação de produtos e processos que eles controlam para sistemas maiores dos quais fazem parte. O próximo passo é ativamente construir o modelo de negócios apropriado e engajar os stakeholders relevantes neste desenvolvimento. Os autores sustentam esta hipótese com o caso de IS por empresas do setor de biogás.

Além de modelos de negócios, autores destacam a importância da conceituação da arquitetura da inovação. Segundo Ethiraj e Posen (2013), a arquitetura do produto é particularmente relevante para a pesquisa e desenvolvimento, porque decisões arquiteturais são feitas nas fases iniciais do processo de inovação, quando P\&D tem um papel protagonista. Estas decisões implicam na facilidade de mudança do produto, a divisão entre recursos de desenvolvimento internos e externos, a habilidade de atingir certos tipos de desempenho de produto, e a forma como o desenvolvimento é gerenciado e organizado. McDermott et al (2013) acrescentam que a definição do conceito de arquitetura da inovação inclui a partição funcional do produto ou serviço em módulos discretos escaláveis, reusáveis, constituídos por elementos funcionais autocontidos e isolados, bem como a definição de interfaces entre subsistemas e transparência da tecnologia por meio de padrões industriais.

Gawer e Cusumano (2014), por sua vez, abordam a conceituação de plataformas e suas interfaces, que devem ser suficientemente abertas para permitir que empresas de fora conectem complementos assim como inovem nestes complementos e criem mais retorno sobre o investimento. Ao mesmo tempo, os autores mencionam a importância de manter certas partes proprietárias como fonte de receita e lucro. Para convencer outras empresas a adotar a plataforma, ela deve desempenhar uma função que é essencial para o sistema tecnológico e resolver um problema de negócios para muitas empresas e usuários da indústria. Além disso, é preciso comprometimento do dono da plataforma em não espremer as margens de lucro de seus complementares. Efeitos de rede poderão ser reforçados por padrões técnicos que tornam a utilização de múltiplas plataformas ou a troca de plataformas difícil ou custosa.

Decisões chave do líder de plataforma são a arquitetura tecnológica, incluindo o grau de modularidade da plataforma, e a estratégia de propriedade intelectual. A arquitetura tecnológica, segundo os autores, deve ser modular e adicionar conectores ou interfaces de forma que outras empresas possam construir sobre. A propriedade intelectual sobre estes conectores deve ser compartilhada para reduzir custos dos complementadores para conectar- 
se à plataforma. Leten et al (2013) também dão destaque na definição do modelo de propriedade intelectual pelo orquestrador do ecossistema que garante a apropriação de valor de todos os parceiros do ecossistema e continui atraindo novos parceiros.

Ainda segundo Gawer e Cusumano (2014) empresas também podem inovar em modelos de negócios e encontrar formas de cobrar diferentes lados do mercado para gerar receita de sua plataforma ou de complementares, além de diferentes formas de transação e promoção. Líderes de plataforma devem se esforçar para estabelecer relacionamentos de negócios que são mutuamente benéficos para os participantes do ecossistema, e ser capaz de articular um conjunto de modelos de negócios que se retroalimentam. Além disso, líderes de plataforma devem conceber uma coalizão ao redor da plataforma, compartilhando a visão e incentivando complementares a cocriar em um ecossistema vibrante, não apenas articulando os modelos de negócios como evangelizando os méritos e potencialidades da arquitetura técnica, compartilhando riscos com complementadores, trabalhar continuamente na legitimidade da empresa no ecossistema e criar uma identidade coletiva para os membros da inovação.

Liu e Rong (2015) adicionam que desenvolvimento de produtos baseado em plataforma começa com uma empresa líder convidando atores chave dentro de um ecossistema de negócios a desenvolver e determinar funcionalidades centrais da plataforma em conjunto. Isso estabelece a fundação para que outras empresas do ecossistema trabalhem juntas, combinando e recombinando diferentes ideias relacionadas ao desenvolvimento de novos produtos.

West e Kuk (2016) também abordam este caso específico de IS em que há inovação de plataforma que possui dois atributos: interfaces bem definidas e um patrocinador da plataforma que fomenta as empresas participantes, provendo abertura seletiva da sua tecnologia. Comunidades de usuários externas tem se tornado cada vez mais importantes para as empresas, fornecendo produtos complementares e feedback dos produtos. Estas comunidades podem ser fomentadas pela empresa focal.

Sintetizando os pontos de diferenciação de FFE de IS em relação à definição do conceito, apresenta-se o Quadro 10. 
Quadro 10 - Síntese de Definição do conceito no FFE de IS.

\begin{tabular}{|l|l|l|}
\hline \multicolumn{1}{|c|}{ Prática no FFE } & \multicolumn{1}{|c|}{ Elemento da prática } & \multicolumn{1}{c|}{ Fontes } \\
\hline $\begin{array}{l}\text { Modelo } \\
\text { negócios }\end{array}$ & $\begin{array}{l}\text { Definição das transações (distribuição } \\
\text { de riscos e retornos) }\end{array}$ & $\begin{array}{l}\text { Amit e Zott (2001), Adner e Kapoor (2010), } \\
\text { Chesbrough et al (2014), Hellström (2015) }\end{array}$ \\
\cline { 2 - 3 } & $\begin{array}{l}\text { Concepção de plataforma/arquitetura } \\
\text { do sistema }\end{array}$ & $\begin{array}{l}\text { Ethiraj e Posen (2013), Leten et al (2013), Gawer } \\
\text { e Cusumano (2014), Liu e Rong (2015), West e } \\
\text { Kuk (2016) }\end{array}$ \\
\hline
\end{tabular}

\subsubsection{Quadro resumo de IS}

Elaborou-se um quadro resumo (Quadro 11) sumarizando a relação entre os elementos do modelo conceitual e os autores da amostra estudada. 


\section{Quadro 11 - Quadro resumo da análise de conteúdo da amostra de IS}

\begin{tabular}{|c|c|}
\hline $\begin{array}{lll}\begin{array}{l}\text { Elemento } \\
\text { conceitual }\end{array} & \text { do modelo } \\
\end{array}$ & Autores na amostra \\
\hline Fatores de influência & $\begin{array}{l}\text { Adner (2006); Adner e Kapoor (2010); Alexy et al (2012); Amit e Zott (2001); } \\
\text { Chesbrough et al (2014); Christensen e Rosenbloom (1995); Ethiraj e Posen } \\
\text { (2013); Gawer e Cusumano (2014); Heger e Rohrbeck (2012); Hellström (2015); } \\
\text { Kapoor (2013); Leten et al (2013); Lipparini e Sobrero (1994); Liu e Rong (2015); } \\
\text { Meuer (2013); Mishra et al (2013); Oh et al (2015); Pinho (2014); Ren et al } \\
\text { (2015); West e Kuk (2016). }\end{array}$ \\
\hline Motor & $\begin{array}{l}\text { Adner (2006); Adner e Kapoor (2010); Alexy et al (2012); Amit e Zott (2001); } \\
\text { Chesbrough et al (2014); Gawer e Cusumano (2014); Heger e Rohrbeck (2012); } \\
\text { Hellström (2015); Kapoor (2013); Leten et al (2013); Lipparini e Sobrero (1994); } \\
\text { Liu e Rong (2015); McDermott et al (2013); Meuer (2013); Mishra e Shah (2009); } \\
\text { Mlecnik (2013); Morgan e Finnegan (2014); Morgan et al (2013); Oh et al (2015); } \\
\text { Pinho (2014); Ren et al (2015); West e Kuk (2016). }\end{array}$ \\
\hline $\begin{array}{l}\text { Identificação } \\
\text { oportunidades }\end{array}$ & $\begin{array}{l}\text { Alexy et al (2012); Amit e Zott (2001); Chesbrough et al (2014); Heger e } \\
\text { Rohrbeck (2012); Leten et al (2013); Liu e Rong (2015); Mlecnik (2013); Morgan } \\
\text { e Finnegan (2014); Morgan et al (2013). }\end{array}$ \\
\hline Análise de oportunidades & $\begin{array}{l}\text { Adner (2006); Alexy et al (2012); Chesbrough et al (2014); Heger e Rohrbeck } \\
\text { (2012); Liu e Rong (2015); Mishra e Shah (2009); Mishra et al (2015); Mlecnik } \\
\text { (2013). }\end{array}$ \\
\hline $\begin{array}{l}\text { Geração } \\
\text { enriquecimento de ideias }\end{array}$ & $\begin{array}{l}\text { Chesbrough et al (2014); Gawer e Cusumano (2014); Hellström (2015); Lipparini } \\
\text { e Sobrero (1994); Liu e Rong (2015); Mlecnik (2013). }\end{array}$ \\
\hline Seleção de ideias & Chesbrough et al (2014); Gawer e Cusumano (2014) \\
\hline Definição do conceito & $\begin{array}{l}\text { Amit e Zott (2001); Chesbrough et al (2014); Ethiraj e Posen (2013); Gawer e } \\
\text { Cusumano (2014); Hellström (2015); Leten et al (2013); McDermott et al (2013); } \\
\text { Morgan e Finnegan (2014); Morgan et al (2013); Oh et al (2015), West e Kuk } \\
(2016) \text {. }\end{array}$ \\
\hline
\end{tabular}

Fonte: Elaborado pela autora.

\subsection{Síntese da Revisão de Literatura de FFE e IS}

A partir dos resultados obtidos da análise de conteúdo, percebe-se que o entendimento de fatores de influência é um ponto fundamental para a gestão do FFE, pois o posicionamento (atual ou desejado) da organização dentro do ecossistema condiciona as possibilidades das demais atividades de FFE. Por exemplo, uma empresa central é capaz de estimular a cooperação das demais organizações complementares por meio de diversos mecanismos de coordenação e colaboração, o que não é viável em empresas de nicho ou com pouco capital de investimento. Uma empresa de nicho pode não ter liberdade de seleção de ideias, devido a efeitos de lock-in tecnológico imposto pelos atores chaves do ecossistema, que por sua vez devem mensurar o impacto da ideia não apenas dentro como fora de suas fronteiras antes de selecioná-la. 
O entendimento de fatores de influência pode se dar por meio de técnicas de mapeamento de ecossistemas de negócios, baseadas em teoria de redes sociais e prospecção tecnológica. A aplicação de tais técnicas também é útil para identificar e avaliar oportunidades de inovação. Na definição de conceitos, verifica-se que ao invés de novos designs de produtos e serviços, em uma IS devem ser propostos novos modelos de negócios, selecionada uma rede de valor no qual se irá competir e o posicionamento estratégico da organização dentro desta rede, o que altera também os clientes do FFE na organização: ao invés de times de desenvolvimento de produtos, os próximos passos devem ser dados pela alta gestão, áreas de desenvolvimento de novos negócios, planejamento estratégico ou mesmo atividades de corporate venture capital.

No FFE de uma IS verifica-se que a experimentação tem o papel não apenas de reduzir incertezas sobre o desempenho futuro dos produtos (como indicado por autores de FFE), como também reduzir as incertezas relacionadas às reações dos atores do ecossistema frente ao novo modelo de negócios, o que beneficia todos os envolvidos. Portanto, pode-se enquadrar a experimentação como mecanismo de coordenação (ou seja, um elemento que a liderança da empresa pode utilizar para acionar o "motor" da inovação no ecossistema). A cocriação e inovação aberta também podem ser mecanismos valiosos, uma vez que se deve entender como capturar valor não apenas para si, mas para outras entidades do ecossistema que contribuem para sua criação. Observa-se que a literatura de FFE pode ser complementar principalmente em relação métodos de estímulo à criatividade e geração de ideias, pouco tratada na literatura de IS.

À luz destas análises, propõe-se o modelo conceitual de gestão FFE de uma IS representado na Figura 5, em que o modelo de FFE de Koen et al (2001) é complementado por elementos específicos ou diferenciadores de IS identificados na literatura selecionada. 


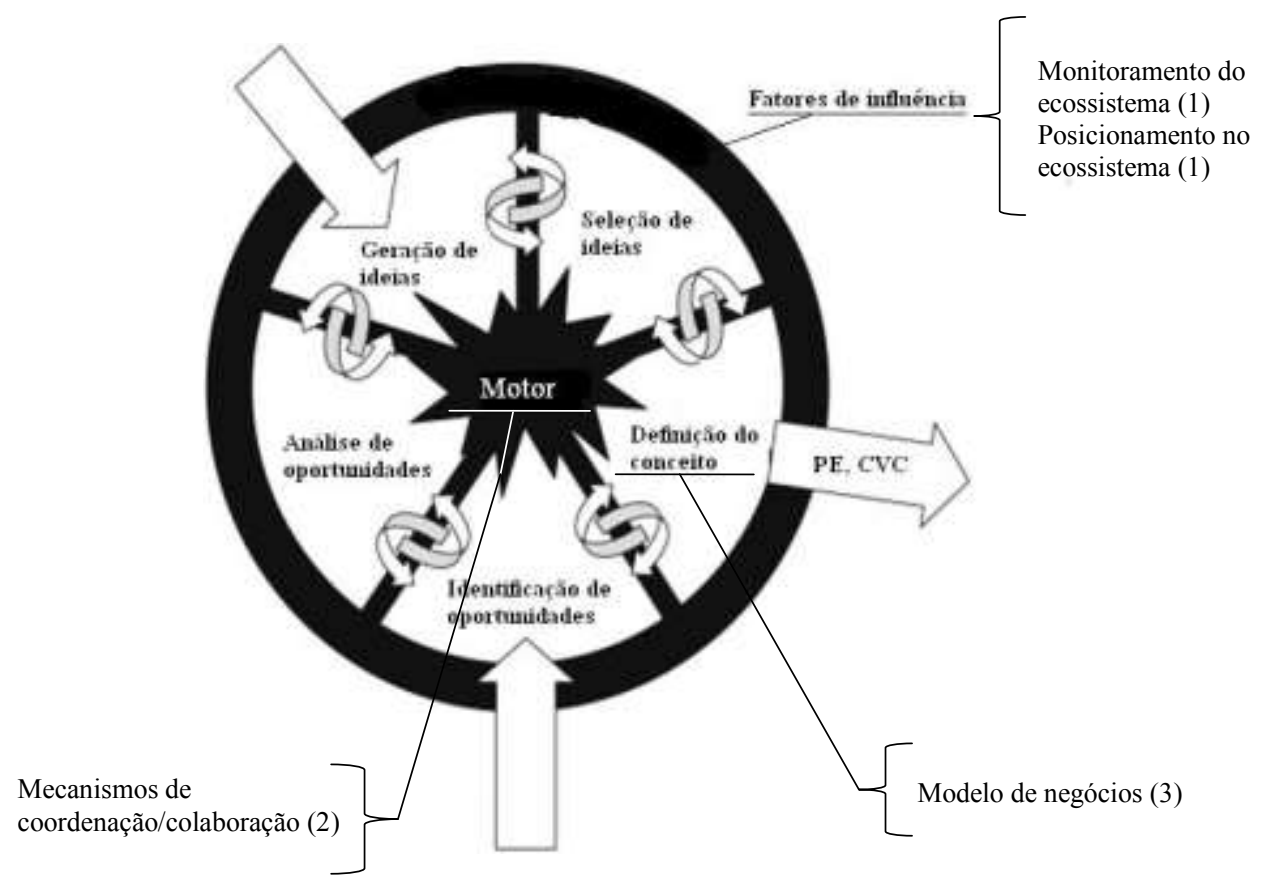

Figura 5 - Complementação do modelo de Koen et al (2001) para FFE de IS.

Nota:

(1) Ver Quadro 8

(2) Ver Quadro 9

(3) Ver Quadro 10

\subsection{Quadro conceitual de FFE de IS}

Com base na revisão sistemática de literatura, conforme objetivo OE 1.1 dessa dissertação, propõe-se um quadro conceitual de FFE para IS representado na Figura 6.

Foram encontradas evidências na literatura de que as práticas gerenciais para FFE de inovações autônomas também são necessárias para IS, porém insuficientes. Mecanismos de coordenação e colaboração, mapeamento e análise de ecossistemas assim como desenvolvimento de novos modelos de negócios foram identificadas como práticas fundamentais para gerenciamento do FFE de IS.

Adicionalmente, como notado anteriormente (MCCARTHY ET AL, 2006), os processos de inovação podem variar de linear a caóticos dependendo do grau de imprevisibilidade. Kim e Wilemon (2002) e Zien e Buckler (1997) enfatizam que o FFE é diferente do desenvolvimento formal de produtos devido ao baixo grau de formalização e alto grau de experimentalismo com característica de incerteza e Adner (2006) nota que IS é ainda mais 
arriscada e incerta que inovações autônomas. Estas características fazem com que este estágio se aproxime de um modelo não linear recursivo, que foi mantido no modelo proposto.

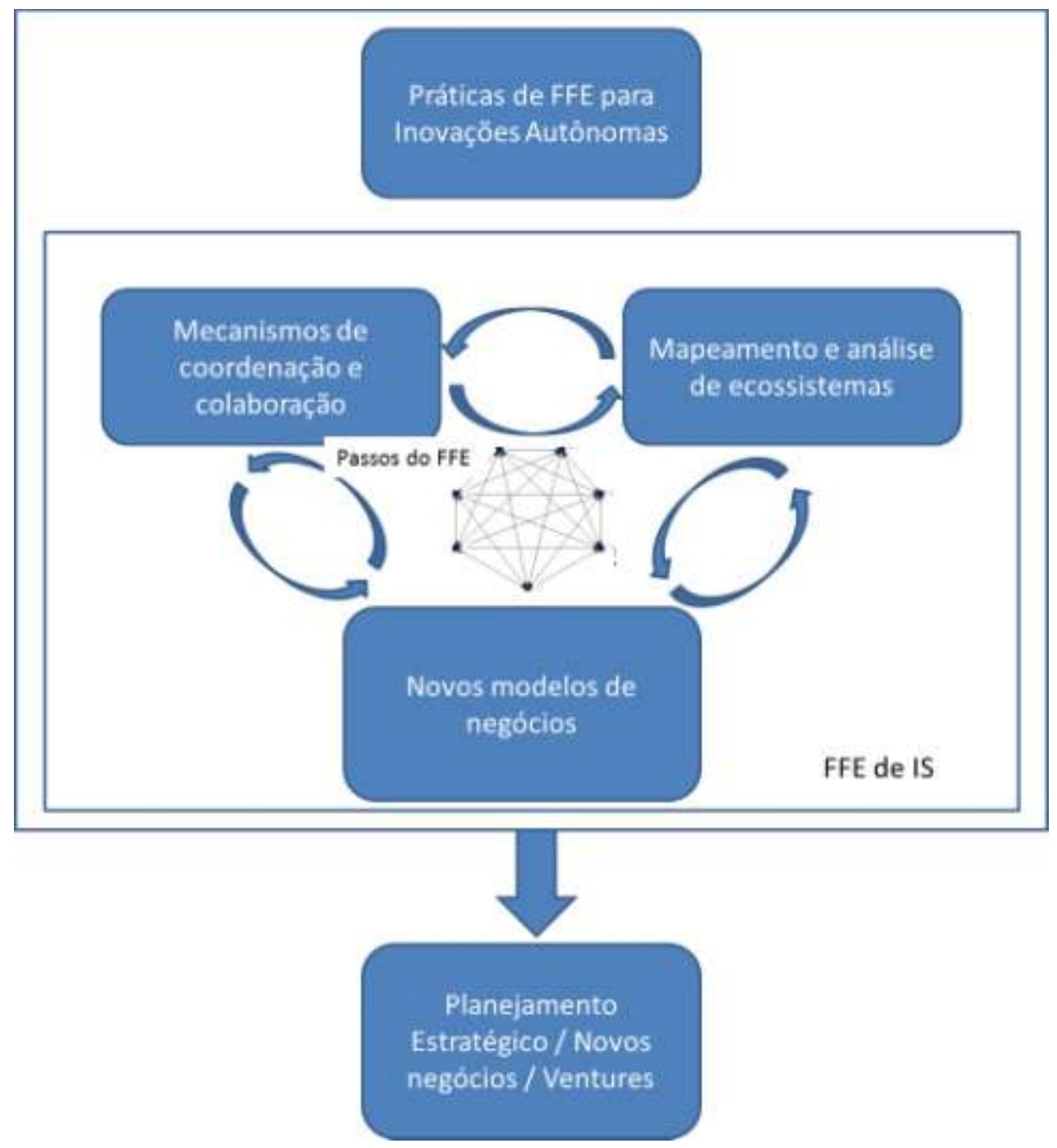

Figura 6 - Modelo conceitual para FFE de IS.

Para exemplificar a não linearidade do modelo conceitual suponha que durante a análise de ecossistema o time visualiza uma nova oportunidade com um ator de uma indústria completamente diferente. Isso pode requerer novos mecanismos de coordenação e colaboração para abarcar este ator, e a inovação resultante deve incluir uma forma deste novo ator gerar e capturar valor. Ao mesmo tempo um mecanismo de coordenação pode se provar ineficiente com outros atores chave, o que pode ativar o mapeamento e análise do ecossistema para encontrar outros atores potenciais ou outros posicionamentos que a empresa deveria explorar. 
Devido à relevância observada no modelo conceitual da do gerenciamento de relacionamentos com atores externos à empresa focal, foram consultadas referências que tratam de gestão stakeholders em gestão de projetos. No entanto, na literatura de gestão de stakeholders as práticas estão mais relacionadas à minimização de riscos (MARTHUR, 2008), ressaltando-se a importância da responsabilidade social, ambiental ou moral da empresa executora em atender a requisitos de stakeholders (DONALDSON E PRESTON, 1995; JAMALI, 2008; ACHTERKAMP, 2008; DARNALL ET AL, 2010; PARK-POAPS E REES, 2010; MINOJA, 2012; MATOS E SILVESTRE, 2013), os quais nem sempre são considerados na tomada de decisão dos gestores por não estarem associados aos objetivos de curto prazo do projeto ou da empresa (DEUTSCH E VALENTE, 2013), mas que geram resultados positivos ou no longo prazo (KATSOULAKOS E KATSOULACOS, 2007) ou considerando-se uma definição mais ampla de sucesso (ROWLINSON E CHEUNG, 2008; MINOJA ET AL, 2010; AALTONEN E VOS, 2011).

Aaltonen e Vos (2011) consolida modelos de gestão de stakeholders em projetos da literatura, e os agrupa por etapa do processo de gestão de stakeholders. As etapas são: (i) coleta de dados, (ii) interpretação dos dados e (iii) formulação de estratégia e tomada de decisão. O Quadro 12 apresenta os modelos revisados por Aaltonen e Vos (2011) atualizado com modelos da amostra da literatura publicada entre 2011 e 2013. 


\section{Quadro 12 - Processo de interpretação e fases de análise de stakeholders do projeto}

\section{correspondentes.}

\begin{tabular}{|c|c|}
\hline $\begin{array}{l}\text { Fase da análise de } \\
\text { stakeholders }\end{array}$ & Exemplos de métodos relacionados a diferentes fases da análise de stakeholders \\
\hline $\begin{array}{l}\text { Coleta de dados - } \\
\text { Coleta de dados } \\
\text { acerca de } \\
\text { stakeholders do } \\
\text { projeto e suas } \\
\text { características. }\end{array}$ & $\begin{array}{ll}\text { - } & \text { Entrevistas presenciais (Varvasovsky e Brugha, 2000) } \\
\text { - } & \text { Técnica de entrevista bola de neve (Cova et al, 1996) } \\
\text { - } & \text { Brainstorming (Calvert, 1995; Vos e Achterkamp, 2006) } \\
\text { - } & \text { Questionários estruturados e semi-estruturados (Cova et al, 1996; Karlsen, 2002) } \\
\text { - } & \text { Diálogo inicial (IFC, 2007) } \\
\text { - } & \text { Relatórios especiais (IFC, 2007) } \\
\text { - } & \text { Relatórios de lições aprendidas (El-Gohary et al, 2006) } \\
\text { - } & \text { (El-Gorkshops, surveys pessoais, grupos de foco, reuniões públicas, audiências públicas } \\
\text { - } & \text { Contabilidade } \\
\text { - } & \text { Construção de cenários (Mont et al, 2013; Warth et al, 2013) } \\
\end{array}$ \\
\hline $\begin{array}{l}\text { Interpretação de } \\
\text { dados - } \\
\text { Identificação e } \\
\text { classificação de } \\
\text { stakeholders }\end{array}$ & 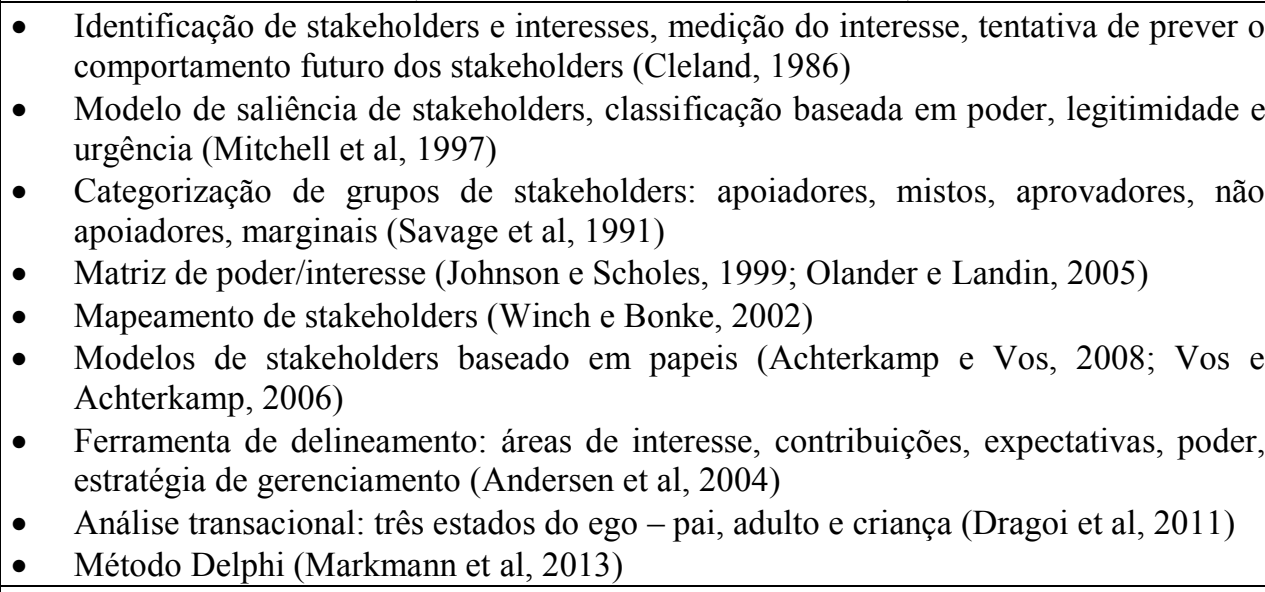 \\
\hline $\begin{array}{l}\text { Tomada de decisão } \\
\text { - Formulação de } \\
\text { estratégia de gestão } \\
\text { de stakeholders } \\
\text { baseada nos } \\
\text { resultados da } \\
\text { identificação e } \\
\text { classificação de } \\
\text { stakeholders. }\end{array}$ & $\begin{array}{l}\text { - Círculo de Stakeholders - ferramenta de medida e visualização da influência de } \\
\text { - } \quad \text { Índice de impacto de stakeholders (Olander, 2007) } \\
\text { - } \quad \text { Aplicação de framework de gestão de incertezas SHAMPU (Ward e Chapman, } \\
\text { - } 2008 \text { ). } \\
\text { - } \quad \text { Pstratégias de comunicação e disseminação de informação (PMI, 2008) } \\
\text { - Empo de engajamento de stakeholders (Bourne e Walker, 2006; IFC, 2007) } \\
\text { - } \quad \text { Processo de envolvimento de stakeholders (El-Golhary et al, 2006) } \\
\text { - Manter satisfeito, gerenciar de perto, monitorar, manter informado (Johnson e } \\
\text { - } \quad \text { Escholes, 1999; Olander e Landin, 2005) } \\
\text { - } \text { Inserção do stakeholder no modelo de negócio (Matos e Silvestre, 2013) } \\
\text { - Ambidestria (Minoja, 2012) } \\
\text { - Co-valuation - valoração feita por stakeholders (Van Schie, 2013) }\end{array}$ \\
\hline
\end{tabular}

Fonte: Adaptado de Aaltonen e Vos (2011). 
Além do processo sugerido por Aaltonen e Vos (2011), dois autores sugerem processos de gestão de stakeholders: (i) Darnall et al (2010) - percepção dos gestores sobre os stakeholders, interpretação da influência dos stakeholders, avaliação da saliência dos stakeholders e estabelecimento de como a estratégia será influenciada e (ii) Walker et al (2008) -método do círculo de stakeholders dividido nas etapas identificar, priorizar, visualizar, engajar e monitorar.

Na literatura de gestão de stakeholders, formas de classificação de stakeholders são as práticas mais referenciadas pelos artigos, sendo a mais citada o modelo de saliência de Mitchell et al (1997). O único modelo desenvolvido exclusivamente para o contexto de gestão de projetos na amostra é o de Achterkamp e Vos (2008), que apresenta a classificação de stakeholders por tipo de papel dentro do projeto (e.g. cliente, owner, conselho, usuário).

Na literatura de gestão de stakeholders outro destaque são as práticas de engajamento e comunicação para estabelecimento de diálogo e participação das partes interessadas nas definições dos projetos (Van de Kerkhof e Wieczorek, 2005; Marthur et al, 2008; Rowlinson e Cheung, 2008; Plaza-Ubeda et al, 2010). No entanto na literatura de inovação sistêmica estes temas praticamente não foram abordados.

Práticas relacionadas à estratégia corporativa que interferem na gestão de stakeholders nos projetos são frequentemente citadas tanto na literatura de stakeholders como de inovação sistêmica. Estas práticas referem-se principalmente a um olhar mais amplo sobre a definição dos modelos de negócios da empresa, de forma a incluir adequadamente todas as partes interessadas, inclusive o meio ambiente, na geração e distribuição de valor (HINTERHUBER, 2002; ADAM E SHAVIT, 2009; MINOJA, 2012; MATOS E SILVESTRE, 2013). Em específico, o grau de integração vertical do negócio pode influenciar no sucesso do projeto de desenvolvimento da inovação, que tende a ser mais vantajosa em fases mais avançadas do ciclo de vida da tecnologia, e menos vantajosa no front end (ADNER E KAPOOR, 2010).

As práticas relacionadas a alinhamento de objetivos ao mesmo tempo em que podem reduzir potenciais conflitos no projeto (CHANDRA E LOOSEMORE, 2010), também podem diminuir a propensão da empresa a inovar, já que um nível de coesão muito alto está relacionado a maior resistência à mudança (MINOJA ET AL, 2010). Minoja (2012) argumenta que "de um ponto de vista estratégico, um critério fundamental de discernimento entre requisitos contraditórios de stakeholders é a aderência e consistência com a clara 
segmentação e decisões de posicionamento". Logo, é necessária a compreensão de que o alinhamento aos objetivos de todos os stakeholders simultaneamente não é viável, e a seleção das questões de partes interessadas a serem atendidas deriva da estratégia corporativa.

O que se propõe no mapeamento de ecossistemas, no entanto, vai além da análise de stakeholders. As diferenças entre a análise de stakeholders e mapeamento ecossistema são de que no mapeamento dos ecossistemas os papéis de cada ator são claras (por exemplo, proposição central de valor, ofertas complementares, fornecimento e suporte), a direção ea natureza das transações são explícitas (se é fluxo de informações, produtos e serviços, dinheiro e créditos, e da qual parte a qual parte). Uma representação ilustrativa do mapeamento do ecossistema é apresentada na Figura 7.

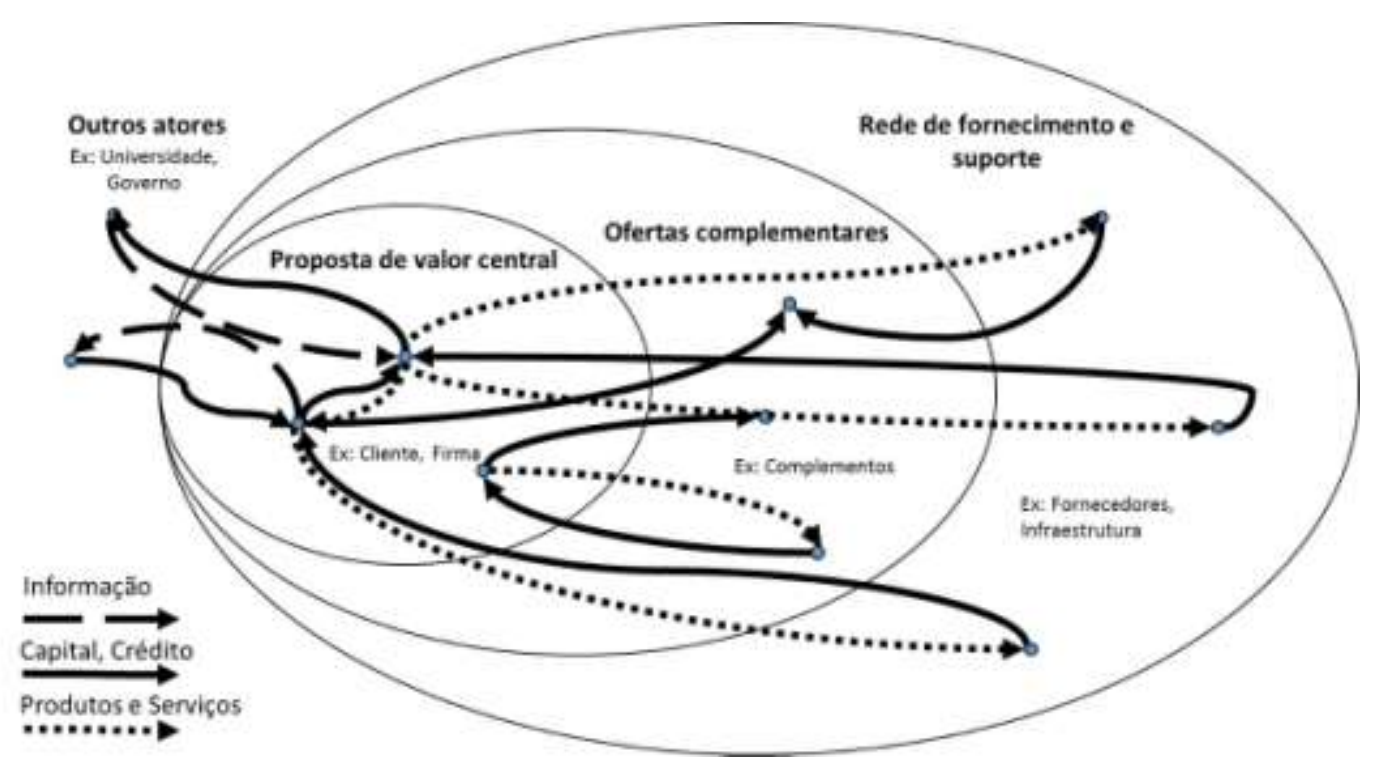

Figura 7 - Representação ilustrativa do mapeamento do ecossistema. 


\section{Resultados da pesquisa: Estudo de caso piloto}

Neste capítulo, apresenta-se o resultado do estudo de caso exploratório piloto realizado em um projeto de desenvolvimento de uma plataforma inovadora na área da saúde.

\subsection{Caracterização do FFE do projeto de IS do estudo de caso piloto}

O caso selecionado é um projeto realizado entre abril de 2009 e agosto de 2012 na cidade de São Paulo, Brasil, cuja organização realizadora é a Troyt Partners, empresa que tem como missão a incubação, desenvolvimento e saída estratégica de novos negócios de tecnologia com potencial para endereçar grandes problemas da sociedade no presente e futuro. O time do projeto foi formado por quatro profissionais seniores com experiência em gestão executiva de grande empresa multinacional na área de tecnologia da informação.

Apesar de ser o desenvolvimento de uma empresa, a Vitalbox foi gerenciada desde o seu início como um projeto pela Troyt. A Vitalbox é uma plataforma online de saúde pessoal e personalizada, onde qualquer pessoa pode fazer uma análise online de riscos e obter um mapa da sua própria saúde, bem como receber desafios diários aprovados por um conselho médico para estimular hábitos saudáveis, baseados em tecnologia no estado da arte de prontuários únicos do paciente no mundo, a plataforma Indivo, desenvolvida em projeto de colaboração entre o MIT, Harvard e Boston Children's Hospital. O conceito do projeto surgiu da constatação de que a saúde é um problema mundial em expansão devido ao envelhecimento da população e prevalência de doenças crônicas, somada à constatação de que investimentos na cura de doenças e não na prevenção serão insuficientes para evitar o colapso no sistema de saúde. O objetivo do projeto é incluir milhões de vidas na plataforma e ser referência em inovação na área de saúde.

As fases do projeto foram:

- Incubação e Fuzzy Front End (abril a dezembro de 2009): fase de constituição da iniciativa, identificação da oportunidade e conceituação do novo negócio. 
- Modelagem do negócio (dezembro de 2009 a outubro de 2010): também chamado pelos sócios de fase de "blueprint", que inclui o modelo de negócios, planejamento estratégico, operacional, comercial e financeiro.

- Realização (outubro de 2010 a março de 2012): desenvolvimento e testes do protótipo do produto e primeiros testes a mercado.

- Pré-operação (março a agosto de 2012): operação assistida do negócio. Ao final deste período considera-se que o projeto de desenvolvimento do novo negócio foi concluído.

Durante o FFE, a identificação da oportunidade deu-se pela construção de cenários, inspirada na metodologia da empresa Shell, por meio da combinação de megatendências indicadas pelas principais consultorias estratégicas do mundo. Adicionalmente haviam sido identificadas oportunidades na área de energias limpas e em negócios sociais para a base da pirâmide. No entanto durante a análise das oportunidades identificou-se que os custos de entrada no mercado de energias limpas eram incompatíveis com o porte da Troyt Partners e que os negócios sociais não gerariam o retorno financeiro determinado pelos sócios.

Foram estabelecidos os seguintes critérios de sucesso do projeto:

- Retorno financeiro: desenvolver um novo negócio que capaz de oferecer um retorno de cinco vezes o valor investido pelos sócios no momento da saída do negócio.

- Critérios de investimento: investimento próprio de no máximo dois milhões de reais.

- Critérios pessoais: cada sócio formalizou critérios de sucesso particulares para o novo negócio. Exemplos: ser reconhecida como empresa bem sucedida em inovação na saúde; se tornar um case de sucesso de Harvard; atender à população de baixa renda. Procedeu-se em seguida a uma análise se o conjunto de critérios combinados era factível de ser obtido.

Atualmente, o posicionamento estratégico da empresa no ecossistema é de nicho, apresentando inovação tecnológica no estado da arte no mundo. Caso o negócio ganhe escala (atualmente há apenas 40 mil usuários), ele poderá dar início a um novo ecossistema de negócios baseado em promoção de saúde em que a Vitalbox e poderá ter um posicionamento 
estratégico de keystone (Iansiti e Levien, 2004) deste ecossistema, ou seja, fornecerá uma plataforma para que outros stakeholders possam gerar valor, por exemplo, parceiros médicos que atuem na área de prevenção e saúde familiar ou serviços para educação da atividade física e educação de regime alimentar. Outro exemplo são empresas que complementem a cadeia de valor de saúde agregando uma oferta de "primeira consulta". Poderá ser uma garantidora da qualidade, sendo uma referência para avaliação da efetividade das ações de promoção de saúde, o que também gera vantagem competitiva na arquitetura do ecossistema de negócios (Jacobides et al, 2006).

A gestão de stakeholders externos foi considerada altamente relevante ao projeto desde o seu início, como pode ser observado nos seguintes trechos da entrevista com o sócio fundador da empresa:

“Já no estudo de viabilidade do projeto Vitalbox, fizemos a identificação de todos os stakeholders envolvidos da saúde, analisamos as tecnologias aplicadas, potenciais usuários etc."

"Tínhamos duas grandes preocupações: uma as barreiras institucionais, fossem legais, do ponto de vista do governo, fiscais, tributárias. (...). A segunda preocupação era a reação da comunidade de saúde, principalmente por não sermos da saúde."

Esta preocupação foi reforçada após a participação da equipe no programa Forces of Change da Universidade de Medicina de Harvard em 2009, momento em que estudaram o caso de uma empresa inovadora americana que fornecia consultas em mini clínicas em lugares estratégicos para tratar de pequenos problemas de saúde, como um resfriado, por exemplo, que passou a dar muito certo e a ameaçar a lucratividade de hospitais locais. Estes hospitais iniciaram um processo de desacreditação dos profissionais da saúde que trabalhavam na empresa, causando o encerramento de suas operações. Neste mesmo programa, a equipe da Vitalbox foi capacitada em formas de combater forças opostas de stakeholders, segundo mostra este trecho da entrevista:

"No Forces of Change, um dos aspectos principais é exatamente como identificar os stakeholders, as suas forças e que metodologia usar para contrapor-se a essas forças. Aprendemos uma metodologia de seis passos de uma professora do curso." 
Uma das ações diretas derivadas deste exercício de análise de stakeholders foi a constituição de um conselho médico da empresa, formado por figurões da saúde no Brasil, para endosso ao produto da Vitalbox e neutralização de forças opostas. Mais de 20 médicos foram consultados para testar as hipóteses do negócio e posteriormente dois foram contratados para compor a equipe da empresa. Porém esta contratação foi feita após a concepção do negócio, como explica o seguinte trecho, fazendo referência ao período de modelagem do negócio:

"A gente fez um deep dive, achamos que não era o momento de trazer um médico para dentro, até por conta da característica fundamental do que a gente fez: como não conhecíamos nada, entendiamos que não era simplesmente pegar o que existia e formar um novo produto ou serviço, pois isso tinha que estar revestido de um novo modelo de negócios para realmente ser uma ruptura."

Preocupou-se também em garantir que todas as agências regulatórias do setor emitissem pareceres de autorização às operações da empresa, mesmo que não exigidas por lei. Por fim, foram realizados diversos experimentos inclusive com equipes da Cruz Vermelha em comunidades carentes, que foram extremamente úteis para o desenvolvimento do produto em concordância com as demandas dos stakeholders. Por exemplo, descobriu-se que a usabilidade do protótipo desenvolvido estava totalmente inadequada para usuários de baixa renda e escolaridade, fazendo com que todo o produto fosse reformulado.

Além da relevância da gestão de stakeholders para mitigação de riscos, ela foi essencial para a concepção do modelo de negócios, considerado como o ponto mais crítico do projeto. Isto porque um dos critérios de sucesso do projeto era viabilizar a plataforma para todas as classes sociais da sociedade brasileira. Para as classes mais altas, o produto pode ser vendido a empresas com interesse em reduzir os custos de benefícios de plano de saúde e promover a qualidade de vida de seus funcionários. Já as classes mais baixas não possuem condições de pagar por este serviço de prevenção de saúde e seus empregadores não fornecem este tipo de benefício. Então, quem pagaria a conta?

Utilizou-se o mapa do ecossistema de negócios para identificar potenciais organizações que se beneficiariam caso as pessoas fossem mais saudáveis. A primeira tentativa foi o governo, já que no Brasil há o Sistema Único de Saúde que oferece serviços de saúde gratuitos para toda a população brasileira. No entanto, por ser uma medida de longo 
prazo e pouco visível, ao contrário da construção de hospitais ou compra de bens físicos, a gestão pública demonstrou pouca capacidade de ambidestria para financiamento do projeto. A segunda tentativa lógica eram operadoras de saúde privada, que hoje apresentam altíssimos níveis de sinistralidade. Porém descobriu-se que seus modelos de negócios estão arraigados na lógica atual do sistema de saúde, e o investimento em prevenção e promoção de saúde não faz parte de sua proposta de valor central, que também se baseia na ocorrência de doenças e uso de serviços de atendimento de saúde.

A solução foi divergir para fora do mapa de stakeholders da indústria de saúde. Neste momento surgiu o elemento de inovação sistêmica no projeto: o financiamento do Vitalbox para a população de baixa renda (bottom of the pyramid) por grandes empresas interessadas na associação de sua imagem à promoção de saúde. Esta oportunidade surge do conceito de mídia de significado, ou seja, mídia com significado: estudos apontados pelos sócios indicam que saúde é um dos maiores temas de preocupação da sociedade global e brasileira, e que a vinculação da marca em canais e serviços que endereçam estas grandes preocupações fornecem um retorno de investimento até oito vezes maior do que o anúncio em mídia tradicional, pela maior probabilidade de engajamento. A conquista desta camada da população cuja renda é discricionária, mas crescente, é de interesse estratégico de diversas indústrias, como a de alimentos, bebidas, artigos esportivos e serviços asociados à qualidade de vida, por exemplo.

Outro stakeholder que tem se mostrado promissor são os sindicatos. Todos os anos os trabalhadores devem pagar um dia de seus salários aos sindicatos e recebem nada em troca, a menos em caso de disputa trabalhista. Logo, fornecer a plataforma Vitalbox pode ser uma forma de retribuição mais visível e direta aos seus beneficiários.

O setor farmacêutico, desde a indústria até as farmácias também foi descoberto como potencial cliente do Vitalbox, por causa do interesse em associar a plataforma de engajamento a programas de fidelidade. Além disso, trata-se de um setor com grande necessidade de melhoria de imagem perante a opinião pública no Brasil. Por fim, o modelo de negócios ainda permite que qualquer usuário use gratuitamente a plataforma, com opção de fazer uma doação online à plataforma, em modelo de crowdfunding. A interação da empresa com os beneficiários finais do seu produto se dá por redes sociais e espaço para perguntas no seu website. 
O próprio produto desenvolvido pela Vitalbox também foi fruto de articulação com stakeholders externos. A parte central da plataforma, composta pelo sistema de análise dos dados do usuário para detecção dos riscos de saúde é operada pela start-up Biosignia, sediada na Carolina do Norte, Estados Unidos, encontrada pelo time mediante pesquisa durante o desenvolvimento do negócio. Além disso, para a proposta de valor de mídia de significado, duas agências de marketing externas são parceiras da Vitalbox. Todo o sistema opera na nuvem, em servidores da Amazon e Google, e foi desenvolvido em plataforma de código aberto (da Atlassian). O financiamento do projeto também depende de uma rede de stakeholders externos, formada por investidores anjo (amigos de longa data) e investidores institucionais (fundos de investimento).

A Figura 8 apresenta o mapa com os principais stakeholders da Vitalbox, produzido de próprio punho pelo entrevistado e complementado a partir das informações dadas na entrevista.

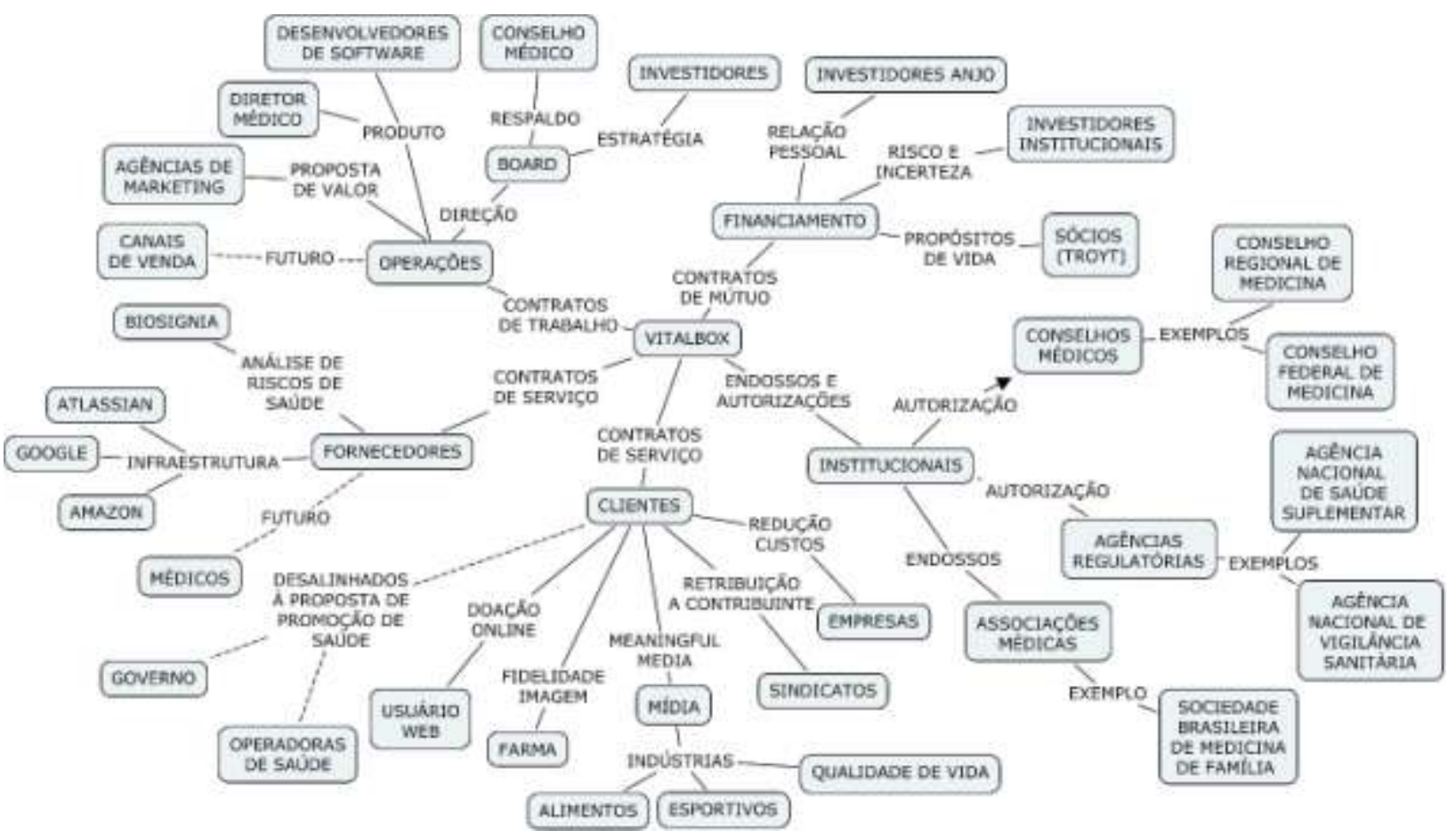

Figura 8 - Mapa de principais stakeholders da Vitalbox

A criação de barreiras de entrada se dará mais pela velocidade de lançamento de novas versões da plataforma do que pela propriedade intelectual, estratégia defendida por Jacobides et al (2006) para vantagens competitivas na arquitetura do ecossistema de negócios. Um ponto de melhoria detectado pelos sócios para é criar formas mais efetivas de garantir o 
engajamento dos usuários para uma mudança perene do comportamento de risco. Para isso, a empresa pretende conectar-se com outros stakeholders inusitados como psicólogos, sociólogos e profisssionais da indústria de games na próxima atualização do produto. Não foi citada intenção de interação direta e presencial com usuários nesta iniciativa, porém ao ser questionado em específico, o sócio entrevistado mantém esta opção em aberto como possibilidade de abordagem.

\subsection{Análise das práticas de gestão do FFE no caso piloto}

Para explorar as práticas de gestão do FFE no caso utilizou-se uma árvore de codificação baseada no modelo conceitual proposto no item 3.5 no Quadro 13 para codificar trechos da entrevista com o sócio fundador da Vitalbox. Foram codificados 64 trechos no total.

Quadro 13 - Árvore de códigos da análise de conteúdo do estudo de caso.

\begin{tabular}{|r|l|}
\hline \multicolumn{1}{|c|}{ Códigos } & \multicolumn{1}{c|}{ Descrição } \\
\hline Entr_FI & Entradas - Fatores de influência \\
\hline \multicolumn{1}{|c|}{ Entr_FI_ME } & Entradas - Fatores de influência - Monitoramento do ecossistema \\
\hline Entr_FI_PO & Entradas - Fatores de influência - Posicionamento no ecossistema \\
\hline Entr_MO & Entradas - Motor \\
\hline Entr_MO_MC & Entradas - Motor - Mecanismo de colaboração, coordenação e auto-regulação \\
\hline Ativ_IO & Atividade de identificação de oportunidades \\
\hline Ativ_AO & Atividade de análise de oportunidades \\
\hline Ativ_GI & Atividade de geração de ideias \\
\hline Ativ_SI & Atividade de seleção de ideias \\
\hline Ativ_DC & Atividade de definição do conceito \\
\hline \multicolumn{1}{|c|}{ Ativ_DC_MN } & Atividade de definição do conceito - Modelo de negócios \\
\hline Saída_PE_CVC & Saídas - para Planejamento Estratégico ou Corporate Venture Capital \\
\hline
\end{tabular}

Como análise inicial, comparou-se o percentual relativo de frequências de cada código tanto da análise de conteúdo da revisão de literatura de inovação sistêmica e FFE como no caso exploratório (Gráfico 1).

Observa-se uma grande similaridade entre as frequências relativas de citação das práticas de gestão do FFE da IS na revisão de literatura e no caso da Vitalbox.

Em ambos os casos, os diversos mecanismos de colaboração, coordenação e autoregulação são as práticas mais relevantes, enquanto a identificação da oportunidade, geração 
de ideias e seleção de ideias não são processos críticos (o que torna o FFE de IS diferenciada de inovações autônomas de produtos).

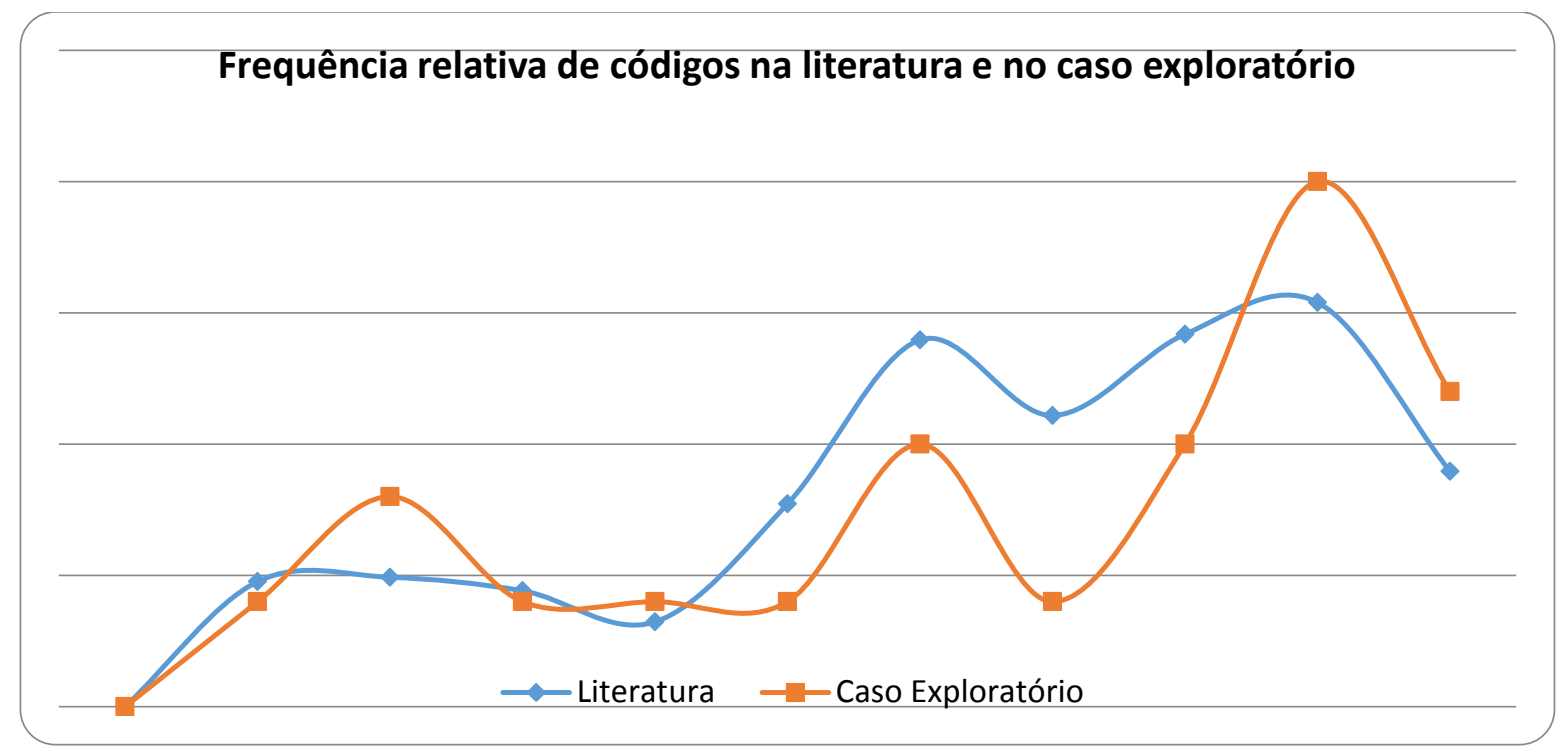

Gráfico 1 - Frequência relativa de códigos da literatura de inovação sistêmica e do caso piloto.

Em seguida cada elemento do modelo conceitual do FFE (conforme Quadro 5) será analisado para o caso piloto de IS.

\subsubsection{Fatores de influência}

O caso piloto confirmou as premissas levantadas na revisão sistemática da literatura de que no FFE de uma IS o mapeamento do ecossistema de negócios e a identificação do posicionamento da inovação dentro deste ecossistema são fundamentais. A importância do monitoramento do ecossistema foi ainda maior no caso do que o observado na literatura, possivelmente por uma contingência específica da área da saúde, pela diversidade complexa de stakeholders e pela criticidade da gestão dos mesmos para o sucesso do empreendimento. Este tópico será discutido em maior detalhe no próximo item da análise, relativo à gestão de stakeholders.

Uma das primeiras análises realizadas pela equipe da Troyt Partners foi o mapeamento formal da rede de stakeholders envolvidos na inovação, antes mesmo de ter uma ideia da solução ou do produto, utilizando-se inicialmente um quadro branco físico, documentado digitalmente a posteriori. Segundo o sócio fundador entrevistado, foram identificadas mais de 
200 categorias de stakeholders no ecossistema de saúde brasileiro, além das relações (e intensidade das relações) entre eles. A intensidade das relações era identificada pela largura dos arcos que ligavam os nós.

Foram analisados em detalhe os atores que possuíam maior número de conexões (grande raio de influência) ou que possuíam muito poder sobre os outros nas relações. Para estes atores foram identificados os seus objetivos no ecossistema e seus instrumentos para influenciar outros atores para garantir o alcance de seus objetivos (por exemplo: instrumentos regulatórios, formação de opinião pública etc). Esta metodologia utilizada se assemelha ao método de análise de atores intitulada MACTOR (GODET, 1991), que se baseia na teoria dos jogos para determinar o fiel da balança de poder entre os atores e estudar suas convergências e divergências quando confrontados a um conjunto de riscos e objetivos.

Em relação ao posicionamento estratégico da empresa no ecossistema, o caso confirma que este é um fator de influência no FFE do projeto de IS. No caso da Vitalbox, foi fundamental:

"Achamos que não era o momento de trazer um médico para dentro, até por conta da característica fundamental do que a gente fez: como a gente não conhecia nada, a gente entendia que não era simplesmente pegar o que existia e formar um novo produto ou serviço, a gente entendia que isso tinha que estar revestido de um novo modelo de negócios para realmente ser uma ruptura."

\subsubsection{Motor}

Analisando-se em maior profundidade os trechos relacionados a mecanismos de colaboração, coordenação e autorregulação, percebe-se que, como proposto no modelo conceitual, os mecanismos de autorregulação predominaram sobre os mecanismos de coordenação, como se pode perceber claramente no seguinte trecho da entrevista, a respeito da possibilidade de agregar o agendamento de consulta ao serviço de análise de riscos de saúde já fornecido pela plataforma atual:

"A não ser que tenha um plano de saúde, se você descobriu que tem um problema de saúde, risco alto de coração, mesmo que seja um duro da vida, vai arrumar um jeito de pagar a consulta, principalmente se for barata, tipo 20, 30 reais. Então vários investidores vieram procurar a gente para fornecer este serviço, a gente conversou com o conselho médico, e ele 
foi contra. Disseram 'não, se fizerem isso, acabaram de botar o pé do lado do tratamento. $O$ objetivo de vocês não é esse'. Meio a contragosto a gente acabou concordando, porque a gente entendeu que se fizesse isso o sucesso financeiro seria acelerado."

No entanto, observou-se a necessidade de disassociar os mecanismos de coordenação e mecanismos de colaboração. De fato, não se encontrou nenhuma citação na entrevista do caso desta empresa de nicho indicando coordenação dos atores, mas diversas citações indicando colaboração com outras empresas de nicho, como se observa neste trecho da entrevista:

"Com os fornecedores a atmosfera é mais de colaboração, principalmente com a Atlassian [desenvolvedora de software aberto]. Por exemplo, faz alguma coisa, volta para a Atlassian e eles colocam no produto deles, mesma coisa que a gente fez com a Indivo [prontuário único do paciente desenvolvido em parceria entre Harvard, MIT e Boston Children's Hospital], fizemos a tradução em português e a gente devolveu para eles, é uma das nossas filosofias usar open source [código aberto]. Uma vez que faz alguma coisa, ela se torna pública, e a reciprocidade por estar usando algo de uma forma gratuita, tem uma colaboração grande. Com a Biosígnia [fornecedora da avaliação de riscos de saúde do usuário] e ambiente interno é uma atmosfera de parceria até porque a gente tem resultados compartilhados. A gente tem com todos eles, inclusive com as agências de publicidade, bônus para distribuir pelo sucesso do negócio, acho que só de bonus dá um milhão, para as agencias dá 300 mil."

Logo, no modelo conceitual os mecanismos de coordenação de fato estão mais associados a empresas plataforma, no entanto os mecanismos de colaboração podem ser associados tanto a empresas plataforma como de nicho. Classificando-se os mecanismos de colaboração aplicados no estudo de caso piloto, obtiveram-se os resultados do Quadro 14.

\section{(Continua)}

\section{Quadro 14 - Mecanismos de colaboração aplicados no caso piloto.}

\begin{tabular}{|l|l|l|}
\hline \multicolumn{1}{|c|}{ Mecanismo } & Classificação & \multicolumn{1}{c|}{ Trecho da entrevista } \\
\hline $\begin{array}{l}\text { Compra de serviço } \\
\text { (com bônus por } \\
\text { desempenho) }\end{array}$ & Transacional & $\begin{array}{l}\text { "Por contrato, a gente tem amarração, se eles [Biosígnia] fecharem as } \\
\text { portas temos direito de uso do produto ad eternum, a gente se protegeu, } \\
\text { mas o que a gente vai fazer com um produto que nao conheço nada? É } \\
\text { só para o seguinte: conseguir segurar as pontas enquanto nao consegue } \\
\text { outra alternativa" }\end{array}$ \\
\hline Contratatação de & Transacional & "Temos o pessoal próprio de desenvolvimento, basicamente \\
\hline
\end{tabular}




\begin{tabular}{|l|l|l|}
\hline $\begin{array}{l}\text { pessoal e terceiros } \\
\text { (com bônus por } \\
\text { desempenho) }\end{array}$ & $\begin{array}{l}\text { desenvolvimento e médicos, a gente tinha dois, um voltado à saúde } \\
\text { pública e outro voltado para empresas. Não dava para ter dois } \\
\text { diretores médicos. A gente optou pelo primeiro até porque pensando no } \\
\text { mapa das forças ele tem uma força política maior, foi presidente da } \\
\text { Sociedade Brasileira de Medicina de Familia, é professor da USP, tem } \\
\text { área de influência maior" }\end{array}$ \\
\hline
\end{tabular}

\begin{tabular}{|c|c|c|}
\hline Mecanismo & Classificação & Trecho da entrevista \\
\hline $\begin{array}{lr}\text { Participação no } \\
\text { conselho de } \\
\text { administração (board) }\end{array}$ & Transacional & $\begin{array}{l}\text { "O conselho médico da Vitalbox fica dentro do board. Tem o board } \\
\text { advisory, onde está o conselho médico e o board de investidores, } \\
\text { que para efeito de governança ficam separados" }\end{array}$ \\
\hline $\begin{array}{l}\text { Treinamento } \\
\text { congressos }\end{array}$ & Relacional & $\begin{array}{l}\text { "Neste momento a gente fez uma série de leituras, foi para o } \\
\text { congresso de saúde o Health Summit de Paris, em agosto fomos } \\
\text { para Harvard para o programa Forces of Change, cujo objetivo era } \\
\text { analisar o impacto do Obamacare" }\end{array}$ \\
\hline $\begin{array}{lr}\text { Pesquisa } & \mathrm{e} \\
\text { desenvolvimento } & \\
\text { colaborativo } & \mathrm{e} \\
\text { Transferência } & \mathrm{de} \\
\text { documentos } & \end{array}$ & Relacional & $\begin{array}{l}\text { "Adotamos o projeto Indivo do MIT e da Harvard como base inicial } \\
\text { de dados, e quando comecamos a fazer testes de stress, jogando } \\
\text { milhões de dados, tivemos que corrigir uma série de erros, pois ele } \\
\text { foi projetado para ser usado dentro de um hospital, e estaríamos } \\
\text { falando de } 3 \text { mil registros, e estamos falando em milhóes de pessoas, } \\
\text { tivemos que refazer um monte de coisas, a fase de protótipo serviu } \\
\text { para isso" }\end{array}$ \\
\hline Networking & Relacional & $\begin{array}{l}\text { "No último evento que teve da Sociedade dos Médicos de Família } \\
\text { eles apresentaram a Vitalbox, recomendaram que o pessoal } \\
\text { explorasse, recomendassem para os clientes, para os pacientes. } \\
\text { Então é aquele negócio, se algum dia vier um ataque dos outros } \\
\text { agentes institucionais, ou de algum figurão, a gente fala, não, mas } \\
\text { este pessoal todo nos apoia" }\end{array}$ \\
\hline Discussões informais & Relacional & $\begin{array}{l}\text { "A gente deve ter entrevistado uns } 20 \text { médicos do círculo íntimo, } \\
\text { contatos que a gente tinha, e umas } 5 \text { ou } 6 \text { empresas para testar } \\
\text { algumas ideias" }\end{array}$ \\
\hline $\begin{array}{l}\text { Colaboração em redes } \\
\text { sociais }\end{array}$ & Relacional & $\begin{array}{l}\text { "Sobre a questão de coletar feedback, hoje é de uma forma } \\
\text { informal, ele [o usuário] pode entrar no Facebook e colocar } \\
\text { comentário e a agência de mídia fica responsável de escalar e falar } \\
\text { para a gente analisar" }\end{array}$ \\
\hline
\end{tabular}

\section{(Conclusão)}

Há uma predominância de mecanismos de colaboração relacionais durante o FFE, com o intuito principal de adquirir conhecimentos, e estabelecimento de mecanismos transacionais na etapa de desenvolvimento formal com os parceiros críticos como forma de mitigação de riscos do conceito de modelo de negócios definido no FFE.

\subsubsection{Identificação de oportunidades}

Foram utilizadas metodologias de estudo de futuro para identificação de oportunidades no caso piloto, coerente com as descobertas Koen et al (2002). Em específico, foram utilizados análise de tendências tecnológicas e do consumidor, inteligência competitiva, 
pesquisa de mercado e planejamento de cenários. Os trechos da entrevista que fundamentam esta observação são:

"A oportunidade foi identificada através de um estudo das megatrends [mega tendências] globais. Estas foram agrupadas em cenários em que algumas delas convergiam e definiam um espaço de oportunidade. Este espaço de oportunidade foi confrontado com o cenário Brasil (político, social, econômico e tecnológico) e com as capacidades dos empreendedores (ex., acesso a capital de investimento) para se definirem oportunidades a atacar."

"A construção se deu durante um longo período (15 meses) em que os sócios fizeram um estudo profundo da oportunidade, em todos os aspectos, através de pesquisa web, leituras, entrevistas, wokshops, cursos, etc., e usaram técnicas (mind mapping, brainstorming, cenários, matriz SWOT, etc.) para desenhar o conceito do negócio. Os envolvidos diretos foram os quatro sócios, cada um focado em uma ou algumas áreas especificas do problema/oportunidade. Consultas individuais foram conduzidas com especialistas (ex., médicos, diretores de marketing, etc.) para validar premissas chave."

Uma particularidade da identificação de oportunidades deste projeto de IS foi a escolha dos clientes e parceiros principais antes da concepção do produto/serviço. Segundo o entrevistado, "A Troyt queria se associar com o paciente, pois era o único realmente interessado em se manter saudável dentro desta indústria que lucra com a doença, e não com a saúde". Oferecer serviços de saúde diretamente para o consumidor final, no Brasil, significa mirar o segmento de mercado menos atraente para as empresas incumbentes, se comparado com outros segmentos como empresariais, hospitais e médicos. Esta determinação foi coerente com a teoria de inovação disruptiva de Christensen (1997). Além disso, propositadamente não foram trazidos alguns dos atores do ecossistema de negócios para as discussões de identificação de oportunidades, justamente por se querer a ruptura do status quo.

\subsubsection{Análise de oportunidades}

Observa-se que a análise de oportunidades é iterativa com o processo de identificação de oportunidades neste caso piloto, o que é coerente com a natureza não linear do modelo. Os principais insumos da análise para quantificação da oportunidade e teste das hipóteses foram 
relatórios setoriais, relatórios de consultorias e cursos realizados no exterior (como o Forces of Change, já citado anteriormente).

Uma dificuldade citada pelo entrevistado foi quantificar o tamanho da necessidade dos clientes na análise da oportunidade, pois os métodos tradicionais mostraram-se insuficientes, como se nota no trecho abaixo:

"Para estimar a adoção das empresas, ou clientes, podemos usar técnicas básicas, quantas empresas existem no Brasil, quais os potenciais usuários, se tiver 1\% do mercado e por aí vai. No meaningful media [mídia de significado] não dá. Começamos a ouvir muitas coisas no mercado, se tiver 1 milhão de usuários, vale uma fortuna, mas quanto é? A Rede Globo gastaria 40 milhões para atingir 1 milhão de pessoas, ficamos em dúvida em como precificar o meaningful media por conta disso, não tinha nenhuma base clara, a gente errou para cima, superestimamos o potencial de receita."

Não foi identificada nenhuma diferença nos métodos de análise da oportunidade para o caso específico de IS. A única diferença notada foi a maior complexidade da análise pois a necessidade de equacionar a distribuição de valor para várias partes interessadas simultaneamente reduz o espectro de oportunidades.

\subsubsection{Geração e enriquecimento de ideias}

Não foi aplicada nenhuma técnica de criatividade específica. A ideia do produto em si foi inicialmente desenvolvida apenas pelos quatro sócios da Troyt Partners. O enriquecimento da ideia, no entanto, contou com uma ampla rede de contatos dos sócios que foram entrevistados durante o processo de validação das ideias iniciais, como uma consequência de um processo social, em concordância com as pesquisas de Kijkuit e Van Der Ende (2007).

Outra característica do processo de geração de ideias condizente com a literatura de FFE foi a utilização de experimentação piloto para enriquecimento da ideia, em concordância com os princípios do design thinking (Brown, 2008), como se pode perceber neste trecho:

"No nosso primeiro teste em campo com o pessoal da Cruz Vermelha que faz estes mutirões, a gente foi fazer o registro da saúde no Jardim Pantanal que ficou alagado na Zona Leste por muito tempo, então a gente percebeu que tinha feito muita coisa errada principalmente na experiência do usuário que para nós era legal, mas para a maioria das pessoas leigas, ou com medo de informática, não se mostrou viável.' 
Porém, como constatou o próprio entrevistado, a concepção da solução em si foi a parte "fácil". A concepção da solução foi simples uma vez que se entendeu claramente as causas raízes do problema da saúde, como se pode observar no trecho abaixo:

“O desenho em si da solução foi muito mais natural, nós temos o problema da saúde, que é o orçamento que não vai pagar a conta nunca, identifiquei qual era o problema chave, são as pessoas ficando doentes com doenças crônicas que drenam todo o orçamento, então a gente conseguiu identificar rapidamente o foco, entendendo que atuar do lado da cura era enxugar gelo, a gente tinha que atuar do lado da prevenção, isso também foi fácil de resolver, montar a tecnologia, o produto em si tambem não foi muito difícil."

A parte mais crítica, segundo o entrevistado, foi a concepção do modelo de negócios. Esta constatação é condizente com o modelo conceitual de FFE apresentado na Figura 5. O procedimento adotado pela equipe do projeto foi identificar dentro do mapeamento de stakeholders quais deles se beneficiariam com a solução, que é voltada à manutenção da saúde dos consumidores finais:

"Mas quem vai pagar a conta? O cara [consumidor final] já mal paga o plano de saúde, pois não tem condições, quem tem condições não paga nada, aí você fala para o cara que ele ainda tem que pagar mais alguma coisa para cuidar da saúde, de jeito nenhum. Aí a gente pensou o seguinte, nao é o individuo que vai pagar. Então a gente começou um trabalho de investigar quem iria se beneficiar com esta solução."

Esta concepção era crítica porque a solução ideal para o consumidor final não era necessariamente a solução ideal segundo o interesse das fontes pagadoras existentes, ao menos não as mais óbvias, o que exigiria ou a aceitação de uma solução sub-ótima para o consumidor final ou o encontro de uma nova fonte pagadora fora do ecossistema de negócios em questão. Na atividade de seleção da ideia as alternativas foram avaliadas, como será explicado no próximo tópico.

\subsubsection{Seleção de ideias}

Foram utilizados métodos tradicionais e formais de avaliação de novos empreendimentos para a tomada de decisão pela continuidade do desenvolvimento da ideia inicial, como mostra o trecho abaixo da entrevista: 
“Os 4 sócios-fundadores da Troyt decidiram pela execução do projeto Vitalbox após os primeiros estudos de viabilidade. Estes envolveram a viabilidade técnica (conseguiríamos reunir as competências necessárias para desenvolver a solução), mercado (existia demanda para a oferta, quais transformações esta oferta implicaria no mercado e nos modelos vigentes, etc.) e financeira (o negócio seria sustentável, daria o retorno esperado, etc.).”

Neste processo de redução de incertezas, como explicitado no item anterior, a maior dificuldade foi descobrir e selecionar a fonte pagadora para o serviço que beneficiaria os consumidores finais, sem comprometer o desenho da solução e o propósito social do negócio, que era um dos critérios de sucesso estabelecidos para o projeto. Para isso, foram realizadas reuniões presenciais com cada "candidato" a fonte pagadora e selecionado o melhor candidato por exclusão, como mostra o trecho abaixo:

"Primeiro [candidato] é o indivíduo, ele se beneficia se ele não ficar doente, mas ele não tem dinheiro para pagar. Alguém se beneficia se ele não fica doente? Bom, o governo. Porque se o cara puder pagar menos com saúde, ele vai gastar mais infraestrutura e político adora estas coisas. Daí a gente foi conversar com prefeituras etc e descobrimos que eles estão pouco se lixando para isso. Foi a primeira vez que a gente tropeçou com o problema da corrupção no governo nesse projeto. Legal, gostei, as pessoas não vão ficar doentes, mas isso não dá voto, prefiro pegar o dinheiro e colocar em uma ambulância ou posto de atendimento. Então falamos bom, o governo não vai pagar esta conta também. Aí a gente pensou, quem vai se beneficiar se o cara não ficar doente, bom, a operadora de saúde, porque o cara diminui a sinistralidade e pronto. Daí a gente descobriu a dura realidade do seguinte: a operadora de saúde precisa que você fique doente, pois é o evento de você ficar doente que gera a necessidade de ter um plano, o que ela quer é que você fique doente de uma forma menos cara. Que não tenha que ir para uma emergência etc. ok, não vai ser a operadora que vai pagar isso. Foi dai que a gente foi buscar o modelo do meaninful media [mídia de significado]. Tanto para o lado das empresas, bom, dai entendemos que as empresas pagariam para que o cara não fique doente, elas já pagam hoje, e continuariam pagando por uma série de razões, daí a gente pensou legal, o primeiro é a empresa, esse facilmente compra. O segundo, ai vinha um pouco das questões do que a gente consideraria um sucesso, para nós não bastava apenas lançar um produto que fosse consumido pela classe A. isso é relativamente fácil. Bom, este produto para a gente considerar um sucesso ele tem que servir 
para a população como um todo. Como eu levo para baixa renda? Daí que veio o meaningful media. Veio por pesquisa, mas não consigo dizer se foi acidente, ou se a gente de cara acabou seguindo o caminho certo e deu de cara com o conceito. Mas rapidamente, depois que a gente endereçou o caminho do meaninful media, a gente rapidamente desenvolveu o modelo. Esse foi o ponto crítico realmente, achar o modelo de negócios, que ainda precisa se provar. Mas parece ser o correto."

Os métodos de seleção aplicados foram mais qualitativos e informais do que quantitativos e formais para este fim, pois se tratava, como foi possível observar na fala do entrevistado, de identificação de alinhamento de objetivos subjetivos e/ou não declarados (e, portanto, não mensurados ou publicados) pelas partes interessadas. Note que houve um elemento de serendipidade para a descoberta e seleção da melhor fonte pagadora para sustentação do modelo de negócios.

\subsubsection{Definição do conceito}

Após a seleção da fonte pagadora, concluiu-se o FFE com a definição do modelo de negócios. Seguindo o modelo de Boons et al (2013), pode-se identificar os seguintes elementos definidos no caso piloto:

- Proposta de valor: orientações personalizadas para promoção de saúde com mecanismos de engajamento ao indivíduo; fornecimento de um veículo de vinculação de imagem positiva às empresas (mídia de significado);

- Cadeia de suprimentos: foram descobertos os fornecedores estratégicos para a sustentabilidade do negócio. O parceiro mais chave foi a empresa responsável pela análise de risco de saúde do indivíduo a partir de suas informações pessoais, a Biosígnia.

- Interface com o cliente: optou-se pela interface web com o cliente final, devido à escalabilidade do canal necessária para massificar a solução para as classes sociais mais baixas.

- Modelo financeiro: o elemento mais complexo da inovação foi equacionar o modelo financeiro, devido ao ineditismo do modelo de negócios e decorrente incerteza na precificação da proposta de valor. O compartilhamento de risco com a rede de parceiros necessários para a entrega da proposta de valor também exigiu 
comprometimentos financeiros dos inovadores a priori em relação à distribuição do valor a ser gerado pelo negócio no futuro. As vinculações financeiras, jurídicas e relacionais realizadas com os demais atores do modelo financeiro foram detalhados no item 4.2.2, na discussão dos mecanismos de coordenação e colaboração.

Os passos seguintes após a definição do conceito foi a decisão estratégica de investimento dos sócios da Troyt Partners, desenvolvimento do piloto e criação de uma nova empresa, também conforme previsto no modelo. Nota-se apenas que a definição do conceito não é uma atividade estanque e que é concluída em um momento específico, mas um processo evolutivo que se aperfeiçoa com os primeiros testes e implementações do negócio. Por esta característica, a empresa do caso estudado optou por um modelo de lançamento de novos releases do produto/serviço aprimorado a cada seis meses, como estratégia de criação de barreira de entrada aos concorrentes.

Conclui-se que o modelo conceitual proposto para o FFE na Figura 6 foi confirmado pelo estudo de caso piloto, sugerindo-se apenas uma modificação: que os mecanismos de coordenação e de colaboração sejam claramente separados, com inclusão dos mecanismos de colaboração também para o caso das empresas de nicho do ecossistema de negócios.

Realizou-se uma análise das práticas de gestão de stakeholders do projeto, indicando as práticas por fase do processo de gestão baseada na revisão de Aaltonen e Vos (2011) identificadas na análise de conteúdo da entrevista transcrita. Os resultados da análise são apresentados no Quadro 15. 
(Continua)

\section{Quadro 15 - Análise de práticas de gestão de stakeholders aplicadas no projeto de inovação sistêmica.}

\begin{tabular}{|c|c|c|}
\hline Fase & Método aplicado & Evidências da entrevista com sócio fundador da Vitalbox \\
\hline $\begin{array}{l}0 \\
0 \\
0 \\
\tilde{J} \\
0 \\
0 \\
0 \\
0 \\
\frac{\pi}{0} \\
0 \\
0\end{array}$ & $\begin{array}{ll}\text { - } & \text { Entrevistas } \\
\text { presenciais } \\
\text { - } & \text { Técnica de } \\
\text { entrevista bola } & \text { de neve } \\
\text { - } & \text { Listas de } \\
\text { stakeholders } & \text { genéricos } \\
\text { - } & \text { Brainstorming } \\
\text { - } & \text { Diálogo inicial } \\
\text { - } & \text { Relatórios } \\
\text { especiais } \\
\text { - Relatórios de } \\
\text { lições } \\
\text { aprendidas } \\
\text { Workshops, } \\
\text { surveys } \\
\text { pessoais, } \\
\text { grupos de foco, } \\
\text { reuniões } \\
\text { públicas, } \\
\text { audiências } \\
\text { públicas } \\
\text { Diálogo virtual } \\
\text { Construção de } \\
\text { cenários }\end{array}$ & $\begin{array}{l}\text { - "A gente deve ter entrevistado uns } 20 \text { médicos do círculo intimo, contatos que a } \\
\text { - } \quad \text { gente tinha, e umas } 5 \text { ou } 6 \text { empresas para testar algumas ideias." } \\
\text { "Noutros colegas testarem, darem feedback" } \\
\text { - "a gente montou um quadro que era do tamanho desta parede, foi cerca de } \\
\text { duzentos, e foi deste tipo mesmo, em grupos, e daí a gente ia abrindo, e não era } \\
\text { nominal, era tipo farmácias" } \\
\text { "Fizemos primeiro uma divulgação em um grupo de médicos, 40, } 50 \text { médicos, } \\
\text { para testar a reação da comunidade médica" } \\
\text { "Neste período pegamos alguns materiais, principalmente da McKinsey, da Booz } \\
\text { - Allen que a gente tinha acesso na época" } \\
\text { "Se no futuro precisarmos buscar os lições aprendidas, todas as pesquisas, } \\
\text { - documentos, desk research, ficaram registradas em uma wiki" } \\
\text { "a gente foi para os congressos de saúde, o Health Summit de Paris, em agosto } \\
\text { fomos para Harvard para o Forces of Change" } \\
\text { "contato direto com os usuários pelo Facebook, diariamente colocamos um post, } \\
\text { eles comentam se gostaram etc, e temos um contato direto pelo canal de suporte" } \\
\text { / "A gente usa o Google Alerts para monitorar agencias reguladoras, leis, } \\
\text { discussoes no Congresso" } \\
\text { "a gente começou a combinar megatendências, focadas em alguns tópicos } \\
\text { especificos, como aumento da população, envelhecimento, intensificação da } \\
\text { digitalização da saúde, isso forma um cenário" }\end{array}$ \\
\hline
\end{tabular}




\begin{tabular}{|c|c|c|}
\hline 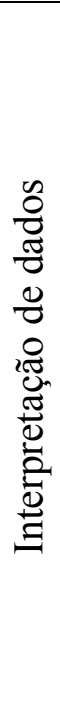 & 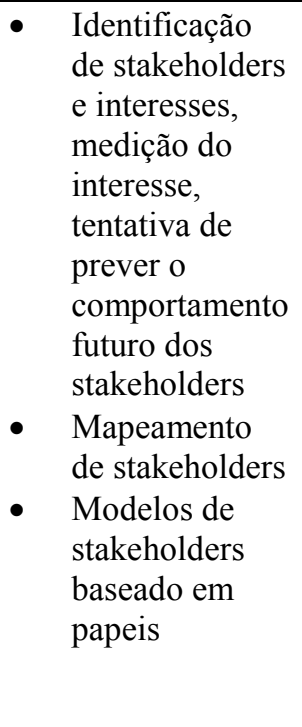 & $\begin{array}{l}\text { - "desde o primeiro momento, esta parte dos stakeholders institucionais talvez } \\
\text { tenha sido o primeiro mapeamento e análise, quando a gente montou o quadro } \\
\text { de como era a saúde do ponto de vista da cura e da prevenção" } \\
\text { "[O mapeamento] era usando diagramas deste tipo, bolinhas, traços para } \\
\text { ligações, esta relação é forte... ', esta é fraca..." } \\
\text { - Mapeamento de stakeholders baseado em papeis: financiamento, institucionais, } \\
\text { clientes, fornecedores e operações. Com cada grupo, a gestão de stakeholders é } \\
\text { diferente: "Com este grupo de investidores, é uma atmosfera de incerteza e risco, } \\
\text { tem uma grande instabilidade de humor. Com os institucionais a atmosfera é } \\
\text { muito formal, há muito cuidado de ambas as partes de colocar no papel o que foi } \\
\text { combinado, de confirmar se o que foi entendido está correto, de estar sempre } \\
\text { pisando em ovos. Com os fornecedores a atmosfera é mais de colaboração. Por } \\
\text { exemplo, faz alguma coisa, devolve para a Atlassian e eles colocam no produto } \\
\text { deles, mesma coisa a gente fez com a Indivo, fizemos a traducao em portugues e } \\
\text { a gente devolveu para eles, é uma das nossas filosofias usar open source. Com a } \\
\text { Biosignia e ambiente interno é uma atmosfera de parceria até porque a gente } \\
\text { tem resultados compartilhados. A gente tem com todos eles, bonus para } \\
\text { distribuir pelo sucesso do negócio." }\end{array}$ \\
\hline 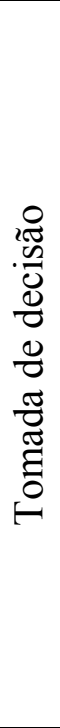 & $\begin{array}{ll}\text { - } & \begin{array}{l}\text { Estratégias de } \\
\text { comunicação e }\end{array} \\
\text { disseminação } \\
\text { de informação } \\
\text { - } \quad \text { Processo de } \\
\text { engajamento } \\
\text { de stakeholders } \\
\text { - Inserção do } \\
\text { stakeholder no } \\
\text { modelo de } \\
\text { negócio }\end{array}$ & $\begin{array}{l}\text { - "Tem uns } 3 \text { ou } 4 \text { modos de relacionamento. Com os investidores institucionais } \\
\text { são reuniões bimestrais e contatos ad hoc via email, telefone, por exemplo, se } \\
\text { tem uma má noticia para comunicar, conversamos com eles e eles vão tentar } \\
\text { dirigir a notícia. Vou tentar um cliente aqui, tenho que ver se o investidor tem } \\
\text { algum relacionamento com ele. Com os institucionais interagimos apenas } 3 \text { ou } 4 \\
\text { vezes, e ficamos monitorando. Com os clientes são processos normais de venda, } \\
\text { reuniões presenciais, apresentações, trocas de emails. Com fornecedores é } \\
\text { esporádico e no vencimento dos contratos. O interno é diário, pessoal, ou por } \\
\text { meio eletrônico." } \\
\text { "Alguns stakeholders chave detêm instrumentos de participação em resultados, } \\
\text { como títulos representando uma quantidade de direitos não-conversíveis em } \\
\text { ações" } \\
\text { "Mas quem vai pagar a conta? o cara já mal paga o plano de saúde, pois não } \\
\text { tem condicoes, e quem tem condições nao paga nada, aí você fala para o cara } \\
\text { que ele ainda tem que pagar mais alguma coisa para cuidar da saúde, de jeito } \\
\text { nenhum. Aí a gente pensou o seguinte, não é o individuo que vai pagar. A gente } \\
\text { começou um trabalho de investigar quem iria se beneficiar com esta solução. } \\
\text { (...) Foi daí que a gente foi buscar o modelo de midia de significado." }\end{array}$ \\
\hline
\end{tabular}

(Conclusão)

Observa-se que as práticas de gestão de stakeholders aplicadas no caso têm características mais semelhantes às práticas indicadas na literatura de inovação sistêmica do que na literatura de stakeholders. Este resultado sugere que a forma de gerir stakeholders em projetos de inovação sistêmica difere significativamente da gestão em projetos tradicionais, e que, de forma geral, a literatura de inovação sistêmica tem aderência empírica quanto à gestão de stakeholders.

No entanto, algumas diferenciações foram encontradas na comparação das práticas aplicadas no caso e a literatura de inovação sistêmica. Por exemplo, as práticas de alinhamento de objetivos entre stakeholders foi relativamente superior. Uma explicação é o 
pequeno porte da empresa, que a impede de simplesmente exercer poder econômico sobre as outras entidades do ecossistema de negócios e a obriga a descobrir e articular interesses comuns. Outro fator é contingencial à indústria de saúde, um sistema complexo, com múltiplos atores, e que necessita de inovações disruptivas (HWANG E CHRISTENSEN, 2008). O alinhamento também foi necessário para definir os critérios de sucesso do projeto dentro da equipe, que foram explicitamente declarados no início do projeto (critérios financeiros - retorno de investimento de 5 vezes e critérios pessoais - e.g. tornar-se referência em inovação em saúde e ser um case de sucesso em Harvard).

Outras práticas mais freqüentes no caso foram relacionamento, análises dinâmicas e aprendizado. Provavelmente isso se deve a questões culturais (a cultura brasileira valoriza o relacionamento para construção de confiança inclusive no ambiente corporativo) e ao fato de que os membros do projeto não pertenciam à indústria de saúde, o que requeriu maior enfoque em aprendizado acerca dos stakeholders e seus interesses. A necessidade de análise dinâmica de stakeholders ao longo de todo o projeto é mais acentuada neste caso devido à incerteza associada aos investidores de capital de risco e imprevisibilidade das relações institucionais, como explica o entrevistado no seguinte trecho:

“[A relação com] investidores flutua muito em função do humor do mercado. O institucional é uma incógnita completa. A gente sabe quem são as entidades, quais as influências entre elas, mas não sabe os passos que vão dar, não sabe o que está ocorrendo no Senado, nos bastidores, como a lei vai se encaminhar e muda de uma hora para outra."

Por outro lado, no caso estudado houve menor ênfase em práticas de autoregulação, padronização e de engenharia ou dinâmica de sistemas, práticas associadas ao pensamento sistêmico. Isto ocorreu porque se optou deliberadamente por criar uma nova indústria livre de paradigmas anteriores ao invés de inserir-se em um sistema existente, evitando-se assim esforços de padronização ou regulação para garantir interoperabilidade com outros stakeholders. 


\section{Resultados dos Estudos de Caso Exploratórios}

O presente capítulo tem por objetivo apresentar os resultados obtidos dos estudos de caso exploratórios.

\subsection{Descrição dos Casos}

Foram estudados os casos envolvendo 8 empresas do ecossistema de Smart Grid, sendo 5 empresas classificadas como Plataforma (keystone) e 3 classificadas como Nicho. Em todos os casos o entrevistado foi o principal gestor do projeto de Redes Inteligentes dentro da organização. Este gestor foi identificado por meio de indicação em notícias disponibilizadas na mídia (especialmente em press releases das próprias empresas) e também por indicação de outros profissionais contatados das organizações estudadas.

As empresas Plataforma são as Distribuidoras de Energia Elétrica, assim classificadas por serem as líderes dos projetos de inovação, orquestradoras dos demais atores envolvidos. São elas que abrem espaço e criam mecanismos para que os demais atores para fazer parte do projeto de inovação, como por exemplo, requisições de propostas e convênios em projetos de pesquisa e desenvolvimento. As empresas de Nicho são fornecedoras de tecnologia, principalmente relacionada à medição inteligente, item fundamental para um projeto de Smart Grid. Possuem conhecimento específico não dominado pela empresa Plataforma. Nos casos estudados, as empresas Nicho caracterizam-se como micro ou médias empresas (menos de 500 funcionários) e as empresas Plataforma são de grande porte.

Nota-se uma variação nos aspectos societários e de nacionalidade das empresas entrevistadas. Ao longo da análise fez-se necessário salientar esta diferenciação porque os mecanismos de coordenação e a definição do modelo de negócios variam de acordo com estes aspectos, que serão tratados em maior detalhe nas seções posteriores.

As características gerais das empresas dos casos estudados são apresentadas na Tabela 6. A fim de preservar a confidencialidade das informações, o nome das empresas foi substituído por letras. Caracterizou-se também o porte da empresa com base no critério de classificação de empresas do Instituto Brasileiro de Geografia e Estatística (IBGE), em relação ao número de funcionários. 
Tabela 6 - Características Gerais das Empresas dos Casos Estudados

\begin{tabular}{|l|l|l|l|l|}
\hline Empresa & $\begin{array}{l}\text { Classificação no } \\
\text { Ecossistema }\end{array}$ & \multicolumn{1}{|c|}{$\begin{array}{c}\text { Porte da } \\
\text { Empresa* }\end{array}$} & $\begin{array}{c}\text { Aspectos } \\
\text { Societários }\end{array}$ & Papel em Smart Grid \\
\hline A & $\begin{array}{l}\text { Plataforma } \\
(\text { keystone })\end{array}$ & Grande & $\begin{array}{l}\text { Nacional } \\
\text { privada }\end{array}$ & $\begin{array}{l}\text { Distribuidora de energia } \\
\text { elétrica }\end{array}$ \\
\hline B & $\begin{array}{l}\text { Plataforma } \\
\text { keystone })\end{array}$ & Grande & $\begin{array}{l}\text { Nacional } \\
\text { pública }\end{array}$ & $\begin{array}{l}\text { Distribuidora de energia } \\
\text { elétrica }\end{array}$ \\
\hline C & $\begin{array}{l}\text { Plataforma } \\
(\text { keystone })\end{array}$ & Grande & $\begin{array}{l}\text { Nacional } \\
\text { pública }\end{array}$ & $\begin{array}{l}\text { Distribuidora de energia } \\
\text { elétrica }\end{array}$ \\
\hline D & $\begin{array}{l}\text { Plataforma } \\
(\text { keystone })\end{array}$ & Grande & $\begin{array}{l}\text { Internacional } \\
\text { privada }\end{array}$ & $\begin{array}{l}\text { Distribuidora de energia } \\
\text { elétrica }\end{array}$ \\
\hline E & $\begin{array}{l}\text { Plataforma } \\
(\text { keystone })\end{array}$ & Grande & $\begin{array}{l}\text { Nacional } \\
\text { privada }\end{array}$ & $\begin{array}{l}\text { Distribuidora de energia } \\
\text { elétrica }\end{array}$ \\
\hline F & $\begin{array}{l}\text { Nicho } \\
\text { G }\end{array}$ & Nicho & $\begin{array}{l}\text { nternacional } \\
\text { privada }\end{array}$ & $\begin{array}{l}\text { Fornecedora dio } \\
\text { Medidores Inteligentes }\end{array}$ \\
\hline H & Nicho & $\begin{array}{l}\text { Nacional } \\
\text { privada }\end{array}$ & $\begin{array}{l}\text { Fornecedora } \\
\text { Medidores Inteligentes }\end{array}$ \\
\hline
\end{tabular}

*Segundo critério de número de funcionários do IBGE.

\subsection{Caracterização do FFE dos projetos de IS}

Tratando-se especificamente da etapa de FFE projetos de IS, que são as unidades de análise desta pesquisa, foram estudados cinco projetos, cada um liderado por uma das empresas Plataforma. Observou-se bastante aderência dos casos estudados com o modelo de Khurana e Rosenthal (1998), ilustrado na Figura 9. Todos os entrevistados citaram um longo período de estudos de benchmarking e análise de tecnologias relacionadas a Redes Inteligentes, condizentes com o que é descrito na Pré Fase Zero do modelo, antes de uma etapa intencional de concepção, planejamento e estudo de viabilidade caracterizadas pelas Fases Zero e Fase Um do modelo.

Como mostra o modelo a Pré Fase Zero é um movimento contínuo de captura e análise de informações, portanto não é possível precisar com exatidão seu início. No entanto, segundo os entrevistados, os movimentos das empresas em direção a Smart Grid começaram entre 5 e 30 anos atrás.

O final da Pré Fase Zero pode ser mais bem delineado porque em todos os projetos estudados houve um kick off formal da pesquisa e desenvolvimento para conceituação e estudo de viabilidade, já que foram realizados dentro do Programa de P\&D ANEEL (Agência 
Nacional de Energia Elétrica), que determina que todas as concessionárias de energia elétrica devem investir pelo menos $0,5 \%$ de sua receita operacional líquida em projetos do gênero.

Já o final da fase de FFE foi marcado em todos os casos por uma decisão de aprovação mediante apresentação de um business case e lançamento de uma RFP (Request For Proposal), ou requisição de propostas em que o conceito das inovações foi consolidado e apresentado para o mercado. Segue-se a este momento um processo formal de desenvolvimento da inovação com especificação detalhada, design, protótipo e validação dos testes.

A Tabela 7 apresenta os itens principais do escopo dos projetos, as empresas entrevistadas envolvidas em cada um dos projetos e os anos de final da Pré Fase Zero, final do FFE e final dos projetos piloto (realizados ou previstos pelos entrevistados).

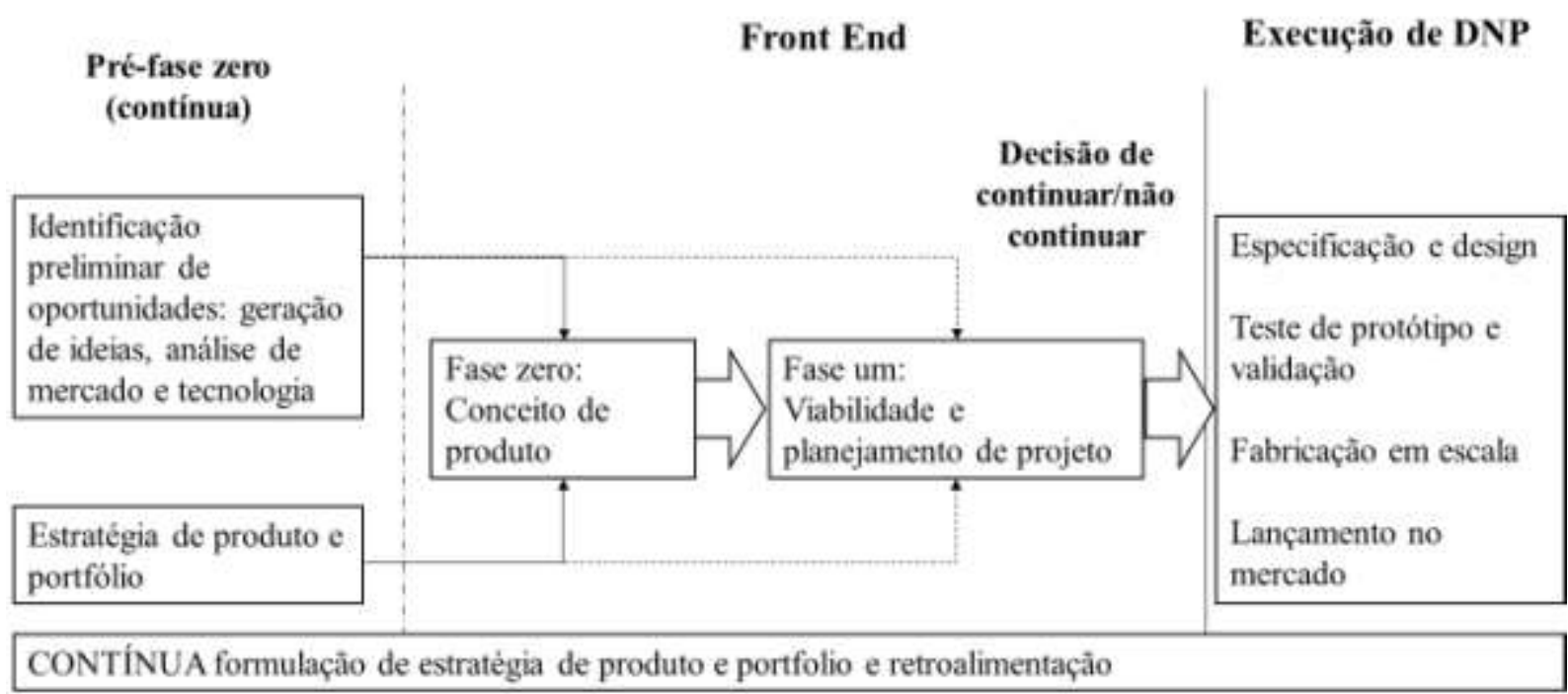

Figura 9 - Modelo de FFE aderente aos casos estudados. Fonte: Khurana e Rosenthal (1998). 
Tabela 7 - Caracterização da etapa de FFE dos casos estudados

\begin{tabular}{|c|c|c|c|c|c|}
\hline Projeto & Empresas & Escopo dos Projetos & $\begin{array}{c}\text { Fim da Pré } \\
\text { fase Zero }\end{array}$ & $\begin{array}{l}\text { Fim do } \\
\text { FFE }\end{array}$ & $\begin{array}{l}\text { Fim do } \\
\text { Piloto* }\end{array}$ \\
\hline $\mathrm{P} 1$ & $\mathrm{~A}$ & $\begin{array}{ll}\text { - } & \text { Medição Inteligente } \\
\text { - } & \text { Automação } \\
& \text { Distribuição } \\
\text { - } & \text { Auto Recuperação }\end{array}$ & 2012 & 2014 & 2018 \\
\hline $\mathrm{P} 2$ & $\mathrm{~B}, \mathrm{~F}, \mathrm{H}$ & $\begin{array}{ll}\text { - } & \text { Medição Inteligente } \\
\text { - } & \text { Medição Multiutilities } \\
\text { - } & \text { Automação } \\
& \text { Distribuição } \\
\text { - } & \text { Geração Distribuída } \\
\text { - } & \text { Automação Residencial } \\
& \text { (descontinuado) } \\
\text { - } & \text { Mobilidade Elétrica (spin } \\
\text { off) }\end{array}$ & 2009 & 2010 & 2015 \\
\hline P3 & $\mathrm{C}, \mathrm{F}, \mathrm{H}$ & $\begin{array}{ll}\text { - } & \text { Medição Multiutilities } \\
\text { - } & \text { Automação } \\
& \text { Distribuição } \\
\text { - Geração Distribuída } & \end{array}$ & 2009 & 2013 & 2015 \\
\hline $\mathrm{P} 4$ & $\mathrm{D}, \mathrm{G}$ & $\begin{array}{ll}\text { - } & \text { Medição Inteligente } \\
\text { - } & \text { Mobilidade Elétrica } \\
\text { - } & \text { Geração Distribuída } \\
\text { - } & \text { Eficiência Energética } \\
\text { - } & \text { Gestão pelo lado da } \\
& \text { demanda }\end{array}$ & 2007 & 2009 & 2015 \\
\hline P5 & $\mathrm{E}, \mathrm{F}, \mathrm{H}$ & $\begin{array}{ll}\text { - } & \text { Medição Inteligente } \\
\text { - } & \text { Automação } \\
& \text { Distribuição } \\
\text { - } & \text { Mobilidade Elétrica }\end{array}$ & 2008 & 2013 & 2016 \\
\hline
\end{tabular}

*Previsão da equipe do projeto

O próximo passo foi verificar se de fato as inovações dos projetos estudados podem ser classificadas como sistêmicas. Foram coletadas evidências positivas principalmente nas entrevistas com empresas Plataforma. Em nenhum dos projetos o esforço de pesquisa e desenvolvimento foi apenas de uma empresa. Muito pelo contrário, os consórcios apresentam dezenas de empresas envolvidas, sem contar a influência direta de órgãos governamentais que regulam o mercado ou financiam iniciativas de inovação.

Nas falas a seguir fica clara a necessidade de orquestração de uma rede de múltiplos atores fora das fronteiras da empresa, desde o FFE das inovações, além da exigência de 
reajustes significativos nas empresas e no agente regulatório para viabilização de desdobramentos futuros dos projetos, aspectos característicos de inovações sistêmicas:

- Projeto 1, Empresa A: “Clientes da concessionária foram envolvidos já na concepção, quando foram estudados os perfis dos clientes das regiões de concessão. Fornecedores foram consultados na concepção do projeto para avaliação das soluções e estão sendo continuamente envolvidos ao longo do projeto nas aquisições. No início do projeto foram realizadas apresentações à agência reguladora (ANEEL), já que o projeto está no programa de P\&D da ANEEL. Foi envolvida também a FINEP, financiadora dos projetos."

- Projeto 2, Empresa B: "Na verdade quem orquestra a implantação é a concessionária de energia, ela que vai provocar o mercado fornecedor, consumidor, desde a implementação, manutenção, atualização. (...) Precisamos ter no mercado brasileiro o Smart Grid como algo que seja fornecido quase que de prateleira, seja equipamentos e serviços, tem que ter este portfólio no mercado brasileiro, seja equipamento, medidores, serviços profissionais capacitados, porque como para montar uma cidade inteligente precisa de vários elos de serviços, energia, água, resíduos sólidos, mobilidade. Para montar esse projeto nós precisamos destes elos também, consultoria, centro de pesquisa, fornecedores de tecnologia, centros educacionais, e vários outros. (...) A gente brinca que Smart Grid é um ecossistema, é muita coisa para você mexer".

- Projeto 3, Empresa C: “O regulador e os próprios fornecedores também, tem segmentos em que pensando no próprio negócio restringem, principalmente em relação a interoperabilidade de comunicação entre dispositivos e equipamentos, acaba criando sistemas proprietários e não sistemas que possam ser compartilhados, tem segmentos de aplicações tecnológicas que acabam restringindo bastante nossa ideia de ter um sistema híbrido no futuro."

- Projeto 4, Empresa D: "Participaram nosso parceiro que produz o medidor, fornecedores de serviços em campo, as empreiteiras, temos a universidade também muito envolvida no projeto. (...) Quem faz parte da criação de valor? Quem vai também ganhar com isso? Nós, a indústria, a universidade, sob o ponto de vista 
transacional diretamente, indiretamente os clientes e o poder público. E melhorar a qualidade do serviço para a sociedade como um todo."

- Projeto 5, Empresa E: “Fizemos uma revisão de especificações técnicas com análise funcional, testamos o apetite do mercado brasileiro, chamamos os principais players para ver se teriam condição de entrar em um projeto deste porte, contrato de longo prazo, com uma série de diferenciais incomuns no Brasil, visitamos empresas no exterior, o resultado foi que em 2013 uma RFP, solicitação de propostas."

Sendo assim caracterizadas as etapas de FFE dos projetos e evidenciado que são IS conforme a definição de trabalho desta dissertação, partimos para a etapa de análise dos casos a partir do modelo conceitual definido na revisão de literatura.

\subsection{Análise das práticas de gestão do FFE nos casos exploratórios}

Nesta seção procedeu-se a análise das práticas de gestão do FFE para os projetos de IS dos casos exploratórios, utilizando-se o procedimento de análise de conteúdo aplicado no estudo de caso piloto (utilizando-se a mesma árvore de códigos), diferenciando-se também as práticas entre empresas Plataforma e empresas de Nicho. Ao longo da análise foram adicionadas observações adicionais independentes do modelo de Koen et al (2002), relacionando-se os trechos com conceitos estudados na revisão de literatura de IS.

Como análise inicial, comparou-se o percentual relativo de frequências de cada código tanto da análise de conteúdo da revisão de literatura de inovação sistêmica e FFE, como dos casos piloto e exploratórios, separando-se as médias relativas das empresas Plataforma das empresas de Nicho (Gráfico 2). Observa-se que em linhas gerais há coerência entre a ênfase dada pela literatura a cada código e a ênfase dada pelo mercado, tanto por empresas Plataforma como Nicho. O item de maior enfoque são os mecanismos de coordenação para todos os casos.

Há, no entanto, certa diferenciação nas atividades de identificação de oportunidade, seleção de ideias, definição do conceito, posicionamento no ecossistema, definição de modelo de negócios e mapeamento do ecossistema de negócios. Observa-se que as empresas de Nicho comentaram relativamente mais do que as de Plataforma sobre identificação de oportunidades. Analisando-se o conteúdo das entrevistas, observa-se uma postura pró ativa das empresas de Nicho na identificação de oportunidades, tanto detectando necessidades não 
atendidas da Plataforma quanto explorando novas tecnologias no estado da arte no Brasil e no mundo. Esta identificação é realizada por meio de reuniões entre Nicho e Plataforma, eventos setoriais em que ambos comparecem e treinamentos realizados principalmente no exterior.

A definição do modelo de negócios e a preocupação em mapear todos os atores envolvidos no ecossistema do negócio são consideravelmente mais enfatizados pelas empresas Plataforma. Nas entrevistas com empresas de Nicho em diversos momentos foram ditas frases como "isto é responsabilidade da concessionária [de energia]" quando questionados a respeito destes dois temas. Já questões de posicionamento da empresa no ecossistema foram mais citadas pelas empresas de Nicho, principalmente pela ênfase no posicionamento como especialista em determinadas tecnologias. Uma hipótese complementar é a de que as concessionárias de energia são claramente as responsáveis por orquestrar os demais atores e liderar a inovação. Já as Nicho podem ter papeis muito diversos e complementares. Uma das empresas Nicho, por exemplo, atua também como Plataforma para o subsistema de medição inteligente. Já outra foca-se em ser altamente especialista em um dos aspectos da medição inteligente, que é a comunicação sem fio.

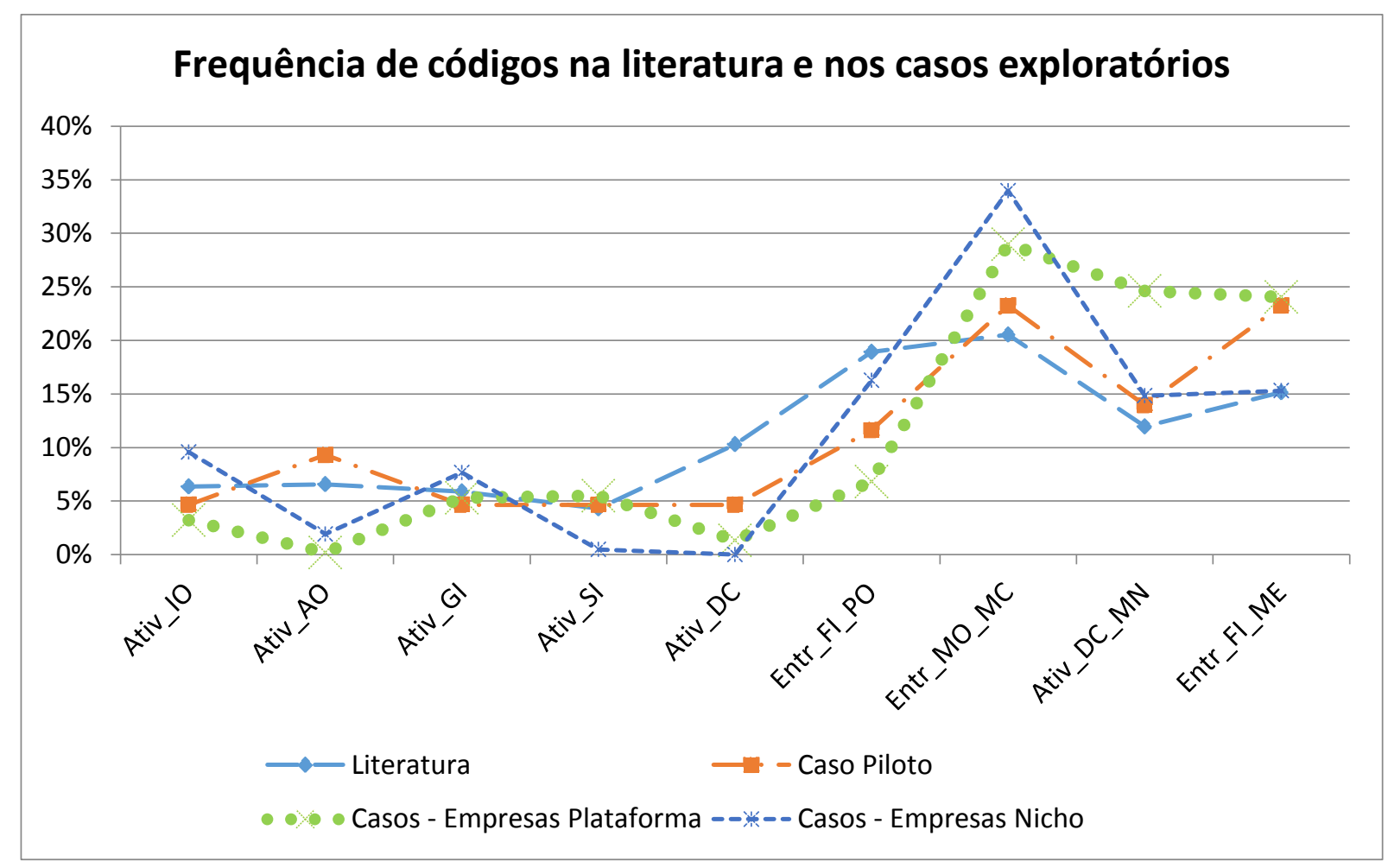

Gráfico 2 - Frequência relativa dos códigos da análise de conteúdo. 
Durante as entrevistas emergiram novos códigos caracterizando cada uma das atividades. Estes códigos e suas frequências são apresentados no Quadro 16 para as empresas Plataforma e no Quadro 17 para as empresas Nicho.

(Continua)

Quadro 16 - Códigos emergentes na análise de conteúdo (Plataforma)

\begin{tabular}{|l|r|}
\hline Códigos da Análise de Conteúdo & Contagem \\
\hline Entr_MO_MC & $\mathbf{1 6 3}$ \\
\hline Coordenação com outros atores do ecossistema & 89 \\
\hline Estrutura organizacional para desenvolvimento da Inovação & 24 \\
Sistêmica & 22 \\
\hline Gestão de stakeholders & 19 \\
\hline Plataforma define padrões a partir de benchmarking & 6 \\
\hline Integração vertical & 1 \\
\hline Distribuição de riscos/retornos & 1 \\
\hline Troca de conhecimentos entre atores do ecossistema & 1 \\
\hline Envolvimento da Alta Cúpula & $\mathbf{1 5 0}$ \\
\hline Ativ_DC_MN & 67 \\
\hline Definir drivers de geração de valor a múltiplos atores & 40 \\
\hline Restrições ao modelo de negócio & 16 \\
\hline Distribuição de riscos/retornos & 9 \\
\hline Exigência de alteração de processos da organização & 8 \\
\hline Business case tradicional & 6 \\
\hline Benefícios provenientes de sinergias entre inovações & 2 \\
\hline Business case formal para inovação sistêmica & 1 \\
\hline Business case com análise estratégica de produtos & 1 \\
\hline Novos relacionamentos no ecossistema & $\mathbf{1 0 5}$ \\
\hline Entr_FI_ME & 36 \\
\hline Mapeamento e análise de stakeholders & 29 \\
\hline Tendências do ecossistema & 20 \\
\hline Necessidade de desenvolver o ecossistema & 6 \\
\hline Troca de conhecimentos entre atores do ecossistema & 6 \\
\hline Incentivos públicos para a Inovação & 6 \\
\hline Plataforma atende a regulações & 1 \\
\hline Consumidor protagoniza inovação & $\mathbf{4 2}$ \\
\hline Propagação de riscos & 16 \\
\hline Saída_PE_CVC & 3 \\
\hline Roadmap tecnológico e plano estratégico de roll out & 2 \\
\hline Troca de conhecimentos entre atores do ecossistema & \\
\hline Spin off & \\
\hline Auditoria de terceiros & 2 \\
\hline
\end{tabular}


(Continua)

\begin{tabular}{|c|c|}
\hline Códigos da Análise de Conteúdo & Contagem \\
\hline Envolvimento da Alta Cúpula & 2 \\
\hline Plataforma influencia regulação & 2 \\
\hline Pivotamento & 1 \\
\hline Exigência de alteração de processos da organização & 1 \\
\hline $\begin{array}{l}\text { Estrutura organizacional para desenvolvimento da Inovação } \\
\text { Sistêmica }\end{array}$ & 1 \\
\hline Gestão de Programa e não Projeto & 1 \\
\hline Entr_FI_PO & 30 \\
\hline Plataforma protagoniza inovação & 13 \\
\hline Plataforma tem reputação - Confiabilidade para outros atores & 8 \\
\hline Plataforma como garantidora da qualidade & 6 \\
\hline Dificuldade de desenvolver o ecossistema & 2 \\
\hline Necessidade de desenvolver o ecossistema & 1 \\
\hline Ativ_GI & 27 \\
\hline Mapeamento e análise de tecnologias & 7 \\
\hline Construção conjunta da ideia Plataforma e Nicho & 5 \\
\hline $\begin{array}{l}\text { Consolidou conhecimentos internamente e depois acionou atores } \\
\text { externos }\end{array}$ & 5 \\
\hline Não começar pela tecnologia & 3 \\
\hline Projeto de engenharia & 2 \\
\hline Projeto de integração de sistemas & 2 \\
\hline Design de interface com usuário & 2 \\
\hline Coordenação com outros atores do ecossistema & 1 \\
\hline Ativ_SI & 25 \\
\hline Critério de seleção do piloto: representatividade do sistema & 14 \\
\hline Seleção típica de inovação autônoma & 3 \\
\hline Envolvimento da Alta Cúpula & 2 \\
\hline Critério de seleção do piloto: facilidade de implantação & 2 \\
\hline Critério de seleção do piloto: benefícios da implantação & 1 \\
\hline $\begin{array}{l}\text { Estrutura organizacional para desenvolvimento da Inovação } \\
\text { Sistêmica }\end{array}$ & 1 \\
\hline $\begin{array}{l}\text { Consolidou conhecimentos internamente e depois acionou atores } \\
\text { externos }\end{array}$ & 1 \\
\hline $\begin{array}{l}\text { Critério de seleção do piloto: possibilidade de testar a integração de } \\
\text { diversos conceitos }\end{array}$ & 1 \\
\hline Ativ_IO & 21 \\
\hline Iniciou como inovação autônoma & 15 \\
\hline $\begin{array}{l}\text { Consolidou conhecimentos internamente e depois acionou atores } \\
\text { externos }\end{array}$ & 6 \\
\hline Entr_MO & 16 \\
\hline Cultura organizacional para desenvolvimento da Inovação Sistêmica & 10 \\
\hline
\end{tabular}




\begin{tabular}{|l|r|}
\hline Códigos da Análise de Conteúdo & Contagem \\
\hline Gestão do conhecimento & 6 \\
\hline Ativ_DC & $\mathbf{7}$ \\
\hline Caracterização como Inovação Sistêmica & 5 \\
\hline Propagação de riscos & 2 \\
\hline Total & $\mathbf{5 8 6}$ \\
\hline
\end{tabular}

(Conclusão)

(Continua)

Quadro 17 - Códigos emergentes na análise de conteúdo (Nicho)

\begin{tabular}{|c|c|}
\hline Códigos da Análise de Conteúdo & Contagem \\
\hline Entr_MO_MC & 89 \\
\hline Coordenação com outros atores do ecossistema & 34 \\
\hline Nicho é Plataforma para outros Nichos & 19 \\
\hline Plataforma buscou Nicho com requisitos definidos & 8 \\
\hline Coordenação de múltiplas áreas internas do Nicho & 6 \\
\hline Plataforma protagoniza inovação & 4 \\
\hline Estrutura organizacional para desenvolvimento da Inovação Sistêmica & 4 \\
\hline Integração vertical & 4 \\
\hline Plataforma determina padrões a partir de benchmarking & 3 \\
\hline Clara definição de reponsabilidades em contrato & 3 \\
\hline Universidade não se envolveu diretamente no desenvolvimento & 1 \\
\hline Distribuição de riscos/retornos & 1 \\
\hline Compromisso de longo prazo entre nicho e plataforma & 1 \\
\hline Coordenação com regulação e entidades de classe é papel da Plataforma & 1 \\
\hline Entr_FI_PO & 34 \\
\hline Nicho apresenta tecnologia para Plataforma & 13 \\
\hline Base instalada qualifica nicho & 4 \\
\hline Nicho atende a regulações, não influencia & 4 \\
\hline Nicho é substituível & 3 \\
\hline Foco no core business, minimizar necessidade futura de outros atores & 3 \\
\hline Nicho é Plataforma para outros Nichos & 3 \\
\hline Integração vertical & 2 \\
\hline Plataforma como garantidora da qualidade & 1 \\
\hline Regulação garantidora da qualidade & 1 \\
\hline Entr_FI_ME & 32 \\
\hline Nicho atende a regulações, não influencia & 11 \\
\hline Incentivos públicos para a Inovação & 7 \\
\hline Coordenação com regulação e entidades de classe é papel da Plataforma & 5 \\
\hline
\end{tabular}




\begin{tabular}{|l|r|}
\hline Tendências do ecossistema & 4 \\
\hline Regulação restringe criação de valor & 2 \\
\hline
\end{tabular}

\begin{tabular}{|c|c|}
\hline Códigos da Análise de Conteúdo & Contagem \\
\hline Roadmap tecnológico & 2 \\
\hline Benchmarking internacional & 1 \\
\hline Ativ_DC_MN & 32 \\
\hline Definir drivers de geração de valor a múltiplos atores & 8 \\
\hline Business case tradicional & 7 \\
\hline Distribuição de riscos/retornos & 6 \\
\hline Clara definição de reponsabilidades em contrato & 4 \\
\hline Regulação restringe criação de valor & 4 \\
\hline Consideração do custo de gestão do modelo de negócios & 2 \\
\hline Projeto turn-key & 1 \\
\hline Ativ_IO & 20 \\
\hline Iniciou como inovação autônoma & 13 \\
\hline Plataforma buscou Nicho com requisitos definidos & 3 \\
\hline Nicho constantemente identifica novas oportunidades & 2 \\
\hline Plataforma protagoniza inovação & 1 \\
\hline Nicho apresenta tecnologia para Plataforma & 1 \\
\hline Ativ_GI & 16 \\
\hline Construção conjunta da ideia Plataforma e Nicho & 11 \\
\hline Nicho integrou as partes da Inovação Sistêmica & 4 \\
\hline Tecnologia desenvolvida para outros países & 1 \\
\hline Saída_PE_CVC & 10 \\
\hline Estrutura organizacional para desenvolvimento da Inovação Sistêmica & 6 \\
\hline Troca de conhecimentos entre atores do ecossistema & 2 \\
\hline Decisão de alta cúpula pela aprovação do conceito & 1 \\
\hline Desdobramento da Inovação Sistêmica & 1 \\
\hline Ativ_AO & 4 \\
\hline Inovações autônomas com pontos em comum, tornando-se Sistêmicas & 2 \\
\hline Estrutura organizacional para desenvolvimento da Inovação Sistêmica & 2 \\
\hline Ativ_SI & 1 \\
\hline Envolvimento da Alta Cúpula & 1 \\
\hline Total & 238 \\
\hline
\end{tabular}

\section{(Conclusão)}

A partir deste levantamento, realizou-se uma análise comparativa de relevância de cada tema para cada empresa e para cada tipo de empresa (Plataforma ou Nicho). Dentro do ecossistema de Redes Inteligentes, as empresas Plataforma são as concessionárias de energia 
elétrica e as empresas Nicho são fornecedoras de tecnologia, especificamente de medidores de energia elétrica eletrônicos e de módulo de comunicação sem fio, que são os principais elementos que compõem uma inovação em redes inteligentes.

\section{Quadro 18 - Importância relativa dos elementos do modelo conceitual nos casos estudados, separados em Plataforma e Nicho}

\begin{tabular}{|c|c|c|c|c|c|c|c|c|c|c|}
\hline \multirow[t]{2}{*}{ Códigos } & \multicolumn{6}{|c|}{ Empresas Plataforma } & \multicolumn{4}{|c|}{ Empresas Nicho } \\
\hline & $\mathbf{A}$ & $\mathbf{B}$ & $\mathbf{C}$ & $\mathbf{D}$ & $\mathbf{E}$ & Plat. & $\mathbf{F}$ & $\mathbf{G}$ & $\mathbf{H}$ & Nicho \\
\hline Entr_MO_MC & $13 \%$ & $21 \%$ & $42 \%$ & $37 \%$ & $24 \%$ & $30 \%$ & $41 \%$ & $37 \%$ & $33 \%$ & $37 \%$ \\
\hline Entr_FI_ME & $23 \%$ & $30 \%$ & $10 \%$ & $18 \%$ & $24 \%$ & $21 \%$ & $13 \%$ & $16 \%$ & $12 \%$ & $13 \%$ \\
\hline Entr_FI_PO & $15 \%$ & $9 \%$ & $4 \%$ & $1 \%$ & $5 \%$ & $7 \%$ & $11 \%$ & $16 \%$ & $17 \%$ & $14 \%$ \\
\hline Ativ_IO & & $1 \%$ & $1 \%$ & $6 \%$ & $10 \%$ & $5 \%$ & $10 \%$ & $8 \%$ & $9 \%$ & $8 \%$ \\
\hline Ativ_AO & & & & $1 \%$ & & $1 \%$ & $3 \%$ & $2 \%$ & & $2 \%$ \\
\hline Ativ_GI & $3 \%$ & $8 \%$ & $1 \%$ & $4 \%$ & $3 \%$ & $4 \%$ & $6 \%$ & $8 \%$ & $6 \%$ & $7 \%$ \\
\hline Ativ_SI & $13 \%$ & $3 \%$ & $3 \%$ & $11 \%$ & & $7 \%$ & $2 \%$ & & & $2 \%$ \\
\hline Ativ_DC_MN & $25 \%$ & $23 \%$ & $30 \%$ & $19 \%$ & $20 \%$ & $26 \%$ & $10 \%$ & $11 \%$ & $20 \%$ & $13 \%$ \\
\hline Saída_PE & $10 \%$ & $5 \%$ & $9 \%$ & $3 \%$ & $14 \%$ & $8 \%$ & $2 \%$ & $7 \%$ & $3 \%$ & $4 \%$ \\
\hline
\end{tabular}

Nota: Destaque em negrito para elementos com peso maior ou igual a $15 \%$ para cada empresa.

Analisando-se as empresas Plataforma entre si, observa-se um peso relativo elevado para mecanismos de coordenação e colaboração em todos os casos, com exceção da empresa A, em que o peso é mediano. Nota-se pela Tabela 7 que a empresa A é a que iniciou a IS em Redes Inteligentes mais tarde dentre os casos estudados (os demais ocorreram aproximadamente no mesmo período), utilizando fornecedores que já tinham experiência prévia em projetos de Redes Inteligentes (ou seja, com nível menor de risco), o que pode ter reduzido o esforço necessário de coordenação e colaboração para iniciação da inovação, sugerindo-se que eventualmente a estratégia de atrasar a iniciação da inovação até que o ecossistema tenha se configurado minimamente pode ter vantagens competitivas. Como efeito negativo deste "atraso" é que a difusão da tecnologia se dará a partir de 2018, enquanto as demais empresas poderão usufruir dos benefícios operacionais resultantes da IS antecipadamente. A empresa A também mostrou-se mais preocupada em defender um posicionamento como referência e garantidor da qualidade no ecossistema, o que também auxilia a explicar porque optou por arriscar menos e aguardar mais.

A relevância de definição de novos modelos de negócios mostrou-se relativamente alta e mais uniforme entre todas as empresas Plataforma. Para as empresas Nicho, a definição do modelo de negócios foi importante de forma mais destacada para a empresa $\mathrm{H}$ por fornecer 
em duas modalidades simultaneamente (como mercadoria/produto final e como licenciamento de propriedade intelectual) um dos componentes fundamentais do medidor eletrônico (o módulo de comunicação sem fio). Empresas Nicho preocupam-se relativamente mais com posicionamento no ecossistema do que Empresas Plataforma. Uma hipótese é a de que a empresa focal neste caso não possui concorrentes, já que possui monopólio sobre a área de concessão para distribuição de energia, enquanto as empresas Nicho precisam concorrer com outros fornecedores de tecnologia, e encontrar um espaço no mercado para se posicionar com vantagem competitiva.

Observa-se que para ambos os tipos de empresa os mecanismos de coordenação e colaboração são os elementos do modelo conceitual com maior relevância medida em frequência de citação durante as entrevistas. Para as empresas de Nicho esta relevância é em média superior à das Plataforma, o que a princípio não é esperado, dado que o papel de orquestrador em geral é realizado pelas empresas Plataforma. Parte da explicação evidenciada pelas entrevistas é que uma empresa de Nicho por sua vez é Plataforma para outro subsistema dentro de redes inteligentes, havendo demanda por mecanismos de coordenação de ambos os lados do ecossistema. A Empresa F, por exemplo, subcontrata e compra tecnologia de diversas outras empresas, sendo líder de consórcios para atendimento a licitações das concessionárias de energia, devendo articular contratualmente tanto com estas empresas fornecedoras/complementares como também com a empresa Plataforma que é a compradora. Uma hipótese adicional para este fenômeno é a menor inferência da empresa Nicho em outros elementos do FFE, como seleção da ideia e definição do conceito do modelo de negócios, se comparado à Plataforma.

Observa-se importância relativa menor do mapeamento e análise do ecossistema para as empresas de Nicho. Isto era esperado porque durante as entrevistas ficou claro que a responsabilidade por articular com um grande número de stakeholders como a ANEEL, autoridades municipais e grupos de consumidores fica a cargo da Plataforma, como observado anteriormente.

Estes itens serão melhor detalhados nas subseções seguintes. 


\subsubsection{Fatores de influência}

A análise dos fatores de influência no FFE de IS a partir dos estudos de caso foi dividida em dois subtemas (posicionamento e mapeamento do ecossistema) e também diferenciados para as empresas Plataforma e Nicho.

Para as empresas Plataforma o ponto mais importante é o posicionamento como protagonista no processo de inovação e se responsabiliza pela orquestração dos demais atores. Para exercer este papel dois fatores se destacam: reputação/confiabilidade e garantia da qualidade. Estes posicionamentos são construídos por ações emblemáticas das empresas ao longo de vários anos que renderam reconhecimento do consumidor e entidades de classe do mercado, como pode se observar nos seguintes trechos:

“A [Empresa B] sempre teve uma veia de inovação muito grande, a [Empresa B] tem praticamente um registro de patente por mês, ela está sempre criando coisas novas, não só para operação do sistema elétrico, mas para o consumidor, como chuveiros, a [Empresa B] sempre procurou inovar, trabalhar o que tem implantado, sustentar a sua rede, seu sistema elétrico, mas pensar também no que pode ser melhorado não só de tecnologia de software e equipamentos, mas de processos também."

"O consumidor tem certa aceitação e envolvimento agradável neste tipo de iniciativa que a [Empresa B] coloca em função da credibilidade, de saber que estamos trabalhando em melhorias mesmo. A gente tem uma coisa boa na [Empresa B] que o consumidor da área de concessão... a [Empresa B] é um patrimônio para ele também, tudo o que é iniciativa da [Empresa B], na maioria esmagadora das vezes é vista com bons olhos, o consumidor se interessa para dar ouvidos, ele quer saber."

"A [Empresa A] foi a vencedora na categoria "Qualidade de Gestão" na premiação da Associação Brasileira dos Distribuidores de Energia Elétrica (Abradee). O prêmio reconhece as melhores distribuidoras de energia do país."

As empresas de Nicho procuram se posicionar como provedora das últimas tendências tecnológicas que atingiram maturidade comercial para implantação em larga escala. Ao contrário das empresas Plataforma, os Nichos reconhecem que são substituíveis e precisam garantir sua participação na Inovação Sistêmica por meio de constante contato com as empresas Plataforma, alta especialização/diferenciação tecnológica e garantindo base 
instalada significativa de sua tecnologia no mercado. O fato de Nicho ter passado pelo crivo de uma empresa Plataforma que é garantidora da qualidade no segmento é determinante para sua sobrevivência e expansão. Alguns trechos que corroboram com estas observações são:

“Olha, não falo essencial, mas acho que a [Empresa G] hoje está servindo de não vou falar modelo, mas de impulsionadora destas soluções de Smart Grid, é o que falei, tem pouquissimas pessoas fazendo, os maiores projetos de Smart Grid no Brasil, os principais acabam na [Empresa G]”.

"Ninguém é essencial, hoje no Brasil tudo é substituível com alternativas, mas diria que a gente [Empresa $\mathrm{H}$ ] é uma peça importante para nossos clientes, em termos de Brasil, em termos de tecnologia no que a gente faz, diria que nós somos os únicos que detemos este tipo de tecnologia, ter um rádio próprio, com stack próprio de rede, rede mesh, para este tipo de aplicação e temos mais de um milhão de residências telemedidas com nossos rádios."

Outra observação é a de que o Nicho está atento às regulamentações, porém possui poucas ações de influência para alteração das mesmas, as quais muitas vezes oferecem barreiras no FFE da IS.

Em relação ao mapemento de atores do ecossistema, todas as empresas Plataforma citaram ter realizado algum mapeamento e análise de stakeholders envolvidos desde a fase de FFE da IS. Os grupos de atores mais citados foram os consumidores, fornecedores, agências reguladoras, agências de fomento, universidades e autoridades dos locais de implantação do projeto. As práticas citadas para este mapeamento e análise foram:

- Pesquisa formal com stakeholders ("Naquela primeira pesquisa que fizemos na área em que implantamos os medidores inteligentes, como era algo muito novo, a gente não sabia qual a abordagem a adotar, se ia ser única para todos os consumidores, nesta pesquisa ficou bem claro que a gente tinha que definir abordagens diferentes para cada tipo de consumidor.").

- Identificação pela equipe do projeto de stakeholders internos e externos (“Quando utilizamos o mapeamento de stakeholders internos e externos ficou bem claro que lá tinha certos atores e stakeholders que nunca tinham participado de algo assim, tipo a empresa de saneamento, trazer para este mundo de redes inteligentes, escolas, setores da educação, houve certo ineditismo nisso aí, mas nada que 
causasse uma ruptura muito grande, porque o assunto Smart Grid de forma geral alguém já ouviu falar, em telejornal, programa de tecnologia, seminário, alguma coisa já foi mencionada, não houve ruptura muito grande nestes contatos também.").

- Reuniões presenciais com stakeholders ("Fomos apresentar o projeto ao regulador, à Secretaria de Energia do Estado, ao regulador, fomos apresentar para a prefeitura, ao PROCON, esses foram os públicos típicos, depois fizemos apresentações ao procurador, ao líder da $O A B$, esses caras foram mapeados como formadores de opinião, fizemos uma apresentação para o presidente da associação dos hotéis e ao presidente da associação dos comerciantes.")

- Participação em eventos setoriais (“O projeto tem sido apresentado frequentemente em Seminários, Congressos e Workshops.”).

Em termos de classificação dos atores neste mapeamento, destacam-se dois métodos utilizados. O primeiro método categoriza os atores por nível de proximidade e abrangência no ecossistema de Smart Grid, sendo que cada nível superior em abrangência influencia em todos os demais das camadas inferiores. Para exemplificar, o mapeamento do ecossistema da Empresa A categorizou os satores em equipe do Projeto estruturante, Execução e Gestão, Clientes e Fornecedores, Mercado e Sociedade e Comunidade, apresentado na Figura 10, e bastante coerente com a representação ilustrativa apresentada na Figura 7 (porém sem detalhar os fluxos de informações, capital, produtos e serviços). Desta forma se tem uma dimensão do efeito de uma ação/posicionamento de um dos atores sobre os demais participantes do ecossistema. 


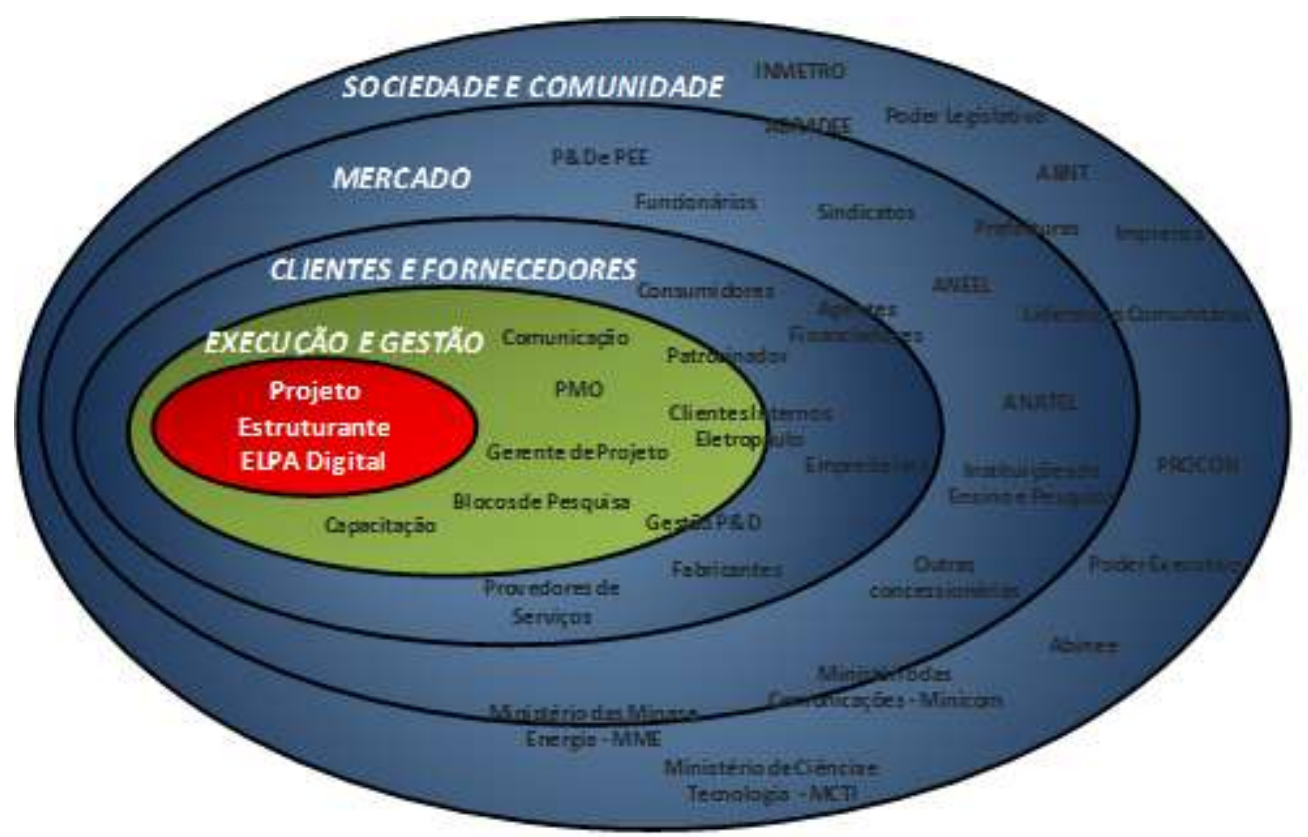

Figura 10 - Mapeamento de atores do ecossistema da Empresa A.

A outra técnica apresentada, específica para classificar o mercado consumidor, foi o desenvolvimento de personas, oriundo do processo de Design Centrado no Usuário, conceito amplo aplicado para descrever o processo de design em que os usuários finais são o componente principal para determinar o resultado final do projeto (ABRAS, MALONEYKRICHMAR, PREECE, 2004). Na abordagem da Empresa B, foi realizada uma pesquisa de campo inicial para identificação de características comuns que representassem os grupos de consumidores em relação a hábitos de consumo de energia, canais de comunicação preferenciais e relacionamento com tecnologia. Para cada arquétipo foi criada uma persona, ou seja, uma personagem fictícia que possui características típicas daquele grupo de pessoas. Cada persona possui nome, idade, hábitos, aparência física, permitindo tratar a concepção do projeto de inovação de forma mais humanizada e não somente mediante a análise "fria" de números. Segue o comentário do gestor do projeto de Smart Grid na Empresa B, a respeito da técnica:

"Não é o processo de segregar, mas tratar diferente quem é diferente, marketing, para esse nivel de abordagem, nesse processo de definir abordagens diferentes para cada classe nós definimos então as personas, você vai ver no material isso aí. Você vai que no material tem uma persona que é uma dona de casa em que se tem uma abordagem especifica, 
é uma pessoa que usa interruptor o dia inteiro em casa, processo de produzir alimentação a base de gás, não elétrico, a energia elétrica conhece se acende ou não quando precisa a lâmpada, ferro esquentou ou não, TV funcionando ou não, a abordagem é diferente para um público mais jovem por exemplo, então definimos personas, desde donas de casa, agentes comerciais, pessoas que lidam com comércio, produtor rural, criança, adolescente e esse povo jovem que está o tempo todo conectado, que tem a tecnologia como algo comum do dia a dia. Fizemos uma abordagem especifica para cada persona para o projeto."

Além da fotografia dos atores, as empresas Plataforma preocupam-se em antecipar as tendências de cada grupo de atores que influenciam o projeto de Inovação Sistema desde a fase de FFE, principalmente relacionadas ao ambiente regulatório, como mostra o seguinte trecho da entrevista: "Dar um exemplo, a ANEEL está sinalizando que ela pode reconhecer na tarifa alguns investimentos que ela não reconheceria, vinculados a redes inteligentes, está em consulta pública, este fato agora desmembrando e podendo ser aplicado, tornando-se realidade, muda completamente a diretriz, pode acelerar ou não."

As empresas Plataforma também frisam a necessidade do desenvolvimento de um ecossistema de negócios para viabilizar a Inovação Sistêmica em larga escala:

- “A gente brinca que Smart Grid é um ecossistema, é muita coisa para você mexer (...) Isso tudo vai desenvolver uma cadeia produtiva, se a gente não trabalhar os pilares, estes vetores, a gente vai ser dificultado na implantação de Smart Grid no Brasil, isso seria pavimentar estrada para que consiga implementar, tudo isso foi identificado porque pusemos a mão na massa."

- “A própria questão de não termos fornecedores nacionais também acaba em alguns segmentos atrapalhando bastante, vinculadas até a questões financeiras, o dólar por exemplo, nosso cálculo de viabilidade já em alguns segmentos começa a pesar e outra questão é a qualidade do prestador de serviço e da força de trabalho que teria para atuar nestas redes, é algo que percebemos que aplicação em larga escala gera um risco, porque quando tem uma equipe própria você consegue treinar exatamente com uma aplicação localizada tem uma solução, agora aplicação em larga escala precisa de apoio fora." 
Outro fator fundamental para o sucesso do FFE de todas as IS estudadas foi o incentivo público ao desenvolvimento de inovação. Todas as cinco empresas Plataforma realizaram projetos de Pesquisa e Desenvolvimento do Programa da ANEEL, órgão regulador do setor que exige que as empresas invistam pelo menos $1 \%$ de sua receita operacional líquida em projetos do gênero. Além disso, a Empresa A obteve financiamento da FINEP - Fundo de Financiamento de Estudos de Projetos e Programas e a Empresa B obteve financiamento do Fundo de Amparo à Pesquisa de seu respectivo estado. Todos os casos também tiveram algum envolvimento de universidades públicas nesta fase inicial.

Pouco investimento formal de mapeamento de stakeholders foi efetuado pelas empresas de Nicho no FFE da IS. O maior destaque nas entrevistas foi o acompanhamento constante do ambiente regulatório, porém sem exercer grande influência sobre o mesmo (“Participamos de todos eles, comitês, reuniões, reuniões do Inmetro, Abinee, Abrade, ABNT, participamos de todos eles, mas nossa influência se restringe a isso, a gente participa da reunião, mas não fazemos nenhum mecanismo paralelo.”). As empresas de Nicho também se beneficiam dos incentivos públicos para inovação, pois as mesmas são contratadas pelas empresas Plataforma na execução dos projetos de P\&D.

Como conclusão sobre este aspecto do modelo conceitual, observou-se portanto suporte empírico para a hipótese do mapeamento e posicionamento da empresa focal no ecossistema, principalmente no caso da Empresa Plataforma. As Empresas Nicho tendem a uma postura mais passiva de apenas observar tendências, não havendo em nenhum dos casos se posicionado como a líder do projeto de IS. Observou-se porém que uma empresa pode ser Nicho em relação a alguns atores no ecossistema e Plataforma em relação a um subsistema.

\subsubsection{Motor - Mecanismos de coordenação}

No FFE de IS foram utilizados diversos mecanismos de coordenação, de acordo com cada ator envolvido. Entre empresas Plataforma e Nicho em todos os casos as empresas Plataforma convidaram representantes das empresas Nicho para reuniões de apresentação das necessidades da concessionária (demandas). As empresas Nicho então elaboraram soluções para estas necessidades, em geral trazendo para conhecimento das concessionárias as novas evoluções tecnológicas no Brasil e no mundo no estado da arte para atender a demanda. Em um dos casos, a empresa Plataforma nesta reunião solicitou diretamente uma dada solução pré 
determinada, porém ao longo das discussões percebeu-se que havia soluções melhores para atender à necessidade. Em outro caso a empresa Nicho ofereceu uma solução tecnológica que não atendia à demanda previamente explicitada, mas permitia atender a outras demandas correlatas. Iniciar pela identificação e exploração da necessidade e não pela tecnologia mostrou-se ser mais eficiente, segundo todos os casos tratados.

Outro mecanismo para alinhamento de demandas e ofertas amplamente utilizado foram os eventos setoriais, principalmente comitês organizados por entidades de classe (por exemplo a Associação Brasileira de Distribuidores de Energia Elétrica - ABRADEE) e por agentes reguladores do setor. A importância da troca de conhecimentos entre empresas Plataforma e entre Plataforma e Nichos foi citada por quatro das sete empresas entrevistadas. Segue comentário da Empresa B a respeito desta troca de conhecimentos:

“Centros de pesquisa, como o nosso parceiro principal, trazem muita informação do mercado. Nosso dia a dia não é olhar para o mercado, é gerar, transmitir e distribuir energia e manter o consumidor satisfeito com isso, manter os indicadores da ANEEL por exemplo, essas empresas trazem pra gente o mercado, o que está acontecendo, quais os direcionamentos, iniciativas, isso é importante pra gente, é o fator que você não pode ser uma ilha, tem que estar conectado a tudo isso."

Em um dos casos (Empresa C), houve uma iniciativa pública do Governo do Estado para ativamente articular os diferentes atores do ecossistema de energia elétrica, tanto para promover energias renováveis quanto avançar na implantação de Redes Inteligentes (Smart Grid). Em dois dos casos (Empresas C e D) foram montados show rooms, ou salas de demonstração de soluções providas pelo mercado, como uma forma de dar visibilidade e assim incentivar as empresas Nicho a fazer investimento em inovações complementares ao projeto de IS de Smart Grid.

Em todos os casos nestes encontros iniciais entre Plataforma e Nichos durante o FFE foram identificadas diversas incertezas, já que o ambiente regulatório e cenário da infraestrutura de energia elétrica e telecomunicações no Brasil impuseram diversas restrições para a solução tecnológica, o que exigiu estudo aprofundado e posteriormente provas de conceito. Para reduzir as incertezas, também em 100\% dos casos estudados houve um contrato entre as Plataformas e os Nichos para execução da etapa de Pesquisa e 
Desenvolvimento incentivada pela Agência Nacional de Energia Elétrica (ANEEL). Segue uma descrição do site da ANEEL a respeito deste incentivo:

"Com vistas a incentivar a busca constante por inovações e fazer frente aos desafios tecnológicos do setor elétrico, foi regulamentado o Programa de Pesquisa e Desenvolvimento $-P \& D$ do segmento.

Neste contexto, as empresas concessionárias, permissionárias ou autorizadas de distribuição, transmissão e geração de energia elétrica devem aplicar anualmente um percentual mínimo de sua receita operacional líquida no Programa de Pesquisa e Desenvolvimento do Setor de Energia Elétrica.

Estão isentos da obrigatoriedade de investir em $P \& D$ aqueles que geram exclusivamente a partir de pequenas centrais hidrelétricas (PCHs), biomassa, cogeração qualificada, usinas eólicas ou solares.

A obrigatoriedade na aplicação desses recursos está prevista em lei e nos contratos de concessão, cabendo à Agência regulamentar o investimento no programa, acompanhar a execução dos projetos e avaliar seus resultados.

A ANEEL estabelece as diretrizes e orientações que regulamentam a elaboração de projetos de P\&D por meio do Manual de Programa de Pesquisa e Desenvolvimento do Setor de Energia Elétrica.

Diferentemente da pesquisa acadêmica pura, que se caracteriza pela liberdade de investigação, os programas de $P \& D$ no setor de energia elétrica deverão ter metas e resultados bem definidos."

Dada a presença deste programa no FFE de todos os cinco casos estudados, o programa mostrou-se fundamental para sucesso da etapa. Para execução dos projetos de P\&D foram elaborados Termos de Outorga vinculando a Plataforma e um centro de excelência (tipicamente institutos de pesquisa ou universidades, porém em um dos casos foi a própria empresa Nicho), detalhando-se o escopo de investigação com base nas articulações de demanda-oferta previamente realizadas. Neste termo permite-se subcontratar as empresas Nicho para fornecer o escopo de desenvolvimento tecnológico e fabricação piloto, em uma relação bastante simbiótica, com cada ator contribuindo com seu recurso (financeiro ou 
expertise) para desenvolvimento do conceito da inovação, sem que nenhum deles pudesse conceituá-la isoladamente.

O escopo dos projetos de P\&D propostos nos casos estudados envolveram etapa de estudos e benchmarking internacional, pesquisa de campo (tanto pesquisas com consumidores quanto estudos para definição/caracterização da localidade de implantação piloto), desenvolvimento de protótipo, homologação, implantação piloto, registro dos aprendizados e planejamento de roadmap para roll out da tecnologia em maior escala.

Como citado anteriormente, como marco do término do FFE, as empresas Plataforma formalizam um Request For Proposal (RFP), ou requisição de propostas em que o conceito das inovações foi consolidado e apresentado para o mercado. Associada à RFP foram elaborados padrões e processos de homologação/certificação de produtos para atender especificamente à rede das empresas Plataforma (adicionais aos processos de homologação exigidos pelas agências regulatórias governamentais, como o Inmetro). Desta forma as empresas Plataforma puderam direcionar os investimentos em P\&D e Inovação das empresas de Nicho, garantindo-se que vários fornecedores tivessem produtos compatíveis para o roll out da Inovação Sistêmica.

Uma empresa Nicho que não foi entrevistada, mas que foi citada pelas empresas B, C, D e G, atuou como plataforma para diversas outras empresas de Nicho do ecossistema de Smart Grid, estabelecendo um processo de homologação formal de fornecedores de equipamentos complementares à sua solução tecnológica, garantindo compatibilidade. As empresas F e H também tiveram relação semelhante entre si, sendo a empresa F Plataforma a empresa $\mathrm{H}$, de Nicho, para desenvolvimento de um subcomponente chave compatível. Neste último caso, no entanto, não foi elaborado um processo de homologação forma aberto para todas as empresas do mercado, caracterizando uma relação de muito maior interdependência e riscos compartilhados entre F e H. Por este motivo, uma das principais preocupações de ambas as empresas foi a assinatura de acordos de propriedade intelectual logo no início do FFE, estipulando até onde iria o domínio de cada uma das partes e posteriormente o valor de royalties.

Nos casos das empresas A, C, D, F, G e $\mathrm{H}$ foram realizados investimentos coordenados na redução de incertezas do FFE entre Plataforma e Nicho, antes de haver um contrato que vinculasse formalmente ambas as partes, puramente baseado em relacionamento 
entre as empresas, com perspectivas de risco e retorno compartilhados futuros, sem garantia estabelecida em contrato de que haveria um pedido de compra em um determinado prazo da empresa Plataforma para a empresa Nicho, e nem garantia de que a empresa Nicho seria capaz de fornecer o produto com a inovação tecnológica homologado. Nestes casos as relações de parceria foram construídas ao longo de mais de 5 anos entre as empresas envolvidas, com papel fundamental do relacionamento interpessoal de confiança entre os profissionais envolvidos.

Outro fator que favorece o investimento conjunto sem garantias é a complexidade do sistema elétrico brasileiro, tanto em termos regulatórios como de infraestrutura, o que impõe sérias barreiras de entrada para novas empresas Nicho e oferece larga vantagem às empresas que desenvolvem conhecimento junto às concessionárias de energia desde o FFE da inovação. Todas as empresas Nicho citaram que em termos tecnológicos não são insubstituíveis, porém por terem largado na frente e terem as primeiras bases instaladas operando, tornam-se extremamente valiosas neste ecossistema cujo mercado atendido é gigantesco. Para se ter uma dimensão deste valor, a Empresa $\mathrm{H}$ possui hoje faturamento anual de $\mathrm{R} \$ 20$ milhões aproximadamente, com cerca de 10 funcionários, ou seja, uma média de R\$ 2 milhões de faturamento por funcionário (sendo que a empresa brasileira fatura, em média, R\$ 3.294,00 por trabalhador, segundo a consultoria Faccin, 2015).

A coordenação entre empresas Plataforma de ecossistemas de negócios distintos que se intersecionam na IS apresentou certas diferenciações e desafios adicionais em relação à coordenação entre uma empresa Plataforma e uma Nicho, provavelmente porque neste último caso a relação de poder ou influência era mais clara, e o benefício para cada lado era balanceado.

Um exemplo de coordenação entre Plataformas foi a coordenação entre a empresa D, Plataforma do setor de energia (distribuidora de energia elétrica) e a empresa Plataforma do setor de telecomunicações (operadora de telefonia), ambas fundamentais para o sucesso de um projeto de Redes Inteligentes. Esta relação foi particularmente desbalanceada, pois a criticidade de telecomunicações para o projeto de Smart Grid era muito maior do que a criticidade do projeto de Smart Grid como um cliente para a empresa de telecomunicações, já que o mesmo se caracteriza por baixo volume de dados trafegados, pelo menos durante as 
etapas iniciais da inovação. O gestor da empresa $D$ apresentou a seguinte visão sobre este desequilíbrio:

“As operadoras não gostam deste tipo de projeto, quer dizer, eles gostam caso consigam vender mais serviços de dados, e naquela altura, talvez por sermos um dos primeiros, as operadoras não estavam preparadas para este tema, não havia whatsapp por exemplo, e estamos falando de três anos atrás, o tema de dados não era tão... estava começando, e como estavam crescendo tanto no $B 2 C$, que no $B 2 B$ estavam em outra, no $B 2 B$ tipicamente é um cliente de dados caro, não é como o cliente de chip."

Tentativas de estabelecer uma rede de telecomunicações mais robusta para atender aos requisitos do projeto de Redes Inteligentes da empresa B também foram frustradas, pela dificuldade de se chegar a um denominador comum de qualidade do serviço e receita para as operadoras de telefonia:

“Já conversei muito com gestores das operadoras, até parceria propuseram mas não conseguimos implementar algo que se tornasse robusto, na confiabilidade que a gente precisa."

A solução dada pela empresa $\mathrm{D}$ foi a de integrar verticalmente este subsistema de telecomunicações dentro do seu escopo de investimento. Criou-se então uma rede de telecomunicações paralela, local e proprietária da empresa $\mathrm{D}$, sobre a qual ela poderia ter confiabilidade e preferência na transmissão de pacotes. Já a empresa B adquiriu uma empresa de Telecom e Tecnologia da Informação.

No caso da empresa C, esta coordenação foi facilitada porque tanto a Plataforma de energia quanto a de telecomunicações faziam parte de um mesmo grupo de empresas, com parte do controle estatal:

"A questão da empresa $C$ ter telecomunicações e ter fibra ótica chegando nas residências de poder ter esse modelo de integração com serviços de telecomunicações de terceiros também é um diferencial importante do projeto. (...) a empresa C telecomunicações, que é parte do grupo da empresa C, fornece serviços de banda larga para os consumidores, inclusive internet de alta velocidade usando a infraestrutura que um dia foi montada para consumo próprio da empresa $C$ em termo de comunicações, automação de subestações, 
automação de usinas, que disseminou de uma certa forma hoje que tem 399 municípios no estado com backbone por fibra ótica."

Situação similar é encontrada na questão de multiutilities (utilização da mesma infraestrutura de Redes Inteligentes para tráfego de dados de energia, água, gás, ou outros). Os casos das empresas B e C, que são empresas públicas, apresentam as iniciativas mais robustas nesta área, pois o poder público detém controle sobre todas as empresas de utilidades envolvidas, pois o risco e retorno apesar de desbalanceado em cada uma das partes, no todo geram um resultado positivo. Tipicamente as empresas de distribuição de energia fazem a maior parte do investimento em inovação, porém os benefícios poderão ser capturados por todas as partes no futuro. $\mathrm{Na}$ empresa $\mathrm{C}$, foram estabelecidos termos de cooperação entre as empresas de utilidades envolvidas, cada uma comprometendo-se a investir no que lhe cabe no projeto e compartilhar todo o conhecimento e resultados gerados pela inovação como contrapartida, como descrito no seguinte comentário do coordenador do projeto:

“Conseguimos configurar um grupo do Smart Grid que não é só empresa C, faz parte a empresa de água, a empresa de gás, ambas tem participação financeira da empresa $C$ acionista e participação de dois institutos, um de tecnologia do estado e outro vinculado mais a pesquisas e desenvolvimentos na área de energia elétrica. Investimentos são suportados pelos planos de orçamento de cada empresa, os mais pesados são da empresa $C$, basicamente define a liberação deste grupo técnico para trabalhar em conjunto sem apropriação de recursos da engenharia, de serviços, a título de fundo perdido pro grupo e define-se o compartilhamento dos resultados e abertura de todas as soluções técnicas para que sejam avaliadas em conjunto e sejam apropriadas para aplicações futuras."

Enquanto as empresas Nicho mantém uma relação com as agências regulatórias de acompanhamento e pouca influência direta, as empresas Plataforma são mais ativas na coordenação com o regulador. Além de acompanhar e acatar às determinações do regulador, a Plataforma foi capaz de influenciá-las, principalmente nas fases iniciais da inovação sistêmica. Segundo os entrevistados, o regulador depende que as empresas Plataforma tomem riscos e experimentem inovações em que as regras não estejam estabelecidas, para que seja gerado o conhecimento necessário para sua determinação. Todas as empresas plataforma citaram em algum momento a importância da troca de conhecimentos entre a empresa e o regulador: 
"Está em teste em escala pequena, mas do ponto de vista estratégico, direciona, a própria ANEEL acompanha isso, quais os pontos que devem ser alterados na resolução, nas próprias regras regulatórias para que consiga tanto o consumidor ter benefício, a concessionária e todos os clientes que não tem microgeração para que possam se apropriar dos ganhos que são redução de perdas, melhoria do nível de tensão, melhoria da qualidade de energia, com a geração distribuida sendo controlada pela concessionária.” (Empresa C).

"Estivemos envolvidos desde o início, nos grupos de trabalho [da ANEEL], na discussão de normas etc (...) perguntaram muita coisa sobre o que fizemos, o que ocorreu bem, o que ocorreu mal, pegaram as empresas que estavam fazendo pilotos e pegaram informações para depois criarem um programa, foi mais assim." (Empresa D).

"No início do projeto foram realizadas apresentações do projeto à agência reguladora (ANEEL), já que o projeto está no programa de P\&D da ANEEL." (Empresa A).

“Eles [grupos de trabalho da ANEEL] tem seus trabalhos, nós temos os nossos e vamos trocando informações, lições aprendidas, isso é muito interessante, senão começa, nessa atividade é comum ficar numa ilha desenvolvendo um teorema qualquer matemático e o outro resolvendo o mesmo teorema e nunca se falou, a gente tenta evitar isso, compartilhar conhecimento. (...) Então é um documento da ANEEL, do setor elétrico, a gente espera que ocorra esta influência, de que haja alguma luz que possa iluminar este projeto, este documento, que torne algo que venha a sustentar alguma defesa de incentivo, alguma atualização nas regulamentações existentes ou regulamentações novas, isso é algo que a gente realmente espera que aconteça, que absorvam todos os projetos e que de lá saia um rascunho ou audiência pública de incentivo, norteamento do setor no Brasil.” (Empresa B).

“ANEEL fizemos apresentação mais do ponto de vista de resultado do que de inovação, claro que gostaram da parte de inovação, tem toda uma plataforma que vai possibilitar outras empresas do Brasil terem proveito disso.” (Empresa E).

O Quadro 19 apresenta um resumo dos mecanismos de coordenação utilizados por cada empresa estudada, contendo uma descrição do mecanismo, sua classificação em transacional e relacional e em quais casos ele esteve presente. Nota-se que há um equilíbrio entre mecanismos transacionais e relacionais para o FFE de IS. 
Observou-se que no caso da Empresa $\mathrm{C}$ foi o único em que todos os mecanismos de coordenação e colaboração levantados foram aplicados. Este fenômeno pode ser explicado pelo fato de que o estado em que esta empresa tem concessão foi o único dentre os casos estudados a ter um Programa Smart Grid lançado pelo governo estadual, além de ser o mesmo estado das Empresas F e H, empresas de Nicho pioneiras em Smart Grid no Brasil. Outro fator é que este é um dos dois casos em que a medição de multiutilidades (água, gás), integra o projeto de inovação, havendo necessidade de termo de cooperação entre as empresas.

Todas as empresas usufruiram de $\mathrm{P} \& \mathrm{D}$ conjunto, muito incentivadas pela regulamentação da ANEEL que determina que um percentual da receita operacional líquida da operadora seja investido para este fim. Subcontratação é a forma mais tradicional de relação entre as partes, acompanhada de eventos setoriais e reuniões/apresentações presenciais. A padronização e homologação de fornecedores também é uma prática tradicional entre as Empresas Plataforma, tendo sido aplicada por exemplo para normalizar e garantir a qualidade de relés automáticos nas subestações elétricas no passado. Porém, mais interessante é observar mecanismos de coordenação e colaboração novos que tiveram que ser criados em decorrência do FFE de IS, tais como termos de cooperação, investimentos coordenados, acordos de propriedade intelectual e showroom para equalizar a distribuição de riscos e retornos. Por exemplo, há um termo de cooperação da Empresa C com empresas de distribuição de água e gás para a mesma região, em que de um lado a Empresa $\mathrm{C}$ investe nos ativos de infraestrutura comum, enquanto as demais investem com recursos humanos e acesso a todas as informações de suas redes de distribuição (que são bastante capilares e podem fornecer o meio para a infraestrutura de telecomunicações cabeada da Rede Inteligente).

Quadro 19 - Mecanismos de coordenação aplicados nos casos estudados.

\begin{tabular}{|c|c|c|c|c|c|c|c|c|c|c|c|}
\hline & & \multicolumn{5}{|c|}{ Plataforma } & \multicolumn{3}{|c|}{ Nicho } & & \\
\hline Mecanismo & Classificação & $\mathbf{A}$ & $\mathbf{B}$ & $\mathbf{C}$ & $\mathbf{D}$ & $\mathbf{E}$ & $\mathbf{F}$ & $\mathbf{G}$ & $\mathbf{H}$ & Total & $\%$ \\
\hline P\&D conjunto & Transacional & $\mathrm{X}$ & $\mathrm{X}$ & $\mathrm{X}$ & $\mathrm{X}$ & $\mathrm{X}$ & $\mathrm{X}$ & $\mathrm{X}$ & $\mathrm{X}$ & 8 & $16 \%$ \\
\hline Termo de cooperação & Transacional & & $\mathrm{X}$ & $\mathrm{X}$ & & & & & & 2 & $4 \%$ \\
\hline Subcontratação & Transacional & $\mathrm{X}$ & $\mathrm{X}$ & $\mathrm{X}$ & $\mathrm{X}$ & $\mathrm{X}$ & $\mathrm{X}$ & $\mathrm{X}$ & $\mathrm{X}$ & 8 & $16 \%$ \\
\hline Padronização/Homologação & Transacional & $\mathrm{X}$ & $\mathrm{X}$ & $\mathrm{X}$ & $\mathrm{X}$ & $\mathrm{X}$ & & & & 5 & $10 \%$ \\
\hline $\begin{array}{l}\text { Propriedade intelectual no } \\
\text { FFE }\end{array}$ & Transacional & & & $\mathrm{X}$ & & & $\mathrm{X}$ & & $X$ & 3 & $6 \%$ \\
\hline Investimentos coordenados & Relacional & $\mathrm{X}$ & & $\mathrm{X}$ & $\mathrm{X}$ & & $\mathrm{X}$ & $\mathrm{X}$ & $\mathrm{X}$ & 6 & $12 \%$ \\
\hline Showroom & Relacional & $\mathrm{X}$ & & $\mathrm{X}$ & & & & & & 2 & $4 \%$ \\
\hline Eventos setoriais & Relacional & $\mathrm{X}$ & $\mathrm{X}$ & $\mathrm{X}$ & $\mathrm{X}$ & $\mathrm{X}$ & $\mathrm{X}$ & $\mathrm{X}$ & $\mathrm{X}$ & 8 & $16 \%$ \\
\hline
\end{tabular}




\begin{tabular}{|l|l|r|r|r|r|r|r|r|r|r|r|} 
Reuniões e apresentações & Relacional & $X$ & $X$ & $X$ & $X$ & $X$ & $X$ & $X$ & $X$ & 8 & $16 \%$ \\
\hline Programa do Governo & Relacional & & & $X$ & & & & & & 1 & $2 \%$ \\
\hline & Total & 7 & 6 & 10 & 6 & 5 & 6 & 5 & 6 & 51 & \\
\cline { 2 - 12 } & $\%$ & $14 \%$ & $12 \%$ & $20 \%$ & $12 \%$ & $10 \%$ & $12 \%$ & $10 \%$ & $12 \%$ & $100 \%$ \\
\hline
\end{tabular}

\subsubsection{Identificação da Oportunidade}

Ao contrário do caso exploratório piloto que já nasceu sob uma perspectiva sistêmica, observou-se que nos casos estudados de Redes Inteligentes a IS foi consequência de inovações autônomas que nasceram de forma independente para resolver problemas específicos e cujas sinergias foram identificadas a posteriori, dando início efetivamente ao FFE da IS.

Um problema crônico no Brasil, segundo a empresa D é a perda comercial de energia elétrica (furto de energia). Para resolver este problema as empresas começaram a investir formentemente em meados dos anos 2000 no desenvolvimento de medidores eletrônicos para fiscalização do consumo de energia elétrica não apenas dos consumidores de média e alta tensão, como também consumidores de baixa tensão. As empresas de Nicho começaram desenvolvendo soluções também muito específicas para resolver estes problemas. A empresa de Nicho F, por exemplo, desenvolveu para diversas concessionárias de energia soluções totalmente direcionadas para combate a perdas, com comunicação por radiofrequência e corte/religa remoto. As declarações da empresa de Nicho $\mathrm{H}$ e da empresa Plataforma $\mathrm{E}$ deixam bem claro que a inovação não nasceu como sistêmica:

“Quando a gente começou o termo Smart Grid nem existia, este termo é relativamente novo, não se falava nisso, o conceito de telemedição era bastante rudimentar, não se falava muito em redes mesh por exemplo, coisas que hoje são comuns há oito anos eram novidades absolutas. Então o que aconteceu foi mais uma oportunidade de negócio que apareceu do que um projeto estabelecido do tipo "vamos entrar na área de smart grid", foi uma oportunidade de ambas as partes, a empresa $F$ entrou nesta área para fazer combate a furto de energia, na realidade o produto principal se aplica para combate a furto de energia e um efeito secundário disso é formar o Smart Metering e o Smart Grid." (Empresa H).

"Tinha uma parte de $P \& D$ que foi bastante forte, formou engenheiros, técnicos, começou por aí, quase que em seguida 2009/10 a empresa E forçada pela necessidade de monitorar fraudes em grandes clientes, comércios, e tal começou a fazer a medição 
inteligente com GPRS, mas de uma forma sem visão global, sem business case, fazendo de forma muito pontual, esta área é complicada, vamos fazer aqui, este medidor tem alarmes, firmware, bem fragmentado. Em paralelo o pessoal de automação, não sei se se lembra o problema de explodir câmara de gases inflamáveis, viu-se que não era gás da empresa E, mas era vazamento de gás subterrâneo e qualquer coisa explodia a câmara. A empresa E foi envolvida neste episódio e começou a automatizar câmaras subterrâneas, sem uma equipe falar com a outra, a empresa E hoje já tem 1700 câmaras já automatizadas, são fabricantes diferentes, com protocolos diferentes, como se fossem ilhas independentes. A diretoria percebendo isso me chamou para fazer um plano para integrar isso tudo, verificar se é atrativo, se tem retorno para conseguir financiamento, foi assim que foi feito business case, que mostrava que dava retorno, em que foi proposto juntar a medição inteligente $e$ automação na mesma solução.” (Empresa E).

Além da inovação sistêmica derivada da combinação entre inovações autônomas realizadas em paralelo, também houve a identificação de oportunidades para ampliação da inovação autônoma com a adição de novas vertentes de negócios que seriam possíveis aproveitando-se os mesmos ativos tangíveis, porém adicionando-se diferentes camadas de inteligência e serviço:

"Foi para fazer não um projeto só de medição, decidimos fazer um projeto mais elevado e que passava por mais ou menos cinco vertentes. Que tivesse a medição inteligente obviamente, depois a mobilidade elétrica, geração distribuída, eficiência energética e depois toda a parte de gestão do consumo e desenvolvimento da comunidade para explicar o que estava acontecendo na cidade. E tudo isso com uma rede de telecomunicações por cima que queríamos utilizar para outras coisas, para automação, no caso, para iluminação pública, para fazer uma parte, nós não estávamos fazendo mas estava no roadmap, telemedição de água, então a ideia era fazer uma rede de telecomunicações que depois a gente pudesse explorar com outros serviços." (Empresa D).

A Empresa A, como será detalhado na sessão seguinte, fez a identificação e análise de oportunidades de forma multidisciplinar, porém dentro da sua própria organização.

As cinco empresas Plataforma entrevistadas declararam que em um primeiro momento a identificação e análise da oportunidade de inovação ocorreu internamente, como uma iniciativa própria e isolada, sem envolvimento de outras empresas. Segundo a empresa $G$, as 
empresas Plataforma tiveram uma abordagem de conceber internamente a inovação e buscou uma solução do Nicho com requisitos já definidos. Ainda segundo a empresa G, as empresas de Nicho preocupam-se em manter contato constante com as empresas Plataforma para precocemente ter conhecimento de oportunidades identificadas por elas e apresentar soluções ou novas tecnologias adequadas para atendê-las.

Nota-se que entre a inovação autônoma e a inovação sistêmica passaram-se pelo menos cinco anos. Uma hipótese a ser investigada no futuro é se a identificação da oportunidade for realizada de forma cooperativa entre as empresas envolvidas já com uma mentalidade de inovação sistêmica trazem maiores benefícios e/ou aceleram o processo de inovação, ou se a realização ágil de inovações autônomas localizadas, independentes com rápida demonstração de benefícios e que depois são integradas a inovações sistêmicas dentro de um programa maior é uma abordagem mais efetiva para concretização da inovação. $O$ fato é que nos casos estudados a segunda abordagem foi a preferida.

\subsubsection{Análise da Oportunidade}

Poucos trechos foram caracterizados como análise de oportunidade nas entrevistas. Como notou-se na identificação de oportunidades, inicialmente foram analisados potenciais de ganho das inovações autônomas e anos depois foram analisadas possibilidades de sinergia entre inovações em um projeto sistêmico de redes inteligentes, em que uma série de serviços poderiam ser prestados sobre uma mesma rede de telecomunicações e ativos eletrônicos sobre o sistema de distribuição de energia.

A partir desta identificação de sinergias, ficou claro principalmente nas entrevistas com as concessionárias $\mathrm{B}, \mathrm{C}, \mathrm{D}$ e E que houve uma extensiva análise dos potenciais de ganho com a implantação de redes inteligentes, em especial em termos de redução de perdas comerciais não técnicas (furto de energia) e aumento de eficiência operacional em um primeiro plano, gestão de energia do lado da demanda, multiutilities, geração distribuída e veículos elétricos em um segundo plano. Os projetos de $\mathrm{P} \& \mathrm{D}$ em cooperação entre empresas Plataforma e Nicho foi considerada fundamental para criação de conhecimento para embasar estas análises da oportunidade.

A Empresa A declarou que "diversas áreas da empresa se reuniram e discutiram com profundidade os possíveis beneficios. Após as discussões e profundos estudos foram adotadas 
premissas para a elaboração de um business case, o qual serviu para nortear o desenvolvimento do projeto".

A empresa Nicho H não executou atividades específicas de análise de oportunidade. A empresa $\mathrm{H}$ foi originada de professores de ensino superior e a tecnologia foi desenvolvida dentro da universidade, ou seja, a princípio sem um objetivo de negócios claro. Quando a também empresa de Nicho F interessou-se pela tecnologia com o objetivo de posicionar-se no mercado de Redes Inteligentes, os desenvolvedores da tecnologia foram apresentados ao caso de negócios e decidiram montar uma empresa para comercialização da tecnologia. A empresa de Nicho G, assim como a F, é uma empresa de mercado que já atuava em outros segmentos ou com outros tipos de produtos para o setor elétrico e planejou estrategicamente sua entrada em Smart Grid avaliando o tamanho da oportunidade de negócios para decisão de investimento. Esta avaliação de oportunidade foi realizada com ferramentas tradicionais de negócios, como tamanho de mercado e retorno sobre investimento, similar a inovações autônomas.

\subsubsection{Geração da Ideia}

Um padrão identificado em três dos cinco projetos de IS foi que após um período de coleta e análise de informações internas e externas (em que as empresas de Nicho foram importantes como fornecedoras de subsídios), as empresas Plataforma ficaram responsáveis pela consolidação deste conhecimento em um escopo de projeto mais concreto, incluindo os requisitos funcionais da solução a ser desenvolvida. Apenas após este processo, outros atores são selecionados para participação no projeto, com uma vinculação contratual. Isto pode ser percebido nos seguintes trechos:

"Pergunta: e na etapa de concepção, quando a oportunidade foi identificada e o piloto começou a ser planejado, as outras partes estavam envolvidas?

Resposta: não, no planejamento do projeto e seleção do local para o piloto, até o final de 2012, a participação era só interna da Empresa C. ” [Empresa C]

"A gente inicia internamente o trabalho e depois vê qual centro de excelência deve ser envolvido, mas tem nuances diferentes entre eles, a princípio não sabe qual o melhor para o projeto, depois é mapeado qual será interpelado convidado contratado no projeto como parceria." [Empresa B]. 
"Pergunta: como o projeto foi concebido? Mais na parte de elaboração do escopo, o que vai ter no projeto, foi feito o planejamento interno e depois envolveram parceiros, ou por exemplo a empresa G também participou desse planejamento?

Resposta: não, essa parte foi toda nossa. O que nós quisemos fazer com o projeto, queríamos testar medição inteligente, esse era o primeiro objetivo. $O$ segundo era testar algumas tecnologias que estávamos na dúvida se iam vingar ou não, iluminação pública com led, geração distribuida e mobilidade elétrica, então sentimos que estes três tínhamos que adicionar lá, depois portamos tudo em um projeto único e foi. Basicamente porque queríamos testar 4 coisas, medição inteligente, iluminação pública com LED, mobilidade elétrica e geração distribuída." [Empresa D].

A Empresa B indicou uma possível explicação para este padrão: para execução da inovação sistêmica foi importante não começar pela tecnologia (que são a especialidade das empresas de Nicho), mas sim pelo entendimento de como os novos processos de negócios devem ser configurados, como pode-se perceber nos trechos abaixo:

“Começar a inovação pela tecnologia é geralmente um erro, tem que entender o que você quer e ver qual a tecnologia adequada e buscá-la. Se começar pela tecnologia você pode criar limitadores sobre os quais você não pode ter controle, isso é comum no mundo corporativo. Vou dar um exemplo inverso, as áreas de negócio recebem informações de um determinado produto, um software por exemplo que vai melhorar o desempenho de uma área de negócios, ele compra, chega para a TI da empresa e pede para instalar, então você tem padrões tecnológicos, ferramentas de desenvolvimento, vários fatores que não são considerados, não adianta a partir da tecnologia implementar o negócio, tem que saber o que você quer implementar." [Empresa B].

Após esta consolidação inicial do que se quer implementar, o refinamento da ideia também conta com a colaboração dos demais atores, como pode-se perceber nas entrevistas com as Empresas de Nicho:

“Eles [concessionárias] fazem uma especificação técnica, daí jogam no mercado. A gente pega uma especificação, monta uma proposta técnica em cima da especificação. Depois tem o work statement, o início do projeto e depois são discutidas algumas possíveis 
alterações no escopo, ao invés de fazer assim, vamos fazer de outro jeito, vai para a mesa de reunião e se for acordado tudo bem." [Empresa G].

"Vai lá apresentar a solução, se não tiver a solução a gente vai bolar alguma. Este é um processo contínuo, estamos sempre nos clientes, semanalmente construindo. Foi uma combinação das duas instituições, a empresa E entra com o que ela precisa e a gente entra com o que tem para cobrir a necessidade. É um trabalho complementar." [Empresa F]

"Pergunta: estes requisitos vinham mais top down da Empresa D?

Resposta: não, eram negociadas algumas coisas porque existem situações principalmente da parte de comunicação de rádio que eles também adequaram o equipamento para ficar mais efetivo em relação a comunicação via rádio. Para a comunicação via rádio precisa tomar alguns cuidados para que tudo funcione melhor, se comparar com comunicação internet por exemplo, então tomaram este cuidado e fizemos uma coisa a quatro mãos, houve concessões da parte deles e da parte nossa também." [Empresa $\mathrm{H}]$.

Após concluída a especificação refinada dos requisitos da inovação sistêmica, reduzindo as incertezas da demanda do mercado, as Empresas de Nicho puderam investir com maior segurança no desenvolvimento de novas tecnologias e sua integração junto às Empresas Plataforma, como evidenciado nos seguintes trechos:

"No caso específico deste projeto de inovação fizemos o desenvolvimento do medidor inteligente eletrônico do zero, no caso a nossa empresa desenvolveu $100 \%$ do medidor em parceria com a Empresa D, a gente pegou nosso expertise de desenvolvimento de software e hardware e juntou com o expertise da Empresa D da medição." [Empresa G]

“A gente preparou, pegou todos estes pedaços da solução, não só equipamento, mas design da rede, onde tem que ter rádio, onde tem que ter repetidor, toda a infraestrutura que eles disponibilizaram porque eles tinham backbone de fibra, onde estavam os pontos de acesso, a gente entendeu todo o legado deles, quais os sistemas em operação, os softwares, como faço esta coleta, como interfaceio com sistema que eles tem de processamento de leitura, análise de fraude, faturamento em cliente, sistema comercial, SAP, tem toda uma estrutura de software funcionando, e a gente tinha que integrar a esta estrutura." [Empresa $\mathrm{F}]$ 


\subsubsection{Seleção da Ideia}

O processo de seleção da ideia em todos os casos envolveu a alta cúpula da empresa, responsável pelo planejamento estratégico da mesma, coerente com o que foi indicado pela literatura.

No caso de redes inteligentes um item de seleção estratégico foi o local onde a inovação seria aplicada. Análises cuidadosas foram realizadas para garantir que a implantação piloto gerasse aprendizados suficientes para o roll-out futuro da inovação. Para isso, buscouse ao máximo que o local selecionado fosse representativo de toda a área de concessão, como pode ser observado nos seguintes trechos das entrevistas:

"Foi escolhida esta cidade, pois constitui amostra significativa do mercado e do sistema elétrico da área de concessão da Empresa A permitindo obter resultados que possam subsidiar o Plano de Expansão do Smart Grid para as demais regiões da empresa." [Empresa A].

"Um dos fatores que levou a fazer nesta cidade é que este poligono elétrico tem todas as características de consumidores, industriais, comerciais, rurais, baixa renda, todo o grupo B, B1, B2, B3, B4, isso facilita no que diz respeito ao relacionamento com consumidor." [Empresa B].

"Escolhemos o site porque representava bem a área de concessão no estado, com relação a densidade de cargas medianas, áreas urbanas, rurais e características da rede elétrica." [Empresa C].

"E tinha uma outra vantagem porque tinha um bom mix de clientes, urbanos, alguma perda comercial e clientes rurais, então era uma boa localização para testes." [Empresa D].

Em todos os projetos, inclusive da Empresa E foi citado o desenvolvimento de um business case para subsidiar a aprovação do projeto, em um processo tradicional de decisão comum às inovações autônomas. De uma forma geral, o processo decisório foi realizado pelas Empresas Plataforma, sem a participação das Empresas Nicho ou outros atores do ecossistema de negócios (Empresas F, G, H). 


\subsubsection{Definiçãa do Conceito}

Em todos os casos estudados confirmou-se a hipótese de que para a definição do conceito da inovação sistêmica é necessário conceber novos modelos de negócios. Dentro desta temática, para as Empresas Plataforma “definir drivers de geração de valor a múltiplos atores" foi o tipo de observação mais frequente nas entrevistas realizadas. Alguns trechos sob este código são evidenciados a seguir:

"Diversas áreas da empresa se reuniram e discutiram com profundidade os possíveis benefícios. Dentre os atores envolvidos na criação de valor estão a própria concessionária, governo, reguladores, clientes, colaboradores, instituições de pesquisa e a cadeia produtiva tecnológica. Para a concessionária haverá aumento de eficiência operacional, maior confiabilidade, redução de perdas, etc. Para os clientes haverá a melhoria na qualidade do atendimento, ganhos pela eficiência energética, possibilidade de autogestão do consumo, além dos benefícios trazidos pelas novas tecnologia. Para a sociedade, governo e reguladores, haverá a promoção dos índices de qualidade, acesso a novas fontes de energia e subsídios para o desenvolvimento do arcabouço regulatório. Há estudos para o desenvolvimento de novos negócios previstos no projeto e, com certeza, novas oportunidades de negócios surgirão." [Empresa A]

"Feito isso começamos então em cima dos pilares principais, transformação empresarial, aquela questão que falei dos mapeamentos de processos, questão da medição inteligente, confundido com Smart Grid, automação na distribuição, melhora muito a eficiência operacional, qualidade da energia, disponibilidade da energia para o consumidor, relacionamento com o consumidor, privacidade de dados, Telecom, obviamente, TI, geração distribuida, automação residencial (este a gente não focou nele porque tivemos muitos empecilhos por causa de mercado).” [Empresa B]

"Pergunta: você acredita que para viabilizar as redes inteligentes vocês vão precisar fazer adaptações no modelo de negócios?

Resposta: sem dúvida nenhuma, em várias questões, até imagino que aspectos de novos negócios, tem tudo para acontecer, dando um exemplo, a própria Empresa $C$ de distribuição pode começar a prestar serviço de automação dentro da residência, serviço de geração distribuida dentro da residência, de operação e manutenção, integrando com a 
Empresa C Telecom em outros serviços, vários outros negócios são possíveis, prestar apoio e serviços também integrando com conceito de cidades inteligentes. Medição integrada, que é água, energia e gás usando a mesma infraestrutura de telecomunicações e até certo nível de TI também. Questão da Empresa C ter telecomunicações e ter fibra ótica chegando nas residências de poder ter esse modelo de integração com serviços de telecomunicações de terceiros também é um diferencial importante do projeto." [Empresa $\mathrm{C}]$.

"No business case incluímos também o ganho para o cliente, por ter acesso a mais informação sobre o seu consumo e com isso aplicamos, fizemos para alguns clientes o retorno do consumo, para eles, e para a sociedade como um todo tinha a redução de emissões, redução de consumo, então o business case como um todo era altamente positivo." [Empresa D]

"Smart grid de uma forma bem simples tem três grandes componentes: dispositivos inteligentes, não só medidor, mas dispositivos quaisquer, de carregador de veículo elétrico passando por chaves automatizadas, religadores, medição distribuida. O segundo é Telecom, parte de redes de telecomunicaçao com a cobertura geográfica, e o terceiro é a parte de software, business intelligence, que vai te ajudar a tomar decisões. E tudo tem que ter inteligência distribuída nas três pernas. (...) Uma coisa verificada em campo que exigiu ajuste do modelo de negócio foi o uso de células de inspeção para combater perda e inadimplência que vai fazer outras coisas também no futuro. Ao invés de usar uma empreiteira ou duas, três poucas grandes para inspecionar fraude, depois de quebrar cabeça passamos a usar pequenas empresas no Simples Nacional, faturamento máximo de 3,6 milhões com 12 a 15 pessoas que tomam conta de área de 20 mil consumidores, 60 mil pessoas, multiplica por 3 de propósito que é área razoável. Por diversos motivos, planejamento tributário fui eu que fiz, Simples paga muito menos imposto de renda pessoa jurídica, isso foi então viabilizador até um certo ponto, permitiu novo modelo de gestão de quem executa serviço na ponta após o Smart Grid estar implantado, que é ir lá vigiar, não adianta ter medidor de alta inteligencia e alguém faz o bypass. Então vai lá, tira o bypass e no dia seguinte fazem de novo. Tem pessoas que ficam lá o tempo todo, com base de equipe próxima, e vem a grande jogada, desde o o dono da empreiteira até o mais simples tem remuneração variável baseada em resultado para não ser corrompido, hoje são 40 destas empresas, deve chegar em 80 em cinco anos." [Empresa E]. 
Também ficou claro nas entrevistas que o papel de concepção dos novos modelos de negócios fica com as Empresas Plataforma, sendo as Empresas de Nicho mais passivas, aguardando definições das concessionárias de energia, como se pode perceber nos seguintes trechos:

"Pergunta: vocês chegaram a calcular os benefícios além da concessionária, mas para outros atores, consumidor, outras partes envolvidas?

Resposta: não, isso a princípio fica mais a cargo da concessionária fazer. A gente não tem interação com consumidor, não tem esta participação no que a Empresa E tem que entregar para a cidade, de ser uma companhia mais verde, a gente usa nossas próprias práticas que tem estes objetivos, mas esta interação mais por este caminho fica mais com a Empresa E. Aos custos que a Empresa E colocou como objetivo para este projeto a gente não consegue abrir o leque para este tipo de serviço agregado não porque a conta não fecha, porque vai estar preparado para tudo isso e se a Empresa E não vai estar considerando isso no business case dela, não consigo agregar nada além do mínimo que pediram senão não fico competitivo." [Empresa F].

"Pergunta: essa plataforma tecnológica pode ser uma plataforma pra que outros serviços sejam agregados usando a mesma infraestrutura?

Resposta: possibilidade existe, é aquilo lá, hoje nós cobrimos a cidade do teste piloto em 90, 80\% com Wimax, é possível, inclusive dentro da própria concessionária existem departamentos que estão se usufruindo desta rede de comunicação que teoricamente, está pegando alguma informação, sinal que não fazia parte do projeto, mas quando você começa a pensar no Smart Grid, você vê que faz parte do Smart Grid comunicar também com um transformador, saber o que está aocntecendo com o transformador, não fazia parte do projeto inicialmente mas o pessoal está se beneficiando desta estrtutura de comunicação existente. Existem coisas, não são iniciativas, mas conversas de fazer a parte de iluminação pública que hoje fica a cargo da prefeitura e tal, então vender serviço pra prefeitura, por exemplo talvez nem todos os pontos pode ter banda suficiente, mas câmera de vigilância é possível colocar nesta rede de comunicação. Um dos motivos para ter proposto Wimax foi isso, criar uma infraestrutura com banda larga para comunicação porque medidor é pouca, mas possibilitar a Empresa $D$ a agregar serviços embaixo disso daí outra coisa que é possível é despachar ordem de serviço para viatura, cara tá na cidade trabalhando, coloca 
uma antena no carro dele e despacha ordem de serviço, comunicação para viatura para fazer manutenção, então é possível, vai virando uma cidade inteligente, a partir do momento que tem uma infraestrutura de comunicação grande consegue agregar serviço, vender serviço, não sei se é a ideia da concessionária, aí vai depender muito da concessionária. Não temos esse foco de colocar alguém embaixo desta rede. No fim das contas isso é da concessionária, a propriedade é dela, depois que acabar o projeto tudo é seu, como vai fazer a gestão disso é a equipe sua, vai querer vender serviços, compartilhar a rede, ela decide o que fazer com o ativo." [Empresa G].

Uma vez entendidos os drivers de geração de valor para os atores envolvidos, foram definidas as formas de distribuição do risco/retorno, traduzidas em alguns casos em instrumentos jurídicos contratuais (contratos de prestação de serviços, de propriedade intelectual) e em outros apenas um compromisso de investimento coordenado baseado em relação de confiança na parceria comercial futura.

Alguns trechos que corroboram com a observação (instrumentos contratuais):

"Os contratos habituais, principalmente o de remuneração dos prestadores de serviço de Telecom tem que ser completamente revistos, a escala que vai ter é outra, as variáveis que usamos hoje já estão superadas, tem uma série de questões comerciais que tem que ser reavaliadas com o fornecedor. (...) Hoje temos por exemplo multiutilities, a Empresa $C$ tem necessidade de ter informações trafegando pela mesma rede em um período de tempo mais curto, por uma série de razões, até para monitoramento do sistema, o medidor é sensor de falta de energia, então existem especificidades diferentes, a Empresa $C$ acaba usando mais banda do canal, então basicamente a disponibilidade é a mesma, mas cada serviço [energia, água, gás] tem volume de dados diferente, então a participação no pagamento do canal é proporcional a isso e as informações vão para um banco de dados comum, com investimento comum, é destinada uma área em que cada uma das empresas vai lá buscar o dado e depois pode usar nas suas ações do dia a dia." [Empresa C].

"Pergunta: e o modelo de negócio é a compra do módulo e embarcam ou é outro tipo de acordo?

Resposta: tem vários tipos de acordo, depende do que for mais conveniente, temos equipamentos com royalties, tem outros que a gente vende, depende do modelo. Tem um 
modelo misto. Sempre nesta área de tecnologia tem duas questões importantes, a primeira delas são valores, é uma negociação constante, e a gente tem negociado certo. A segunda tão importante quanto é a parte de propriedade intelectual, isso foi muito bem negociado desde o início e a gente nunca teve problema nenhum nesta área porque desde o início ficou bem estabelecido o que era de quem. Mas é tão importante quanto os valores." [Empresa H].

Alguns trechos que corroboram com a observação (relacionamentos de confiança):

"Pergunta: quando tem a medição de água e gás, você coleta os dados, é proprietário e fornece para as outras?

Resposta: a nossa empresa deu entrada no fundo da agência de fomento à pesquisa do estado da área de concessão e convidou as empresas de água e gás do estado, que não vão ter custos, a Empresa B prove tudo e vai disponibilizar os dados para elas." [Empresa B]

"Pergunta: no momento da decisão de investimentos, foi uma decisão interna da Empresa D, envolveu o grupo lá fora, e também citou que teve investimentos de outras empresas, como a Empresa G. Ela decidiu de forma independente fazer este investimento, ou também foi uma coisa que vocês combinaram?

Resposta: independente. Ela entendeu que tinha uma oportunidade comercial, e fez um investimento próprio dela." [Empresa D].

"A empresa E ajuda os pequenos empresários, muitos são ex empresa E que saíram para abrir negócio [complementar relacionado a Redes Inteligentes]”. [Empresa E].

Além dos drivers de criação de valor e formas de distribuição do risco e retorno, foi evidenciada em todos os casos a consideração das restrições ao modelo de negócios. Neste tópico destacam-se, evidentemente, as questões regulatórias do segmento:

“O opex está muito alto e tem um limite de reconhecimento na tarifa, assim como capex, então quando for balancear isso aí, se o capex tá baixo, vou comprar de qualidade pior ou comprar menos, o que vai refletir no consumidor, na tarifa e consequentemente antes de amortizar o ativo vai substituir ele gerando mais custo no capex, ou mais custo no opex porque está dando muita manutenção, isso tem que ser balanceado, isso tem que estar reconhecido na tarifa, então um plano de tarifa que permita que faça, que te dê esta margem de equilíbrio. A partir da revisão tarifária é que ela vai falar hoje eu posso atualizar tecnologicamente minha rede de distribuição, se hoje estou com atualização de 30\%, vou 
aumentar para $60 \%$, aumentar $100 \%$ a atualização tecnológica. Isso depende muito do que é permitido na tarifa, na revisão tarifária, tudo se retroalimenta e o ponto inicial, a combustão da máquina para mover tudo é o regulador, políticas públicas.” [Empresa B].

"Quando fala de novos negócios para as distribuidoras chega um ponto que não é atrativo, o negócio distribuição é algo tão regulado que outras receitas que não estejam modeladas elas tem que necessariamente ser capturadas como beneficio na tarifa, não acho que no todo seja ruim, mas se não tiver uma parte diretamente para as empresas não fomenta essas necessidades, então este tipo de situação que precisa ser revista e a regra do jogo está muito clara na auditoria da Aneel, ela é muito forte em cima das empresas, do ponto de vista financeiro, contábil, dos processos, este tipo de coisa não ajuda muito o investimento em renovação e modernização do sistema." [Empresa C].

"Mas tem alguns fatores de suporte, primeiro, o regulador reconhece na base de ativos o acréscimo de custo do medidor e de todos os equipamentos instalados na rede que hoje não existem. Basicamente qual é o conceito, estou a fazer capex para reduzir opex, esse é o conceito. O problema é que no modelo atual não se valoriza isso. Se vou gastar 200 reais em um medidor, mas o medidor tradicional custa 50, o regulador só reconhece 50, então 150 foi perda minha, isso faz com que eu não tenha incentivo para fazer isso, esse é o motivo porque no Brasil nós não conseguimos fazer isso. Depois nós quantificamos isso, mas no futuro teremos ganhos com tarifas mais flexíveis. Era uma distribuição de investimentos. Eu tenho um pico de carga, tenho que substituir um transformador, posso não substituir se eu der um incentivo para os clientes se eles baixarem o consumo em ponta. E isso eu consigo evitar um investimento e passar para frente, mas isso ficou fora do business case." [Empresa D].

As empresas B, C e E destacaram ainda a necessidade de avaliação e redesenho dos processos de negócios básicos da empresa com a inovação, coerente com a definição de inovação sistêmica de Taylor e Levitt (2004):

"Porque não é só embarcar a tecnologia, o processo vai mexer muito, o processo de negócio, foram mapeados 80 processos de negócios que seriam afetados com Smart Grid. (...) Como é um projeto novo a gente tentou minimizar o risco de ter muito dado e pouca informação. A gente ainda assim tem um tsunami de dados e uma marolinha de informação. A gente não pegou este tsunami de dados e transformou em tsunami de informação, mas o 
suficiente para alimentar as regras de negócios da casa. Porque quando faz um mapeamento do processo de dados de redes inteligentes, neste caso de distribuição, a gente trabalha com dados impressionantes. Até então, os dados como estão disponíveis hoje, eles atendem mais ou menos 8 regras de negócios, 8 processos e seus subprocessos. Só com os dados que a gente já chegou, este tsunami que a gente já transformou em informação útil, já transformou em 34, isso só no primeiro momento, então é progressão quase que geométrica ter que trabalhar dados de redes inteligentes." [Empresa B].

"Temos modernização de software no centro de controle que está acontecendo, justamente por causa dos investimentos em dispositivos inteligentes que tem na rede, que são o principal retorno da defesa da substituição desses softwares para proporcionar novos benefícios que hoje estão sendo subutilizados. " [Empresa C].

"Esse projeto foi de transformação, muda muito processo, identificamos alguns óbvios, se tem medição não precisa de leiturista, corte religa remoto não precisa fazer, muda procedimento equipe física de corte religa, tem outros que não são tao óbvios. ” [Empresa E].

\subsubsection{Saída do FFE}

Confirmou-se a hipótese de envolvimento da alta cúpula responsável pela estratégia da empresa na saída do FFE em todos os casos estudados. Em um dos casos, da Empresa E, houve inclusive a atuação de uma auditoria independente sobre o business case dado o nível de riscos envolvidos na inovação sistêmica. Porém não foi confirmada a hipótese nestes casos de que uma das possíveis saídas seria um processo de planejamento estratégico ou de corporate venture capital (criação de uma spin off, por exemplo).

Ao invés disso, a atividade subsequente foi a estruturação de uma equipe de desenvolvimento da implementação piloto da inovação sistêmica com uma característica multidisplinar, incluindo recursos humanos tanto das Empresas Plataforma como as Empresas Nicho sob uma mesma coordenação de projetos, com alocação na Empresa Plataforma de poucos recursos em tempo integral (5 a 9 profissionais) e em sua maioria alocação em tempo parcial de grande número profissionais que permaneciam com suas funções no negócio em paralelo (estrutura matricial). Nas empresas Nicho foram montadas equipes dedicadas apenas para projetos piloto de inovação em Smart Grid, porém em alguns casos atuando 
simultaneamente em mais de um projeto de inovação sistêmica para diferentes clientes de distribuição de energia.

A partir daí todas as empresas adotaram práticas de gerenciamento de projetos tradicionais, como as preconizadas pelo Project Management Institute para iniciação, planejamento, execução e monitoramento e controle das implementações piloto, como podese perceber nos seguintes trechos:

"Os projetos a gente acompanha no dia a dia, tem tantos os gerentes de projeto do $P \& D$ quanto os gerentes do projeto da Empresa E, esta relação entre nós é bem próxima, tem reuniões semanais entre áreas justamente para alinhar o que preciso entregar e quando." [Empresa F].

"Sou o gerente de projetos dos projetos, faço interface da Empresa $G$ com os clientes, faço o meio de campo, controlando os prazos, custos, fazendo a interface com os clientes, sobra esta tarefa difícil para mim, dar as notícias boas, as ruins, os atrasos, os avanços." [Empresa G].

Além de gestão de projetos, as empresas Plataforma também adotaram práticas de gestão de programas, já que cada projeto foi subdividido em subprojetos, tais como medição inteligente, geração distribuída, multiutilidades, veículo elétrico, automação e self healing.

Observa-se que as atividades previstas de planejamento estratégico e eventualmente de corporate venture capital estão previstas para ocorrerem no término da implementação piloto. Dentro do contexto de planejamento estratégico, quatro das cinco empresas Plataforma afirmaram ter como objetivo o desenvolvimento de um roadmap tecnológico e planejamento para roll-out da inovação em toda a área de concessão utilizando os subsídios de conhecimento provenientes da execução do piloto, como se observa nos seguintes trechos:

“O presente projeto [implementação piloto] objetiva implementar infraestruturas tecnológicas, aplicações e funcionalidades de Redes Inteligentes adequadas à rede, ao mercado e aos desafios estratégicos e operacionais prioritários da Empresa A para criar um modelo de implantação replicável em toda a área de concessão da Empresa A, o chamado Road Map Tecnológico e Estratégico." [Empresa A].

“Este é o caminho que a gente está seguindo desde 2009, conceber um projeto, definir área de implantação piloto, implantar, coletar informação, estudar e produzir um plano de 
implantação, este é o objetivo do programa, produzir um plano de negócios que caiba na rede de concessão. A Empresa B caminha a passos largos para realmente implantar uma rede de Smart Grid na área de concessão, estamos trabalhando em um plano diretor que vai nortear todos os trabalhos a partir de 2016." [Empresa B]

“Começamos em 2009 então a implementação piloto para avaliar os resultados destas tecnologias, principalmente os beneficios que trariam para a gente traçar um roadmap para aplicação em torno de 10-15 anos." [Empresa C].

Uma outra saída esperada da implementação piloto é a retroalimentação dos agentes reguladores com subsídios de conhecimento para atualização dos mecanismos regulatórios a fim de incentivar e viabilizar a expansão do Smart Grid em todo o território nacional, como mostram os seguintes trechos:

"Então, é um documento da Aneel, do setor elétrico, a gente espera que ocorra esta influência, de que haja alguma luz que possa iluminar este projeto, este documento, que torne algo que venha a sustentar alguma defesa de incentivo, alguma atualização nas regulamentações existentes ou regulamentações novas, isso é algo que a gente realmente espera que aconteça, que absorvam todos os projetos e que de lá saia um rascunho ou audiência pública de incentivo, norteamento do setor no Brasil.” [Empresa B].

"Está em teste em escala pequena, mas do ponto de vista estratégico, direciona, a própria Aneel acompanha isso, quais os pontos que devem ser alterados na resolução, nas próprias regras regulatórias para que consiga tanto o consumidor ter benefício, a concessionária e todos os clientes que não tem microgeração para que possam se apropriar dos ganhos que são redução de perdas, melhoria do nível de tensão, melhoria da qualidade de energia, com a geração distribuída sendo controlada pela concessionária." [Empresa C].

"Para a Aneel fizemos apresentação mais do ponto de vista de resultado do que de inovação, claro que gostaram da parte de inovação, tem toda uma plataforma que vai possibilitar outras empresas do Brasil terem proveito disso, a Empresa F por exemplo está ampliando a fábrica aqui, está montando o que fazia lá fora de hardware, firmware, rádios, medidores com rádio embutido dentro dele, com padrões definidos pela regulamentação brasileira. (...) Fizemos reunião com Aneel para mostrar resultado, negociar tarifa." [Empresa E]. 
Além da troca de conhecimentos com os reguladores, também foram citadas trocas de conhecimento entre atores do ecossistema de negócios durante e após a execução das implementações piloto, principalmente em grupos de trabalho promovidos pela agência regulatória e entidades de classe, como a ABRADEE.

Em dois dos casos (Empresa B e Empresa D) foram citadas empresas spin offs que foram criadas como investimento do grupo empresarial para executar novos negócios da companhia, porém em um primeiro momento mais voltadas para exploração comercial de energias renováveis. Ambas citaram, no entanto, que estas spin offs futuramente podem abarcar novos negócios provenientes da implementação piloto de Redes Inteligentes.

Notou-se, portanto, uma necessidade de revisão do modelo conceitual, definindo-se a saída do FFE como a implementação de projeto piloto da inovação sistêmica com a finalidade de mitigação de riscos por meio de aprendizados baseados em experiência concreta. Apenas após esta etapa é realizado o planejamento estratégico de longo prazo e eventual corporate venture capital. 


\section{Síntese dos estudos de caso exploratórios}

Consolidando-se os casos estudados frente ao modelo conceitual, realizou-se o Quadro 20 sintetizando as principais práticas aplicadas no FFE de IS.

\section{Quadro 20 - Análise cruzada dos casos exploratórios.}

\begin{tabular}{|c|c|c|c|c|c|c|c|c|c|c|c|}
\hline \multirow{2}{*}{$\begin{array}{l}\text { Elemento do } \\
\text { modelo } \\
\text { conceitual }\end{array}$} & \multirow{2}{*}{$\begin{array}{l}\text { Práticas identificadas nos } \\
\text { casos exploratórios }\end{array}$} & \multicolumn{6}{|c|}{ Empresas Plataforma } & \multicolumn{4}{|c|}{ Empresas Nicho } \\
\hline & & $\mathbf{A}$ & B & $\mathrm{C}$ & D & $\mathbf{E}$ & $\%$ & $\mathbf{F}$ & $\mathbf{G}$ & $\mathbf{H}$ & $\%$ \\
\hline \multirow{10}{*}{$\begin{array}{l}\text { Fatores de } \\
\text { influência - } \\
\text { Mapeamento } \\
\text { do } \\
\text { Ecossistema }\end{array}$} & Identificação de atores & $\mathrm{X}$ & $\mathrm{X}$ & $\mathrm{X}$ & $\mathrm{X}$ & & 80 & & & & $\mathbf{0}$ \\
\hline & Posicionamento dos atores & $\mathrm{X}$ & $\mathrm{X}$ & & & & 40 & & & & $\mathbf{0}$ \\
\hline & Criação de personas & & $\mathrm{X}$ & & & & 20 & & & & $\mathbf{0}$ \\
\hline & Pesquisa de campo & $\mathrm{X}$ & $\mathrm{X}$ & & $\mathrm{X}$ & $\mathrm{X}$ & 80 & & & & $\mathbf{0}$ \\
\hline & Reuniões de atualização & $\mathrm{X}$ & $\mathrm{X}$ & $\mathrm{X}$ & $\mathrm{X}$ & $\mathrm{X}$ & 100 & $\mathrm{X}$ & $\mathrm{X}$ & $\mathrm{X}$ & 100 \\
\hline & Atualização em eventos & $\mathrm{X}$ & $\mathrm{X}$ & $\mathrm{X}$ & $\mathrm{X}$ & $\mathrm{X}$ & 100 & $\mathrm{X}$ & $\mathrm{X}$ & & 67 \\
\hline & Articulação com regulador & $\mathrm{X}$ & $\mathrm{X}$ & $\mathrm{X}$ & $\mathrm{X}$ & $\mathrm{X}$ & 100 & & & & $\mathbf{0}$ \\
\hline & Acompanhamento regulação & $\mathrm{X}$ & $\mathrm{X}$ & $\mathrm{X}$ & $\mathrm{X}$ & $\mathrm{X}$ & 100 & $\mathrm{X}$ & $\mathrm{X}$ & & 67 \\
\hline & Benchmarking internacional & $\mathrm{X}$ & $\mathrm{X}$ & $\mathrm{X}$ & $\mathrm{X}$ & $\mathrm{X}$ & 100 & $\mathrm{X}$ & $\mathrm{X}$ & & 67 \\
\hline & $\%$ & 89 & 100 & 67 & 78 & 67 & 80 & 44 & 33 & 11 & 18 \\
\hline \multirow{4}{*}{$\begin{array}{lr}\text { Fatores de } \\
\text { Influência } \\
\text { Posição no } \\
\text { Ecossistema } \\
\end{array}$} & Protagonista orquestrador & $\mathrm{X}$ & $\mathrm{X}$ & $\mathrm{X}$ & $\mathrm{X}$ & $\mathrm{X}$ & 100 & & & & $\mathbf{0}$ \\
\hline & Garantidor da qualidade & $\mathrm{X}$ & $\mathrm{X}$ & $\mathrm{X}$ & $\mathrm{X}$ & $\mathrm{X}$ & 100 & & & & $\mathbf{0}$ \\
\hline & Vanguarda tecnológica & & & & & & $\mathbf{0}$ & $\mathrm{X}$ & $\mathrm{X}$ & $\mathrm{X}$ & 100 \\
\hline & $\%$ & 67 & 67 & 67 & 67 & 67 & 67 & 33 & 33 & 33 & 33 \\
\hline \multirow{11}{*}{$\begin{array}{l}\text { Motor - } \\
\text { Mecanismos } \\
\text { coordenação } \\
\text { e colaboração }\end{array}$} & P\&D conjunto & $\mathrm{X}$ & $\mathrm{X}$ & $\mathrm{X}$ & $\mathrm{X}$ & $\mathrm{X}$ & 100 & $\mathrm{X}$ & $\mathrm{X}$ & $\mathrm{X}$ & 100 \\
\hline & Termo de cooperação & & $\mathrm{X}$ & $\mathrm{X}$ & & & 40 & & & & $\mathbf{0}$ \\
\hline & Subcontratação & $\mathrm{X}$ & $\mathrm{X}$ & $\mathrm{X}$ & $\mathrm{X}$ & $\mathrm{X}$ & 100 & $\mathrm{X}$ & $\mathrm{X}$ & $\mathrm{X}$ & 100 \\
\hline & Padronização/Homologação & $\mathrm{X}$ & $\mathrm{X}$ & $\mathrm{X}$ & $\mathrm{X}$ & $\mathrm{X}$ & 100 & & & & $\mathbf{0}$ \\
\hline & Propriedade intelectual & & & $\mathrm{X}$ & & & 20 & $\mathrm{X}$ & & $\mathrm{X}$ & 67 \\
\hline & Investimentos coordenados & $\mathrm{X}$ & & $\mathrm{X}$ & $\mathrm{X}$ & & 60 & $\mathrm{X}$ & $\mathrm{X}$ & $\mathrm{X}$ & 100 \\
\hline & Showroom & $\mathrm{X}$ & & $\mathrm{X}$ & & & 40 & & & & $\mathbf{0}$ \\
\hline & Eventos setoriais & $\mathrm{X}$ & $\mathrm{X}$ & $\mathrm{X}$ & $\mathrm{X}$ & $\mathrm{X}$ & 100 & $\mathrm{X}$ & $\mathrm{X}$ & & 67 \\
\hline & Reuniões e apresentações & $\mathrm{X}$ & $\mathrm{X}$ & $\mathrm{X}$ & $\mathrm{X}$ & $\mathrm{X}$ & 100 & $\mathrm{X}$ & $\mathrm{X}$ & $\mathrm{X}$ & 100 \\
\hline & Programa do Governo & & & $\mathrm{X}$ & & & 20 & & & & $\mathbf{0}$ \\
\hline & $\%$ & 70 & 60 & 100 & 60 & 50 & 68 & 60 & 50 & 50 & 53 \\
\hline \multirow{4}{*}{$\begin{array}{l}\text { Identificação } \\
\text { de } \\
\text { oportunidade }\end{array}$} & Expansão de autônomas & & $\mathrm{X}$ & $\mathrm{X}$ & $X$ & $\mathrm{X}$ & 80 & $\mathrm{X}$ & & & 33 \\
\hline & Consolidação da Plataforma & $\mathrm{X}$ & $\mathrm{X}$ & $\mathrm{X}$ & $\mathrm{X}$ & $\mathrm{X}$ & 100 & & & & $\mathbf{0}$ \\
\hline & Acompanha Plataforma & & & & & & $\mathbf{0}$ & $\mathrm{X}$ & $\mathrm{X}$ & $\mathrm{X}$ & 100 \\
\hline & $\%$ & 33 & 67 & 67 & 67 & 67 & 60 & 67 & 33 & 33 & 44 \\
\hline \multirow{3}{*}{$\begin{array}{l}\text { Análise de } \\
\text { oportunidade }\end{array}$} & Business case tradicional & $\mathrm{X}$ & $\mathrm{X}$ & $\mathrm{X}$ & $\mathrm{X}$ & $\mathrm{X}$ & 100 & $\mathrm{X}$ & $\mathrm{X}$ & $\mathrm{X}$ & 100 \\
\hline & Sinergia entre autônomas & $\mathrm{X}$ & $\mathrm{X}$ & $\mathrm{X}$ & $\mathrm{X}$ & $\mathrm{X}$ & 100 & $\mathrm{X}$ & & & 33 \\
\hline & $\%$ & 100 & 100 & 100 & 100 & 100 & 100 & 100 & 50 & 50 & 67 \\
\hline \multirow{4}{*}{$\begin{array}{l}\text { Geração de } \\
\text { ideias }\end{array}$} & Troca de conhecimentos & $\mathrm{X}$ & $\mathrm{X}$ & $\mathrm{X}$ & $\mathrm{X}$ & $\mathrm{X}$ & 100 & $\mathrm{X}$ & $\mathrm{X}$ & $\mathrm{X}$ & 100 \\
\hline & Especificação de requisitos & $\mathrm{X}$ & $\mathrm{X}$ & $\mathrm{X}$ & $\mathrm{X}$ & $\mathrm{X}$ & 100 & & & & 100 \\
\hline & Refinamento com Nicho & $\mathrm{X}$ & $\mathrm{X}$ & $\mathrm{X}$ & $\mathrm{X}$ & $\mathrm{X}$ & 100 & $\mathrm{X}$ & $\mathrm{X}$ & $\mathrm{X}$ & 100 \\
\hline & $\%$ & 100 & 100 & 100 & 100 & 100 & 100 & 67 & 67 & 67 & 100 \\
\hline $\begin{array}{ll}\text { Seleção } \\
\text { ideias }\end{array}$ & Envolvimento alta cúpula & 100 & 100 & 100 & 100 & 100 & 100 & 0 & $\mathbf{0}$ & 0 & 0 \\
\hline
\end{tabular}




\begin{tabular}{|c|c|c|c|c|c|c|c|c|c|c|c|}
\hline \multirow{2}{*}{ 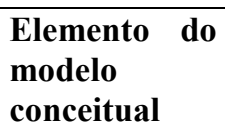 } & \multirow{2}{*}{$\begin{array}{l}\text { Práticas identificadas nos } \\
\text { casos exploratórios }\end{array}$} & \multicolumn{6}{|c|}{ Empresas Plataforma } & \multicolumn{4}{|c|}{ Empresas Nicho } \\
\hline & & $\mathbf{A}$ & B & $\mathbf{C}$ & D & $\mathbf{E}$ & $\%$ & $\mathbf{F}$ & G & $\mathbf{H}$ & $\%$ \\
\hline \multirow{7}{*}{$\begin{array}{lr}\text { Definição } & \text { do } \\
\text { conceito } & - \\
\text { Novos } & \\
\text { modelos } & \text { de } \\
\text { negócios } & \end{array}$} & Quantificar valor aos atores & $\mathrm{X}$ & $\mathrm{X}$ & $\mathrm{X}$ & $\mathrm{X}$ & $\mathrm{X}$ & 100 & & & & $\mathbf{0}$ \\
\hline & Regulação restringe conceito & $\mathrm{X}$ & $\mathrm{X}$ & $\mathrm{X}$ & $\mathrm{X}$ & $\mathrm{X}$ & 100 & $\mathrm{X}$ & $\mathrm{X}$ & & 67 \\
\hline & $\begin{array}{ll}\begin{array}{l}\text { Distribuição } \\
\text { (contrato) }\end{array} & \text { riscos } \\
\end{array}$ & & & $\mathrm{X}$ & & & 20 & $\mathrm{X}$ & & $\mathrm{X}$ & 33 \\
\hline & Relacionamento confiança & & $\mathrm{X}$ & & $\mathrm{X}$ & $\mathrm{X}$ & 60 & & $\mathrm{X}$ & & 33 \\
\hline & Redesenho de processos & & $\mathrm{X}$ & $\mathrm{X}$ & & $\mathrm{X}$ & 60 & & & & $\mathbf{0}$ \\
\hline & Business Model Generation & & & & & & $\mathbf{0}$ & & & & $\mathbf{0}$ \\
\hline & $\%$ & 40 & 80 & 80 & 60 & 80 & 68 & 40 & 40 & 20 & 33 \\
\hline \multirow{6}{*}{$\begin{array}{l}\text { Saídas do } \\
\text { FFE }\end{array}$} & Implantação piloto & $\mathrm{X}$ & $\mathrm{X}$ & $\mathrm{X}$ & $\mathrm{X}$ & $\mathrm{X}$ & 100 & $\mathrm{X}$ & $\mathrm{X}$ & $\mathrm{X}$ & 100 \\
\hline & Estruturação de equipe & $\mathrm{X}$ & $\mathrm{X}$ & $\mathrm{X}$ & $\mathrm{X}$ & $\mathrm{X}$ & 100 & $\mathrm{X}$ & $\mathrm{X}$ & & 67 \\
\hline & Práticas gestão projetos & $\mathrm{X}$ & $\mathrm{X}$ & $\mathrm{X}$ & $\mathrm{X}$ & $\mathrm{X}$ & 100 & $\mathrm{X}$ & $\mathrm{X}$ & & 67 \\
\hline & Práticas gestão programas & $\mathrm{X}$ & $\mathrm{X}$ & $\mathrm{X}$ & $\mathrm{X}$ & $\mathrm{X}$ & 100 & & & & $\mathbf{0}$ \\
\hline & Lições aprendidas - trocas & $\mathrm{X}$ & $\mathrm{X}$ & $X$ & $\mathrm{X}$ & $\mathrm{X}$ & 100 & & & $\mathrm{X}$ & 33 \\
\hline & $\%$ & 100 & 100 & 100 & 100 & 100 & 100 & 60 & 60 & 40 & 53 \\
\hline
\end{tabular}

(Conclusão)

Verifica-se claramente a maior preocupação das empresas Plataforma com o mapeamento e análise do ecossistema em relação às empresas de Nicho, o que é coerente com o posicionamento estratégico adotado pelas mesmas (protagonista orquestrador $\mathrm{x}$ vanguarda tecnológica). Em duas empresas foram adotados processos de mapeamento mais sofisticados como classificação de atores e posicionamento em relação à empresa e desenvolvimento de personas para representar os grupos de atores (especialmente clientes finais). As práticas mais frequentes são reuniões de atualização (entre Plataforma e Nichos), articulação em eventos setoriais, acompanhamento da regulação e benchmarkings internacionais. As técnicas de mapeamento de ecossistema mais sofisticadas, agregando análise de redes e classificação de fluxos de informação, capital, crédito, produtos e serviços, no entanto, não foram observadas nos casos exploratórios.

A empresa B destaca-se aplicando todas as práticas de mapeamento do ecossistema mencionadas. No estudo deste caso ficou claro o reconhecimento precoce da inovação com caráter sistêmico, preocupando-se desde as etapas iniciais em não se focar apenas em elementos de tecnologia, como também redesenho de processos internos, engajamento do consumidor final e desenvolvimento de uma cadeia produtiva para Redes Inteligentes. $\mathrm{O}$ posicionamento das empresas Plataforma como garantidoras da qualidade criando padrões de homologação auxiliam na consolidação do ecossistema de negócios, reduzindo riscos para novos atores realizarem investimentos. 
Quanto aos mecanismos de colaboração e coordenação, observa-se o papel primordial do agente regulador como fomentador da IS, principalmente em decorrência da compulsoriedade de investimento em pesquisa e inovação imposta em sua regulamentação para as concessionárias de energia elétrica e de ações conjuntas com entidades de classe para articulação do tema entre empresas, condizente com os estudos de Leten et al (2013). Esta relação, no entanto, não é unidirecional. Os resultados e aprendizados obtidos na IS de cada Empresa Plataforma fornece o subsídio para novas regulamentações do agente governamental, que por sua vez fomentarão novos ciclos de evolução da IS de redes inteligentes.

Interessante observar mecanismos de coordenação e colaboração novos que tiveram que ser criados em decorrência do FFE de IS, tais como termos de cooperação, investimentos coordenados, acordos de propriedade intelectual e showroom para equalizar a distribuição de riscos e retornos, elementos não presentes na literatura de FFE.

Observaram-se dois fenômenos não previstos inicialmente no modelo conceitual. Em relação ao primeiro, a identificação da oportunidade de IS partir de iniciativas de inovação autônoma independentes em que foram vislumbradas possibilidades de integração para ampliar a geração de valor posteriormente às suas implantações. Vale ressaltar que foi necessário conscientemente no FFE criar uma iniciativa de inovação nova a fim de realizar esta integração, que foi maior do que a soma das partes (não foi apenas a junção das duas equipes originais, por exemplo). Em relação ao segundo, a saída do FFE não é diretamente novo planejamento estratégico ou criação de novas empresas: uma implantação piloto precede esta atividade. Porém, um roadmap tecnológico, roll-out de implantação e spin offs estão previstos após a avaliação dos resultados do projeto piloto.

Verificou-se em todos os projetos a definição de modelos de negócios na atividade de definição do conceito do FFE de IS, sendo as empresas Plataforma as responsáveis por quantificar benefícios não apenas de sua empresa, como também para demais atores da cadeia produtiva, consumidores e sociedade como um todo. Os modelos de negócios foram definidos ou mediante instrumentos contratuais (em menor frequência) ou mediante relacionamento de confiança derivado de parcerias que já haviam sido iniciadas previamente ao projeto de IS, coerente com a teoria de estruturas mínimas institucionais para sustentar organizações temporárias de co-desenvolvimento (VAN DER MEER-KOOISTA E SCAPENS, 2015). Em três dos cinco casos de empresas Plataforma verificou-se explicitamente a necessidade de 
redesenho de processos de negócios internos da organização, como previsto por Taylor e Levitt (2004).

Não foram aplicadas técnicas específicas de modelamento de novos negócios mais recentes, como por exemplo as recomendadas por Osterwalder et al (2010), o que é compreensível dado o período em que o FFE dos projetos de IS estudados ocorreram. Trata-se de um elemento a ser estudado com mais profundidade em estudos de casos em que o FFE teve início após a difusão destas técnicas no mercado.

Observou-se também clara diferenciação entre as práticas adotadas pelas Empresas Plataforma e Empresas Nicho. A preocupação em fomentar um ecossistema de fornecedores, as articulações com os complementares (operadoras de telefonia, por exemplo), a criação de padrões industriais, mecanismos de interface e regras de participação na IS foram determinados pela Empresa Plataforma, que neste caso específico era a concessionária de energia elétrica. No prisma de liderança (ADNER, 2012), as concessionárias eram as únicas com uma relação de custo benefício grande o suficiente para justificar seu maior risco como orquestrador do ecossistema de negócios de redes inteligentes. Para a Empresa Nicho, as práticas de FFE na IS foram próximas do que se observou na literatura de FFE para inovação autônoma.

Para as empresas Plataforma entrevistadas, o caráter sistêmico da inovação foi citado mais de uma vez em todos os casos, e ressaltada a importância de haver mais pesquisas acerca de como desenvolver e fomentar novos ecossistemas de negócios. Para estas empresas Plataforma, propõe-se o quadro conceitual atualizado da Figura 11 como diretriz para o FFE de IS 


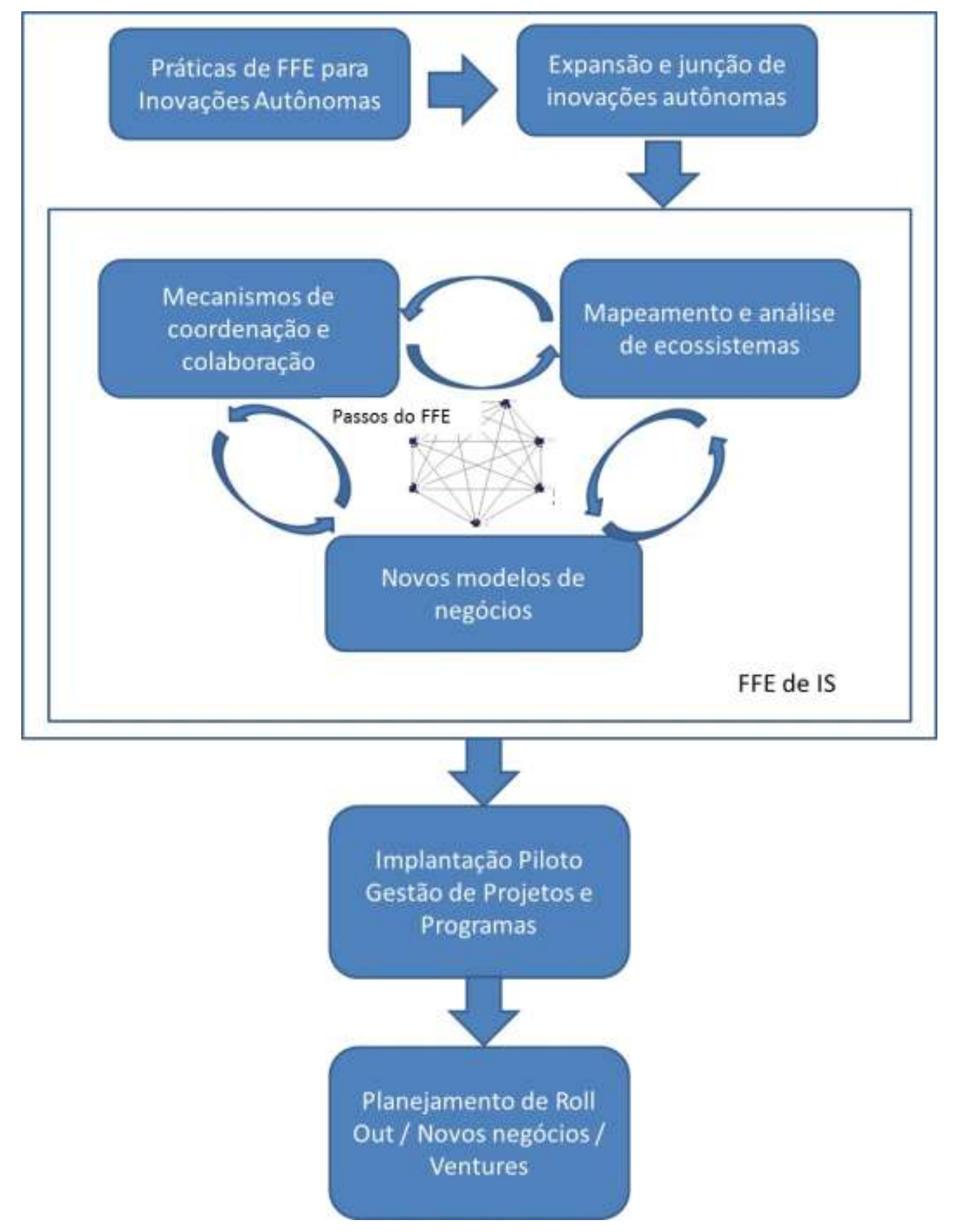

Figura 11 - Quadro conceitual atualizado após análise dos estudos de caso exploratórios. 


\section{Conclusões e Considerações Finais}

Este trabalho teve por objetivo explorar as práticas de FFE para a tipologia de IS. A partir de uma revisão sistemática da literatura, foi possível verificar que as etapas do FFE de IS podem ser as mesmas da literatura de FFE, portanto, o quadro conceitual tem como base as etapas do modelo de FFE de Koen et al (2001), o mais abrangente identificado na literatura. Não obstante, no quadro teórico, observaram-se diferenças relevantes nas saídas das etapas do FFE, levando-se em conta as especificidades para a IS.

Portanto, o quadro conceitual apresentado contribui com a literatura ao delinear estas especificidades, que incluem a necessidade de mapeamento e posicionamento de atores no ecossistema de negócios, que possuem relação de interdependência com a empresa focal, a aplicação precoce de mecanismos de coordenação e colaboração para minimizar os riscos da inovação e a concepção de novos modelos de negócios e não apenas novos produtos e serviços como resultado deste processo. Também foi possível identificar diferenças destas práticas entre Empresas Plataforma e Empresas Nicho, sendo tipicamente mais presentes no escopo das Empresas Plataforma. Como implicações para a pesquisa científica, este trabalho contribui para ampliar o restrito conhecimento existente a respeito de IS e, de forma inédita, relacioná-lo com o vasto conhecimento de metodologias de desenvolvimento de novos produtos em inovações autônomas, em específico relacionando às etapas iniciais e caóticas do processo de inovação chamada nesta pesquisa de FFE. Com evidências empíricas, a pesquisa tabém investigou o FFE de IS em dois setores distintos o setor de saúde e de redes inteligentes, o que permitiu verificar que no que concerne ao FFE de IS as fases, entradas e saídas guardam semelhança.

O trabalho resultou em um quadro conceitual de FFE para IS que pode ser operacionalizado e replicado em estudos futuros. Observou-se que as práticas de FFE de inovação autônoma fazem parte da gestão de IS, e inclusive em muitos casos a IS pode se iniciar na empresa Plataforma como uma inovação autônoma que foi expandida ou combinada com outras inovações autônomas. No entanto, estas práticas são insuficientes, são necessários mecanismos de colaboração e coordenação para minimização de riscos do codesenvolvimento, mapeamento e análise do ecossistema de negócios identificando todos os atores envolvidos na geração e captura do valor, como eles se relacionam e o seu respectivo posicionamento no ecossistema. Por fim, identificou-se que o conceito resultante do FFE em 
IS não são novos produtos ou serviços, mas novos modelos de negócios, tanto para a empresa Plataforma internamente (redesenho de processos de negócios) como em sua relação com os demais atores do ecossistema. Como próximos passos a partir da aprovação do FFE, identifica-se a necessidade de implantação piloto antes de uma decisão estratégica de roll out, roadmap tecnológico e criação de novas empresas (corporate venturing). Nesta implantação piloto, as empresas Plataforma podem se beneficiar ao adotar práticas de gestão de programas e não apenas gestão de projetos, promovendo a boa execução não só de cada subprojeto individualmente, como também a interrelação entre os projetos.

A literatura atual está majoritariamente focada na tipologia de inovação incremental versus radical. Este trabalho visa, portanto dar maior destaque à diferenciação baseada na interdependência da inovação da empresa focal com inovações de outros atores que não estão sob controle direto da organização. O conhecimento em gestão de stakeholders mostrou-se complementar ao de práticas de FFE para IS, porém não suficiente para explicar o sucesso de iniciativas de IS.

Como implicações gerenciais, este trabalho oferece uma síntese das melhores práticas de gestão de FFE para IS encontradas na literatura e em experiência prática nos casos exploratórios. A partir das definições conceituais de FFE e IS acredita-se que é possível que gestores façam uma análise crítica de projeto desde os momentos iniciais da inovação quanto à sua classificação não apenas quanto ao grau de descontinuidade, mas também de interdependência com o restante do ecossistema e, em consequência disso, escolher quais práticas e quantos esforços devem ser alocados e por quê. Outra implicação importante é a de que inovações autônomas independentes já praticadas pela empresa podem ser fontes de oportunidades para uma IS que é maior do que a simples soma das partes. Um olhar crítico sobre o portfólio de inovações atuais da empresa sob este ângulo pode ser inserido nas práticas administrativas da empresa.

O conceito de IS ainda não está totalmente consolidado e poucos artigos na revisão sistemática de literatura utilizaram este termo específico para referenciá-lo, tendo sido necessária a utilização de termos correlatos descritos em artigos que de fato tratavam do tema pesquisado, o que também apresenta uma limitação potencial para identificação da totalidade de artigos que tratam do assunto. 
Outra limitação do estudo é que foi realizado em apenas dois tipos de indústria: indústria de saúde preventiva de indústria de redes inteligentes no Brasil. A contingência do segmento e da região limitam o escopo de generalização das conclusões. A indústria de redes inteligentes no Brasil é incipiente e poucas empresas possuem de fato uma iniciativa de FFE bem sucedida de IS, o que limita o campo amostral, além do acesso a apenas uma pessoa de cada empresa participante para entrevistas. Felizmente, mesmo com amostra reduzida foi possível obter evidências tanto de Empresas Plataforma quanto Empresas de Nicho e encontrar padrões em comum que subsidiaram a proposição do modelo conceitual.

O presente trabalho também abre espaço para uma série de estudos futuros. Uma linha de estudos é a operacionalização dos construtos desenvolvidos no modelo conceitual para aplicação de métodos quantitativos para validação do mesmo. Outra oportunidade é a de explorar se os mesmos padrões são observados em outras indústrias além das estudadas neste trabalho. Cada elemento do modelo conceitual de FFE de IS (mapeamento e posicionamento no ecossistema, mecanismos de coordenação e colaboração e novos modelos de negócios) pode ser pesquisado em maior profundidade em um nível não apenas tático como operacional para orientar o gerenciamento de projetos de IS (o que, quem, como, onde, quando e por quê de cada um dos elementos).

A partir da revisão de literatura e principalmente dos estudos de caso, notou-se a relevância de elementos da abordagem efetual para o FFE de IS (em contraste com a predominância de práticas segundo a abordagem causal da literatura de FFE de inovações autônomas). Ao invés de terem sido planejadas como IS desde o momento inicial, notou-se que a partir da troca de conhecimentos, reunião de competências e aproveitamento de oportunidades emergentes, inovações autônomas foram de forma evolutiva se tornando IS, envolvendo gradualmente mais atores no ecossistema de inovação. Portanto, recomenda-se como linha de pesquisa futura a confirmação da hipótese de adequação da teoria de efetuação para IS.

A IS terá cada vez mais relevância tendo em vista a maior complexidade do conhecimento e necessidade de especialização das empresas para domínio do estado da arte e manutenção de sua competitividade, crença reforçada pela análise da literatura mais recente e experiências observadas nos estudos de caso. Não basta ter apenas uma boa execução de inovação isoladamente. Não basta ouvir e entender as necessidades do cliente líder. Não basta 
conceber um produto ou serviço inovador. É preciso compreender, e, caso se deseje ser uma Empresa Plataforma, orquestrar as ligações entre os atores chave do ecossistema de negócios. Mesmo antes de iniciar o desenvolvimento formal da inovação. 


\section{Referências}

AALTONEN, K. Project stakeholder analysis as an environmental interpretation process. International Journal of Project Management, vol. 29, n. 2, p. 165-183, 2011.

ABRAS, C., MALONEY-KRICHMAR, D., PREECE, J. User-Centered Design. In Bainbridge, W. Encyclopedia of Human-Computer Interaction. Thousand Oaks: Sage Publications, 2004.

ACHTERKAMP, M. C., VOS, J. Investigating the use of the stakeholder notion in project management literature, a meta-analysis. International Journal of Project Management, vol. 26, n. 7, p. 749-757, 2008.

ADAM, A., SHAVIT, T. Roles and responsibilities of boards of directors revisited in reconciling conflicting stakeholders interests while maintaining corporate responsibility. Journal of Management \& Governance, vol. 13, n. 4, p. 281-302, 2008.

ADNER, R. Match your innovation strategy to your innovation ecosystem. Harvard Business Review, vol. 84, n. 4, p. 1-11, 2006.

ADNER, R. The wide lens: What Successful Innovators See That Others Miss. Portfolio: Londres, 2012.

ADNER, R., KAPOOR, R. Value creation in innovation ecosystems: how the structure of technological interdependence affects firm performance in new technology generations. Strategic Management Journal, vol. 31, n. 3, p. 306-333, 2010.

AKBAR, H., MANDURAH, S. Project-conceptualisation in technological innovations: A knowledge-based perspective. International Journal of Project Management, vol. 32, n. 5, p. 759-772, 2014.

ALAM, I. Removing the fuzziness from the fuzzy front-end of service innovations through customer interactions. Industrial Marketing Management, vol. 35, n. 4, p. 468-480, 2006. 
ALEXY, O., GEORGE, G., \& SALTER, A. J. Cui Bono? The selective revealing of knowledge and its implications for innovative activity. Academy of Management Review, vol. 38, n. 2, p. 270-291, 2013.

AMIT, R., ZOTT, C. Value creation in e-business. Strategic Management Journal, vol. 22, p. 493-520, 2011.

ANDERSSON, M., LINDGREN, R., HENFRIDSSON, O. Architectural knowledge in interorganizational IT innovation. Journal of Strategic Information Systems, vol. 17, n. 1, p. 19-38, 2008.

ARTTO, K., KULVIK, I., POSKELA, J., TURKULAINEN, V. The integrative role of the project management office in the front end of innovation. International Journal of Project Management, vol. 29, n. 4, p. 408-421, 2011.

BERINGER, C., JONAS, D., KOCK, A. Behavior of internal stakeholders in project portfolio management and its impact on success. International Journal of Project Management, vol. 31, n. 6, p. 830-846, 2013.

BJORK, J., MAGNUSSON, M. Where Do Good Innovation Ideas Come From? Exploring the Influence of Network Connectivity on Innovation Idea Quality. Journal of Product Innovation Management, vol. 26, p. 662-670. 2009.

BOCKEN, N., ALLWOOD, J. Strategies to reduce the carbon footprint of consumer goods by in fl uencing stakeholders. Journal of Cleaner Production, vol. 35, p. 118-129, 2012.

BOCKEN, N. M. P., FARRACHO, M., BOSWORTH, R., KEMP, R. (2014). The front-end of eco-innovation for eco-innovative small and medium sized companies. Journal of Engineering and Technology Management - JET-M, vol. 31, n. 1, p. 43-57, 2014.

BÖRJESSON, S., DAHLSTEN, F., E WILLIANDER, M. Innovative scanning experiences from an idea generation project at Volvo Cars. Technovation, vol. 26, n. 7, p. 775-783. 2006. 
BOTHOS, E., APOSTOLOU, D., E MENTZAS, G. Collective intelligence with web-based information aggregation markets: The role of market facilitation in idea management. Expert Systems with Applications, vol. 39, n. 1, p. 1333-1345. 2012.

BREM, A., VOIGT, K.-I. Integration of market pull and technology push in the corporate front end and innovation management-Insights from the German software industry. Technovation, vol. 29, n. 5, p. 351-367, 2009.

BRETTEL, M., MAUER, R., ENGELEN, A., E KÜPPER, D. Corporate effectuation: Entrepreneurial action and its impact on R\&D project performance. Journal of Business Venturing, vol. 27, n. 2, p. 167-184, 2012.

BRÖRING, S., CLOUTIER, L. M., LEKER, J. The front end of innovation in an era of industry convergence: Evidence from nutraceuticals and functional foods. $\mathbf{R}$ and $\mathbf{D}$ Management, vol. 36, n. 5, p. 487-498, 2006.

BUTTOUD, G., KOUPLEVATSKAYA-BUTTOUD, I., SLEE, B., WEISS, G. Barriers to institutional learning and innovations in the forest sector in Europe: Markets, policies and stakeholders. Forest Policy and Economics, vol. 13, n. 2, p. 124-131, 2011.

CHANDRA, V., LOOSEMORE, M. Mapping stakeholders' cultural learning in the hospital briefing process. Construction Management and Economics, vol. 28, n. 7, p. 761-769, 2010.

CHAUDHRY, R., FISCHLEIN, M., LARSON, J., HALL, D., PETERSON, T., WILSON, E., STEPHENS, J. Policy Stakeholders' Perceptions of Carbon Capture and Storage: A Comparison of Four U.S. States. Journal of Cleaner Production, vol. 52, p. 21-32, 2013.

CHESBROUGH, H., KIM, S., AGOGINO, A. Chez panisse: building an open innovation ecosystem. California Management Review, vol. 56, n. 4, p. 144-171, 2014.

CHRISTENSEN, C. The Innovator's Dilemma. Boston: Harvard Business School Press, 1997. 
CHRISTENSEN, C; RAYNOR, M. The Innovator's Solution. Boston: Harvard Business School Press, 2003.

COOPER, R. G. Perspective: The Innovation Dilemma: How to Innovate When the Market Is Mature. Journal of Product Innovation Management, vol. 28, n. 1, p. 2-27, 2011.

CRAWFORD, M.; BENEDETTO, A. D. New Products Management. 8 ed. New York: McGraw-Hill/Irwin, 2006.

DA SILVA, H. A. P. Protetor de Rede Inteligente e Relé Digital com tecnologia nacional integrando Proteção, Controle, Telecomando e Monitoramento, viabilizando Smart Grid e Geração Distribuída a partir dos Sistemas de Distribuição Subterrâneos nas Grandes Metrópoles. Tese de Doutorado do Programa de Pós-Graduação em Energia (EP/FEA/IEE/IF) da Universidade de São Paulo. São Paulo, 2011.

DAHAN, E., HAUSER, J. R., HARDY, R., KIM, A., LEE, L., LIN, B., MCARDLE, M. The Virtual Customer. Journal of Product Innovation Management. vol. 19, n. 5, p. 332-353. 2001.

DAHL, D., MOREAU, P. The influence and value of analogical thinking during new product ideation. Journal of Marketing Research, vol. 39, p. 47-60, 2002.

DARNALL, N., HENRIQUES, I., SADORSKY, P. Adopting Proactive Environmental Strategy: The Influence of Stakeholders and Firm Size. Journal of Management Studies, vol. 47, n. 6, p. 1072-1094, 2010.

DE ANA, F. J., UMSTEAD, K. A., PHILliPS, G. J., CONNER, C. P. Value driven innovation in medical device design: A process for balancing stakeholder voices. Annals of Biomedical Engineering, vol. 41, n. 9, p. 1811-1821, 2013.

DE BRENTANI, U., REID, S. The Fuzzy Front-End of Discontinuous Innovation: Insights for Research and Management. Journal of Product Innovation Management, vol. 29, n. 1, p. 70-87. 2012.

DEUTSCH, Y., VALENTE, M. Compensating Outside Directors with Stock: The Impact on Non-Primary Stakeholders. Journal of Business Ethics, vol. 116, n. 1, p. 67-85, 2012. 
DRAGOI, M., POPA, B., BLUJDEA, V. Improving communication among stakeholders through ex-post transactional analysis - case study on Romanian forestry. Forest Policy and Economics, vol. 13, n. 1, p. 16-23, 2011.

DRIESSEN, P., KOK, R., HILLEBRAND, B. Mechanisms for stakeholder integration: Bringing virtual stakeholder dialogue into organizations. Journal of Business Research, vol. 66, n. 9, p. 1465-1472, 2013.

EDQUIST, C. Systems of Innovation perspectives and challenges. African Journal of Science, Technology, Innovation and Development, vol. 2, n. 3, p. 14-45. 2010.

EISENHARDT, K. M. Building Theories from Case Study Research. Academy of Management Research, v. 14, n. 4, p. 532-550, 1989.

ETHIRAJ, S. K., POSEN, H. E. Do Product Architectures Affect Innovation Productivity in Complex Product Ecosystems? Advances in Strategic Management, vol. 30, p. 127-166, 2013.

FIXSON, S. K., PARK, B., MARION, T. J., AVE, H., E HALL, H. Back-loading: a potential side effect of employing digital design tools in new product development. Journal of Product Innovation Management, vol. 29, p. 140-156, 2012.

FLINT, D. J. Compressing new product success-to-success cycle time - Deep customer value understanding and idea generation. Industrial Marketing Management, vol. 31, p. 305-315. 2002 .

FORZA, C. Survey Research in Operations Management: A Processed-based Perspective. International Journal of Operations \& Production Management, v. 22, n. 2, p. 152-194, 2002.

FRISHAMMAR, J., LICHTENTHALER, U., KURKKIO, M. The front end in non-assembled product development: A multiple case study of mineral- and metal firms. Journal of Engineering and Technology Management - JET-M, vol. 29, n. 4, p. 468-488, 2012. 
GAWER, A., CUSUMANO, M. A. Industry platforms and ecosystem innovation. Journal of Product Innovation Management, vol. 31, n. 3, p. 417-433, 2014.

GEPHART, R. Qualitative Research and the Academy of Management Journal. Academy of Management Journal, v. 47, n. 4, p. 454-462, 2004.

GODET M. Actors' moves and strategies: the Mactor method. Futures, vol. 23, n. 6, p. 605622.1991.

GREENWOOD, M., KAMOCHE, K. Social accounting as stakeholder knowledge appropriation. Journal of Management \& Governance, vol. 17, n. 3, p. 723-743, 2012.

GRIFFITHS-HEMANS, J., GROVER, R. Setting the Stage for Creative New Products: Investigating the Idea Fruition Process. Journal of the Academy of Marketing Science, vol. 34, n. 1, p. 27-39. 2006.

GROENVELD, P. Roadmapping integrates business and technology. Research-Technology Management, vol. 40, n. 5, p. 48-55, 1997.

HALLSTEDT, S. I., THOMPSON, A. W., LINDAHL, P. Key elements for implementing a strategic sustainability perspective in the product innovation process. Journal of Cleaner Production, vol. 51, p. 277-288, 2013.

HEGER, T., ROHRBECK, R. Strategic foresight for collaborative exploration of new business fields. Technological Forecasting and Social Change, vol. 79, n. 5, p. 819-831, 2011.

HEIKKURINEN， P., BONNEDAHL， K. Corporate responsibility for sustainable development: A review and conceptual comparison of market- and stakeholder-oriented strategies. Journal of Cleaner Production, vol. 43, p. 191-198, 2013.

HEISING, W. The integration of ideation and project portfolio management - A key factor for sustainable success. International Journal of Project Management, vol. 30, n. 5, p. 582$595,2012$. 
HELLSTRÖM, M., TSVETKOVA, A., GUSTAFSSON, M., WIKSTRÖM, K. Collaboration mechanisms for business models in distributed energy ecosystems. Journal of Cleaner Production, vol. 102, p. 226-236, 2014.

HOLMES, S., MOIR, L. Developing a conceptual framework to identify corporate innovations through engagement with non-profit stakeholders. Corporate Governance, vol. 7, n. 4, p. 414-422, 2007.

HONG, P., NAHM, A. Y., DOLL, W. J. The role of project target clarity in an uncertain project environment. International Journal of Operations \& Production Management, vol. 24, p. 1269-1291, 2004.

ILEVBARE, I. M., PROBERT, D., PHAAL, R. (2014). Towards risk-aware roadmapping: Influencing factors and practical measures. Technovation, vol. 34, n. 8, p. 399-409, 2014.

JAMALI, D. A Stakeholder Approach to Corporate Social Responsibility: A Fresh Perspective into Theory and Practice. Journal of Business Ethics, vol. 82, n. 1, p. 213-231, 2007.

KAPOOR, R. Collaborating with complementors: what do firms do? Advances in Strategic Management, vol. 30, p. 3-25, 2013.

KATSOULAKOS, T., KATSOULACOS, Y. Integrating corporate responsibility principles and stakeholder approaches into mainstream strategy: a stakeholder-oriented and integrative strategic management framework. Corporate Governance, vol. 7, n. 4, p. 355-369, 2007.

KHURANA, A., ROSENTHAL, S. Integrating the FFE of New Product Development. MIT Sloan Management Review, vol. 38, n. 2, p. 103-120, 1997.

KHURANA, A., ROSENTHAL, S. Towards holistic "front ends" in new product development. Journal of Product Innovation Management, vol. 15, p. 57-74, 1998.

KIHLANDER, I., RITZÉN, S. (2012). Compatibility before completeness - Identifying intrinsic conflicts in concept decision making for technical systems. Technovation, vol. 32, n. 2, p. 79-89, 2012. 
KIJKUIT, B., E VAN DEN ENDE, J. The Organizational Life of an Idea: Integrating Social Network, Creativity and Decision-Making Perspectives. Journal of Management Studies, vol. 44, n. 6, p. 863-882, 2007.

KIJKUIT, B., E VAN DEN ENDE, J. With a Little Help from Our Colleagues: A Longitudinal Study of Social Networks for Innovation. Organizational Studies, p. 492-510, 2006.

KIM, J. E WILEMON, D. Focusing the fuzzy front-end in new product development. R\&D Management, vol. 32, n. 4, p. 269-279, 2002.

KLINK, R. R., E ATHAIDE, G. An Illustration of Potential Sources of Concept-Test Error. Journal of Product Innovation Management, vol. 23, n. 4, p. 359-370, 2006.

KOBAYASHI, H. A systematic approach to eco-innovative product design based on life cycle planning. Advanced Engineering Informatics, vol. 20, n. 2, p. 113-125, 2006.

KOEN, P., AJAMIAN, G., BURKART, R., ClAMEN, A., DAVIDSON, J., AMORE, R. D., ELKINS, C. Providing clarity and a common language to the "FFE". Research Technology Management, p. 46-55, 2001.

KOEN, P. A.; et al. FFE: Effective Methods, Tools and Techniques. In: BELLIVEAU, P.; GRIFFIN, A.; SOMERMEYER, S. The PDMA Toolbook for new product development. New York: John Wiley \& Sons, 2002.

KOSTOFF, R. N. Systematic acceleration of radical discovery and innovation in science and technology. Technological Forecasting and Social Change, vol. 73, n. 8, p. 923-936, 2006.

LAI, I., LAM, F. Perception of various performance criteria by stakeholders in the construction sector in Hong Kong. Construction Management and Economics, vol. 28, n. 4, p. 377-391, 2010.

LANGERAK, F., JAN HULTINK, E., E ROBBEN, H. The role of predevelopment activities in the relationship between market orientation and performance. R\&D Management, vol. 34, n. 3, p. 295-309, 2004. 
LEE, C., LEE, H., SEOL, H., E PARK, Y. Evaluation of new service concepts using rough set theory and group analytic hierarchy process. Expert Systems with Applications, vol. 39, n. 3, p. 3404-3412, 2012.

LETEN, B., VANHAVERBEKE, W., ROIJAKKERS, N. CLERIX, A, VAN HELLEPUTTE, J. California Management Review, vol. 55, n. 4, p. 51-64, 2013.

LETTL, C., HERSTATT, C. Users as inventors and developers of radical innovation : An explorative case study analysis in the field of medical technology. R and D Management, vol. 36, n. 3, p. 251-272, 2006.

LIPPARINI, A., SOBRERO, M. The glue and the pieces: Entrepreneurship and innovation in small-firm networks. Journal of Business Venturing, vol. 9, n. 2, p. 125-140, 1994.

LIU, G., RONG, K. The Nature of the Co-Evolutionary Process: Complex Product Development in the Mobile Computing Industry's Business Ecosystem. Group \& Organization Management, vol. 40, n. 6, p. 809-842, 2015.

LO, C., WANG, C., HUANG, C. The national innovation system in the Taiwanese photovoltaic industry: A multiple stakeholder perspective. Technological Forecasting and Social Change, vol. 80, n. 5, p. 893-906, 2013.

LOCKE, K.; GOLDEN-BIDDLE, K. Constructing Opportunities for Contribution: Structuring Intertextual Coherence and "Problematizing" in Organizational Studies. Academy of Management Journal, v. 40, n. 5, p. 1023-1062, 1997.

MAGNUSSON, P. Exploring the Contributions of Involving Ordinary Users in Ideation of Technology-Based Services. Journal of Product Innovation Management, vol. 26, n. 5, p. 578-593, 2009.

MARKMANN, C., DARKOW, I.-L., VON DER GRACHT, H. A Delphi-based risk analysis - Identifying and assessing future challenges for supply chain security in a multi-stakeholder environment. Technological Forecasting and Social Change, vol. 80, n. 9, p. 1815-1833, 2013 
MASSEY, A., MONTOYA-WEISS, N., O’DRISCOLL, T. Performance-centered design of knowledge-intensive processes. Journal of Management Information Systems, vol. 18, n. 4, p. 37-58, 2002.

MATHUR, V., PRICE, A., AUSTIN, S. Conceptualizing stakeholder engagement in the context of sustainability and its assessment. Construction Management and Economics, vol. 26, n. 6, p. 601-609, 2008.

MATOS, S., SILVESTRE, B. Managing stakeholder relations when developing sustainable business models: the case of the Brazilian energy sector. Journal of Cleaner Production, vol. 45, p. 61-73, 2013.

MCDERMOTT, G., MUDAMBI, R., PARENTE, R. Strategic Modularity and the Architecture of Multinational Firm. Global Strategy Journal, vol. 3, n. 1, p. 1-7, 2013.

MEUER, J. Archetypes of Inter-firm Relations in the Implementation of Management Innovation: A Set-theoretic Study in China's Biopharmaceutical Industry. Organization Studies, vol. 35, n. 1, p. 121-145, 2014.

MINOJA, M. Stakeholder Management Theory, Firm Strategy, and Ambidexterity. Journal of Business Ethics, vol. 109, n. 1, p. 67-82, 2012.

MINOJA, M., ZOLLO, M., CODA, V. Stakeholder cohesion, innovation, and competitive advantage. Corporate Governance, vol. 10, n. 4, p. 395-405, 2010.

MISHRA, A., CHANDRASEKARAN, A., MACCORMACK, A. Collaboration in MultiPartner R\&D Projects: The Impact of Partnering Scale and Scope. Journal of Operations Management, vol. 33-34, p. 1-14. 2015.

MISHRA, A., SHAH, R. In union lies strength: Collaborative competence in new product development and its performance effects. Journal of Operations Management, vol. 27, n. 4, p. 324-338, 2009.

MOENAERT, R. K., DE MEYER, A., SOUDER, W. E., E DESCHOOLMEESTER, D. $\mathrm{R} \& \mathrm{D} / \mathrm{marketing}$ communication during the fuzzy front-end. IEEE Transactions on Engineering Management, vol. 42, n. 3, p. 243-258, 1995. 
MONT, O., NEUVONEN, A., LÄHTEENOJA, S. Sustainable lifestyles 2050: Stakeholder visions, emerging practices and future research. Journal of Cleaner Production, vol. 63, p. 24-32, 2013.

MONTOYA-WEISS, M., O’DRISCOLL, T. From experience: applying performance support technology in the FFE. Journal of Product Innovation Management, vol. 17, p. 143-161, 2000.

MORGAN, L., FELLER, J., FINNEGAN, P. Exploring value networks: theorising the creation and capture of value with open source software. European Journal of Information Systems, vol. 22, n. 5, p. 569-588, 2013.

MORGAN, L., FINNEGAN, P. Beyond free software: An exploration of the business value of strategic open source. Journal of Strategic Information Systems, vol. 23, n. 3, p. 226$238,2014$.

MURPHY, M., ARENAS, D. Through Indigenous Lenses: Cross-Sector Collaborations with Fringe Stakeholders. Journal of Business Ethics, vol. 94, n. S1, p. 103-121, 2011.

MURPHY, S., KUMAR, V. The front end of new product development: a Canadian survey. R\&D Management, vol. 27, n. 1, p. 5-15, 1997.

OH, J., KOH, B., RAGHUNATHAN, S. Value appropriation between the platform provider and app developers in mobile platform mediated networks. Journal of Information Technology, vol. 30, n. 3, p. 245-259, 2015.

OH, J., YANG, J., E LEE, S. Managing uncertainty to improve decision-making in NPD portfolio management with a fuzzy expert system. Expert Systems with Applications, vol. 39, n. 10, p. 9868-9885, 2012.

OSTERWAlder, A., PIGNEUR, Y., CLARK, T. Business Model Generation: A Handbook for Visionaries, Game Changers, and Challengers. 278 p. 2010.

PARK-POAPS, H., REES, K. Stakeholder forces of socially responsible supply chain management orientation. Journal of Business Ethics, vol. 92, n. 2, p. 305-322, 2010. 
PINHO, N., BEIRÃO, G., PATRÍCIO, L., P. FISK, R. Understanding value co-creation in complex services with many actors. Journal of Service Management, vol. 25, n. 4, p. 470 493, 2014.

PLAZA-ÚBEDA, J., DE BURGOS-JIMÉNEZ, J., CARMONA-MORENO, E. Measuring stakeholder integration: Knowledge, interaction and adaptational behavior dimensions. Journal of Business Ethics, vol. 93, n. 3, p. 419-442, 2010.

POSKELA, J, MARTINSUO, M. Management Control and Strategic Renewal in the Front End of Innovation. Journal of Product Innovation Management, vol. 26, n. 6, p. 671-684, 2009.

REID, S. E. E DE BRENTANI, U. The FFE of New Product Development for Discontinuous Innovations: A Theoretical Model. Journal of Product Innovation Management, vol. 21, p. 170-184, 2004.

REID, S. E., E BRENTANI, U. Market Vision and the Front End of NPD for Radical Innovation: The Impact of Moderating Effects. Journal of Product Innovation Management, vol. 29, p. 124-139, 2012.

REINERTSEN, D. G. Taking the Fuzziness Out of the FFE. Research Technology Management, vol. 42, n. 6, p. 25-31, 1999.

REN, S. J., HU, C., NGAI, E. W. T., ZHOU, M. An empirical analysis of inter-organisational value co-creation in a supply chain: A process perspective. Production Planning \& Control, vol. 26, n. 7, p. 1-12, 2015.

RICE, M.P., KELLEY, D., PETERS, L. AND O'CONNOR, G.C. Radical innovation: triggering initiation of opportunity recognition and evaluation. R\&D Management, vol. 31, n. 4, p. 409-420, 2001.

RIEL, A., NEUMANN, M., TICHKIEWITCH, S. Structuring the early fuzzy front-end to manage ideation for new product development. CIRP Annals - Manufacturing Technology, vol. 62, n. 1, p. 107-110, 2013. 
ROBERTSON, C., LAMIN, A., LIVANIS, G. Stakeholder Perceptions of Offshoring and Outsourcing: The Role of Embedded Issues. Journal of Business Ethics, vol. 95, n. 2, p. 167-189, 2010.

ROHRBECK, R., HÖLZLE, K., GEMÜNDEN, H. G. Opening up for competitive advantage - How Deutsche telekom creates an open innovation ecosystem. R and D Management, vol. 39, n. 4, p. 420-430, 2009.

ROHRBECK, R., SCHWARZ, J. O. The value contribution of strategic foresight: Insights from an empirical study of large European companies. Technological Forecasting and Social Change, vol. 80, n. 8, p. 1593-1606, 2013.

ROWLINSON, S., CHEUNG, Y. Stakeholder management through empowerment: modelling project success. Construction Management and Economics, vol. 26, n. 6, p. 611-623, 2008.

SALOMO, S., WEISE, J., GEMÜNDEN, H. G. NPD Planning Activities and Innovation Performance: The Mediating Role of Process Management and the Moderating Effect of Product Innovativeness. Journal of Product Innovation Management, vol. 24, p. 285-302, 2007.

SCHEINER, C. W., BACCARELLA, C. V., BESSANT, J., VOIGT, K. I. Thinking patterns and gut feeling in technology identification and evaluation. Technological Forecasting and Social Change, vol. 101, p. 112-123, 2015.

SCHIRR, G. R. Flawed Tools: The Efficacy of Group Research Methods to Generate Customer Ideas. Journal of Product Innovation Management, vol. 29, n. 3, p. 473-488, 2012.

SMITH, P., REINERTSEN, D. Shortening the product development cycle. ResearchTechnology Management, vol. maio-junho, p. 44-49, 1992.

SOUKHOROUKOVA, A., SPANN, M., E SKIERA, B. Sourcing, Filtering, and Evaluating New Product Ideas: An Empirical Exploration of the Performance of Idea Markets. Journal of Product Innovation Management, vol. 29, n. 1, p. 100-112, 2012. 
SPANJOL, J., QUALLS, W., ROSA, J. How Many and What Kind? The Role of Strategic Orientation in New Product Ideation. Journal of Product Innovation Management, vol. 28, n. 2, p. 236-250, 2011.

STEVENS, E. Fuzzy front-end learning strategies: Exploration of a high-tech company. Technovation, vol. 34, n. 8, p. 431-440, 2014.

STEVENS, G. A., E BURLEY, J. Piloting the rocket of radical innovation. ResearchTechnology Management, vol. março-abril, p. 16-25, 2003.

TAYLOR, J. E LEVITT, R. Understanding and managing systemic innovation in projectbased industries. In Innovations: Project management research, Newton Square: Project Management Institute, p. 83-99 2004

TEECE, D. J. Capturing value from knowledge assets: The new economy, markets for knowhow, and intangible assets. California Management Review, vol. 40, n. 3, p. 55.1998.

THANASOPON, B., PAPADOPOULOS, T., VIDGEN, R. The role of openness in the fuzzy front-end of service innovation. Technovation, vol. 47, p. 32-46, 2016.

THOMSON, D. A pilot study of client complexity, emergent requirements and stakeholder perceptions of project success. Construction Management and Economics, vol. 29, n. 1, p. 69-82, 2011.

TOOR, S.-R., OGUNLANA, S. Beyond the "iron triangle": Stakeholder perception of key performance indicators (KPIs) for large-scale public sector development projects. International Journal of Project Management, vol. 28, n. 3, p. 228-236, 2010.

TYL, B., VALLET, F., BOCKEN, N. M. P., REAL, M. The integration of a stakeholder perspective into the front end of eco-innovation: a practical approach. Journal of Cleaner Production, vol. 108, p. 543-557, 2015.

VAN AKEN, J. E., E WEGGEMAN, M. P. Managing learning in informal innovation networks: overcoming the Daphne-dilemma. R\&D Management, vol. 30, n. 2, p. 139-149, 2000. 
VAN DE KERKHOF, M., WIECZOREK, A. Learning and stakeholder participation in transition processes towards sustainability: Methodological considerations. Technological Forecasting and Social Change, vol. 72, n. 6, p. 733-747, 2005.

VAN DER MEER-KOOISTRA, J., SCAPENS, R. W. Governing product co-development projects: The role of minimal structures. Management Accounting Research, vol. 28, p. 6891, 2015.

VAN RIEL, A., SEMEIJN, J., HAMMEDI, W., HENSELER, J. Technology-based service proposal screening and decision-making effectiveness. Management Decision, vol. 49, n. 5, p. 762-783, 2011.

VAN SCHIE, N., DUIJN, M., EDELENBOS, J. Co-Valuation: Exploring Methods for Expert and Stakeholder Valuation. Journal of Environmental Assessment Policy and Management, vol. 13, n. 4, p. 619-650, 2011.

VAN TRIJP, H., VAN KLEEF, E. Newness, value and new product performance. Trends in Food Science \& Technology, vol. 19, n. 11, p. 562-573, 2008.

VERGANTI, R. Planned flexibility: Linking anticipation and reaction in product development projects. Journal of Product Innovation Management, vol. 16, n. 4, p. 363-376, 1999.

VERWORN, B., HERSTATT, C., \& NAGAHIRA, A. The FFE of Japanese new product development projects : impact on success and differences between incremental and radical projects. R\&D Management, vol. 38, n. 1, p. 1-19, 2008.

VOSS, C.; TSIKRIKTSIS, N.; FROHLICH, M. Case Research in Operations Management. International Journal of Operations \& Production Management, v. 22, n. 2, p. 195-219, 2002.

WAGNER, S. M. Tapping supplier innovation. Journal of Supply Chain Management, vol. abril, p. 37-52, 2012.

WALKER, D., BOURNE, L., SHELLEY, A. Influence, stakeholder mapping and visualization. Construction Management and Economics, vol. 26, n. 6, p. 645-658, 2008. 
WANG, X., HUANG, J. The relationships between key stakeholders' project performance and project success: Perceptions of Chinese construction supervising engineers. International Journal of Project Management, vol. 24, n. 3, p. 253-260, 2006.

WEBSTER, J., WATSON, R. T. Analyzing the past to prepare for the future: Writing a literature review. MIS Quarterly, vol. 26, n. 2, p. 13-23, 2002.

WEST, J., KUK, G. The complementarity of openness: How MakerBot leveraged Thingiverse in 3D printing. Technological Forecasting and Social Change, vol. 102, p. 169-181, 2016.

WOWAK, K., CRAIGHEAD, C., KETCHEN, D., HULT, G. Toward a "Theoretical Toolbox" for the Supplier-Enabled Fuzzy Front End of the New Product Development Process. Journal of Supply Chain Management, vol. 52, n. 1, p. 66-81, 2015.

WARTH, J., VON DER GRACHT, H., \& DARKOW, I.-L. A dissent-based approach for multi-stakeholder scenario development - The future of electric drive vehicles. Technological Forecasting and Social Change, vol. 80, n. 4, p. 566-583, 2013.

WU, Q., LUO, X., SLOTEGRAAF, R. J., ASPARA, J. Sleeping with competitors: the impact of NPD phases on stock market reactions to horizontal collaboration. Journal of the Academy of Marketing Science, vol. 43, n. 4, p. 490-511, 2014.

XIAO, L. Discussion of How to Promote the Development of Chinese IOT Industry. China Investment Technology, vol.294, p. 73-76, 2010.

ZIEN, K. A., BUCKLER, S. A. Dreams to market: crafting a culture of innovation. Journal of Product Innovation Management, vol. 14, p. 274-287, 1997. 


\section{Anexo I}

(Continua)

Tabela 8 - Amostra de artigos sobre FFE utilizada e respectivo fator de impacto.

\begin{tabular}{|c|c|c|c|c|c|}
\hline Primeiro Autor & Ano & Periódico & $\mathbf{C}$ & JCR & I \\
\hline Khurana, A & 1997 & Sloan Management Review & 152 & 3.036 & 618 \\
\hline Dahl, DW & 2002 & Journal Of Marketing Research & 160 & 2.256 & 524 \\
\hline Khurana, A & 1998 & Journal Of Product Innovation Management & 176 & 1.696 & 477 \\
\hline Reid, SE & 2004 & Journal Of Product Innovation Management & 162 & 1.696 & 439 \\
\hline Dahan, E & 2002 & Journal Of Product Innovation Management & 150 & 1.696 & 407 \\
\hline Koen, $\mathrm{P}$ & 2001 & Research-Technology Management & 187 & 1.017 & 379 \\
\hline Alam, I & 2006 & Industrial Marketing Management & 105 & 1.82 & 299 \\
\hline Groenveld, $\mathrm{P}$ & 1997 & Research-Technology Management & 127 & 1.017 & 258 \\
\hline Kim, J & 2002 & R \& D Management & 115 & 0.848 & 214 \\
\hline Kijkuit, B & 2007 & Journal Of Management Studies & 42 & 3.763 & 205 \\
\hline Salomo, S & 2007 & Journal Of Product Innovation Management & 72 & 1.696 & 197 \\
\hline Brem, A & 2009 & Technovation & 51 & 2.526 & 183 \\
\hline Moenaert, RK & 1995 & Ieee Transactions On Engineering Management & 86 & 1.103 & 183 \\
\hline Lettl, C & 2006 & R \& D Management & 98 & 0.848 & 183 \\
\hline Montoya-Weiss, MM & 2000 & Journal Of Product Innovation Management & 57 & 1.696 & 156 \\
\hline Griffiths-Hemans, J & 2006 & Journal Of The Academy Of Marketing Science & 30 & 3.818 & 149 \\
\hline Verganti, R & 1999 & Journal Of Product Innovation Management & 52 & 1.696 & 143 \\
\hline Magnusson, PR & 2009 & Journal Of Product Innovation Management & 48 & 1.696 & 132 \\
\hline Rosenthal, SR & 2006 & Journal Of Product Innovation Management & 46 & 1.696 & 127 \\
\hline Wagner, SM & 2012 & Journal Of Supply Chain Management & 25 & 3.857 & 126 \\
\hline Flint, DJ & 2002 & Industrial Marketing Management & 40 & 1.82 & 116 \\
\hline Zien, KA & 1997 & Journal Of Product Innovation Management & 40 & 1.696 & 111 \\
\hline Kostoff, RN & 2006 & Technological Forecasting And Social Change & 35 & 2.058 & 110 \\
\hline Brettel, M & 2012 & Journal Of Business Venturing & 22 & 3.678 & 108 \\
\hline van Trijp, HCM & 2008 & Trends In Food Science \& Technology & 18 & 4.651 & 107 \\
\hline Verworn, B & 2008 & R \& D Management & 57 & 0.848 & 107 \\
\hline Kobayashi, H & 2006 & Advanced Engineering Informatics & 39 & 1.627 & 105 \\
\hline Hallstedt, SI & 2013 & Journal Of Cleaner Production & 20 & 3.844 & 102 \\
\hline Bjork, J & 2009 & Journal Of Product Innovation Management & 36 & 1.696 & 100 \\
\hline van Riel, ACR & 2011 & Management Decision & 40 & 1.429 & 100 \\
\hline Kijkuit, B & 2010 & Organization Studies & 24 & 2.886 & 97 \\
\hline Poskela, J & 2009 & Journal Of Product Innovation Management & 33 & 1.696 & 92 \\
\hline Verworn, B & 2009 & Research Policy & 20 & 3.117 & 86 \\
\hline Rice, MP & 2001 & R \& D Management & 43 & 0.848 & 81 \\
\hline Stevens, GA & 2003 & Research-Technology Management & 39 & 1.017 & 81 \\
\hline Reinertsen, DG & 1999 & Research-Technology Management & 38 & 1.017 & 79 \\
\hline Smith, PG & 1992 & Research-Technology Management & 36 & 1.017 & 75 \\
\hline Rohrbeck, R & 2009 & R \& D Management & 36 & 0.848 & 68 \\
\hline Bröring, S & 2006 & R \& D Management & 36 & 0.848 & 68 \\
\hline Hong, $\mathrm{P}$ & 2004 & International Journal of Op. \& Prod. Manag. & 23 & 1.736 & 66 \\
\hline Langerak, F & 2004 & R \& D Management & 33 & 0.848 & 63 \\
\hline Andersson, M & 2008 & Journal Of Strategic Information Systems & 16 & 2.692 & 63 \\
\hline Artto, $\mathrm{K}$ & 2011 & International Journal Of Project Management & 17 & 2.436 & 62 \\
\hline Soukhoroukova, A & 2012 & Journal Of Product Innovation Management & 21 & 1.696 & 59 \\
\hline Cooper, RG & 2011 & Journal Of Product Innovation Management & 21 & 1.696 & 59 \\
\hline Spanjol, J & 2011 & Journal Of Product Innovation Management & 21 & 1.696 & 59 \\
\hline Van Aken, JE & 2000 & R \& D Management & 30 & 0.848 & 57 \\
\hline
\end{tabular}




\begin{tabular}{|l|l|l|l|l|l|}
\hline Primeiro Autor & Ano & Periódico & C & JCR & I \\
\hline Börjesson, S & 2006 & Technovation & 15 & 2.526 & 56 \\
\hline Massey, AP & 2002 & Journal Of Management Information Systems & 17 & 2.062 & 55 \\
\hline Rohrbeck, R & 2013 & Technological Forecasting And Social Change & 17 & 2.058 & 55 \\
\hline Heising, W & 2012 & International Journal Of Project Management & 11 & 2.436 & 41 \\
\hline Lee, C & 2012 & Expert Systems With Applications & 9 & 2.24 & 32 \\
\hline Oh, J & 2012 & Expert Systems With Applications & 8 & 2.24 & 29 \\
\hline Stevens, E & 2014 & Technovation & 4 & 2.526 & 18 \\
\hline Bothos, E & 2012 & Expert Systems With Applications & 4 & 2.24 & 16 \\
\hline Bocken, NMP & 2014 & Journal of Engineering \& Technology Manag & 4 & 2.06 & 15 \\
\hline Kihlander, I & 2012 & Technovation & 3 & 2.526 & 14 \\
\hline Riel, A & 2013 & Cirp Annals-Manufacturing Technology & 2 & 2.542 & 11 \\
\hline Ilevbare, IM & 2014 & Technovation & 2 & 2.526 & 11 \\
\hline Frishammar, J & 2012 & Journal of Engineering \& Technology Manag & 2 & 2.06 & 9 \\
\hline Akbar, H & 2014 & International Journal Of Project Management & 1 & 2.436 & 7 \\
\hline Scheiner, CW & 2015 & Technological Forecasting And Social Change & 1 & 2.058 & 6 \\
\hline Wowak, KD & 2016 & Journal Of Supply Chain Management & 0 & 3.857 & 5 \\
\hline Tyl, B & 2015 & Journal Of Cleaner Production & 0 & 3.844 & 5 \\
\hline Wu, QS & 2015 & Journal Of The Academy Of Marketing Science & 0 & 3.818 & 5 \\
\hline de Ana, FJ & 2013 & Annals Of Biomedical Engineering & 0 & 3.195 & 4 \\
\hline Thanasopon, B & 2016 & Technovation & 0 & 2.526 & 4 \\
\hline van der Meer-Kooistra, J & 2015 & Management Accounting Research & 0 & 2.125 & 3 \\
\hline
\end{tabular}

\section{(Conclusão)}

Fonte: Elaborado pela autora. Nota: C - citações; JCR - fator de impacto do Journal Citation

Report, I - impacto do artigo. 


\section{Anexo II}

(Continua)

Tabela 9 - Amostra de artigos de inovação sistêmica utilizada e respectivo fator de impacto.

\begin{tabular}{|c|c|c|c|c|c|}
\hline Primeiro Autor & Ano & Periódico & $\mathbf{C}$ & JCR & $\mathbf{I}$ \\
\hline Amit, R & 2001 & Strategic Management Journal & 734 & 3.341 & 3191 \\
\hline Christensen, CM & 1995 & Research Policy & 285 & 3.117 & 1177 \\
\hline Adner, R & 2010 & Strategic Management Journal & 139 & 3.341 & 608 \\
\hline Lipparini, A & 1994 & Journal Of Business Venturing & 88 & 3.678 & 416 \\
\hline Mishra, A & 2009 & Journal Of Operations Management & 81 & 3.818 & 395 \\
\hline Adner, R & 2006 & Harvard Business Review & 127 & 1.574 & 329 \\
\hline Alexy, O & 2013 & Academy Of Management Review & 26 & 7.475 & 229 \\
\hline Sobrero, $\mathrm{M}$ & 2001 & Management Science & 61 & 2.482 & 216 \\
\hline Mihm, J & 2003 & Management Science & 55 & 2.482 & 195 \\
\hline Gupta, S & 1999 & Marketing Science & 64 & 1.86 & 186 \\
\hline Mikkola, JH & 2003 & R \& D Management & 66 & 0.848 & 124 \\
\hline Cui, A & 2012 & Journal Of Marketing & 20 & 3.938 & 104 \\
\hline Heger, $\mathrm{T}$ & 2012 & Technological Forecasting And Social Change & 21 & 2.058 & 67 \\
\hline Gawer, A & 2014 & Journal Of Product Innovation Management & 18 & 1.696 & 51 \\
\hline Bogers, M & 2012 & Creativity And Innovation Management & 22 & 1.016 & 46 \\
\hline Mcdermott, $\mathrm{G}$ & 2013 & Global Strategy Journal & 5 & 3.694 & 28 \\
\hline Mlecnik, E & 2013 & Journal Of Cleaner Production & 4 & 3.844 & 24 \\
\hline Davies, A & 2014 & International Journal Of Project Management & 6 & 2.436 & 24 \\
\hline Meuer, J & 2014 & Organization Studies & 5 & 2.886 & 23 \\
\hline Saguy, I & 2014 & Trends In Food Science \& Technology & 3 & 4.651 & 23 \\
\hline Morgan, L & 2013 & European Journal Of Information Systems & 5 & 2.213 & 19 \\
\hline Leten, B & 2013 & California Management Review & 7 & 1.25 & 18 \\
\hline Hjelmgren, D & 2013 & Industrial Marketing Management & 3 & 1.82 & 11 \\
\hline $\mathrm{Ma}, \mathrm{C}$ & 2012 & Industrial Marketing Management & 3 & 1.82 & 11 \\
\hline Mishra, A & 2015 & Journal Of Operations Management & 1 & 3.818 & 10 \\
\hline Shao, J & 2012 & Transactions In Gis & 3 & 1.398 & 10 \\
\hline Alin, $\mathrm{P}$ & 2013 & Project Management Journal & 3 & 1.143 & 9 \\
\hline Szajnfarber, Z & 2013 & Acta Astronautica & 3 & 1.122 & 8 \\
\hline Jong, $\mathrm{S}$ & 2014 & Research Policy & 1 & 3.117 & 8 \\
\hline Spanjol, J & 2012 & Journal Of Product Innovation Management & 2 & 1.696 & 8 \\
\hline Morgan, L & 2014 & Journal Of Strategic Information Systems & 1 & 2.692 & 7 \\
\hline Mani, D & 2014 & Information Systems Research & 1 & 2.436 & 7 \\
\hline Pinho, N & 2014 & Journal Of Service Management & 1 & 2 & 6 \\
\hline $\mathrm{Oh}, \mathrm{J}$ & 2015 & Journal Of Information Technology & 0 & 4.525 & 6 \\
\hline Hellström, M & 2015 & Journal Of Cleaner Production & 0 & 3.844 & 5 \\
\hline Chesbrough, $\mathrm{H}$ & 2014 & California Management Review & 1 & 1.25 & 5 \\
\hline Nasr, E & 2015 & European Journal Of Operational Research & 0 & 2.358 & 3 \\
\hline West, J & 2016 & Technological Forecasting And Social Change & 0 & 2.058 & 3 \\
\hline Gehringer, A & 2016 & Technological Forecasting And Social Change & 0 & 2.058 & 3 \\
\hline $\mathrm{Wu}, \mathrm{J}$ & 2015 & Industrial Marketing Management & 0 & 1.82 & 3 \\
\hline Ren, $\mathrm{S}$ & 2015 & Production Planning \& Control & 0 & 1.466 & 2 \\
\hline Pittz, T & 2015 & Management Decision & 0 & 1.429 & 2 \\
\hline De Klerk, $\mathrm{S}$ & 2015 & Management Decision & 0 & 1.429 & 2 \\
\hline Perrons, RK & 2014 & Journal Of Petroleum Science And Engineering & 0 & 1.416 & 2 \\
\hline Liu, $\mathrm{G}$ & 2015 & Group \& Organization Management & 0 & 1.4 & 2 \\
\hline Weiber, $\mathrm{R}$ & 2014 & Total Quality Management \& Business Excellence & 0 & 1.323 & 2 \\
\hline
\end{tabular}




\begin{tabular}{|l|l|l|l|l|l|}
\hline Primeiro Autor & Ano & Periódico & C & JCR & I \\
\hline Kapoor, R & 2013 & Collaboration \& Competition In Business Ecosystems & 3 & NA & NA \\
\hline Ethiraj, SK & 2013 & Collaboration \& Competition In Business Ecosystems & 3 & NA & NA \\
\hline
\end{tabular}

\section{(Conclusão)}

Fonte: Elaborado pela autora. Nota: C - citações; JCR - fator de impacto do Journal Citation

Report, I - impacto do artigo, NA - não aplicável. 


\section{Anexo III}

Roteiro da entrevista com o sócio fundador da Vitalbox.

\section{Background do projeto}

a. Background, papeis e responsabilidades do entrevistado

b. Características do projeto do Vitalbox (valor monetário para desenvolvimento do negócio, importância estratégica, relacionamento com cliente e avaliação de sucesso)

c. Descrição da organização que realizou o projeto

d. Descrição da rede de clientes e de subcontratados

e. Qual tipo de projeto foi desenvolvido?

f. O que o preocupou mais em relação a este projeto?

g. O que foi feito para conclui-lo com sucesso?

h. Quais foram os maiores sucessos e fracassos no projeto?

i. Que questões deveriam ter recebido mais atenção?

j. Que eventos do projeto devem ser lembrados como questões importantes para o futuro?

k. Como a cultura deste mercado se tornou visível na execução do projeto?

2. Rede de atores externos do projeto. Nota: foco especialmente nas questões relacionadas a atores externos, faça as próximas questões e sempre peça por exemplos.

a. Quais eram as principais partes da rede de organizações executando o projeto?

b. Desenhar a rede de atores (peça ao entrevistado desenhar o ecossistema de negócios e explicá-lo)

i. Caracterização de papeis

ii. Caracterização de relacionamentos

iii. Foco em atores externos

c. Que tipos de mudanças importantes ocorreram na composição do ecossistema de negócios?

d. Como você caracterizaria a atmosfera na rede de atores?

e. De que forma os relacionamentos com os stakeholders externos foram gerenciados?

i. Reuniões

ii. Fluxo de informações

iii. Contratos

iv. Diretrizes

f. Quais foram os atores externos mais importantes? (faça mais questões sobre seus papeis, responsabilidades, relacionamentos e como eram gerenciados)

g. Que tipo de organizações oponentes foram envolvidas e como elas foram tratadas? 
3. Linha do tempo do projeto. Nota: focar especialmente em eventos críticos e inesperados relacionados a atores externos, faça as próximas questões e pergunte por exemplos:

a. Utilizando uma linha do tempo do projeto, passe por todos os eventos críticos e marcos do projeto

b. Para cada evento crítico/marco do projeto:

i. Quais foram as origens deste evento?

ii. Quando eles aconteceram?

iii. Quem foi envolvido?

iv. Como gerenciaram o evento ou marco?

v. Que tipos de efeitos o evento crítico ou o marco nos relacionamentos com os stakeholers tiveram no projeto?

c. Relacionamento com os atores externos:

i. Quando cada ator chave foi envolvido no projeto?

ii. Como ele foi envolvido?

iii. Como se deu a evolução do vínculo com o ator ao longo do projeto?

iv. Já existia um relacionamento entre o ator e a sua empresa?

\section{FFE de Inovação sistêmica}

a. Como esta oportunidade de inovação foi identificada/construída? Quais foram as pessoas envolvidas nesta identificação? Como foram envolvidas?

b. Como a ideia da Vitalbox foi concebida? Quais foram as pessoas envolvidas nesta concepção? Como foram envolvidas?

c. Após a concepção da ideia, quem participou da decisão pelo seu desenvolvimento? Em que momento esta decisão foi tomada? Que elementos foram utilizados para a decisão?

d. Que mecanismos de coordenação ou colaboração com stakeholders externos foram aplicados para o desenvolvimento desta inovação?

e. No modelo de negócios concebido no projeto:

i. Quais stakeholders fazem parte da criação de valor? Como foram gerenciados?

ii. Como este valor é distribuído hoje entre estes stakeholders? Como foram gerenciados?

iii. Que stakeholders ameaçam ou restringem a criação ou distribuição do valor? Como foram gerenciados?

iv. Houve necessidade ou oportunidade de criação de um novo ecossistema de negócios que não existia anteriormente? Ou seja, criou-se uma relação inédita de negócios entre os stakeholders?

f. Avaliação do posicionamento estratégico e vantagem competitiva na arquitetura. A Vitalbox:

i. Pode ser considerada essencial neste novo ecossistema criado? 
ii. Detém uma plataforma que permite que outros stakeholders criem valor sobre ela?

iii. É vista como uma garantidora da qualidade dos serviços prestados ao consumidor final dentro deste ecossistema de negócios?

\section{Análise e gestão de stakeholders no projeto de inovação}

a. Com que palavras você descreveria a gestão de stakeholders deste projeto?

b. Como e por quem as interfaces com atores externos foram gerenciadas?

c. Você poderia descrever o processo de análise e monitoramento de stakeholders do projeto?

d. Que tipos de processos você possui para coletar dados relacionados a stakeholders externos e interpretá-los (dê um exemplo)?

i. Como você mapeia os stakeholders (quando, por quem)

ii. De onde você recebe informações?

iii. Que tipos de ferramentas você utiliza para categorizar stakeholders?

iv. Onde esta informação é documentada?

v. Como você processa a informação?

vi. Que tipos de documentação relacionada a stakeholders você possui?

vii. Como você decide as ações de gestão de stakeholders?

viii. Qual a regularidade da coleta de dados relacionados a stakeholders?

ix. Como você utiliza as lições de projetos anteriores?

e. É fácil conduzir análise e monitoramento de stakeholders neste ambiente? Por que e por que não?

f. Como você vê a análise e monitoramento de stakeholders como uma parte da gestão de projetos deste projeto em particular?

g. O que foi especialmente supreendente em relaçào à análise e monitoramento de stakeholders do projeto?

h. Que diferenças culturais você notou em relação à análise de stakeholders do projeto?

i. Quais foram as partes mais desafiadoras em relação à análise e monitoramento de stakeholders?

j. O que você melhoraria no processo de análise de stakeholders?

k. Como a análise dos stakeholders do projeto difere das diretrizes da empresa mãe?

1. Há apoio suficiente para análise de stakeholders? (como/ por que não?) Quem provê suporte? O que mais poderia ser feito?

\section{Contexto local}

a. Stakeholders externos (número, interações, papeis) - discutir mais baseado nas questões anteriores

b. Como você descreveria o ambiente de stakeholders externos do seu projeto?

c. Você acha que é fácil conseguir informações do ambiente externo do projeto? Por que/Por que não? (foco especial em stakeholders externos) 
d. Quão previsível ou imprevisível você classificaria o seu ambiente local? Dê exemplos

e. Você acha que é fácil detectar mudanças no ambiente do projeto? Por que/por que não? Como?

f. Descreva situações em que o ambiente influenciou no projeto (exemplos de eventos interessantes)

g. Como você se familiarizou às práticas deste mercado?

h. Que tipo de eventos aconteceram devido à falta de conhecimento sobre o ambiente de negócios específico? Exemplos. 